\title{
APROVECHAMIENTO DE HORMIGON RECICLADO EN OBRAS VIALES
}

\author{
Gino F. FLOR CHAVEZ
}

Tesis presentada para el grado de

MAGISTER ESTRUCTURADA EN INGENIERIA VIAL

Área Departamental Construcciones, Facultad de Ingeniería, U.N.L.P. Octubre, 2012. 



\title{
Universidad Nacional de La Plata Facultad de Ingeniería
}

\section{APROVECHAMIENTO DE HORMIGON RECICLADO EN OBRAS VIALES}

\author{
Gino F. FLOR CHAVEZ
}

Director: Dr. Ing. Raúl L. Zerbino

Subdirector: Ing. Rosana Marcozzi

Tesis presentada para el grado de

MAGISTER ESTRUCTURADA EN INGENIERIA VIAL

Área Departamental Construcciones, Facultad de Ingeniería, U.N.L.P. Octubre, 2012. 



\section{Agradecimientos}

Quiero expresar mi más sincero agradecimiento al Ing. Raúl Zerbino por la colaboración y dedicación durante la ejecución de esta tesina. También quiero agradecer especialmente a la Ing. Rosana Marcozzi por la dirección, enseñanza y tiempo dedicado a este trabajo.

Al Ing. Horacio Osio por su aporte en esta tesis.

Al director del LEMIT (Laboratorio de Entrenamiento Multidisciplinario para la Investigación Tecnológica) Ing. Luis Traversa por permitir la realización del trabajo de investigación en dicho laboratorio. A todo el personal que trabaja en las áreas de Tecnología del Hormigón y Tecnología Vial por la colaboración brindada de manera desinteresada en la realización de los diferentes ensayos.

Por último, quiero agradecer especialmente a mi familia: mi papá Gino, mi mamá Fátima que han sido mi ejemplo, guía y sustento para seguir adelante, a mis hermanos María Julia, María Cristina y Carlos por el apoyo brindado incondicionalmente. A mis abuelos: Armando ( $\dagger$ ), Estrella $(\dagger)$ y Zoila por su ejemplo de superación incasable, por su comprensión y confianza, por su amor y amistad incondicional, a mis tíos, primos y amigos. 


El aprovechamiento de residuos aparece como un tema prioritario para preservar el consumo de recursos naturales, cubrir necesidades crecientes de materia prima y fundamentalmente minimizar la necesidad de espacios para la disposición de residuos protegiendo al medio ambiente.

El objetivo de esta tesis es desarrollar un enfoque holístico del problema de reciclado de pavimentos urbanos, a partir del análisis de un caso específico en la zona del Gran La Plata, donde de hecho existen numerosos pavimentos que requieren de reparación y reconstrucción.

El estudio se realizó sobre las fracciones fina y gruesa de agregados reciclados obtenidos a partir de la trituración de losas que eran retiradas de un bacheo próximo a avenida 122 y calle 43 de La Plata. Luego de caracterizar estos agregados, se analizaron varias alternativas de uso entre las que se incluyen hormigones con diferentes niveles de resistencia $(\mathrm{H}-13$ y $\mathrm{H}-30)$, pavimentos asfálticos y estabilizados granulares, realizando además un estudio comparativo con mezclas similares elaboradas sólo con agregados naturales. Los hormigones $\mathrm{H} 13$ con agregados reciclados presentaron propiedades similares a los elaborados con agregados naturales, mientras que en los H30 se redujo ligeramente la resistencia. Al incorporar agregado reciclado (grueso y fino) en concreto asfáltico en caliente no se cumplieron los requisitos de la norma vigente, al emplear sólo la fracción fina se alcanzaron los parámetros requeridos pero creció la rigidez. En el estabilizado granular mezclando agregado reciclado grueso y fino en diferentes porcentajes, resultó un Valor Soporte inferior al requerido para bases y mayor al exigido para subbases.

Finalmente se realiza un estudio de los costos de construcción de pavimentos y bases granulares con agregados reciclados. A partir del mismo surge que, incluso sin considerar los beneficios ambientales, existen alternativas que implican un ahorro económico considerable comparado con el uso de agregados naturales, principalmente en lo relacionado con el costo de los materiales y su transporte al sitio de trabajo. 


\section{Abstract}

The use of residues appears as a priority topic to preserve the consumption of natural resources, to cover increasing needs of raw material and mainly to minimize the areas for waste disposal protecting the environment.

The objective of this thesis is to develop a holistic approach to the problem of recycling urban pavements, based on the analysis of a specific case in the area of Gran La Plata, where there are many pavements requiring repair and reconstruction.

The study was performed on the fine and coarse fractions of recycled aggregates obtained from crushing concrete slabs that were removed from within a patching near 122 avenue and 43 street, La Plata. After characterizing these aggregates, several alternative uses were considered including concrete of different strength levels $(\mathrm{H}-13$ and $\mathrm{H}-30)$, asphalt pavement and granular stabilization; there were also performed a comparative studies with similar mixtures incorporating only natural aggregates.

Concrete $\mathrm{H}-13$ with recycled aggregate showed similar properties than concrete prepared with natural aggregates; in concrete $\mathrm{H}-30$ it was found a light decrease in strength. When recycled aggregate (coarse and fine) was incorporated in hot asphalt concrete the standard requirements were not achieved; using only the fine fraction of the recycled aggregate the required parameters were achieved but it appeared an increase in stiffness. In the granular stabilization, combining different percentages of coarse and fine recycled aggregates, the CBR was lower than the required for granular bases and higher than the value required for sub-bases.

Finally, it was performed a study of the construction costs of pavements and granular bases with recycled aggregates. It was found that, even without considering environmental benefits, there are alternatives that involve significant costs saving when compared with the use of natural aggregates, mainly regarding the materials and transport costs. 


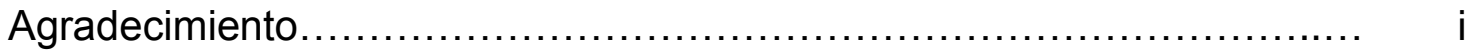

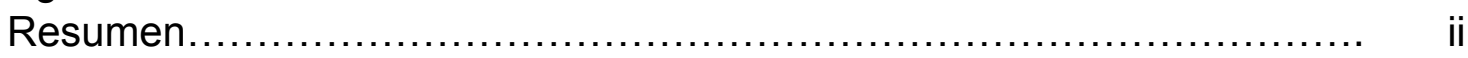

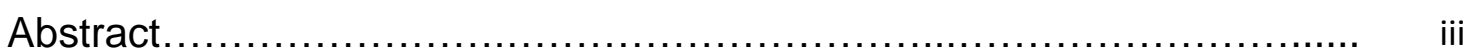

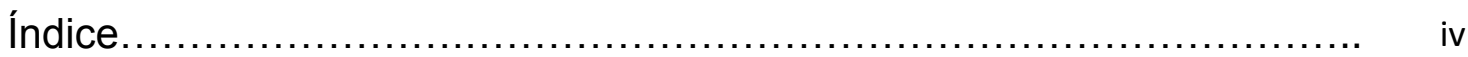

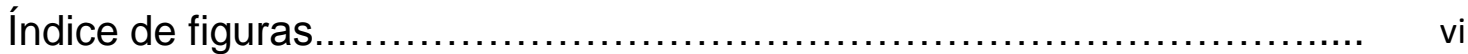

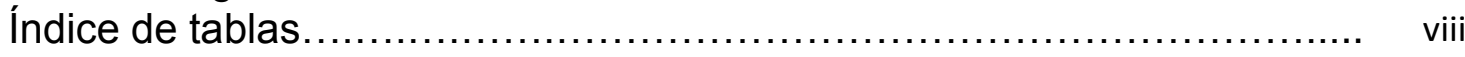

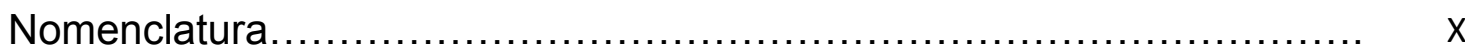

\section{CAPÍTULO 1: INTRODUCCION}

1.1.- Residuos de construcción y demolición.................................... 1

1.2.- Objetivos............................................................... 4

1.3.- Estructura de la tesis.................................................. 5

\section{CAPÍTULO 2: ESTADO DEL ARTE}

2.1.- Áridos Reciclados............................................................. 7

2.2.- Uso del árido reciclado obtenido del hormigón.......................... 9

2.3.- Uso de AR en nuevos hormigones y efectos sobre sus propiedades. $\quad 15$

2.3.1.- Efecto sobre las propiedades del hormigón en estado fresco...... 15

2.3.2.- Efecto sobre las propiedades mecánicas del hormigón.............. 18

2.4.- Uso de AR en concretos asfalticos y efectos sobre sus propiedades. 23

2.5.- Uso de AR en bases granulares y efectos sobre las propiedades..... 31

2.6.- Forma de obtención de los agregados reciclados....................... 36

2.7.- Propiedades de los agregados reciclados provenientes del Hormigón................................................................. 40

\section{CAPÍTULO 3: PROGRAMA EXPERIMENTAL}

3.1.- Introducción............................................................. 50

3.2.- Obtención del árido reciclado .......................................... 52

3.3.- Metodología del ensayo .............................................. 55

3.3.1.- Caracterización del agregado grueso.................................. 55

3.3.2.- Caracterización del agregado fino..................................... 58

3.3.3.- Caracterización de hormigones....................................... 58

3.3.4.- Caracterización de mezclas asfálticas................................ 61

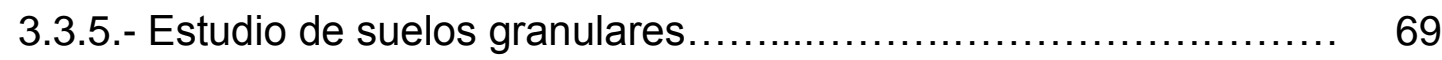

\section{CAPÍTULO 4: CARACTERIZACION DEL ARIDO RECICLADO}

4.1.- Introducción.......................................................... $\quad 70$

4.2.- Caracterización del agregado grueso.................................... 71

4.3.- Caracterización del agregado fino...................................... 76 


\section{CAPÍTULO 5: HORMIGONES RECICLADOS}

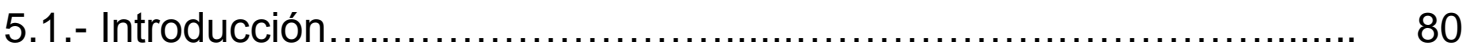

5.2.- Materiales y mezclas.................................................. 80

5.3.- Propiedades en estado fresco........................................ 82

5.4.- Propiedades en estado endurecido................................... 84

5.5.- Discusión y conclusiones sobre las experiencias en hormigones...... 88

\section{CAPÍTULO 6: MEZCLAS ASFALTICAS CON AGREGADOS}

\section{RECICLADOS}

6.1.- Introducción.............................................................. 91

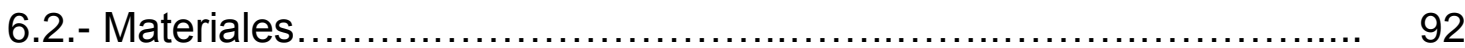

6.3.- Mezclas con AGR y AFR ............................................... 94

6.4.- Mezclas con AGN y AFR................................................ 100

6.5.- Evaluación de la performance de mezclas con AFR...................... 104

6.6.- Consideraciones finales.................................................. 109

6.7.- Recomendaciones................................................. 110

\section{CAPÍTULO 7: BASE GRANULAR CON AGREGADOS RECICLADOS}

7.1.- Introducción............................................................ 111

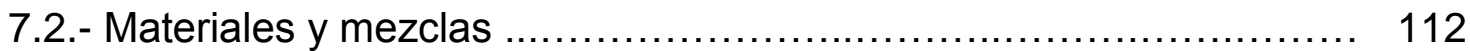

7.3.- Conclusiones............................................................. 119

\section{CAPÍTULO 8: ANALISIS DE COSTO}

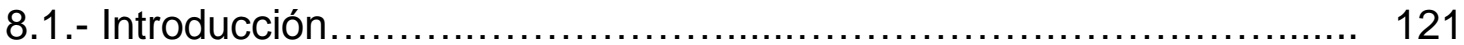

8.2.- Análisis de precio unitario ................................................ 122

8.2.1.- Datos de referencia................................................... 123

8.2.2.- Análisis comparativo de precios unitarios para diferentes aplicaciones .......................................................... 126

8.3.- Análisis del material necesario para reconstruir una vía................ 138

8.4.- Consideraciones finales................................................... 141

\section{CAPÍTULO 9: CONCLUSIONES Y RECOMENDACIONES}

9.1.- Conclusiones de la tesis..................................................... 143

9.2.- Recomendaciones para estudios futuros............................. 146

CAPÍTULO 10: REFERENCIAS BIBLIOGRAFICAS

Referencias bibliográficas.......................................... 148 


\section{Índice de figuras}

Figura 2.1: Variación de la resistencia a compresión con diferentes relación a/c para hormigones reciclados y convencionales (Adaptado de Rasheeduzzafar y Khan, 1984)....

Figura 2.2: Parámetros Marshall de las mezclas: (a) \% de vacíos, (b) VAM, (c) RBV y (d) Estabilidad (Yoon-Ho Cho et al, 2010)

Figura 2.3: Resultado del Wheel Tracking (Yoon-Ho Cho et al, 2010)...... Figura 2.4: Humedad óptima y densidad máxima de compactación (Poon et al, 2006).

Figura 2.5: Evolución de la capacidad portante a lo largo del tiempo:

áridos reciclados (ARB-I y ARV-II) y árido calizo.

Figura 2.6: Trituradora de mandíbulas

Figura 2.7: Trituradora de rodillo.

Figura 2.8: Trituradora de impacto

Figura 2.9: Trituradora de cono.

Figura 2.10: Características de los agregados gruesos reciclados

Figura 3.1: Pedazos de losas de pavimento usados en la obtención de áridos.

Figura 3.2: Testigos de losas de pavimentos.

Figura 3.3: Trituradoras empleadas.

Figura 3.4: Forma y tamaño de las puntas utilizadas en el ensayo.

Figura 3.5: Característica de la muestra utilizada en el ensayo de carga

Puntual.

Figura 3.6: Ensayo de tracción indirecta según norma IRAM 1658.

Figura 3.7: Ensayo de tracción indirecta.

Figura 3.8: Equipos: Balanza y comparador empleados para medir la pérdida de peso y la contracción por secado.....

Figura 3.9: Equipo necesario para la obtención de módulo de Rigidez......

Figura 3.10: Curva Deformación - Tiempo en el ensayo de Wheel

Tracking.

Figura 3.11: Ensayo de Daño por humedad.

Figura 4.1: Curvas granulométricas de los agregados gruesos utilizados en pavimentos rígidos.

Figura 4.2: Curvas granulométricas de los agregados gruesos utilizados en mezclas asfálticas......

Figura 4.3: Desarrollo de ensayos de carga puntual, muestra de agregados ensayados.

Figura 4.4: Curvas granulométricas de los agregados finos.

Figura 5.1: Asentamiento medido para hormigones tipo H30. (Izq. con AGN y Der. con AGR).

Figura 5.2: Resistencia a compresión de los hormigones.

Figura 5.3: Rendimiento de los hormigones.

Figura 5.4: Resistencias a compresión diametral y flexión de los hormigones. 
Figura 5.5: Módulos de elasticidad estático de los hormigones.............. 87

Figura 5.6: Contracción por secado de los hormigones..................... 88

Figura 5.7: Pérdida de peso de los hormigones............................ 88

Figura 6.1: Temperaturas de mezclado y compactación..................... 94

Figura 6.2: Degradación del material reciclado en el mezclado y

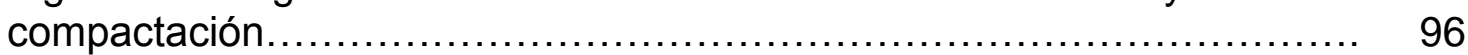

Figura 6.3: I-D19: Granulometrías originales y recuperadas................ 97

Figura 6.4: I-G19 SS: Granulometrías originales y recuperadas............ 97

Figura 6.5: I-G19 CS: Granulometrías originales y recuperadas............ 98

Figura 6.6: Degradación de la mezcla I-D19..................................... 98

Figura 6.7: Degradación de la mezcla I-G19 SS................................. 99

Figura 6.8: Degradación de la mezcla I-G19 CS............................ 99

Figura 6.9: Parámetros volumétricos obtenidos con el barrido de ligante para un CAC II-D19.................................................... 101

Figura 6.10: Parámetros volumétricos obtenidos con el barrido de ligante para un CAC II- G19................................................ 102

Figura 6.11: III-D19: Granulometrías originales y recuperadas............. 107

Figura 6.12: III-G19: Granulometrías originales y recuperadas.............. 107

Figura 6.13: Curva de profundidad de huella en el ensayo de WTT........ 108

Figura 7.1: Granulometría de la base granular con AR ..................... 113

Figura 7.2: Obtención de las condiciones óptimas de compactación......... 114

Figura 7.3: Degradación de los agregados reciclados después del ensayo Proctor......................................................... 115

Figura 7.4: Hinchamiento de las probetas sumergidas en agua............. 116

Figura 7.5: Ensayos de Valor Soporte (CBR) sobre probetas de base

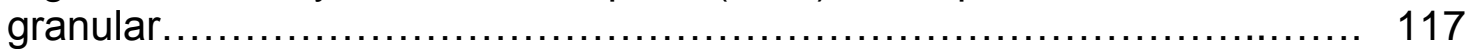

Figura 7.6: P.U.V. seco vs CBR.......................................... 118

Figura 7.7: Granulometría de una subbase granular con AR ................ 119 
Tabla 2.1: Tipos de trituradoras empleadas ................................. 39

Tabla 2.2: Propiedades específicas de cada sistema de trituración......... $\quad 40$

Tabla 2.3: Mortero adherido a los áridos según varios autores.............. 41

Tabla 2.4: Densidad del AGR según varios autores........................... 44

Tabla 2.5: Absorción en AR en comparación con AN según varios

autores.

Tabla 2.6: Desgaste "Los Ángeles" del AGR según varios autores......

Tabla 3.1: Propiedades del hormigón de origen.............................

Tabla 3.2: Normas de ensayo para caracterización de agregados...........

Tabla 3.3: Normas de ensayo para agregados finos.....

44

46

48

52

55

Tabla 4.1: Granulometría de los agregados gruesos......................... 72

Tabla 4.2: Propiedades de los agregados gruesos.......................... $\quad 74$

Tabla 4.3: Resistencia estimada a partir de ensayos de carga puntual

sobre las partículas de los agregados gruesos.

Tabla 4.4: Granulometría de los agregados finos.

Tabla 4.5: Propiedades de los agregados finos empleados en mezclas asfálticas.

Tabla 5.1: Proporciones de las distintas mezclas.

Tabla 5.2: Propiedades en estado fresco de los hormigones................ 82

Tabla 5.3: Propiedades mecánicas de los hormigones.

Tabla 6.1: Ensayo de los Ángeles con distintas combinaciones de AGR y

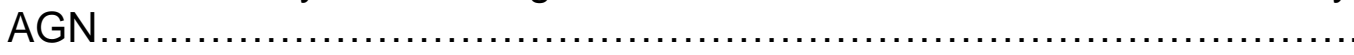

Tabla 6.2: Caracterización del asfalto para uso vial por Penetración.........

Tabla 6.3: I-CAC que incorporan la totalidad de AR....

Tabla 6.4: Parámetros Marshall obtenidos en las distintas CAC..............

Tabla 6.5: II-CAC que incorporan la totalidad de AFR y AGN....

Tabla 6.6: Parámetros de las mezclas con el contenido óptimo de asfalto adoptado

100

Tabla 6.7: Dosificación definitiva de las mezclas asfálticas de la serie II...

Tabla 6.8: Serie III. Propiedades de las mezclas.

Tabla 6.9: Daño por humedad.

Tabla 6.10: Parámetros de ahuellamiento en la mezcla III-D19.

Tabla 7.1: Propiedades del suelo empleado para la elaboración de la base granular.

Tabla 7.2: Composición de la base granular....

Tabla 7.3: Granulometría de los distintos materiales y la resultante para elaborar una base granular

Tabla 7.4: Valores obtenidos y requisitos de DNV para bases de pavimento.

Tabla 8.1: Planilla General de costos de Materiales

Tabla 8.2: Planilla General de costo de Mano de Obra.....

Tabla 8.3: Planilla General de costo de Transporte de materiales.

Tabla 8.4: APU de la Subbase Granular con $A R, e=0,20 m\left(U=m^{2}\right)$. 
Tabla 8.5: APU de la Subbase Granular con $A N, e=0,20 m\left(U=m^{2}\right) \ldots \ldots \quad 130$ Tabla 8.6: APU de Pavimento de hormigón simple H13R, e =0,20 m $\left(\mathrm{U}=\mathrm{m}^{2}\right)$

Tabla 8.7: APU de Pavimento de hormigón simple H13N, e = 0,20 m $\left(\mathrm{U}=\mathrm{m}^{2}\right)$

Tabla 8.8: APU de Pavimento de hormigón simple H30R, e = 0,25 m $\left(\mathrm{U}=\mathrm{m}^{2}\right)$

Tabla 8.9: APU de Pavimento de hormigón simple $\mathrm{H} 30 \mathrm{~N}$, e = 0,25 m $\left(\mathrm{U}=\mathrm{m}^{2}\right)$

Tabla 8.10: APU de Base asfáltica con AFR, e = 0,10 m (inc. Riego de liga) $\left(\mathrm{U}=\mathrm{m}^{2}\right)$

Tabla 8.11: APU de Base asfáltica con AFN, e = 0,10 m (inc. Riego de liga) $\left(\mathrm{U}=\mathrm{m}^{2}\right)$

Tabla 8.12: Análisis de Precio Unitario de los diferentes casos. 136

Tabla 8.13: Síntesis de Precio unitario de los diferentes rubros.

Tabla 8.14: Cantidad de material necesario para la vía

Tabla 8.15: Presupuestos de obra para el tramo de vía: Estabilizado

Tabla 8.16: Presupuestos de obra para el tramo de vía: $\mathrm{H} 13+\mathrm{H} 30$ 
AASHTO: American Association of State Highway and Transportation Officials

Ab: $\quad$ Absorción de agua [\%]

a/c: Razón agua/cemento (en peso)

ACl: $\quad$ American Concrete Institute

AFN: $\quad$ Agregado fino natural

AFR: $\quad$ Agregado fino reciclado

AGN: $\quad$ Agregado grueso natural

AGR: $\quad$ Agregado grueso reciclado

Al: $\quad$ Asphalt Institute

AN: $\quad$ Agregado natural

APU: $\quad$ Análisis de Precio unitario

AR: $\quad$ Agregado reciclado

ASTM: American Society for Testing and Materials

As: $\quad$ Asentamiento

CA: $\quad$ Cemento asfáltico

CAC: $\quad$ Concreto Asfáltico en caliente

CEDEX: Centro de Estudios y Experimentación de Obras Públicas

CIRSOC: Centro de Investigación de los Reglamentos Nacionales de Seguridad para las Obras Civiles

CPA: $\quad$ Comisión Permanente del Asfalto

COV: $\quad$ Coeficiente de Variación

Da: $\quad$ Densidad aparente de la mezcla asfáltica

DNV: $\quad$ Dirección Nacional de Vialidad

Dr: $\quad$ Densidad relativa real

Ds: Densidad relativa aparente del agregado seco

Dsss: $\quad$ Densidad en condición de saturado y superficie seca

E: $\quad$ Módulo de elasticidad estático

EHE: Instrucción del Hormigón Estructural

EN: $\quad$ Norma Europea

F: $\quad$ Fluencia

f'c: $\quad$ Resistencia a compresión

ftc: Resistencia a tracción por compresión diametral

h: Hora

HC: $\quad$ Hormigón convencional

HR: $\quad$ Hormigón reciclado

H.R.B: Highway Research Board

IE: Índice de elongación

IL: $\quad$ Índice la lajosidad

IRAM: Instituto Argentino de Normalización y Certificación

LA: $\quad$ Desgaste de Los Ángeles [\%] 
LEMIT: Laboratorio de Entrenamiento Multidisciplinario para la Investigación Tecnológica

MR: $\quad$ Módulo de rotura en flexión

PETG: $\quad$ Pliego de Especificaciones Técnicas Generales (PUETG)

PUV: $\quad$ Peso por unidad de volumen del hormigón

PUVs: $\quad$ Peso por unidad de volumen del agregado en estado suelto

RAP: $\quad$ Reclaimed Asphalt Pavement

RCD: $\quad$ Residuos de construcción y demolición

RBV: $\quad$ Relación betún vacíos [\%]

s: Desvío estándar

Sm: $\quad$ Módulo de Rigidez

Tn: $\quad$ Toneladas

VAM: Vacíos del agregado mineral [\%]

WTT: Wheel Tracking Test 


\section{Capítulo 1}

\section{INTRODUCCIÓN}

\section{1.- RESIDUOS DE CONTRUCCION Y DEMOLICION}

En la actualidad se reconoce que la utilización indiscriminada de recursos naturales constituye una causa del deterioro paulatino y progresivo del medio ambiente. Este comentario nos acerca a la línea temática de este trabajo que se orienta a establecer mecanismos de reutilización de los materiales de construcción principalmente provenientes del hormigón.

El reciclado y reutilización de residuos de construcción y demolición (RCD) se ha extendido prácticamente a todos los países desarrollados en los últimos años, fundándose tanto en razones de valorización comercial como medioambientales, unidos a una creciente concienciación ciudadana, respecto a la necesidad de ver la forma de reciclar los materiales que han cumplido su vida útil.

Existen grandes atractivos y ventajas para el empleo de los RCD sea como reemplazo parcial o total del agregado natural, fino o grueso, principalmente aquellos que provienen de la trituración de hormigones viejos, procedentes de diversas obras de infraestructura. Como fuera indicado entre los motivos que justifican el uso de RCD aparecen fundamentalmente la preservación del medio ambiente, la conservación de los recursos naturales, la reducción de los costos y el aprovechamiento racional de la energía.

Los primeros estudios documentados sobre la caracterización de materiales provenientes de la demolición de pavimentos, para su empleo como agregados en hormigón, datan de mediados de la década del '40 realizado por 
los europeos hecho que se encuentra directamente vinculado con el período de postguerra y cuya finalidad era la búsqueda de una aplicación para estos materiales de desecho. De este modo, ello permitiría reducir grandes cantidades de escombros o desechos originados por la destrucción de las ciudades, lo cual requeriría una menor necesidad de terrenos para su disposición, a la vez que disminuiría la demanda de materiales vírgenes necesarios para la reconstrucción de los centros urbanos [Nixon, 1978; Olorunsogo y Padayachee, 2002].

Ya en 2002 se daba cuenta que la industria del hormigón empleaba a nivel mundial aproximadamente 10 billones de toneladas de arena y roca natural, generando más de 1 billón de toneladas en RCD cada año [Mehta, 2002]. En tal sentido, en Estados Unidos se estimaba que dichos residuos alcanzan valores del orden de 250 a 300 millones de toneladas/año. Por su parte, a comienzos de este siglo en Japón se generaban 85 millones de toneladas/año de residuos de construcción, de los cuales un $40 \%$ correspondían a desechos de hormigón [Kasai, 2004]. En la Comunidad Europea se estimaba que la generación de RCD era del orden de los 200 a 300 millones de toneladas anuales, lo cual equivale entre 0,5 a 1 tonelada per cápita por año. Asimismo, aproximadamente el $28 \%$ de estos desechos fueron reciclados hacia fines de la década del '90 [Lauritzen, 2004]. Considerando datos del 2005 surge que en el caso de Alemania, los RCD ascienden a 88,6 millones de toneladas anuales de los cuales el $69 \%$ es reciclado y utilizado para la elaboración de materiales de construcción, y de ello, sólo 1,9 millones de toneladas (aproximadamente $3,1 \%$ ) es empleado como agregado para hormigón [Müller, 2005]. Holanda genera anualmente 20 millones de toneladas/año de RCD, equivalente a 1,25 toneladas por habitante, de los cuales más del $95 \%$ es reutilizado, mayormente para subbases de caminos y sólo un 3,3 \% en la elaboración de nuevos hormigones [Janssen y Put, 2005]. En España la generación de residuos es de 38,5 millones de toneladas, y un $20 \%$ constituye desechos de hormigón [Vázquez, 2005]. Por otra parte en Israel la cantidad de residuos de construcción es del orden de 7,5 millones de toneladas anuales, equivalente a 1,1 tonelada per cápita por año; siendo la mayoría de ellos depositados como relleno en sitios tanto legales como ilegales 
[Katz et al, 2005]. Respecto a datos de producción de hormigón en Argentina se estima que está por encima de los 4 millones de metros cúbicos anuales pero no aparecen mayores ejemplos sobre el uso de hormigón reciclado.

Otro de los beneficios es el relacionado con el costo del transporte; en países como la Argentina con una gran extensión territorial y grandes zonas de llanura, el traslado de los agregados naturales desde los yacimientos 0 canteras hasta los centros urbanos posee un impacto importante en el costo influyendo directamente en el precio de la construcción. Lo contrario sucedería con el uso de agregados reciclados, ya que el lugar de generación es el mismo en el cual se dan las posibilidades para su empleo.

La importancia e interés en el uso de RCD se refleja en muchos países como Japón, EE.UU., Bélgica, Holanda, Reino Unido, entre otros, que han elaborado normas, reglamentos o recomendaciones para tal fin. Los RCD pueden emplearse como agregados para la producción de bases y subbases granulares de camino o en hormigones estructurales. En algunos casos, dichos documentos datan de aproximadamente dos décadas atrás [Grúbl y Rühl, 1998; Hansen, 1986; RILEM, 1994; Balázs et al, 2008; Kasai, 1994; Vyncke y Rousseau, 1994; Janssen y Put, 2005; Poon, 2005]. Un claro ejemplo a nivel internacional lo constituye España, quien en el año 2001 comenzó a llevar a cabo el Plan Nacional de Residuos de Construcción y Demolición (PNRCD 2001-2006), cuyo fin es alcanzar un porcentaje de empleo del material reciclado en la elaboración de hormigones cercano al 60 \%. Actualmente, con más de 200 plantas recicladoras se encuentra en desarrollo el II Plan Nacional de Residuos de Construcción y Demolición (II PNRCD 2007-2015), el cual forma parte del Plan Nacional Integrado de Residuos (PNIR 2008-2015), dentro del cual algunos de los objetivos planteados incluyen la reducción de los RCD, la clausura de vertederos inadecuados, la recolección controlada y correcta gestión de los RCD en un $95 \%$, y el reciclaje del $40 \%$ de los RCD a partir de 2011. Debe mencionarse que España ya posee una recomendación para el uso de los agregados gruesos reciclados en hormigones con requerimientos resistentes de tipo estructural, admitiendo su empleo hasta un máximo de $20 \%$ en reemplazo del agregado grueso natural [EHE, 2008]. 
En Argentina, en cambio, no se da la misma situación ya que se carece de algún tipo de normativa o recomendación para el empleo de materiales reciclados provenientes de desechos de la construcción. No obstante laboratorios como el LEMIT y algunas universidades vienen investigando el uso del material reciclado en hormigones con niveles de resistencia y durabilidad similares a los exigidos para los hormigones con agregados naturales.

Dentro de este panorama se propuso evaluar un caso concreto de interés para la provincia de Buenos Aires y en particular para la Dirección de Vialidad, que es el reciclado de pavimentos en la zona del Gran La Plata. Este caso tiene la potencialidad de aplicarse como antecedente a otros conglomerados urbanos del Gran Buenos Aires.

\section{2.- OBJETIVOS}

El objetivo principal de esta tesis es estudiar las alternativas de uso de RCD para un caso específico: el agregado reciclado (AR) obtenido a partir de pavimentos urbanos en la zona del Gran La Plata. El análisis se desarrolla con un enfoque holístico considerando tanto aspectos tecnológicos como el impacto económico, para el aprovechamiento en diferentes materiales utilizados en obras viales: hormigones, concretos asfálticos o bases granulares.

Entre los objetivos específicos se destacan:

- Caracterizar el material proveniente de pavimentos urbanos,

- Evaluar las posibilidades de uso del material integral, de algunas fracciones o su combinación con agregados naturales para elaborar hormigones, concretos asfálticos o bases granulares,

- Verificar experimentalmente los casos de mayor interés,

- Analizar las ventajas y desventajas tecnológicas con respecto al uso de agregados naturales,

- Realizar un análisis comparativo de costos con respecto al uso de agregados naturales,

- Elaborar recomendaciones acerca de las alternativas de reciclado y aprovechamiento de pavimentos urbanos. 


\section{3.- ESTRUCTURA DE LA TESIS}

Esta tesis se encuentra dividida en dos partes en lo que se refiere a su desarrollo experimental. La primera parte está enfocada a evaluar las propiedades físico-mecánicas del agregado reciclado proveniente de la trituración de losas de pavimento de la ciudad de La Plata. En la segunda parte se realiza la verificación de posibles usos del AR en el campo vial, incluyendo hormigones, mezclas asfálticas y estabilizados granulares.

En el presente capítulo se dio un panorama general del impacto del tema elegido y de los objetivos buscados. En el capítulo 2 se desarrolla un estado del arte que incluye las características generales de los agregados reciclados, las formas de obtención y características de las plantas productoras. Asimismo se sintetizan los diferentes usos del hormigón reciclado y las propiedades de los materiales resultantes, en especial considerando las tres aplicaciones seleccionadas para el aprovechamiento del AR: nuevos hormigones, concretos asfálticos y estabilizados granulares.

En el capítulo 3 se sintetiza el programa experimental y se detallan los métodos de ensayos empleados en cada caso.

En el capítulo 4 se analizan las propiedades y características del agregado reciclado tanto la fracción gruesa como la fina obtenidas a partir de los pedazos de losas de pavimento.

En el capítulo 5 se presentan los estudios realizados para la verificación de las propiedades del hormigón que incorpora AR. Las propiedades encontradas son comparadas con mezclas similares elaboradas con agregados naturales.

En el capítulo 6 se verifican las propiedades de dos mezclas asfálticas, una densa y otra gruesa elaboradas con agregados reciclados. Además se evalúa la performance de dichas mezclas.

En el capítulo 7 se presentan las experiencias obtenidas elaborando una base granular con agregados reciclados, llegando a encontrar la capacidad portante como aporte estructural en un pavimento. 
En el capítulo 8 se realiza un análisis de precios comparando el costo de elaborar hormigones, concretos asfalticos y subbases granulares con agregados naturales y los elaborados con agregados reciclados, y posteriormente se plantea su aplicación a la resolución de un caso.

En el capítulo 9 se detallan las conclusiones y recomendaciones acerca del uso de $A R$, y finalmente en el capítulo 10 se indican las referencias bibliográficas. 


\section{Capítulo 2}

\section{ESTADO DEL ARTE}

\section{1.- ARIDOS RECICLADOS}

En un contexto general, se entiende por árido reciclado $(A R)$ aquél "árido resultante del procesamiento de materiales inorgánicos utilizados previamente en la construcción". La materia prima para su obtención, son pues, los materiales pétreos generados como residuo durante los procesos de construcción y demolición. Los residuos de hormigón de cemento Portland y áridos naturales, machacados, cribados y procesados en plantas de reciclado dan lugar al material secundario "árido reciclado de hormigón." Este material tiene su origen de un solo material, el hormigón. El árido reciclado obtenido no se lo puede considerar un material homogéneo, ya que la diferencia de su composición estará en función principalmente del mortero presente en el residuo. También hay que considerar la presencia de subcomponentes, que pueden admitirse hasta un cierto límite, siempre que sean de naturaleza pétrea [Robas, 2009].

La necesidad de la utilización de áridos reciclados en la construcción está fundamentada por motivos de índole medioambiental, debido a la generación de grandes volúmenes de residuos de difícil gestión de degradación de paisajes para la obtención del agregado.

Existen numerosos estudios que han evaluado las propiedades de los áridos reciclados, obteniéndose una gran dispersión de resultados ya que la calidad de los mismos dependen de numerosos factores, como pueden ser, la resistencia del hormigón anterior, el grado de limpieza que presentan los áridos, las técnicas de procesamiento utilizadas. 
Los otros tipos de áridos reciclados para Etxeberria et al, (2003) son:

Árido reciclado cerámico: Árido que se obtiene por procesamiento de material predominantemente cerámico. El $85 \%$ de este árido debe tener una densidad seca superior a $1600 \mathrm{~kg} / \mathrm{m}^{3}$ en la norma holandesa, para evitar materiales excesivamente porosos y ligeros.

Áridos reciclados mixtos: Definido en la norma holandesa como un árido que deberá contener un porcentaje mayor del $50 \%$ de hormigón con una densidad seca superior a $2100 \mathrm{~kg} / \mathrm{m}^{3}$ y no más del $50 \%$ de materiales pétreos reciclados de distinta naturaleza que el hormigón, incluyendo los cerámicos con una densidad seca mayor de $1600 \mathrm{~kg} / \mathrm{m}^{3}$. Muchas normativas no permiten el uso de estos dos últimos tipos en hormigón estructural. Otras, como la holandesa, toleran el uso de árido reciclado cerámico en hormigones no estructurales. Este tipo de árido puede considerarse como un árido ligero. Su empleo aumenta el contenido de aire y obliga también a una relación agua/cemento $(\mathrm{a} / \mathrm{c})$ mayor provocando una disminución de la resistencia a compresión y del módulo de elasticidad del hormigón.

El único tipo de árido reciclado que puede ser admisible para elaborar hormigón estructural es el "árido reciclado de hormigón" que no tiene betún y eso ayuda a una mayor resistencia de la nueva interface que se creará entre la nueva pasta de cemento y los áridos reciclados y deben imponérsele valores límites para las impurezas que puedan tener efectos negativos sobre la resistencia y durabilidad [Etxeberria et al, 2003].

El uso de las fracciones finas del árido reciclado de hormigón implica, entre otros inconvenientes, un aumento muy notable de la retracción por secado y de la fluencia debido a la mayor cantidad de agua que precisan en su dosificación [Hansen y Narud, 1983]. Por ello, en Europa sólo se permite el uso de las fracciones gruesas que reducen notablemente las diferencias con respecto a un hormigón con áridos convencionales. En general, puede decirse que los áridos reciclados de hormigón de tamaño $\geq 4 \mathrm{~mm}$ son potencialmente aptos para la fabricación de hormigón, cumpliendo en su caso las especificaciones complementarias para cada aplicación concreta. 
Las diferentes normas o recomendaciones consideran que si se reemplaza menos de un $20 \%$ el agregado natural (AN) por reciclado (AR), las propiedades mecánicas del hormigón permanecen prácticamente constantes. Cuando se empleen porcentajes mayores deberá analizarse sus limitaciones.

En cuanto a su utilización como agregado grueso en mezclas asfálticas no existe norma alguna que lo recomiende, Paranavithana y Mohajerani (2006) han encontrado que el uso de agregados gruesos provenientes de AR disminuye los valores de algunas propiedades volumétricas, el módulo resiliente y el creep, pero que igualmente se encuentran dentro de límites especificados. Otros investigadores como Cerutti et al (2009) recomienda su usos para bases asfálticas, estabilizados y como capa de rodadura para red terciaria.

En el siguiente apartado se muestran los principales antecedentes en el uso de agregados reciclados en la elaboración de hormigones, concretos asfálticos y estabilizados granulares.

\section{2.- USO DEL ARIDO RECICLADO OBTENIDO DEL HORMIGON}

Los antecedentes en el uso de hormigón triturado como agregado para la elaboración de nuevos hormigones reciclados, bases y subbases granulares se remontan a varias décadas atrás, generalmente asociados a la destrucción de grandes ciudades por la Segunda Guerra Mundial. La utilización de grandes áreas de terrenos destinados para depositar los escombros y el aumento en la demanda de materiales vírgenes para la reconstrucción de las grandes ciudades, motivaron el estudio de las propiedades de dicho material con el fin de emplearlo en la elaboración de nuevos materiales fundamentalmente en reemplazo del agregado natural en hormigones. Cabe citar los estudios de la Building Contractors Society (Japón 1978) y el reciclado de pavimentos en USA; información sobre procesos de obtención y propiedades que fue recopilada por el Comité del ACI (2002). En Europa se propicia su uso desde hace más de una década y se han desarrollado normativas y recomendaciones al respecto [RILEM, 1994].

Si bien diversos trabajos han demostrado la factibilidad del empleo de hormigón reciclado como agregado, con frecuencia su aplicación fue orientada 
a la elaboración de hormigones de baja calidad. En la actualidad el mayor conocimiento de sus propiedades han demostrado que es posible lograr hormigones con niveles de resistencia y durabilidad similares a los exigidos para hormigones elaborados con agregados naturales de densidad normal. La mayoría de los autores coinciden que el hormigón reciclado puede utilizarse sin mayores precauciones en varias aplicaciones que normalmente no demandan grandes niveles de resistencia; incluso existen referencias de hormigones de alta resistencia elaborados con agregados reciclados, aunque la falta de uniformidad del agregado es una de las mayores dificultades para lograr este tipo de hormigón [Hansen, 1983].

Los áridos procedentes de pavimentos de hormigón suelen presentar una mayor homogeneidad, menor presencia de posibles productos contaminantes en origen, requieren en muchos casos equipos y tecnologías específicas, y la incidencia del transporte en el costo de la valorización y puesta en obra de los áridos reciclados en la misma carretera es menor. El tamaño de los escombros es muy heterogéneo y depende del tipo de técnica de demolición utilizada.

La composición química de los escombros de hormigón depende de la composición del árido utilizado en su producción, puesto que más del $75 \%$ del total del hormigón lo constituye el árido, siendo el resto de los componentes de hidratación del cemento, silicatos y aluminatos cálcicos hidratados o hidróxidos de calcio.

La aplicación de áridos reciclados cada vez es más habitual en el campo de la construcción, en ámbitos variados como son la construcción de explanadas, pavimentos, o en la fabricación de hormigón. El destino de estos materiales reciclados dependerá de la naturaleza y composición mayoritaria de los residuos. Así, mientras para las explanaciones se suelen utilizar materiales procedentes tanto de residuos cerámicos, como de asfalto, de hormigón o mezcla de estos, para otras aplicaciones más restrictivas, como la fabricación de hormigones, los materiales reciclados suelen proceder de residuos de hormigón o en algún caso de mezcla de residuos de hormigón y cerámicos. 
Cada una de estas aplicaciones obligó a fijar distintos niveles de experiencia en las propiedades del árido reciclado [CEDEX, 2009].

Los agregados reciclados procedentes de hormigón para obras de tierras y terraplenes deben tenerse en cuenta la homogeneidad del residuo así como la ausencia de armaduras y contaminantes. Según la Norma Francesa NF - P 11 - 300, estos materiales son adscritos a la familia F7 de subproductos industriales y se recomiendan emplearlos en terraplenes y explanadas. Algunas administraciones norteamericanas de carreteras permiten el empleo de pedazos de hormigón, siempre y cuando no superen el tamaño máximo (150 $200 \mathrm{~mm})$.

La mayor parte de los países que permiten la utilización de áridos reciclados de hormigón en carreteras, exigen a este material las mismas especificaciones que presenta el árido natural, imponiendo además un contenido mínimo de hormigón y máximo de impurezas (materia orgánica, yeso, etc.). Cuando se utilizan en capas granulares sin tratar, inicialmente la capacidad soporte puede ser menor en comparación con las capas granulares convencionales, debido a la mayor dificultad para su compactación, pero a lo largo del tiempo se suele cementar, igualando o superando la capacidad soporte de otros materiales granulares y disminuyendo su permeabilidad. En Francia, por ejemplo, el 75 - 80 \% de la producción de hormigón triturado se emplea en capas granulares [CEDEX, 2009].

Generalmente las principales aplicaciones de los áridos procedentes de hormigón triturado son: árido grueso para hormigones, árido fino para morteros o para elaboración de cementos y la combinación de estas dos fracciones para subbases granulares. En general, los áridos gruesos reciclados procedentes de hormigón, pueden ser utilizados tanto para hormigón en masa como para hormigón armado, manteniéndose los criterios de dosificación de los hormigones convencionales. La normativa española como la alemana y las Recomendaciones RILEM solo permiten el uso hasta un $20 \%$ de sustitución de árido natural por áridos reciclados proveniente de la trituración de hormigones.

Las principales propiedades del hormigón reciclado que se ven afectadas son la demanda de agua del hormigón fresco reciclado que es mayor 
que la del hormigón hecho con agregados naturales y el consumo de cemento que para la misma resistencia es algo mayor. La densidad del hormigón reciclado es inferior a la del hormigón original; con el reemplazo del $100 \%$ del árido grueso, se puede obtener una densidad entre un 10 - $20 \%$ menor [Vries, 1993].

Sustituciones de hasta $30 \%$ del árido convencional por árido reciclado, no alteran de forma significativa la resistencia a compresión del nuevo hormigón. Cuando se sustituye el $100 \%$ del árido grueso, la resistencia a compresión puede disminuir entre un 10 y un $20 \%$. [Waingrigh et al, 1993]. El módulo elástico del hormigón reciclado es siempre inferior (entre un 15 y un 40 $\%)$ al del hormigón de referencia y alcanza los valores menores cuando se utiliza también árido fino reciclado [Ravindrarajah et al, 1985].

La retracción y fluencia del hormigón reciclado se mantienen cuando el reemplazo del árido grueso es inferior al $20 \%$, mientras que con un reemplazo del $100 \%$ de árido grueso la retracción puede aumentar hasta un $50 \%$ y la fluencia entre un 30 - $60 \%$. Si se utiliza también árido fino reciclado ambos valores aumentan aún más [RILEM, 1992].

Para la misma dosificación, tanto la absorción como la porosidad del hormigón con árido reciclado aumentan. Según estudios españoles [Barra, 1996] en un hormigón de referencia con absorciones comprendidas entre 5 y $6 \%$, y porosidad entre 11 y $13 \%$, puede alcanzar valores de absorción del orden del 8 a $9 \%$, y porosidad entre 16 y $20 \%$.

La utilización de áridos reciclados provenientes de hormigón están incluidos en diferentes normativas europeas, norteamericanas y asiáticas, donde la mayoría limita el uso de este agregado, como en los casos de hormigón en masa y armado de resistencia característica no superior a 40 $\mathrm{N} / \mathrm{mm}^{2}$, quedando excluido su empleo en hormigón pretensado. El árido reciclado debe obtenerse a partir del machaqueo de hormigón convencional excluyendo el reciclaje de hormigones especiales tales como hormigones ligeros, hormigones con fibras o aquellos fabricados con cemento aluminoso, etc. La utilización del árido reciclado en hormigones que vayan a estar expuestos a ambientes agresivos, estará condicionada por la necesidad de 
tomar precauciones especiales. La mayoría de recomendaciones limita el contenido de árido grueso reciclado al $20 \%$ en peso sobre el contenido total de agregado grueso. Con esta limitación, las propiedades finales del hormigón reciclado apenas se ven afectadas en relación a las que presenta un hormigón convencional, siendo necesaria, para porcentajes superiores, la realización de estudios específicos y experimentación complementaria en cada aplicación [CEDEX, 2009].

Las alternativas para el reciclado de hormigón provenientes del pavimento no se limitan al caso bien demostrado de la factibilidad de obtención de agregados gruesos para realizar nuevos hormigones. Existen también muchos ejemplos de incorporación de materiales reciclados en pavimentos tanto rígidos como flexibles y capas constituyentes del paquete estructural. En Italia la reutilización de materiales marginales es práctica corriente en la construcción de pavimentos para aeropuertos y caminos. Muchas investigaciones han confirmado la posibilidad de usar AR para estabilizar bases ligadas o no con cemento, para estabilizados granulares de uso como subbases y bases de pavimentos flexibles [Pasetto, 2000]. Si bien, en general, se ha encontrado que la calidad del material a reciclar es inferior a la calidad de los materiales vírgenes, se ha preferido por ser más barato y ambientalmente amigable.

En estudios de más de 10 años de data se evalúa el uso de agregados triturados de demoliciones, tanto losas de hormigón como de mampostería, en mezclas asfálticas con la función de base en el paquete estructural del pavimento [Montepara, 2000]. Si bien en estos materiales es más difícil controlar la calidad y homogeneidad del residuo resultante, se han podido preparar mezclas asfálticas de similar comportamiento y respuesta mecánica que la misma mezcla preparada con agregados vírgenes.

También se ha comprobado que con estos materiales se pueden presentar similares comportamientos frente a las deformaciones permanentes 0 ahuellamiento o aún mejorarlos. Shen et al (2004) han probado con diferentes porcentajes de reemplazo de agregados vírgenes, tanto la fracción gruesa como fina, en una mezcla asfáltica en caliente, concluyendo que las mezclas 
realizadas con el $100 \%$ de agregado reciclado o una combinación de gruesos reciclados y finos naturales de trituración presentan mejor comportamiento frente al ahuellamiento que las mezclas que incorporaban el $100 \%$ de agregados naturales triturados.

Respecto de otras propiedades de las mezclas asfálticas con agregados reciclados, Paranavithana y Mohajerani (2006) han encontrado que el uso de agregados gruesos provenientes de la trituración de hormigones disminuye los valores de algunas propiedades volumétricas, el módulo resiliente y el creep, pero que igualmente se encuentran dentro de límites especificados.

Como se dijo anteriormente, los agregados reciclados tienen el mortero de cemento adjunto a la superficie de los agregados originales lo que hace que presenten menor densidad y gran porosidad. Esta porosidad se traduce en mayores contenido de asfalto si se buscan propiedades volumétricas (como porcentajes de vacíos) similares a las de una mezcla con agregados menos porosos [Wong et al, 2007]. En el trabajo citado el contenido de asfalto se incrementó de 5,3 a 7 \% cuando se reemplazó el filler de una mezcla asfáltica por finos de trituración de RCD. Los módulos resilientes y la resistencia al creep se vieron incrementadas en las mezclas con finos de RCD en comparación con la mezcla asfáltica elaborada con filler granítico.

En el ámbito local, se han realizado varios trabajos para evaluar el efecto de la incorporación de materiales producto de trituración de hormigón dentro de las diferentes capas estructurales de un pavimento. Cerutti (2009) determina parámetros mecánicos de mezclas asfálticas y estabilizados con importantes contenidos de agregados reciclados, concluye que las mismas presentan valores de módulo de rigidez y Estabilidad Marshall suficientes para formar parte de capas de subbases y bases o incluso carpetas de rodamiento para la red terciaria. Appolloni y Morano (2009) utilizan RCD en mezclas asfálticas en caliente y en frío concluyendo que su uso es técnicamente factible para la construcción de bases asfálticas.

Hace pocos años en una obra de pavimentación en el acceso al puerto de Quequén, en la ciudad de Necochea, provincia de Buenos Aires, surgió la alternativa de obtener agregados a partir de las losas de hormigón que habían 
sido removidas, con el consiguiente impacto ambiental positivo. Se realizó el ajuste en laboratorio para el diseño y caracterización de hormigones con agregados reciclados en base a los requisitos establecidos por la Dirección de Vialidad de Buenos Aires (DVBA) y luego su posterior aplicación en obra. Se realizaron hormigones reemplazando un 50 y $100 \%$ del agregado grueso natural por agregado reciclado alcanzando resistencias del orden de $30 \mathrm{MPa}$ a la edad de 28 días [Zerbino et al, 2006].

\section{3.- USO DE AR EN NUEVOS HORMIGONES Y EFECTOS SOBRE SUS PROPIEDADES}

El uso de áridos reciclados en nuevos hormigones requiere establecer las cantidades óptimas de cemento, agua, agregados y aditivos que nos permitan obtener una determinada trabajabilidad en estado fresco y un valor estipulado de resistencia una vez endurecido.

Resulta conveniente realizar ensayos previos para determinar la cantidad de agua libre necesaria para obtener una determinada consistencia y así conocer la verdadera relación agua/cemento para conseguir una resistencia adecuada.

Las propiedades de los hormigones fabricados con AR se ven afectadas negativamente a medida que aumenta el porcentaje de agregado sustituido. No suele sobrepasarse el $50 \%$ de sustitución del agregado grueso cuando se pretende emplear en hormigón con fines estructurales. En cambio para hormigones pobres (con $f^{\prime} c<15 \mathrm{MPa}$ ) se puede reemplazar la totalidad del AGN por el AGR obteniendo propiedades mecánicas muy parecidas.

\subsection{1.- EFECTO SOBRE LAS PROPIEDADES DEL HORMIGON FRESCO Consistencia}

La incorporación total de áridos reciclados secos en el hormigón produce en general un aumento de la consistencia cuando se mantiene la misma relación agua/cemento. Debido a la elevada absorción que presenta el árido reciclado, durante el proceso de amasado una cierta cantidad de agua será retenida por los áridos, generando un aumento de consistencia en ocasiones importante y una reducción de la relación agua/cemento efectiva. Así, el aumento de la demanda de agua se debe principalmente a la mayor absorción 
de los áridos reciclados y al cambio de granulometría del árido, fundamentalmente por generación de finos durante el amasado, aunque también pueden influir otros factores como su forma angular y su textura rugosa. Además, la pérdida de trabajabilidad es más rápida, ya que después del amasado el árido continúa absorbiendo agua. Esto presenta un problema cuando se trata de un hormigón fabricado en planta, para el que se produce un intervalo de tiempo entre la producción y la puesta en obra.

Otros estudios realizados por Kashino y Takahashi (1988) han obtenidos consistencias similares entre hormigones elaborados con áridos reciclados y con áridos naturales.

La mayoría de bibliografía recomiendan tres opciones para tener una determinada consistencias. Se deberá proceder como primera opción estimar la cantidad de agua adicional mediante ensayos previos; la segunda opción recomienda saturar el AGR antes de ser amasado y como tercera opción utilizar un aditivo plastificante y/o superplastificante.

La segunda opción permite diferenciar entre razones a/c total y efectiva, según se considere o no el agua extra adicionada pero no asegura la cantidad de agua absorbida por el material, ya que esta dependerá de que el agregado entre en contacto directo solo con el agua de mezcla, con la pasta de cemento o con el mortero del hormigón [Vásquez y Barra, 2002]. Sin embargo, este método sería efectivo si el agregado se mantuviera por lo menos 30 minutos sumergido en el agua total de mezclado ya que durante dicho tiempo estaría absorbiendo alrededor del $90 \%$ de su capacidad [Buttler, 2003]. Otros autores [Di Maio et al, 2002] sugieren saturar los agregados reciclados durante 24 horas previo a su empleo, evitando de esta forma que absorban parte del agua de mezclado, ahorrando tiempo considerable en producción de hormigón en cantidades importantes.

La adición de un aditivo superplastificante en un momento permitirá corregir la consistencia del hormigón sin añadir más agua hasta un límite, ya que podría provocar segregación en la mezcla. El aumento de costo de fabricación puede verse compensado por la baja relación a/c y aumento de la resistencia, en relación con las dos opciones citadas anteriormente. Este 
aditivo se recomienda añadirlo un poco antes de la colocación del hormigón en el encofrado para que este no sea retenido por el árido.

\section{Densidad y aire naturalmente incorporado}

La densidad del hormigón fresco elaborado con áridos reciclados es inferior a la del hormigón convencional, debido a la menor densidad que presenta estos áridos como consecuencia del mortero adherido al agregado natural. Los valores de densidad pueden variar entre 2,13 y 2,40 kg/dm ${ }^{3}$ según diversos autores [Hansen y Narud, 1983; Sri Ravindrarajah y Tam, 1985; ACl, 2002; Hernández y Fornasier, 2005].

Referente al aire ocluido, algunos estudios determinan una variación inferior al $7 \%$ entre el hormigón convencional y el hormigón reciclado, constatando que no presentan variaciones importantes [Hansen y Narud, 1983]. Contrariamente, en otros estudios concluyeron que el contenido de aire en hormigones reciclados resulta superior al de hormigones convencionales de similares características [Di Maio et al, 2001; Hernández y Fornasier, 2005], señalando incluso que la causa que produce dicho fenómeno no resulta del todo clara [Katz, 2003].

\section{Peso por Unidad de Volumen}

La menor densidad que presentan los AGR, debido a la mayor porosidad del mortero de cemento presente en sus partículas, origina que el peso por unidad de volumen en estado fresco de las mezclas recicladas sea inferior a las elaboradas con agregados naturales del mismo tipo. Este hecho fue confirmado por diferentes autores [Hansen y Narud, 1983; Sri Ravindrarajah y Tam, 1985; ACI, 2002; Hernández y Fornasier, 2005], quienes obtuvieron valores de PUV de 50 a $150 \mathrm{~kg} / \mathrm{m}^{3}$ menores que en las mezclas convencionales. Este hecho hace que cuanto mayor sea el porcentaje de agregado reciclado menor será el PUV de las mezclas con ellos elaboradas [Di Maio et al, 2002; Topçu y Sengel, 2004].

También se ha indicado que la disminución en el PUV de las mezclas recicladas puede ser atribuida, en parte, a un mayor contenido de aire naturalmente incorporado que pueden presentar las mezclas recicladas [Katz, 2003]. 


\section{Exudación}

En el caso que se utilicen AGR secos, la exudación del hormigón preparado con este material presentará valores inferiores a los obtenidos con hormigones convencionales, debido a que los áridos reciclados retienen mayor cantidad de agua por la elevada absorción que poseen. En cambio, si se utiliza agregados reciclados previamente saturados, la exudación será similar a la del hormigón convencional.

\subsection{2.- EFECTO SOBRE LAS PROPIEDADES MECÁNICAS}

Las propiedades del hormigón reciclado pueden verse afectadas negativamente respecto a las de un hormigón convencional con la misma dosificación. El módulo de elasticidad y las resistencias pueden reducirse, y la retracción y fluencia pueden aumentar en comparación con hormigones de similares resistencias que contienen únicamente áridos naturales. En general la permeabilidad de los hormigones reciclados es más alta que la del hormigón convencional, tienen mayor capacidad de succión y resisten peor la exposición a temperaturas altas. Estas variaciones se deben fundamentalmente al aumento de la cantidad de mortero adherido al árido y serán mayores a medida que se aumente el porcentaje de sustitución de árido natural por árido reciclado.

\section{Resistencia a la compresión}

Debido a las características físico-mecánicas de los agregados reciclados, el porcentaje de empleo como reemplazo de los agregados naturales será de importancia en el comportamiento resistente de los hormigones. Las diferentes investigaciones hechas a través de todo este tiempo ha verificado que la resistencia a compresión del hormigón reciclado resulta semejante a la del hormigón convencional hasta un $30 \%$ de reemplazo del AGN por AGR [Limbachiya et al, 2000; Gómez et al, 2001]. En otros casos, dicho comportamiento se verificó hasta reemplazos del $50 \%$ en mezclas que habían sido elaboradas con un contenido de cemento de $350 \mathrm{~kg} / \mathrm{m}^{3}$, mostrando una disminución de resistencia del $16 \%$ el hormigón preparado con $100 \%$ de AGR [Gonçalves et al, 2004]. Si bien no presentan ninguna justificación respecto a dicho descenso de la resistencia, se debe mencionar que, al tener en consideración la absorción de los agregados, las mezclas recicladas fueron 
elaboradas con mayor cantidad de agua. Por tal motivo, si bien consideran que la razón a/c efectiva es igual en las mezclas de referencia y reciclada, la razón $\mathrm{a} / \mathrm{c}$ total es muy superior en los hormigones reciclados, lo cual puede ser motivo de la disminución en la resistencia a compresión.

Estudios de laboratorio realizados a nivel nacional han mostrado que la resistencia a compresión de los hormigones reciclados es semejante a la de sus pares convencionales hasta reemplazos del $75 \%$ [Di Maio et al, 2002; Di Maio et al, 2005; Zega et al, 2006], ya sea que los AGR provengan de hormigones previamente elaborados para tal fin o que hayan sido obtenidos a partir de la trituración de hormigones de procedencia desconocida.

En general, la resistencia a compresión en los hormigones fabricados con AGR disminuye con respecto a los convencionales, manteniendo en ambos la misma relación agua/cemento, siendo esta más significativa cuanto mayor sea el porcentaje de árido grueso sustituido. Las causas más influyentes son:

1. La cantidad de mortero adherido a la matriz rocosa provoca que el árido reciclado tenga una menor resistencia mecánica que el árido natural.

2. Un aumento de zonas débiles en la masa del hormigón endurecido al utilizar áridos reciclados, debido a la superficie de contacto entre el agregado natural y el mortero adherido que contiene se suma a la superficie de contacto, más débiles aún, existente entre el árido reciclado y el mortero nuevo.

Además, ratificando lo dicho anteriormente, varios estudios indican que la resistencia a compresión del hormigón reciclado está gobernada por la razón a/c del nuevo mortero y que la resistencia del hormigón a partir del cual se obtuvieron los agregados reciclados no tiene influencia.

Al analizar la influencia de la razón a/c del nuevo hormigón sobre la resistencia a compresión de los hormigones reciclados, se observó que para razones $\mathrm{a} / \mathrm{c}<0,45$ la resistencia a compresión del hormigón reciclado era hasta un $30 \%$ inferior a la del hormigón convencional de similares características; mientras que para razones $a / c>0,45$ ambos tipos de hormigones presentaban similares resistencias (Ver figura 2.1). Asimismo, se 
indica que para razones $\mathrm{a} / \mathrm{c}<0,40$ la resistencia de los hormigones reciclados no se incrementa de manera significativa [Rasheeduzzafar y Khan, 1984].

En coincidencia con esto otros investigadores hallaron niveles de resistencia a compresión de hormigones con AGR similares a los obtenidos con hormigones elaborados con AN para razones agua/cemento elevada, mientras que para bajas razones a/c la resistencia a compresión disminuye [Hernández y Fornasier, 2005].

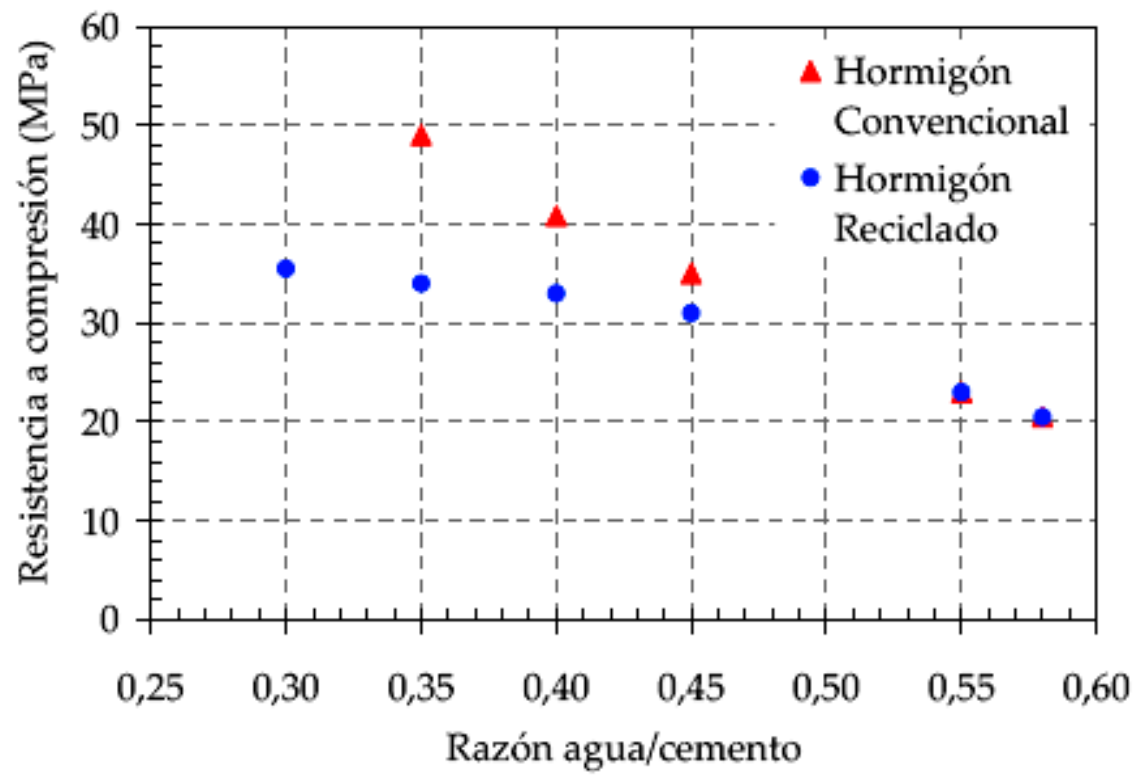

Figura 2.1: Variación de la resistencia a compresión con diferentes relaciones a/c para hormigones reciclados y convencionales (Adaptado de Rasheeduzzafar y Khan, 1984).

Basándose en los resultados mencionados en la figura anterior, otros autores señalaron que al disminuir la razón a/c siempre se consiguieron aumentos de resistencia en los hormigones reciclados, aunque no proporcionales a los hallados en hormigones convencionales. Igualmente se verifica que para un determinado nivel resistente, el contenido de cemento de los hormigones reciclados es mayor que en los hormigones convencionales, incrementándose al hacerlo más resistente [Vázquez y Barra, 2002]. Este hecho fue confirmado por otros autores quienes concluyeron que no sólo los valores de resistencia a compresión del hormigón reciclado son menores a los del hormigón convencional sino que también la diferencia de resistencia entre 
el hormigón convencional y el reciclado disminuye a medida que la razón a/c se incrementa [Sri Ravindrarajah et al, 1988; Hernández y Fornasier, 2005].

Cuando el hormigón de origen de los áridos reciclados no presenta una uniformidad elevada al proceder de distintas partidas, la variación entre los valores de resistencia entre el hormigón convencional con el reciclado puede alcanzar valores que llegan hasta el $25 \%$ [Hansen T, 1982].

Con relación al empleo de la fracción fina reciclada, se suele indicar que la misma puede ocasionar inconvenientes debido a su elevado contenido de polvo e impurezas [Grübl y Rühl, 1998]. Su utilización ha conducido a resultados dispares en diferentes estudios. En este sentido, algunos autores han concluido que la resistencia de los hormigones elaborados con agregados grueso y fino reciclados era inferior a la de los elaborados con AGR y agregado fino natural, y que ambos presentaban resistencias inferiores a la de los hormigones convencionales [Buyle-Bodin y Hadjieva-Zaharieva, 2002]. Otros, en cambio, observaron que no había diferencias en los valores de resistencia de los diferentes hormigones reciclados elaborados empleando la fracción fina y/o gruesa reciclada triturada a distintas edades, aunque sí de estos respecto al hormigón de referencia, alcanzando a los 28 días una resistencia del $76 \%$ de dicho hormigón [Katz, 2003]. De manera contraria a lo señalado, Ajdukiewicz y Kliszczewicz (2002) concluyeron que la resistencia de los hormigones reciclados era semejante a la de los hormigones elaborados con agregados naturales, ya sea que para su elaboración hayan empleado la fracción gruesa o que también hayan utilizado la fracción fina reciclada. En estas últimas experiencias utilizaron agregados reciclados provenientes de la trituración de diferentes estructuras demolidas, con edades de entre 2 y 7 años. El rango de resistencias de estos hormigones estaba comprendido entre 35 y $70 \mathrm{MPa}$.

Contrariamente, existen estudios que confirman que la sustitución únicamente del árido fino natural por el árido fino reciclado disminuye la resistencia de 3,4\% para un porcentaje de sustitución del $20 \%$ hasta un 7,6 \% cuando se sustituye el 100 \% [Evangelista et al, 2007]. 


\section{Módulo de elasticidad estático}

El hormigón por su carácter compuesto posee un módulo de elasticidad estático intermedio entre el del agregado natural y el de la pasta de cemento. En consecuencia, el mismo resulta fuertemente afectado por el tipo de agregado grueso que contenga el hormigón [Mehta y Monteiro, 1998].

Más allá de la influencia sobre la resistencia del hormigón, la mayoría de los autores coinciden en que los efectos del uso de agregados reciclados son más importantes sobre la rigidez del hormigón. Se encontraron fuertes caídas en el módulo de elasticidad [Sri Ravindrarajah et al, 1987; Di Maio et al, 2002; Gomez-Soberon, 2002], la cual resulta más notoria cuando se incrementa el porcentaje de reemplazo de agregado natural por agregado reciclado, debido a la menor rigidez y densidad de este último.

En los hormigones elaborados con agregados reciclados, el contenido de mortero será superior al de un hormigón convencional, el de la nueva matriz y el que aportan los agregados reciclados, por lo cual es de esperar que el módulo de elasticidad del hormigón reciclado resulte, en principio, inferior al de un hormigón convencional de igual nivel resistente y elaborado con agregados naturales del mismo tipo. Diferentes autores han indicado disminuciones del 8 al $15 \%$ en el valor del módulo estático de los hormigones reciclados respecto a los convencionales de igual resistencia, disminuyendo dicha diferencia al aumentar la resistencia de los hormigones [Sri Ravindrarajah y Tam, 1985; Ajdukiewicz y Kliszczewicz, 2002]. Como era de esperarse, la disminución del módulo de elasticidad será mayor cuanto más elevado sea el porcentaje de AGR utilizado [Di Maio et al, 2002; Zega et al, 2006].

\section{Resistencia a tracción}

La mayoría de los autores coinciden que existe una disminución en un rango de $\pm 15 \%$ de la resistencia a tracción indirecta de los hormigones reciclados con relación a los convencionales de similares características [Sri Ravindrarajah y Tam, 1985]. En algunos casos indican que la variación de la razón a/c tiene mayor influencia sobre la resistencia a compresión que sobre la resistencia a tracción, aunque el hormigón reciclado se comporta de manera 
similar al convencional ante dicha variación de la razón a/c [Sri Ravindrarajah et al, 1987].

Respecto al tamaño máximo del agregado grueso, Tavakoli y Soroushian (1996) indican que la resistencia a tracción de los hormigones reciclados, no se vio afectada por una variación del mismo, mientras que un mayor tamaño máximo provocó un leve incremento de la misma en hormigones convencionales. Los valores de resistencia a tracción obtenidos fueron, en mayor parte superiores en los hormigones convencionales que en los reciclados.

Otros estudios indican similar variación de la resistencia a tracción por compresión diametral con la razón a/c para los hormigones reciclados y convencionales, disminuyendo su resistencia a medida que el porcentaje de agregado reciclado es mayor [Di Maio et al, 2001; Gómez et al, 2001; Gómez-Soberón, 2002].

En referencia a la resistencia a flexión se dice que el comportamiento del hormigón reciclado en este ensayo resulta similar al que se obtiene en tracción por compresión diametral, es decir, presenta un menor módulo de rotura que el hormigón convencional. La variación de la razón a/c tiene más influencia sobre el ensayo de compresión que sobre este ensayo y el comportamiento del hormigón reciclado frente a la variación de la razón a/c es semejante al de un hormigón convencional [Sri Ravindrarajah et al, 1987].

Hernández y Fornasier (2005) concluyeron que el empleo de AGR de menor resistencia, evaluada a través del ensayo de desgaste Los Ángeles, conduciría a la obtención de un menor módulo de rotura en flexión en los hormigones con ellos elaborados.

\section{4.- USO DE AR EN CONCRETO ASFALTICOS Y EFECTOS SOBRE SUS PROPIEDADES}

Cabe decir que dada la enorme cantidad de agregados que se consumen en los pavimentos de carreteras, parece adecuado pensar en la posibilidad del uso de los AR en sus diversas capas. En este sentido, en la actualidad existen diversas investigaciones y normativas sobre la 
caracterización de hormigones estructurales elaborados con áridos reciclados y experiencias sobre el empleo de estos materiales en carreteras como capas granulares y capas tratadas con conglomerantes hidráulicos. Sin embargo, no existen muchos estudios técnicos sobre la utilización de AR para pavimentos asfálticos ya que muchos autores se han dedicado al estudio del reciclado de este pavimento, o sea el RAP, que mezclado con ciertos agregados vírgenes, emulsiones, conglomerantes, etc., se ha convertido en una importante herramienta con buenos resultados para la reutilización del material proveniente del fresado de la capa asfáltica.

La mayoría de autores coinciden que no se pueden elaborar mezclas asfálticas utilizando el $100 \%$ de estos agregados reciclados debido a su elevada absorción y desgaste de Los Ángeles, cuyos valores están por encima de los parámetros que exige cualquier normativa.

Pérez et al (2007) indican que los parámetros mecánicos de las mezclas con áridos grueso reciclados son similares a los de las mezclas fabricadas únicamente con áridos naturales de cantera. Sin embargo, las mezclas bituminosas con áridos reciclados tuvieron un mal comportamiento frente a la disminución de la resistencia por pérdida de cohesión por la acción del agua. No obstante, mediante la selección de materiales de mejor calidad y corrección de este mal comportamiento, existen posibilidades de utilizar AGR en mezclas bituminosas. Para esto elaboró 3 diferentes mezclas asfálticas: la primera con $100 \%$ de AN, la segunda con $100 \%$ de AR y por último con $50 \% A R+50 \%$ AN. Los resultados obtenidos con el método Marshall evidenciaron la imposibilidad de utilizar únicamente árido reciclado en mezcla ya que se observó que las mismas tenían poca cohesión, el árido más grueso no se encontraba correctamente envuelto por el betún y el conjunto tenía un aspecto terroso. Este comportamiento se debe a la excesiva porosidad del árido; al aumentar la superficie específica del mismo, se requieren mayores cantidades de betún para conseguir la suficiente cohesión. Esta mezcla cumplió con todos los parámetros Marshall excepto el VAM (Vacíos agregado mineral), por tanto, no se cumplió este criterio preceptivo para la fabricación de mezclas bituminosas en caliente para su uso en carreteras. Del análisis de los resultados anteriores se optó por dosificar las mezclas con AR utilizando un 
$50 \%$ de este material, reduciendo así la absorción del agregado y el desgaste que sufre este en el mezclado y compactación. A partir de los resultados obtenidos del ensayo Marshall se seleccionaron las proporciones óptimas de asfalto para cada tipo de mezcla que cumpliera con los requisitos (PG - 3 de la Normativa Española) para las diferentes categorías de tráfico. La mezcla elaborada con agregados naturales para capa de rodadura y base asfáltica cumplía los requisitos para las categorías de tráfico T3 y T4. En cambio la mezcla para capa de rodadura con $50 \%$ de agregado reciclado cumplía todos los requisitos desde $\mathrm{T} 1$ hasta $\mathrm{T} 4$, en cambio la mezcla fabricada para base asfáltica con $50 \%$ de AR sólo cumplía los requisitos para trafico T4. [(T00

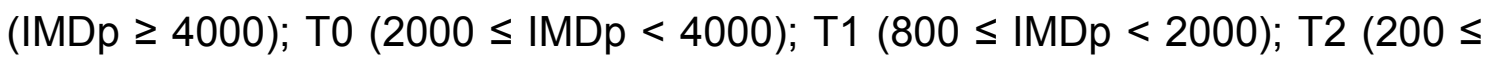
IMDp < 800); T3 (50 S IMDp < 200); T4 (IMDp < 50); (IMDp = Intensidad media diaria de vehículos pesados)]. El Índice de resistencia conservada para las mezclas de capa de rodadura y base asfáltica obtenida son ligeramente superiores al $75 \%$. Con respecto a las mezclas con AR la resistencia conservada no cumple con los valores mínimos de las especificaciones. Los valores de la base asfáltica elaborada con AR fueron inferiores a los obtenidos para la capa de rodadura. Los resultados logrados en la base asfáltica se pueden explicar en base al elevado porcentaje de huecos en mezcla que presenta sumado a la naturaleza arcillosa de los RCD. En el ensayo de deformaciones permanentes (Wheel Tracking Test) las deformaciones sufridas por la mezcla con AN son mayores que las deformaciones que sufren las mezclas con AR, es decir, se comportan mejor frente a las deformaciones plásticas. Respecto a la ley de Fatiga, las mezclas para base asfáltica con presencia de $A R$ tienen el mismo comportamiento que las fabricadas con AN. Las mezclas para capa de rodadura con AN presentan un mejor comportamiento que las hechas con AR, aunque estas últimas se puede decir que tienen un comportamiento aceptable. En el ensayo de Módulo dinámico, las mezclas construidas con AR tenían mayor rigidez. Las rigideces concuerdan de manera razonable con la capacidad de soportar las cargas de las mezclas, reflejadas en los valores de Estabilidad obtenidos en los ensayos Marshall. Los bajos valores de módulos ponen de manifiesto un punto de debilidad de las mezclas fabricadas con AN. Al no ser lo suficientemente rígidas, con el paso del tráfico, se deformarían de manera excesiva al no 
absorber de forma adecuada las tensiones. Esto podría favorecer una fisuración temprana de la mezcla más superficial al tener una capa de base poco rígida.

Otros autores confirman que existe un cambio significativo en la distribución de tamaño de las partículas de agregado grueso que contengan las mezclas preparadas con AR. Se observó antes y después de la mecánica de mezclado y compactación que existe una rotura del mortero de cemento relativamente débil. Este cambio en su granulometría y una mayor demanda de ligante provoca una disminución del Módulo Resiliente de las mezclas elaboradas con AR ya que pierden capacidad de carga, pero sus valores están dentro de los límites aceptables. Estos autores también analizaron otras propiedades de la mezcla asfáltica con AGR, encontrando una disminución de la densidad aparente y del VAM, un incremento en los porcentajes de vacíos y estabilidad de la mezcla en diferencia de una mezcla elaborada con AN [Paranavithana et al, 2006].

Otros estudios recomiendan la utilización del AFR para la elaboración de mezclas asfálticas. Las investigaciones se hicieron con 4 tipos de mezclas con una combinación de agregados naturales y reciclados con un asfalto PG 64 22. La mezcla I fue todo agregado natural; la mezcla II consta de AGN y AFR; la mezcla III estaba constituida de AGR y AFN; por último la mezcla IV constaba solamente de agregados gruesos y finos reciclados. Ellos vieron beneficioso evaluar el desempeño de las mezclas, cuyo diseño son determinados por el método Superpave y el método Marshall debido a que en muchos países las especificaciones para la elaboración de base granular asfáltica sigue siendo este último. Las diferentes mezclas diseñadas por el método Marshall se le analizaron el porcentaje de vacíos, el VAM, el RBV y la Estabilidad. Las mezclas I y II cumplían todos los requisitos ya que se encontraron dentro de los límites, la mezcla III no cumplía con el VAM y RBV y por último la mezcla IV solo cumplía con la Estabilidad (Ver figura 2.2). Ellos confirman que el material grueso juega un papel importante en el proceso de compactación del Marshall ya que las mezclas III y IV muestran menores VAM en comparación con los valores de las mezclas I y II, a pesar que esa tendencia no se observó en el compactador giratorio. Con base a estos 
resultados concluyeron que el porcentaje de ligante óptimo determinado por los dos métodos fueron muy parecidos, pero aseguran que el método Marshall no puede ser un método apropiado para simular las condiciones de la mezcla asfáltica en campo, debido a que la carga dinámica de compactación puede ocasionar una rotura en el agregado grueso, produciendo resultados inesperados. Sobre el ensayo de Tracción indirecta, las probetas fueron compactadas con el compactador giratorio de Superpave. Las mezclas II dieron los valores más altos (entre 1,2 a $1,6 \mathrm{~N} / \mathrm{mm}^{2}$ ), seguidos de las mezclas III (entre 1,2 a $1,4 \mathrm{~N} / \mathrm{mm}^{2}$ ) y por último con valores más bajos las mezclas I y IV dieron tensiones parecidas (entre 1,0 a $1,2 \mathrm{~N} / \mathrm{mm}^{2}$ ). Referente al ensayo de Deformaciones permanentes (Wheel Tracking Test) podemos ver que la mezcla II tienen menores deformaciones/ número de repeticiones seguido de la mezcla III, mezcla I y por último la mezcla IV (Ver figura 2.3). Los autores concluyen que las mezclas II y III pueden ser utilizado como base granular asfáltica y que su medio de evaluación de propiedades, el método Marshall posiblemente cauce fricción en el AR y por lo tanto lleva a una subestimación de las propiedades para la ingeniera de mezclas asfálticas en caliente con AR [Yoon-Ho Cho et al, 2010].

Sobre investigaciones hechas en el país, recomiendan el uso del AGR para bases granulares asfálticas [Appolloni et al, 2009]. El estudio se fundamentó con la utilización de agregados gruesos reciclados provenientes de hormigones $\mathrm{H}-30$ con diferentes tipos de cemento además de hormigones desconocidos y antiguos. El desgaste de Los Ángeles que fueron sometidos los AGR cumplían los requisitos para base granular (entre 30 a $33 \%$ y solo el de procedencia desconocida $40 \%$ ). Las probetas fueron realizadas con un asfalto AC - 20 con una composición de 60 \% AGR, $30 \%$ AFN y $10 \%$ de arena silícea. Los resultados obtenidos dieron Estabilidades elevadas, altos valores de Módulo dinámico a diferentes temperaturas, como así también importantes valores de Tracción indirecta. 

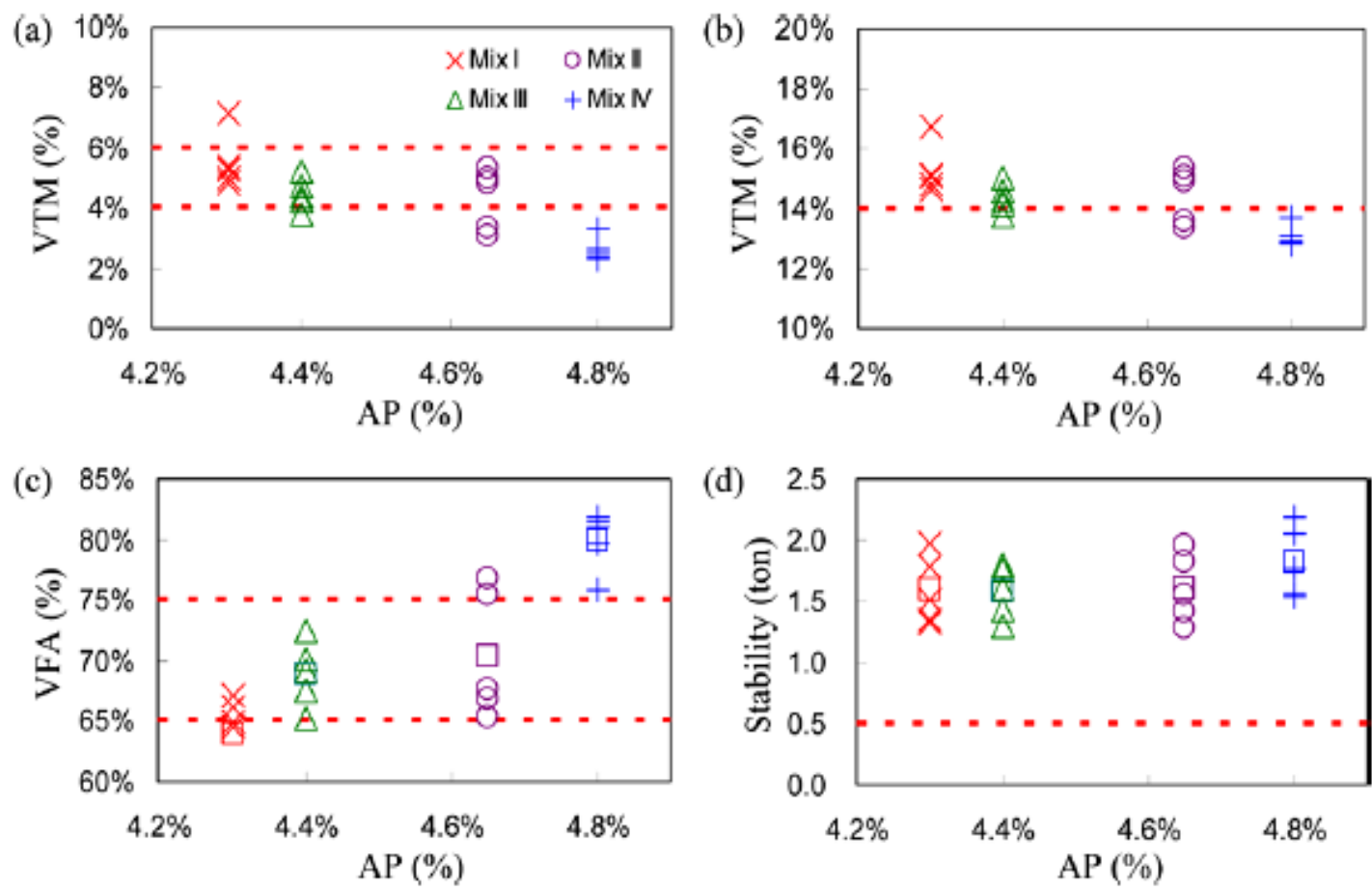

Figura 2.2: Parámetros Marshall de las mezclas: (a) \% de vacíos, (b) VAM, (c) RBV y (d) Estabilidad (Yoon-Ho Cho et al, 2010).

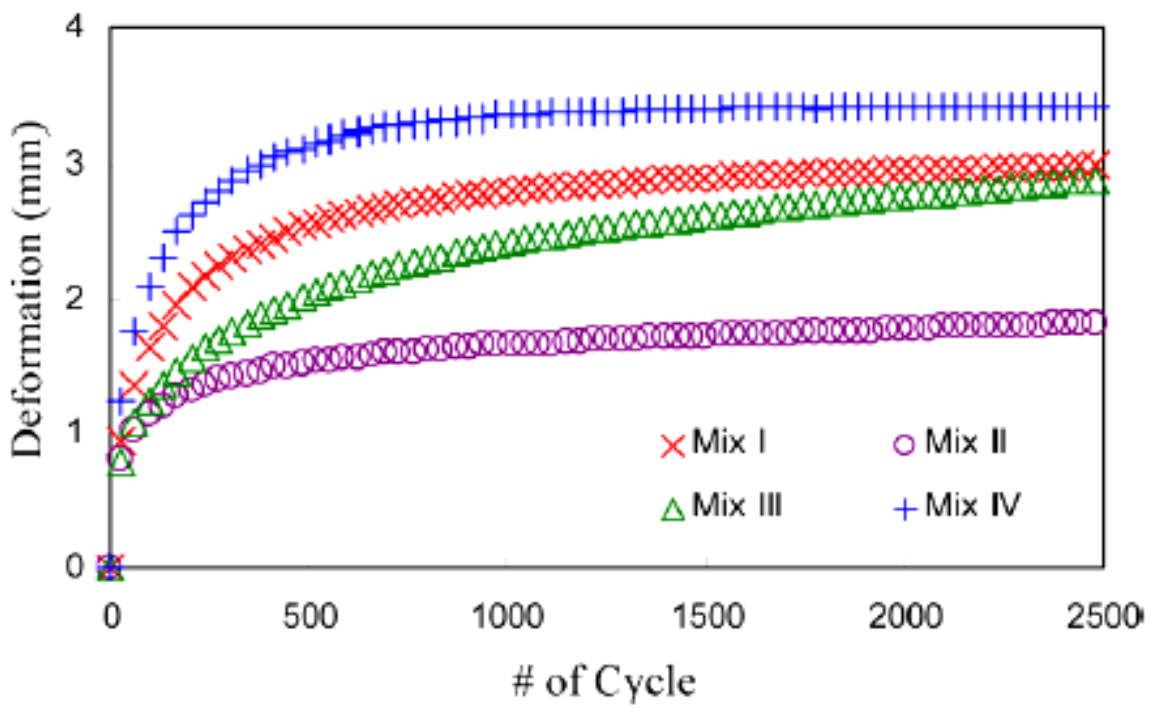

Figura 2.3: Resultado del Wheel Tracking (Yoon-Ho Cho et al, 2010).

Otros autores no recomiendan el uso de AR con agregados de canto rodado ya que la falta de fricción interna provoca que la mezcla tenga mayores deformaciones permanentes [Shen et al, 2004]. El estudio de ellos abarca la preparación de mezclas asfálticas para obtener el contenido óptimo de betún y luego someterlas al ensayo de Wheel Tracking Test. Las mezclas fueron preparada con distinto tenor de áridos reciclados y canto rodados (mezcla 1: 
$100 \%$ AN; mezcla 2: $100 \%$ AGR y AFR; mezcla 3: $50 \%$ AGR y AFR + $50 \%$ AGN Y AFN; y la mezcla 4: $100 \%$ AGR y $100 \%$ AFN). Los resultados muestran que las mezclas 2 y 4 tienen deformaciones más pequeñas seguida de la mezcla 1 dejando por último a la mezcla 3 que presenta tanta inestabilidad que no califica para su uso. Ellos concluyen que los AR al ser triturados le aportan a la mezcla mayor fricción interna provocando una mayor resistencia a las deformaciones permanentes en comparación de las mezclas con canto rodado.

Otra posible uso del agregado reciclado proveniente del hormigón es como agregado fino o como relleno mineral en mezclas asfálticas utilizando la fracción fina $<3,15 \mathrm{~mm}$. El estudio trata de la viabilidad del uso parcial o total del AFR en mezclas asfálticas utilizando diferentes porcentajes y tratamiento del agregado fino. La primera opción fue utilizar la fracción $<0,075 \mathrm{~mm}$ en un $6 \%$ sin tratar, la segunda y tercera opción fue la utilización de la fracción < $3,15 \mathrm{~mm}$ en un $45 \%$, sin tratar y con tratamiento térmico (o calcinación) respectivamente. En la fracción fina sin tratar se encontró presencia de cuarzo, calcita y portlandita sin importar la composición de los tamaño y la trituración mecánica con la que se hayan obtenidos estos agregados reciclados. En cambio el material fino expuesto a tratamiento térmico da origen a una descarbonatación que desaparece en su totalidad provocando una pérdida de masa pero grandes cantidades de cal. El contenido de asfalto aumentó de acuerdo a la cantidad de AF hasta un $7 \%$, la mezcla con un $6 \%$ necesitó un $5,3 \%$ de asfalto, la mezcla con $45 \%$ sin tratar un $6,5 \%$ y la mezcla con $45 \%$ con tratamiento de calcinación un $7 \%$ de betún. Los valores de los parámetros Marshall esenciales satisfacen los límites impuestos por la especificación, a excepción de los valores ligeramente inferiores de RBV en dos de las mezclas. Las probetas también fueron sometidas a módulo Resiliente observando que las mezclas híbridas con $6 \%$ de AR obtuvieron un módulo y resistencia a la fluencia similar al obtenido con agregados graníticos. En cambio las mezclas con el $45 \%$ de sustitución presentaron mayor resistencia que las convencionales y las híbridas con un $6 \%$ de sustitución. Las probetas con $45 \%$ de sustitución con tratamiento térmico dieron valores más altos que todos debido a la cal libre obtenida con dicho tratamiento, mejorando también el 
rendimiento a la fluencia; quedando demostrado el uso posible de este material como sustitución parcial o total en mezclas asfálticas [Wong et al, 2006].

Otros autores contradicen que un mayor contenido de AR hasta un $50 \%$ mejora el comportamiento de mezclas bituminosas. Mills-Beale et al (2010) mediante el método Superpave evaluó el potencial de mezclas con AR donde concluye que este puede servir como sustituto útil en carreteras de tráfico bajo. Los resultados muestran que la deformación permanente (WTT) es menor a mayor cantidad de AR, pero un mayor porcentaje al $75 \%$ de este agregado dará lugar a un criterio de falla en las propiedades de las mezclas asfálticas. En cuanto al módulo Dinámico, este se incrementa con la reducción de cantidades de AR en mezcla. Referente al Daño por humedad, la combinación de AR y AN podrían satisfacer este ensayo para bajo tráfico pero sin superar el $75 \%$ de AR en la mezcla. Otra propiedad que expone la investigación es que las mezclas con AR necesitan menor esfuerzo de compactación (menos índice de compactación) existiendo la posibilidad de importantes ahorro de energía pero afirma que este ahorro no tiene que comprometer las propiedades de rendimiento de las mezclas bituminosas.

Además de utilizarlo como agregado fino en mezclas asfálticas para reemplazar la arena 0-6 de trituración, varios autores estudiaron la posibilidad de usarlos como filler para dichas mezclas [Shen et al, 2011]. La fracción utilizada del AFR fue $<1,18 \mathrm{~mm}$ y hubo comparaciones con un filler de piedra caliza. En los ensayos de difracción de rayos $X$ se observó que el AFR coincide con las investigaciones citadas anteriormente donde se expresa que la fracción está compuesta por calcita, cuarzo y aluminio, mientras que el filler común está compuesto únicamente de calcita. Las mezclas elaboradas con estos distintos filler fueron sometidas a distintos ensayos para poder evaluar sus propiedades. El Módulo de tracción Indirecta de la mezcla con AFR presenta un módulo superior al obtenido en mezclas preparadas con filler común, pero se lo asocia a la estructura del esqueleto del agregado grueso para temperaturas de 5 y 25 C mientras que el módulo a $40 \stackrel{\circ}{\circ}$ está determinado por las características del asfalto, pero su valor puede conducir a una mejor resistencia al ahuellamiento. En cuanto a su comportamiento a bajas temperaturas los resultados indican que el uso de AFR como relleno tiene un ligero descenso de su rendimiento en 
comparación con la mezcla de control pero su valor está dentro del permitido. En lo referente al comportamiento a altas temperaturas, se observó que las probetas elaboradas con filler común presentan mayor deformación que las elaboradas con filler proveniente del AFR, poniendo de manifiesto que las mezclas elaboradas con AR presentan mayor módulo de Rigidez, confirmando así los resultados del módulo de Tracción Indirecta a $40 \stackrel{\circ}{\circ}$. Respecto al Daño por humedad o sensibilidad al agua, las mezclas con filler proveniente del AFR poseen una mejor resistencia mientras que el filler común es más sensible al agua, esto se debe a la gravedad específica de AR es menor a la del filler común, teniendo más volumen y mayor absorción de asfalto, mejorando la resistencia al daño por humedad. Respecto al ensayo de fatiga, las mezclas con AFR como relleno mineral presentan menor tasa de evolución de daño. Esto indica claramente que el AFR se puede utilizar como material de relleno para mejorar el comportamiento de las mezclas a fatiga, al daño por humedad y a las altas temperaturas.

\section{5.- USO DE AR EN BASES GRANULARES Y EFECTOS SOBRE SUS PROPIEDADES}

La aplicación más común de los agregados reciclados en Europa y la mayoría de los estados de Norteamérica es en capas de base y subbases granulares de nuevos pavimentos, con o sin aglomerante hidráulico, siendo su proceso de almacenamiento, manipulación y puesta en obra similar al de los agregados naturales.

Las bases granulares permiten la reutilización de los residuos de hormigón próximos a la zona de trabajo y además, construir plataformas más resistentes, estables y por ende más duraderas.

Mediante el uso de estos agregados reciclados se pueden sustituir materiales con problemas geotécnicos y baja capacidad de soporte, anular sus riesgos y mejorar sus propiedades hasta alcanzar valores característicos de materiales de elevadas prestaciones. Contrariamente a la solución tradicional que consistía en llevar ese material (pedazos de losas hormigón) a botaderos y transportar mejores materiales de préstamos (yacimientos y canteras), las estabilizaciones con agregados reciclados del hormigón permiten eliminar estas 
afecciones medioambientales, incluyendo la que supone el transporte de suelos naturales. Para que los áridos reciclados se puedan emplear como material granular en subbases y bases de carreteras, su granulometría debe estar comprendida en alguno de los husos granulométricos fijados por cualquier normativa de cada país. Los áridos reciclados provenientes de la construcción por lo general cumplen con los husos granulométricos y con diversas exigencias como el coeficiente de forma, partículas trituradas, equivalente de arena, materias orgánicas y cantidad de azufre. En referencia al porcentaje de desgaste Los Ángeles depende principalmente de la abrasión sufrida por los áridos naturales y el hormigón. Estudios recientes han puesto de manifiesto que en el ensayo Los Ángeles todo el mortero adherido a los áridos reciclados de hormigón se pulveriza, este efecto puede ser atribuible a la naturaleza porosa, grietas y menor resistencia del mortero adherido y es un limitante importante para el uso como material granular. La mayoría de normativas lo sugieren para tráficos menores de 200 vehículos pesados/día.

Algunos autores también identifican que el contenido de compuestos de azufre totales es una propiedad crítica de los áridos reciclados. Sin embargo, el contenido de compuestos de azufre totales de los AR de hormigón (fracción 0/2 mm) está por debajo del límite [Vegas et al, 2008].

Sherwood (2001) propone que en carreteras de bajo costo y volumen de tráfico, la reducción razonada de los requisitos de las normas nacionales podría aumentar el uso de materiales secundarios. Así, aunque los áridos reciclados mixtos no cumplan con el porcentaje de desgaste Los Ángeles y el contenido de compuestos de azufre totales por un estrecho margen, podrían ser utilizados como subbase en la construcción de caminos rurales.

Debido a su angulosidad y la posibilidad de un cierto nivel de recementación, el agregado reciclado puede servir muy bien en una aplicación de base de graduación densa [ACPA 2009]. Un informe reciente de la NCHRP (2008) señala que sus propiedades se ven afectadas tanto en base como en subbases granulares elaborada con agregados reciclados. Las propiedades afectadas incluyen la resistencia al corte, rigidez, resistencia, durabilidad, susceptibilidad a las heladas, y permeabilidad. Sin embargo, el principal 
indicador de desempeño de una capa estabilizada es la resistencia al corte y la rigidez según lo determinado por la prueba de módulo resiliente. Con respecto a estas propiedades, el AR posee un buen desempeño, a pesar que la rigidez no fue tan alta en comparación con las capas de base construida con agregados naturales o una mezcla de AR con AN.

La facilidad de las operaciones de trituración para producir agregados de mayor tamaño angular permitiendo que una capa tenga buenas condiciones estructurales de apoyo cuando el AR se utiliza en una capa de base drenable. La preocupación con el uso de AR en un sistema graduado abierto es el contenido de polvo, los lixiviados y los problemas de alcalinidad. Una forma de tratar estos problemas es a través de un lavado del agregado reciclado antes de la colocación para reducir las partículas finas que contribuyen significativamente a aumentar el $\mathrm{pH}$ y lixiviados sedimentados que puedan obstruir los colectores en el sub-sistemas de drenaje superficial [Bruinsma, 1995]. Las bases granulares con áridos reciclados puede aumentar el nivel de $\mathrm{pH}$ de la humedad del subsuelo que se esté en contacto con los sistemas de drenaje y aguas subterráneas. Este efecto se reduce con el tiempo como valores de $\mathrm{pH}$ estabilizado a niveles normales.

En cuanto a la relación entre Humedad y Densidad, algunos autores señalan que el árido natural tiene una mayor densidad seca y menor absorción de agua. Los áridos reciclados de hormigón tienen una menor densidad seca y mayor absorción de agua. En los áridos reciclados de hormigón y en los áridos naturales, la densidad de partículas tras secado en estufa, la fracción gruesa es mayor que la obtenida en la fracción fina. En los áridos reciclados de hormigón y en el árido natural la absorción de agua de la fracción fina es superior a la de la fracción gruesa, superando el árido fino reciclado al natural [Jiménez et al, 2010].

La prenormativa del Gobierno Vasco (2011) afirma que los áridos reciclados presentan densidades máximas y humedades óptimas de compactación similares a la de suelos naturales y otro tipo de material granular. Se observa un incremento de la humedad óptima cuanto mayor contenido de material cerámico ofrezca el árido reciclado (Ver figura 2.4). Asimismo, la 
combinación de hormigón y cerámico parece inducir mayores densidades de compactación, como consecuencia de una mayor generación de finos procedentes de la fragmentación tanto del mortero adherido al árido reciclado de hormigón, como del material cerámico. Los resultados obtenidos manifiestan tendencias similares a los obtenidos por Poon de la Universidad de Hong Kong, tal y como se ilustra en la figura 2.4 .

En cuanto al ensayo de Proctor modificado, algunos estudios expresan que el árido natural tiene una mayor densidad seca máxima y menor contenido de humedad óptima que los áridos reciclados de hormigón. Las capas granulares elaboradas con áridos naturales tiene un mayor valor de CBR que el realizado con áridos reciclados de hormigón. Basándose en el alto valor del CBR y en la ausencia de hinchamiento en los áridos reciclados de hormigón se puede esperar que posea una aceptable capacidad de carga y estabilidad estructural [Jiménez et al, 2010].

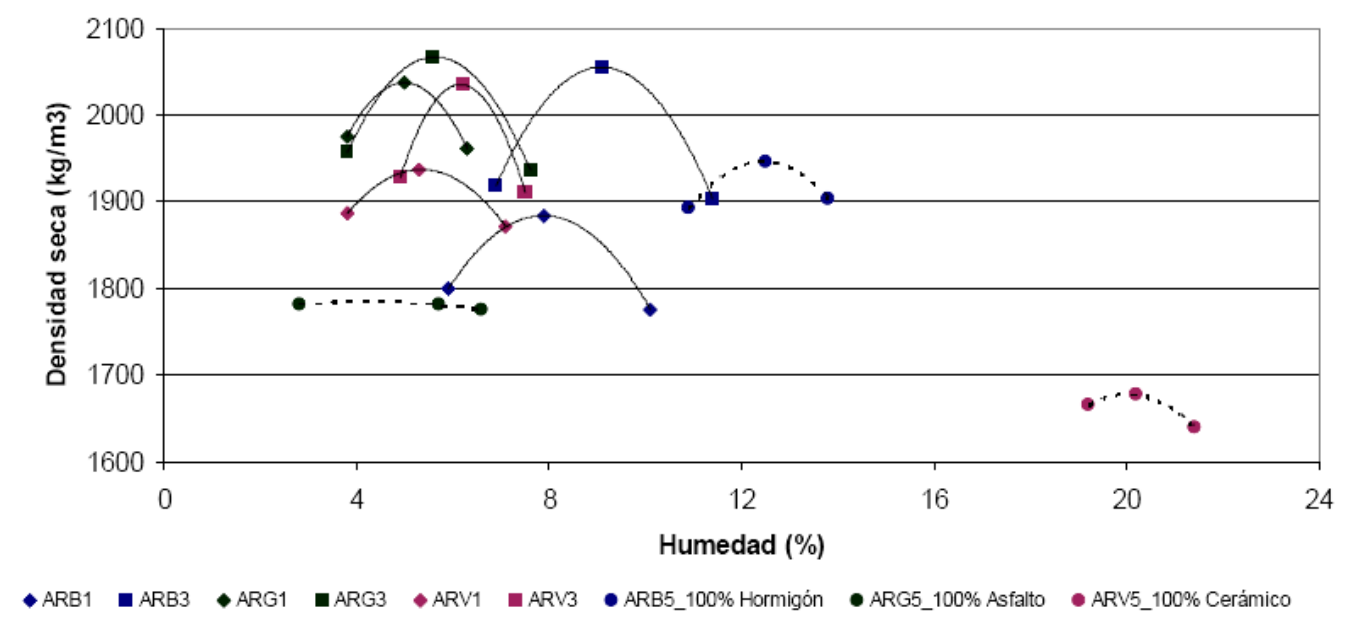

Figura 2.4: Humedad óptima y densidad máxima de compactación (Poon et al, 2006).

Otras investigaciones explican una mayor capacidad portante, medida a partir de su índice CBR, asociada a la presencia conjunta de hormigón y material cerámico en el árido reciclado. El incremento de resistencia mecánica se puede atribuir, bien a reacciones puzolánicas entre los finos y la portlandita presente en el hormigón, en presencia de agua, bien a cierta hidraulicidad remanente del cemento contenido en los áridos reciclados de hormigón, constatando la mejora de capacidad portante a lo largo del tiempo e inclusive 
superando la capacidad portante de muestras con áridos naturales. [Pre normativa del Gobierno Vasco, 2011].

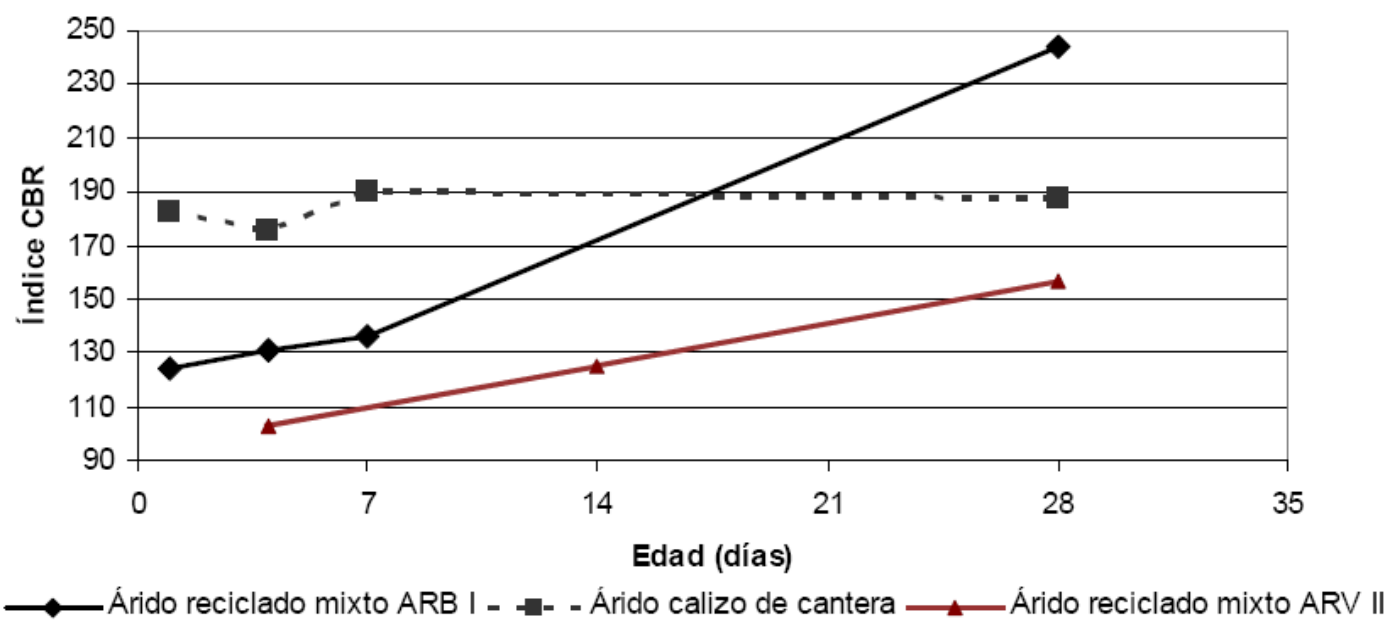

Figura 2.5: Evolución de la capacidad portante a lo largo del tiempo: áridos reciclados (ARB-I y ARV-II) y árido calizo.

A tenor de los resultados de la figura 2.5, el índice CBR a 14 días resulta ser entre un $20 \%$ y $30 \%$ superior al obtenido a 4 días para las muestras de árido reciclado mixto. Asimismo, el índice CBR a 28 días resulta ser superior en un $50 \%$ al obtenido a 4 días.

Otros autores han confirmado el crecimiento de su rigidez con el tiempo [Arm, 2001] por medio de estudios realizados durante 2 años para evaluar la rigidez de las capas de subbases granulares elaboradas con RCD. Se realizaron estudios en laboratorio como en campo (por medio del FWD) confirmando que existe un claro aumento con el tiempo en el módulo resiliente. Dicho aumento es el más grande en los primeros meses y luego disminuye, esta crecida en la rigidez es debido a la propiedad de auto-cementación que posee el árido reciclado. Las mediciones de campo muestran un crecimiento más considerable en la rigidez que en las pruebas hechas en laboratorio, duplicando su valor dos años después de la construcción. Las capas de subbases elaboradas con áridos naturales, en su mayoría granito triturado no muestran ningún crecimiento en la rigidez, ni en el laboratorio ni en el campo.

La auto-cementación que proporciona el árido reciclado en capas granulares originó un estudio más profundo sobre el agregado proveniente del RCD [Poon et al, 2006]. Ellos indican que es factible el uso tanto del agregado 
grueso como fino del reciclado para capas granulares. Estos investigadores pensaban que el árido fino reciclado $(<5 \mathrm{~mm})$ tenían más probabilidades de ser la principal causa de las propiedades de auto-cementación del AFR y para su estudio este agregado fue sometido a diferentes pruebas (difracción de rayos $\mathrm{X}$, medición del $\mathrm{pH}$, resistencia a la compresión y la permeabilidad de los diversos tamaños de la fracción fina: $<0,15$ y 0,3-0,6 mm conocida como fracciones activas). En el ensayo de rayos $X$ encontró presencia de silicato dicálcico y silicato tricálcicos) en las fracciones finas $<0,15 \mathrm{~mm}$. Los resultados obtenidos demostraron que las causas de las propiedades de autocementación se atribuyen a las propiedades intrínsecas del AFR, que podrían verse afectadas por la edad, grado y cantidad de los materiales cementicios utilizados en el hormigón original de la cual los AR fueron obtenidos. La edad, el grado y la cantidad de cemento sería el factor decisivo de la cuantía de cemento sin hidratar y de la presencia de silicato dicálcico en el mortero adherido del agregado fino reciclado. También concluye que la capacidad portante que ofrece los áridos reciclados en subbases granulares es inferior que la capacidad portante que ofrece los AN, pero al pasar los meses esta capacidad portante de las capas elaboradas con AR aumenta considerablemente por la auto-cementación como aspecto positivo, pero como aspecto negativo consideran que esta propiedad de auto-cementación debe tener un límite ya que la capa granular tendería a tener una mayor pérdida de permeabilidad solo si se pretende la realización de una capa drenante.

\section{6.- FORMA DE OBTENCIÓN DE LOS AGREGADOS RECICLADOS}

Los RCD dan lugar a la generación de una gran variedad de materiales granulares los cuales se pueden dividir en dos grandes grupos, los provenientes de los desechos de mampostería y los obtenidos a partir de la trituración de hormigones.

Indistintamente de la procedencia del hormigón, losas de pavimento u hormigón estructural su trituración permite generar materiales granulares cuya distribución de tamaño de partículas se ajusta, totalmente o en parte, a la distribución de tamaños que se exigen a los agregados. Este material granular es conocido como agregados reciclados. 
Los métodos y sistemas para la remoción de hormigón de las estructuras a reparar o demoler incluyen desde equipos de alto rendimiento hasta herramientas manuales utilizadas para trabajos menores que tienen como finalidad reducir el tamaño de la estructura para poder ser transportado y depositado ocupando el menor espacio posible o ser manipulado en obra. El tamaño al que va hacer reducido la estructura o losa dependerá de las características de la trituradora empleada para la generación de reciclados. Otra opción para la trituración y fracturación de losa sin remoción del material para obtener agregados para bases granulares es el "rubblizing". Esta técnica consiste en la rotura de losa por resonancia o rotura de losa por impacto de martillos oscilantes y/o guillotina.

Las plantas de producción de agregados reciclados presentan características muy semejantes a las empleadas para la producción de agregados naturales, con la incorporación de electroimanes para la separación del acero y otros equipos adicionales para la eliminación de los contaminantes. Para obtener la menos cantidad de contaminantes y reducir la contaminación del material reciclado se realiza una separación minuciosa de los materiales generados en la demolición de estructuras separándolos de madera, plástico, tierra, etc.

Las plantas de producción de áridos reciclados pueden ser fijas, móviles y semimóviles y el sistema de procesamiento de esta dependerá el uso que se le va a dar al agregado reciclado. Las plantas móviles o semimóviles tienen un limitante en el tamaño de trituración, su tamaño máximo es $700 \mathrm{~mm}$ y posee rendimiento promedio de 100 toneladas por hora mientras que las plantas fijas que son muy parecidas a las utilizadas para la obtención de agregados vírgenes, poseen una mayor gama de capacidad y pueden tener un rendimiento de 300 a 400 toneladas por hora.

Otro tipo de clasificación de estas plantas puede ser por su grado de generación. Las plantas o equipos de primera generación son aquellas que no poseen mecanismos para eliminación de contaminantes. Las plantas de segunda generación añaden sistemas mecánicos o manuales de eliminantes de contaminantes previo a la trituración y son las más utilizadas en el reciclado 
de hormigón. Y por último existen equipos o plantas de tercera generación que están basadas en la reutilización de materiales secundarios, considerado como contaminantes de áridos reciclados.

La mayoría de las trituradoras utilizadas en los sistemas de producción de agregados emplean una combinación de cuatro mecanismos básicos: impacto, fricción, corte y compresión para producir la fractura del material. Dentro de los diferentes tipos de trituradoras existentes, se pueden mencionar las de mandíbulas (figura 2.6), de rodillos (figura 2.7), de impacto (figura 2.8) y de conos (figura 2.9), entre otras.
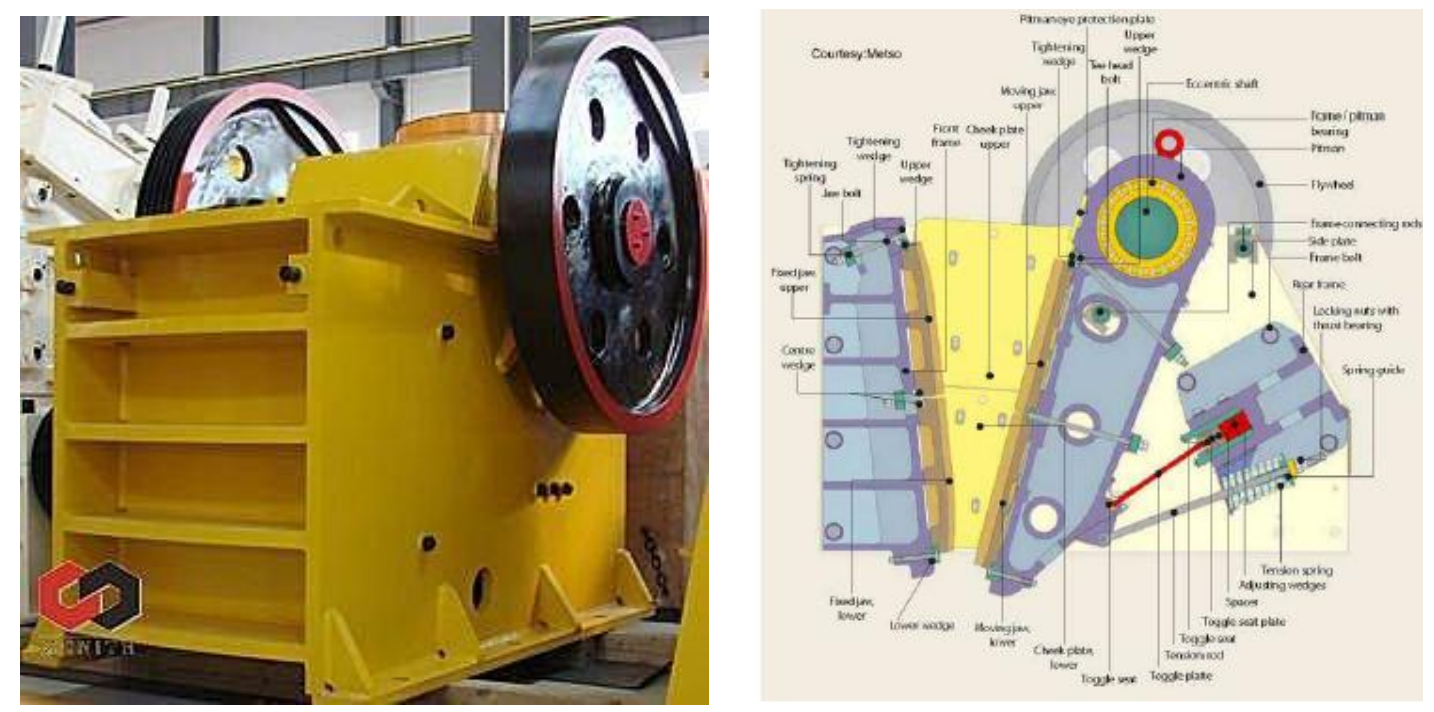

Figura 2.6: Trituradora de mandíbulas. (Fuente: www.liming.com).
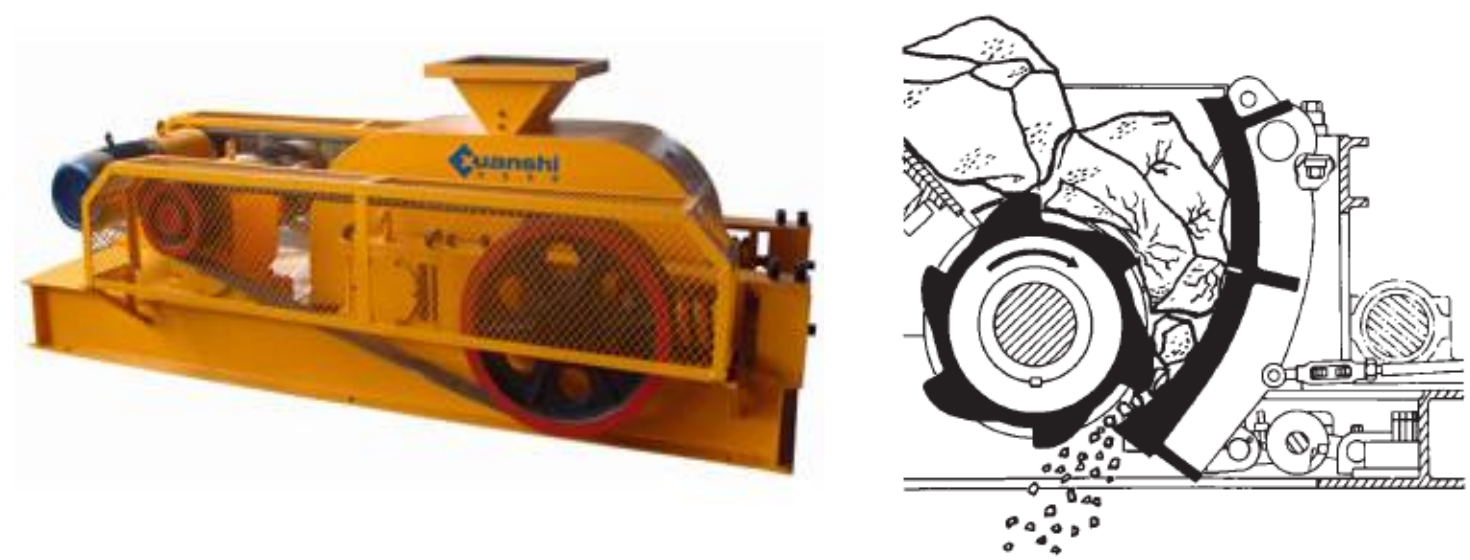

Figura 2.7: Trituradora de rodillo. (Fuentes: $\underline{w w w . l i m i n g . c o m}, \underline{w w w . p e n n c r u s h e r . c o m})$. 

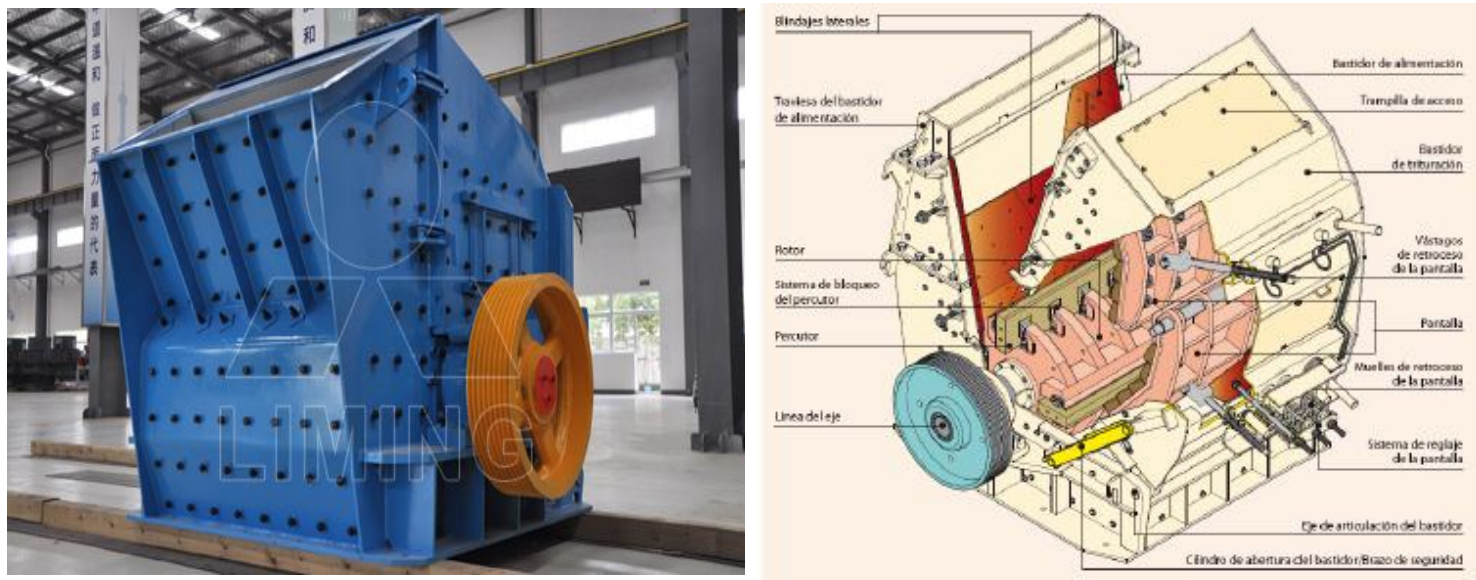

Figura 2.8: Trituradora de impacto. (Fuentes: www.liming.com, www.shangai.com).
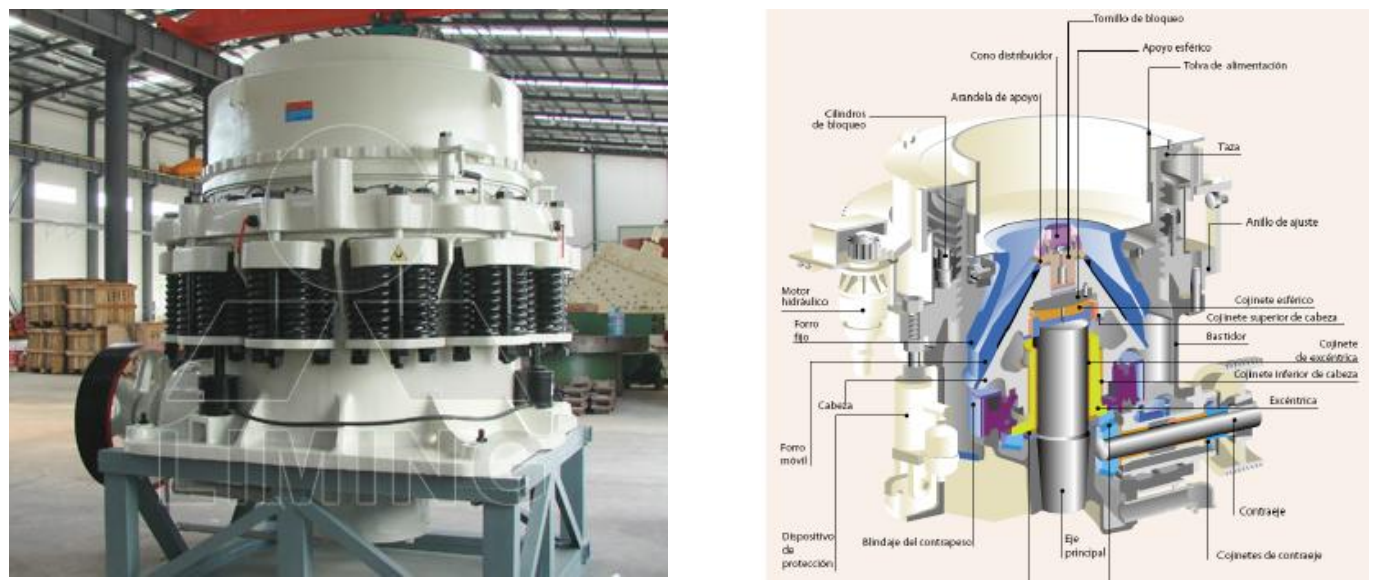

Figura 2.9: Trituradora de cono. (Fuente: www.shangai.com).

Puede existir uno o varios procesos de trituración, la combinación más frecuente para la trituración primaria y secundaria toma de referencia a los Países Bajos, donde existe un adelanto considerable en la obtención de áridos procedente de la construcción que se puede observan en la tabla 2.1 .

Tabla 2.1: Tipos de trituradoras empleadas.

\begin{tabular}{|c|c|}
\hline TRITURACION PRIMARIA & TRITURACION SECUNDARIA \\
\hline Trituradora de mandíbula & Trituradora de rodillo \\
\hline Trituradora de mandíbula & Trituradora de impacto \\
\hline Trituradora de impacto & Trituradora de impacto \\
\hline Trituradora de impacto & \\
\hline
\end{tabular}

La tabla 2.1 se puede observar la combinación de diferentes equipos de trituración para obtener agregados reciclados. La utilización del tipo de 
trituradora dependerá básicamente de su costo de producción, consumo de energía y de la calidad de producto que se obtenga. La tabla 2.2 muestra las ventajas de las trituradoras usadas más reiteradamente en la obtención de áridos según la Asociación Europea de Demolición:

Tabla 2.2: Propiedades específicas de cada sistema de trituración.

\begin{tabular}{lccc}
\hline \multicolumn{1}{c}{ PROPIEDADES } & TRITURADORA DE & $\begin{array}{c}\text { TRITURADORA DE } \\
\text { CONO }\end{array}$ & IMPACTO \\
\hline Capacidad & Alto & Medio & Bajo \\
Costo de producción & Bajo & Medio & Alto \\
Desgaste & Bajo & Bajo & Alto \\
Calidad del árido & Bajo & Medio & Alto \\
Contenido de finos & Bajo & Medio & Alto \\
Consumo de energía & Bajo & Medio & Alto \\
\hline
\end{tabular}

En los Países Bajos, donde existe un adelanto considerable en la obtención de áridos procedente de la construcción, recomiendan en su normativa el uso de la trituradora de mandíbula para la primera trituración debido a su costo y rendimiento y como segunda trituración la de impacto, obteniendo una mejor calidad del agregado.

\section{7.- PROPIEDADES DE LOS AGREGADOS RECICLADOS PROVENIENTES DEL HORMIGON}

\section{Composición y características visuales}

El aspecto visual que presenta los agregados reciclados es diferente al agregado natural debido a la presencia de mortero de cemento adherido al agregado natural. La cantidad de mortero adherido hace que los agregados reciclados presenten diferentes propiedades a los agregados naturales, que se refleja en un aumento de absorción, una menor densidad, mayor desgaste que incide en la dureza del agregado. Los agregados reciclados obtenidos de la trituración tienen aspecto visual diferente ya que se puede encontrar agregado natural sin mortero, un agregado que esté conformado de una parte de mortero y otra parte de roca, y un tercer agregado que sólo esté compuesto de mortero, tal como se observa en la figura 2.10. Las cantidades relativas de cada una de ellos estará en función de las características del hormigón que se tritura, como resistencia, tamaño máximo del agregado, características de la roca natural, 
etc., y del método de procesamiento utilizado para la obtención de los agregados reciclados, incluyendo el tipo y la cantidad de trituradoras empleadas [Hansen y Narud, 1983; Limbachiya et al, 2000; Sánchez de Juan y Alaejos Gutiérrez, 2009].

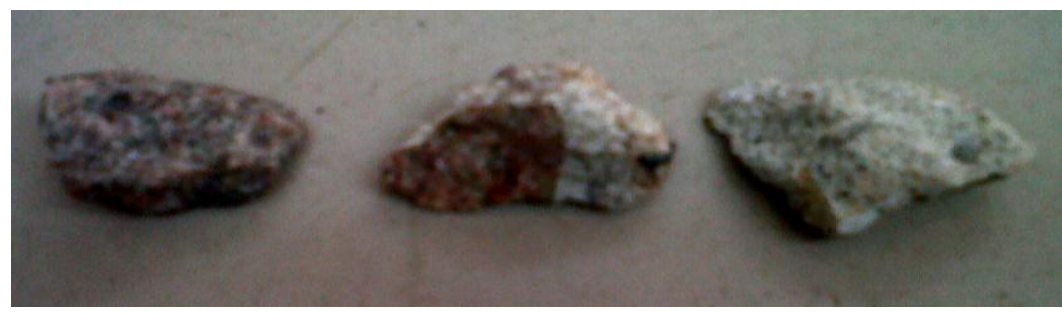

Figura 2.10: Aspecto de los agregados gruesos reciclados.

La cantidad de mortero adherido estará en función de las trituraciones sucesivas que tenga el objeto a demoler.

Tabla 2.3: Mortero adherido a los áridos según varios autores.

\begin{tabular}{lcc}
\hline Referencia & \% Mortero Adherido & Tamaño árido \\
\hline Ravindrarajah 87 & $54 \%(\mathrm{a} / \mathrm{c}=0,51)$ & $5 / 37,5 \mathrm{~mm}$ \\
\hline Ravindrarajah 88 & $20 \%$ & $20 / 30 \mathrm{~mm}$ \\
& $45-65 \%$ & $<0,30 \mathrm{~mm}$ \\
\hline Yagishita & $40,2 \%(\mathrm{a} / \mathrm{c}=0,45)$ & $10 / 20 \mathrm{~mm}$ \\
\hline Barra M. 1966 & $51,7 \%$ & $12 / 20 \mathrm{~mm}$ \\
& $52,9 \%$ & $6 / 12 \mathrm{~mm}$ \\
\hline Nagataki 2000 & $52,3 \%$ & $\mathrm{AG}$ \\
\hline Vázquez E. 2002 & $40,5 \%$ & $10 / 20 \mathrm{~mm}$ \\
& $49,5 \%$ & $5 / 10 \mathrm{~mm}$ \\
\hline Sánchez M. 2005 & $30,8 \%$ & $4 / 16 \mathrm{~mm}$ \\
\hline
\end{tabular}

\section{Granulometría}

La granulometría del AGR depende directamente del tipo de trituración al que es sometido, de ahí se deduce que la composición granulométrica de los mismos resulta independiente del nivel resistente del hormigón a partir del cual son obtenidos [Hansen y Narud, 1983; Sri Ravindrarajah y Tam, 1985]. Las trituradoras de impacto producen mayor cantidad de agregados finos ya que puede generar partículas de menor tamaño mientras que las trituradoras de cono o de mandíbulas dan una cantidad de finos inferior. Debido a la variedad 
de tamaño que se obtiene en la trituración es necesario separar en fracciones gruesa y fina.

La granulometría obtenida varía por los diferentes métodos de trituración y dentro de los límites establecidos para los AGN [Hansen, 1986]. Otros autores llegaron a las mismas conclusiones luego de triturar hormigones a distintas edades comprendidas entre 1 y 28 días [Katz, 2003; Buttler, 2003].

Con relación al AFR, sus características resultan muy semejantes a las de una arena de trituración, con partículas angulosas y un elevado contenido de polvo. En consecuencia, su módulo de finura resulta muy superior al de la mayoría de los agregados naturales de río, siendo incluso mayor que el valor máximo admitido para la elaboración de hormigones estructurales [Hansen y Narud, 1983; Buyle-Bodin y Hadjieva-Zaharieva, 2002; Khatib, 2005], ocasionando que la granulometría del AFR, al igual que sucede con las arenas de trituración, se encuentre en su mayor parte fuera de los límites establecidos por las normas para arenas naturales.

Si bien existen estudios que evalúan las propiedades del AFR y su influencia en la elaboración de hormigones [Khatib, 2005; Evangelista y Brito, 2007], en general se desaconseja su utilización para la elaboración de hormigones estructurales [Hansen, 1986; Grübl y Rühl, 1998; Buyle-Bodin y Hadjieva-Zaharieva, 2002]. En cuanto a la cantidad de AGR disponible del total de agregados obtenidos en la trituración, algunas investigaciones antiguas concluyen que la cantidad de material fino reciclado $(<4,75 \mathrm{~mm}$ ) es mayor a medida que la resistencia del hormigón que se tritura disminuye [Sri Ravindrarajah y Tam, 1985], debido al menor contenido de cemento y mayor cuantía de arena que presentan los hormigones más pobres; pero estudios más recientes confirman que la fracción fina generada por la trituración está comprendida entre 25 y $30 \%$, independientemente de la resistencia del hormigón [Buttler, 2003].

La mayoría de normas que rigen en países desarrollados para los áridos reciclados establecen la limitación del AFR para la preparación de hormigones en porcentajes menores al $5 \%$ si el árido reciclado proviene del hormigón. 


\section{Densidad}

La capa de mortero adherido en el árido reciclado es el principal causante de la variación de las características físicas del agregado. Una de las características físicas que disminuye con relación a los áridos naturales es su densidad debido a la porosidad que presentan dichos agregados. La fracción fina obtenida es la que menor densidad tiene debido a que presentan una mayor cantidad de mortero después de su etapa de trituración.

Muchas investigaciones concluyen que la calidad de los hormigones originales no tiene una marcada influencia sobre la densidad de los agregados reciclados generados a partir de su trituración [Hansen y Narud, 1983; Sri Ravindrarajah y Tam, 1985; Katz, 2003]. Sin embargo, se ha observado una menor densidad en los agregados reciclados provenientes de un hormigón de pavimento de baja calidad [Tavakoli y Soroushian, 1996], variando sus valores entre un 5 y $15 \%$.

La tabla 2.4 expone valores de densidades tanto del AGN como del AGR de acuerdo a su tamaño, tipo de agregado, relación a/c o resistencia a la compresión del hormigón del cual se obtuvo el AGR. 
Tabla 2.4: Densidad del AGR según varios autores.

\begin{tabular}{|c|c|c|c|c|c|}
\hline Referencia & $\begin{array}{l}\text { Fracción } \\
(\mathrm{mm})\end{array}$ & Densidad AGR & $\begin{array}{c}\text { Densidad } \\
\text { AGN }\end{array}$ & $\begin{array}{c}\text { Tipo de } \\
\text { AGN }\end{array}$ & Observaciones \\
\hline & $4-8$ & 2,$34 ; 2,35 ; 2,34$ & 2,50 & & Razón a/c \\
\hline Hansen y Narud, & $8-16$ & 2,$45 ; 2,44 ; 2,42$ & 2,62 & Calizo & 0,$40 ; 0,70 ; 1,20$ \\
\hline 1963 & $16-32,0$ & 2,$48 ; 2,49 ; 2,48$ & 2,61 & & respectivamente \\
\hline $\begin{array}{l}\text { Sri Ravindrarajah y } \\
\text { Tan, } 1985\end{array}$ & $5-37,5$ & 2,$44 ; 2,46 ; 2,44$ & 2,67 & Granítico & $\begin{array}{c}\text { Razón a/c: 0,51; } \\
0,60 ; 0,73 \\
\text { respectivamente }\end{array}$ \\
\hline $\begin{array}{l}\text { Sri Ravindrarajah } \\
\text { et al, } 1988\end{array}$ & $\begin{array}{c}4,75-9,5 \\
9,5-13,2 \\
13,2-19,0 \\
>19,9\end{array}$ & $\begin{array}{l}2,54 \\
2,52 \\
2,46 \\
2,47\end{array}$ & 2,67 & Granítico & $f^{\prime} \mathrm{c}: 60 \mathrm{MPa}$. \\
\hline $\begin{array}{l}\text { Tavakoli y } \\
\text { Soroushian, } 1996\end{array}$ & $\begin{array}{l}4,5-19,0 \\
4,75-25,0\end{array}$ & $\begin{array}{l}2,41 ; 2,26 \\
2,45 ; 2,37\end{array}$ & $\begin{array}{l}2,63 \\
2,69\end{array}$ & Calizo & $\begin{array}{l}\text { f'c: } 50 \text { y } 44 \mathrm{MPa} \text {, } \\
\text { Respectivamente }\end{array}$ \\
\hline Poon et al, 2004 & $\begin{array}{l}4,75-10,0 \\
10,0-20,0\end{array}$ & $\begin{array}{l}2,33 \\
2,37\end{array}$ & $\begin{array}{l}2,62 \\
2,62\end{array}$ & Granítico & \\
\hline $\begin{array}{l}\text { Machado y Latterza, } \\
1997\end{array}$ & $4,75-9,5$ & 2,45 & 2,88 & Basalto & $\begin{array}{c}f^{\prime} \mathrm{c}: 22 \mathrm{MPa} ; \mathrm{a} / \mathrm{c}: \\
0,68\end{array}$ \\
\hline Hernández y & $4,75-20,0$ & 2,49 & 2,72 & Granítico & Laboratorio \\
\hline Fornasier, 2005 & $6-20,0$ & 2,41 & 2,72 & Granítico & Planta \\
\hline $\begin{array}{l}\text { Cuneo Simian y } \\
\text { Duran, } 1995\end{array}$ & $\begin{array}{l}4,75-19,0 \\
4,75-19,0 \\
4,75-19,0\end{array}$ & $\begin{array}{l}2,55 \\
2,45 \\
2,66\end{array}$ & $\begin{array}{l}2,75 \\
2,65 \\
2,98\end{array}$ & $\begin{array}{l}\text { Granítico } \\
\text { Silíceo trit } \\
\text { Basalto }\end{array}$ & $\mathrm{a} / \mathrm{c}: 0,56$ \\
\hline Katz, 2003 & $\begin{array}{l}2,36-9,5 \\
9,5-25,0\end{array}$ & $\begin{array}{l}2,35 ; 2,38 ; 2,32 \\
2,59 ; 2,60 ; 2,55\end{array}$ & & & $\begin{array}{c}\text { AGR a edades } \\
13 \text { y } 28 \text { días }\end{array}$ \\
\hline
\end{tabular}

Contrariamente a lo señalado anteriormente, en un estudio reciente se indica una disminución de la densidad de los AGR a medida que se incrementa la resistencia del hormigón de origen [Padmini et al, 2009], debido a que los agregados que provienen de hormigones con menor resistencia presentan menor contenido de mortero que los originados de hormigones con resistencias más elevadas, dando como resultado una mayor densidad en el primero de los casos.

En conclusión se puede decir que las características de los AN dependen principalmente de la característica de la roca, mientras que los AR dependerán tanto de la característica de la roca como del mortero adherido al árido. La diferencia entre las densidades del AN con respecto al AR pueden variar entre un 5 a $15 \%$. 


\section{Absorción de agua}

La absorción de los AGR es muy superior a la absorción del AGN debido al contenido de mortero que presenta dicho árido. En áridos naturales los valores de la absorción oscilan entre un $0 \%$ y un $4 \%$, mientras que los diferentes estudios afirman que la absorción de los áridos reciclados va desde $3,5 \%$ hasta un $13 \%$.

La mayoría de autores confirman la influencia del tamaño del árido reciclado sobre la absorción, ya que en fracciones más finas la absorción es mayor debido a la cantidad de mortero adherido en ellas es superior que en las fracciones más gruesas (Ver tabla 2.5).

Las absorciones de los AGR para una misma fracción de agregado, resultan muy similares entre sí independientemente de la relación a/c con la que se preparó el hormigón. Al igual que en el caso de la densidad, este comportamiento es atribuido al mortero del hormigón original presente en las partículas que componen el agregado reciclado [Hansen y Narud, 1983; Sri Ravindrarajah y Tam, 1985].

Sin embargo, Tavakoli y Soroushian (1996) indican mayor absorción en los agregados reciclados obtenidos de hormigones de inferior calidad, hecho que se produjo para dos tamaños máximos diferentes de dicho agregado.

Pero una investigación más reciente realizada por Padmini et al (2009) indican mayores absorciones en los AGR al incrementarse la resistencia de los hormigones de origen, verificado para tres tamaños máximos diferentes, hecho atribuido a un menor contenido de mortero de los AGR que provienen de los hormigones con menor resistencia debido a su eliminación durante el proceso de triturado.

En la tabla 2.5 puede observarse que los AGR presentan absorciones variables entre 3,5 y $9 \%$, las cuales resultan muy superiores a las obtenidas con AGN, que en general son inferiores al $2 \%$. 
Tabla 2.5: Absorción en AR en comparación con AN según varios autores.

\begin{tabular}{|c|c|c|c|c|c|}
\hline Referencia & $\begin{array}{l}\text { Fracción } \\
\text { (mm) }\end{array}$ & Absorción AGR & $\begin{array}{c}\text { Absorción } \\
\text { AGN }\end{array}$ & $\begin{array}{c}\text { Tipo de } \\
\text { AGN }\end{array}$ & Observaciones \\
\hline & $4-8$ & 8,$5 ; 8,7 ; 8,7$ & 3,70 & & Razón a/c \\
\hline Hansen y Narud, & $8-16$ & 5,$0 ; 5,4 ; 5,7$ & 1,8 & Calizo & 0,$40 ; 0,70 ; 1,20$ \\
\hline 1983 & $16-32,0$ & 3,$8 ; 4,0 ; 3,7$ & 0,8 & & respectivamente \\
\hline $\begin{array}{l}\text { Sri Ravindrarajah y } \\
\text { Tan, } 1985\end{array}$ & $5-37,5$ & 5,$4 ; 4,5 ; 4,7$ & 0,3 & Granítico & $\begin{array}{l}\text { Razón a/c 0,51; } \\
0,60 ; 0,73 \\
\text { respectivamente }\end{array}$ \\
\hline \multirow{4}{*}{$\begin{array}{l}\text { Sri Ravindrarajah } \\
\text { et al, } 1988\end{array}$} & $4,75-9,5$ & 6,4 & & & \\
\hline & $9,5-13,2$ & 5,5 & 0,35 & Granítico & f'c: $60 \mathrm{MPa}$. \\
\hline & $13,2-19,0$ & 5,4 & & & \\
\hline & $>19,9$ & 5,4 & & & \\
\hline Tavakoli y & $4,5-19,0$ & 4,$5 ; 8,1$ & 2,0 & Calizo & f'c: 50 y $44 \mathrm{MPa}$ \\
\hline Soroushian, 1996 & $4,75-25,0$ & 3,$6 ; 6,6$ & 1,0 & & respectivamente \\
\hline \multirow[t]{2}{*}{ Gómez et al, 2001} & $5-10,0$ & 7,0 & 1,1 & Calizo & \\
\hline & $10-20,0$ & 6,0 & 0,9 & & \\
\hline \multirow[t]{2}{*}{ Poon et al, 2004} & $4,75-10,0$ & 7,6 & 1,2 & Granítico & \\
\hline & $10,0-20,0$ & 6,3 & 1,2 & & \\
\hline $\begin{array}{l}\text { Buyle-B y Hadjieva- } \\
\text { Z, } 2002\end{array}$ & $6-20,0$ & 6,0 & 0,2 & $\begin{array}{l}\text { Silíceo } \\
\text { triturado }\end{array}$ & \\
\hline Hernández y & $4,75-20,0$ & 5,0 & 0,5 & Granítico & Laboratorio \\
\hline Fornasier, 2005 & $6-20,0$ & 5,1 & 0,5 & Granítico & Planta \\
\hline \multirow{3}{*}{$\begin{array}{l}\text { Cuneo Simian y } \\
\text { Duran, } 2002\end{array}$} & $4,75-19,0$ & 5,5 & 0,2 & Granítico & \\
\hline & $4,75-19,0$ & 6,8 & 0,8 & $\begin{array}{l}\text { Silíceo } \\
\text { triturado }\end{array}$ & $\mathrm{a} / \mathrm{c}: 0,56$ \\
\hline & $4,75-19,0$ & 5,8 & 0,6 & Basalto & \\
\hline \multirow[t]{3}{*}{ Katz, 2003} & $2,36-9,5$ & 9,$7 ; 8,1 ; 8,0$ & & & AGR a edades \\
\hline & $9,5-25,0$ & 3,$7 ; 4,1 ; 4,9$ & & & 1, 3 y 28 días \\
\hline & $4,75-10,0$ & 4,$6 ; 4,8 ; 5,0$ & 0,3 & & f'c: $34,48,55 \mathrm{MPa}$, \\
\hline \multirow[t]{2}{*}{ Padmini et al, 2009} & $4,75-20,0$ & 3,$7 ; 4,1 ; 4,9$ & 0,3 & Granítico & respectivamente \\
\hline & $4,75-40,0$ & 2,$2 ; 2,5 ; 2,8$ & 0,3 & & \\
\hline
\end{tabular}

En referencia a estudios realizados en Argentina, Di Maio et al 2002, encontró que el agregado grueso reciclado presentaba absorciones de agua de $5,4 \%$, independientemente de la calidad del hormigón de origen, mientras que la absorción del agregado natural fue de 0,5\%. 


\section{Resistencia al desgaste}

El ensayo de desgaste por abrasión Los Ángeles nos proporciona una idea de la resistencia y tenacidad del agregado debido a la pérdida de peso del árido. En este ensayo el agregado está sometido a la abrasión entre partículas y al desgaste provocado por las esferas de fundición de hierro. Debido a la presencia de interfaces entre los agregados y la pasta de cemento, en general, la resistencia del hormigón resulta inferior a la de la roca que compone el agregado [Ziegeldorf, 1983] y a la del propio mortero [Giaccio y Zerbino, 1997]. Llevado esto a los agregados reciclados obtenidos de la trituración de hormigones, es de esperar que la resistencia de dichos agregados sea inferior a la de los AGN, debido a la existencia de dichas interfaces en las partículas que componen los agregados reciclados.

Las primeras investigaciones sobre el comportamiento de este material ante el ensayo de Los Ángeles se observó que cuanto menor es la calidad del agregado reciclado es mayor el desgaste. [Hansen y Narud, 1983; Tavakoli y Soroushian, 1996; Hernández y Fornasier, 2005; Tabsh y Abdelfatah, 2009]. Este comportamiento es atribuido a la presencia del mortero que se encontraba adherido a las partículas de los agregados reciclados, el cual se desgasta más rápido que el agregado natural como se puede apreciar en la tabla 2.6.

En la tabla 2.6 muestra el desgaste del agregado reciclado en función del tamaño de la partícula considerada, característica del hormigón de origen y tipo de agregado natural. 
Tabla 2.6: Desgaste Los Ángeles del AGR según varios autores.

\begin{tabular}{|c|c|c|c|c|c|}
\hline Referencia & $\begin{array}{c}\text { Fracción } \\
\text { (mm) }\end{array}$ & Desgaste AGR & $\begin{array}{c}\text { Desgaste } \\
\text { AGN }\end{array}$ & $\begin{array}{c}\text { Tipo de } \\
\text { AGN }\end{array}$ & Observaciones \\
\hline \multirow{3}{*}{$\begin{array}{l}\text { Hansen y Narud, } \\
1983\end{array}$} & $4-8$ & 30,$1 ; 32,6 ; 41,4$ & 25,9 & \multirow{3}{*}{ Calizo } & Razón a/c \\
\hline & $8-16$ & 26,$7 ; 29,2 ; 37,0$ & 22,7 & & 0,$40 ; 0,70 ; 1,20$ \\
\hline & $16-32$ & 22,$4 ; 25,4 ; 31,5$ & 18,8 & & respectivamente \\
\hline $\begin{array}{l}\text { Sri Ravindrarajah y } \\
\text { Tan, } 1985\end{array}$ & $5-37,5$ & 37,$2 ; 40,8 ; 40,8$ & 18,1 & Granítico & $\begin{array}{c}\text { Razón a/c 0,51; } \\
0,60 ; 0,73 \\
\text { respectivamente }\end{array}$ \\
\hline \multirow{4}{*}{$\begin{array}{l}\text { Sri Ravindrarajah } \\
\text { et al, } 1988\end{array}$} & $4,75-9,5$ & 36,2 & \multirow{4}{*}{18,5} & \multirow{4}{*}{ Granítico } & \multirow{4}{*}{ f'c: $60 \mathrm{MPa}$. } \\
\hline & $9,5-13,2$ & 31,6 & & & \\
\hline & $13,2-19,0$ & 27,7 & & & \\
\hline & $>19,0$ & 28,8 & & & \\
\hline Tavakoli y & $4,5-19,0$ & 26,$4 ; 41,7$ & 22,9 & Calizo & f'c: 50 y $44 \mathrm{MPa}$, \\
\hline Soroushian, 1996 & $4,75-25,0$ & 28,$7 ; 42,7$ & 22,9 & & respectivamente \\
\hline Hernández y & $4,75-20,0$ & 32,0 & 19,0 & Granítico & Laboratorio \\
\hline Fornasier, 2005 & $6-20,0$ & 40,0 & 19,0 & Granítico & Planta \\
\hline \multirow{3}{*}{$\begin{array}{l}\text { Cuneo Simian y } \\
\text { Duran, } 1995\end{array}$} & $4,75-19,0$ & 29,2 & 22,0 & Granítico & \multirow{3}{*}{$\mathrm{a} / \mathrm{c}: 0,56$} \\
\hline & $4,75-19,0$ & 42,5 & 37,0 & Silíceo trit & \\
\hline & $4,75-19,0$ & 31,9 & 21,6 & Basalto & \\
\hline \multirow[t]{2}{*}{ Gómez et al, 2001} & $5-10,0$ & 29,9 & 21,2 & Calizo & \\
\hline & $10-20,0$ & 33,4 & 21,6 & Calizo & \\
\hline $\begin{array}{l}\text { Tabsh y Abdelfatah, } \\
2009\end{array}$ & $4,75-25,0$ & 28,$0 ; 33,0$ & 24,0 & & $\begin{array}{l}\text { f'c: } 50 ; 30 \mathrm{MPa} \text {, } \\
\text { respectivamente }\end{array}$ \\
\hline
\end{tabular}

Con toda esta bibliografía se puede concluir que la presencia de mortero en los AR permite mayor desgaste de las partículas incidiendo directamente en la pérdida de peso de los agregados, con porcentajes de desgaste que varía entre 22 y $42 \%$. Los factores que más influyen en definitiva en el desgaste de los AR a más de la densidad y absorción son el tamaño de las partículas, el procesamiento empleado en la planta y la resistencia del hormigón de origen. El CIRSOC vigente exige un desgaste inferior al $50 \%$, para el caso de hormigones expuestos a la abrasión, la perdida debe ser inferior del $30 \%$. En cambio las recomendaciones de la CPA exige que para capa de rodadura el desgaste del agregado sea menor al $25 \%$ y para otras capas (base asfáltica) inferior al $30 \%$. 


\section{Índices de lajosidad y elongación}

Los planos de fractura orientados que poseen la mayoría de rocas naturales puede hacer que el proceso de trituración produzca una importante cantidad de partículas lajosas en los AGN [Poole y Sims, 2003; Czarnecka y Gillott, 1982]. En el caso de los hormigones que se trituran, los planos de debilidad (interfaces) se encuentran distribuidos sin una orientación definida, provocando que los AGR presenten bajos porcentajes de partículas lajosas.

Gómez et al, (2001); Hernández y Fornasier, (2005) han hallado que la presencia de mortero adherido a las partículas de agregado natural produce una modificación en la forma de las partículas de los agregados reciclados, resultando valores menores para el índice de lajas y similares o superiores para el índice de elongación en los AGR con respecto a los AGN. 


\section{Capítulo 3}

\section{PROGRAMA EXPERIMENTAL}

\section{1.- INTRODUCCION}

El programa experimental fue realizado a partir de la recolección de pedazos de losas de hormigón correspondientes a trabajos de bacheo realizado en la zona de intersección de la Avenida 122 y la calle 43 de la ciudad de La Plata.

Considerando que el principal objetivo de este trabajo de tesis es evaluar las diferentes alternativas de uso para el aprovechamiento de este residuo, se procedió a la obtención de diferentes fracciones de agregados reciclados (AR), tanto la fracción gruesa como la fina, y realizando varios programas específicos para explorar su uso en reemplazo de agregados naturales, sea para la elaboración de nuevos hormigones, para incorporarlos en mezclas asfálticas o estabilizados granulares.

El estudio experimental llevado a cabo consta de 4 etapas. La primera consistió en la obtención y estudio de las propiedades físico-mecánicas de los agregados reciclados, las que como referencia fueron comparadas con la de los agregados naturales seleccionados para realizar las diversas experiencias. Además de la granulometría, índice de lajosidad y elongación, absorción de agua y densidad se extrajeron pequeños testigos de las losas de hormigón, previo a la trituración, de forma tal de tener como referencia el nivel de resistencia del hormigón de origen. En el caso de las fracciones finas se evaluó su granulometría, densidad, absorción, equivalencia de arena y plasticidad de la fracción fina que pasa tamiz \# 200. La segunda etapa aborda la utilización 
de agregados gruesos reciclados (AGR) para elaborar hormigones de uso vial. En este caso se plantearon dos alternativas, mezclas de baja resistencia para bases y hormigones estructurales (tipo $\mathrm{H}-30$ ) para losas de pavimento. En este caso se estudiaron las propiedades en estado fresco, diferentes propiedades físicas y mecánicas en estado endurecido. Los resultados fueron comparados con hormigones convencionales $(\mathrm{HC})$ de similares características elaborados en su totalidad con agregados naturales.

Como tercera etapa se planteó el uso de agregados gruesos y finos en la composición de dos mezclas asfálticas densas (CAC D19), una para carpeta de rodadura y otra para base asfáltica. Debido a la alta tasa de agregado grueso alterado por el proceso de compactación Marshall solamente se empleó el agregado fino reciclado (AFR) en reemplazo de la totalidad de la arena de trituración. Se realizó el diseño de las mezclas mediante la metodología Marshall. Se analizaron parámetros volumétricos (densidad, densidad máxima teórica, vacíos, VAM, RBV) y parámetros mecánicos (Estabilidad y Fluencia Marshall) a fin de obtener los correspondientes porcentajes óptimos de asfalto. Una vez diseñadas las mezclas asfálticas se verificaron daño por humedad, resistencia al ahuellamiento, módulo de rigidez y resistencia a tracción por compresión diametral.

Finalmente en la cuarta etapa se analizó el uso del agregado reciclado para elaborar una base granular. Esta base granular estaba compuesta de agregados reciclados, utilizando tanto la fracción gruesa como la fracción fina. En este caso se evaluaron la compactación de la mezcla, valor soporte e hinchamiento.

En el presente capítulo se describe el proceso de obtención del agregado triturado. Luego se presentan los diferentes materiales componentes empleados en las experiencias incluyendo los agregados reciclados, los agregados naturales, el suelo, el cemento portland y el ligante bituminoso. Por último se detallan los métodos y dispositivos de ensayo empleados a lo largo de las diferentes etapas de la campaña experimental. 


\section{2.- OBTENCION DEL ARIDO RECICLADO}

El hormigón de origen de los agregados reciclados fue obtenido del levantamiento de losas fracturadas que eran retiradas dentro de un programa de bacheo (Ver figura 3.1). Se pudo observar que dicho hormigón fue elaborado con agregados graníticos, muy frecuentes en la zona del Gran La Plata, y que se obtienen del centro de la provincia de Buenos Aires. De algunos pedazos de losas, se extrajeron testigos cilíndricos de $75 \mathrm{~mm}$ de diámetro que fueron aserrados a $150 \mathrm{~mm}$ de altura. Tres de ellos se encabezaron para realizar ensayos de compresión determinando la resistencia y el módulo de elasticidad; así mismo se midieron la densidad y la absorción en agua (Ver figura 3.2).

Los resultados obtenidos sobre los testigos de los pavimentos se indican en la tabla 3.1, se trata de un hormigón de resistencia media del orden de 47,9 $\mathrm{MPa}$, dándonos cuenta que tienen propiedades físicas-mecánicas muy parecidas.

Tabla 3.1: Propiedades del hormigón de origen.

\begin{tabular}{|l|c|c|c|c|}
\hline \multirow{2}{*}{\multicolumn{1}{|c|}{ Propiedades }} & \multicolumn{3}{c|}{ Testigos } & \multirow{2}{*}{ Promedio } \\
\cline { 2 - 4 } & $\mathbf{1}$ & $\mathbf{2}$ & $\mathbf{3}$ & \\
\hline Dsss & 2,35 & 2,33 & 2,34 & 2,34 \\
\hline Absorción [\%] & 4,32 & 4,06 & 4,01 & 4,1 \\
\hline Resistencia a compresión [MPa] & 48,8 & 46,0 & 48,8 & 47,9 \\
\hline Módulo de Elasticidad [GPa] & & 45,6 & 38,4 & 42,0 \\
\hline
\end{tabular}

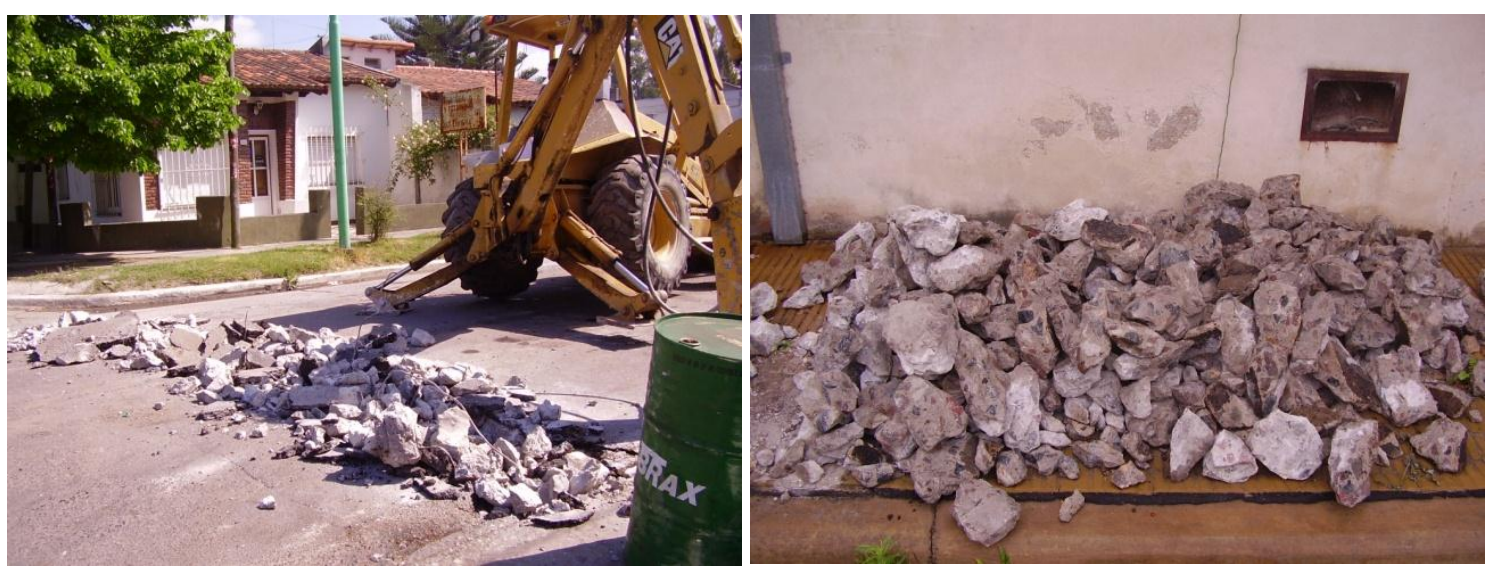

Figura 3.1: Pedazos de losas de pavimento usados en la obtención de áridos. 

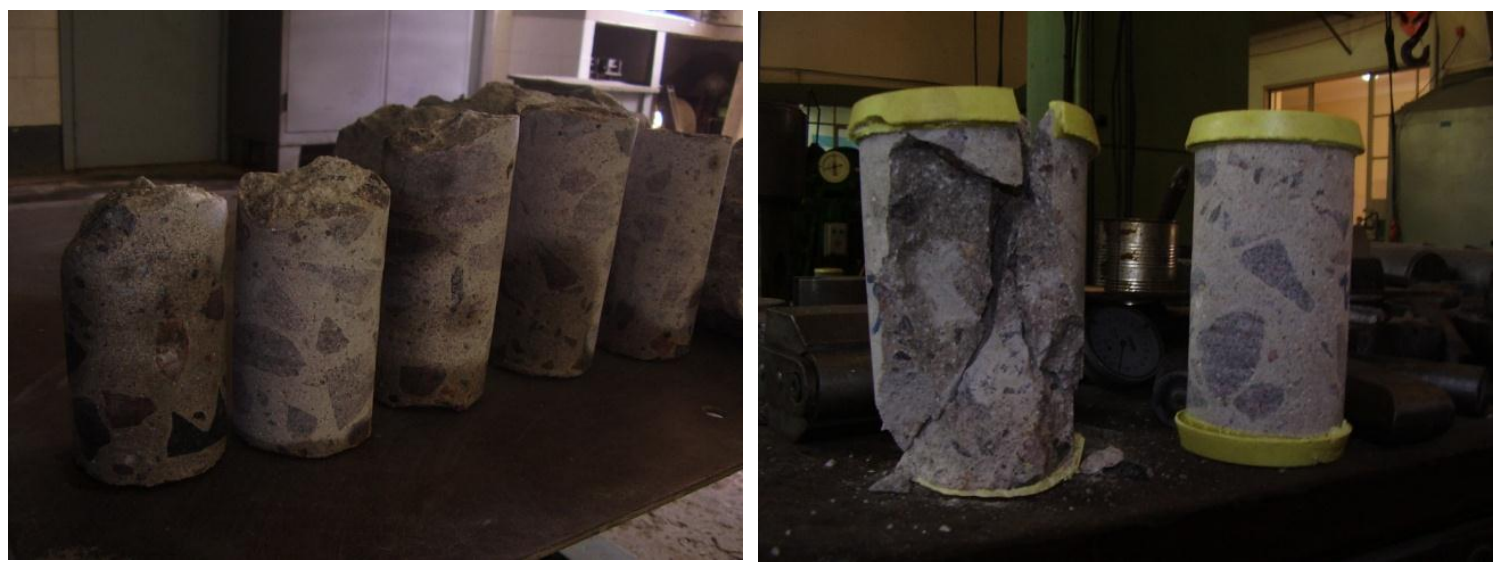

Figura 3.2: Testigos obtenidos de las losas de pavimento.

Los agregados reciclados fueron obtenidos mediante el empleo de una trituradora de mandíbulas (Ver figura 3.3.a) generando partículas de agregados con un tamaño menor a $50 \mathrm{~mm}$. Con el fin de generar AGR de tamaño nominal 4,75-38 mm y poder aprovechar el material cuyo tamaño excedía el límite mencionado, se empleó una segunda trituradora más pequeña, también de mandíbulas (Ver figura 3.3.b), generando partículas de tamaño máximo $12,7 \mathrm{~mm}$. El procedimiento de trituración adoptado para la generación de los agregados reciclados, consistió en triturar los pedazos de losas de hormigón mediante la primera trituradora, tamizar el material con una malla de abertura $38 \mathrm{~mm}$ y procesar la fracción retenida mediante la segunda trituradora. El material resultante de este último proceso no fue mezclado con el obtenido de la primera trituradora, para poder tener dos granulometrías diferentes y así poderlos usar en las diferentes etapas. Posteriormente se tamizaron los triturados por una malla de abertura $4,75 \mathrm{~mm}$, obteniéndose AGR de tamaño nominal 4,75-19 mm para mezclas asfálticas y 4,75-38 mm para la elaboración de hormigones y una combinación de las dos fracciones en diferentes proporciones para una base granular. También fue considerada la fracción del AFR (pasa tamiz $N^{\circ} 4,75 \mathrm{~mm}$ ) para elaborar mezclas asfálticas y base granular. 

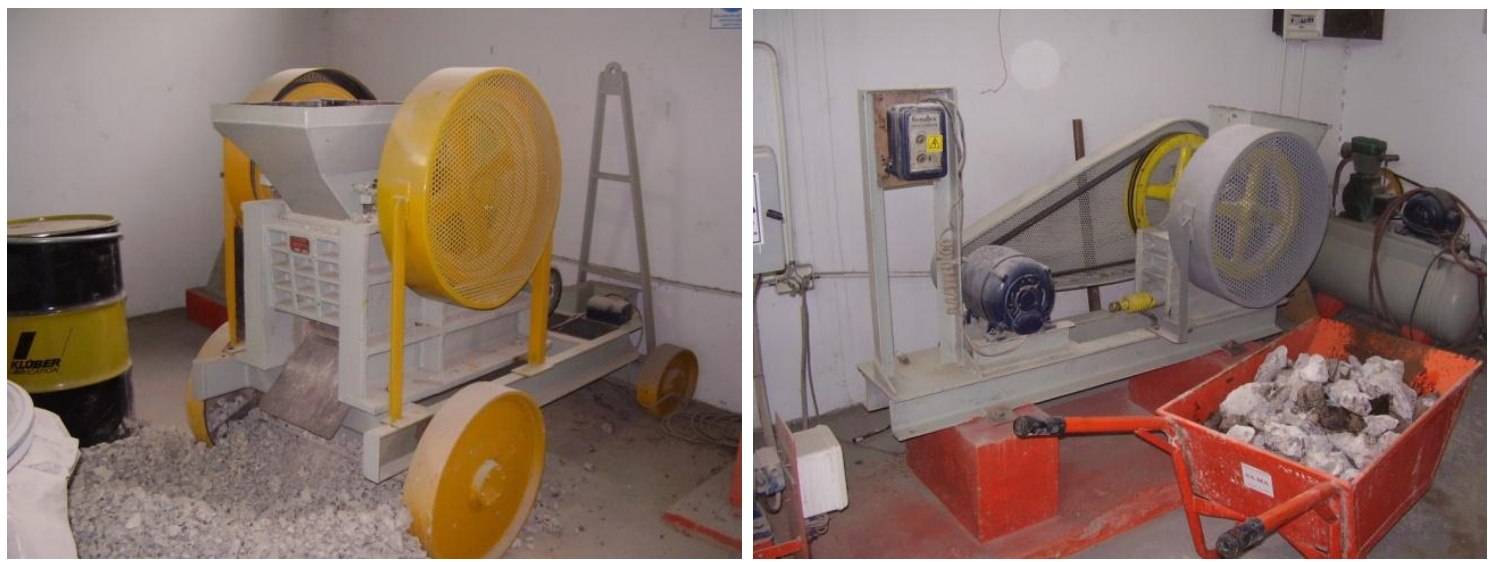

Figura 3.3: Trituradoras empleadas.

Para el desarrollo experimental del plan de tesis se seleccionaron y caracterizaron las dos fracciones, tanto gruesa como fina del AR obtenidas por medio de la trituración evaluando sus propiedades físico-mecánicas para poderlas comparar con las propiedades de los agregados naturales. Una vez comparadas y analizadas las propiedades de los AR se pensó en diferentes usos que se le podía dar a este material.

Se elaboraron distintos tipos de hormigones para aplicaciones viales utilizando como materiales árido grueso reciclado tamaño nominal 10-38 mm (R38), árido grueso granítico tamaño nominal 10-30 mm (G25), cemento Portland compuesto (CPC40), arena Silícea para hormigón (ASH) y superfluidificante Glenuim (AD).

En cuanto a la elaboración de mezclas asfálticas se analizaron dos opciones. Como primera opción la utilización del $100 \%$ de áridos reciclados, componiendo la fracción gruesa con el material retenido por el tamiz de abertura $38 \mathrm{~mm}$ que fue pasado por una segunda trituración hasta obtener agregados de tamaño inferior a 1" y como agregado fino el obtenido de las dos trituraciones. Una segunda opción fue el uso solamente del árido fino reciclado. Los materiales utilizados para el estudio de estas mezclas fueron: árido grueso reciclado tamaño nominal 6-20 $\mathrm{mm}(\mathrm{R} 19)$, árido grueso granítico tamaño nominal 6-20 mm (G19), arena fina reciclada 0-6 mm (R0-6), arena de trituración granítica 0-6 mm (G0-6), arena silícea (AS), cal, filler y cemento asfáltico convencional (CA-30). 
La otra opción de uso de estos áridos reciclados fue para el diseño de estabilizados granulares utilizando una combinación de los AGR obtenido de las dos trituraciones, AFR y un suelo seleccionado. Los materiales utilizados para su estudio fueron: árido grueso reciclado tamaño nominal 6-20 mm (R19), árido grueso reciclado tamaño nominal $10-38 \mathrm{~mm}$ (R38), árido fino reciclado 0-6 mm (R0-6) y suelo seleccionado (SS).

\section{3.- METODOLOGIAS DE ENSAYO}

\subsection{1.- CARACTERIZACION DE AGREGADOS GRUESOS}

Las propiedades evaluadas sobre los AGN incluyeron granulometría, densidad en condición de saturado y superficie seca (Dsss), densidad seca (Ds), absorción de agua en inmersión, pérdida de peso por desgaste Los Ángeles, pasa tamiz $75 \mu \mathrm{m}$, peso por unidad de volumen en estado suelto (PUVs), índices de lajosidad (IL) y elongación (IE). En la tabla 3.2 se indican las normas IRAM utilizadas en cada uno de los ensayos mencionados.

Tabla 3.2: Normas de ensayo para caracterización de agregados.

\begin{tabular}{|l|c|}
\hline \multicolumn{1}{|c|}{ Propiedades } & Normas IRAM \\
\hline Granulometría & IRAM 1505 \\
\hline Densidad y Absorción & IRAM 1533 \\
\hline Desgaste Los Ángeles & IRAM 1532 \\
\hline Pasa tamiz 75 $\mu \mathrm{m}$ & IRAM 1540 \\
\hline PUVs & IRAM 1548 \\
\hline Índice de lajosidad & IRAM 1687-1 \\
\hline Índice de elongación & IRAM 1687-2 \\
\hline
\end{tabular}

Como en la Argentina no se cuenta con normativas y/o recomendaciones para la evaluación de agregados reciclados, sus propiedades fueron determinadas mediante la aplicación de normas vigentes en el país para los AGN.

En cuanto a la resistencia al desgaste determinada mediante la máquina Los Ángeles dado el tamaño nominal de los mismos, se adoptaron las graduaciones " $A$ " y "B" definidas en la norma. Para ensayar la graduación "A" se obtuvieron $1250 \pm 10 \mathrm{~g}$ de cada una de las siguientes fracciones del material: $37,5-25 ; 25-19 ; 19-12,7$ y $12,7-9,5$, con un peso total aproximado de $5000 \pm 10 \mathrm{~g}$. Este material fue llevado al tambor de ensayo incorporando 12 
bolas de acero cuyo peso se ajustó al límite de la norma de $5000 \pm 25 \mathrm{~g}$. Para la graduación "B" se emplearon $2500 \pm 10 \mathrm{~g}$ de cada una de las siguientes fracciones del material: $25-19 \mathrm{~mm}$ y 12,7-9,5 mm, con un peso total aproximado de $5000 \pm 10 \mathrm{~g}$. Este material fue llevado al tambor de ensayo incorporando 11 bolas de acero cuyo peso se ajustó al límite de la norma de $4584 \pm 25 \mathrm{~g}$. Los agregados junto con las bolas fueron sometidas a 500 vueltas del tambor de la citada máquina. Luego, el material resultante fue tamizado por el tamiz IRAM № 12 registrándose el peso del material en él retenido.

Además de los ensayos citados anteriormente, a los agregados gruesos se le realizó un ensayo de carga puntual mediante el cual se estimó la resistencia de las partículas de cada tipo de agregado, de este modo se pueden comparar las capacidades resistentes de las partículas de agregado reciclado con respecto a los agregados naturales. Dicho ensayo fue realizado según el método sugerido por la Sociedad Internacional de Mecánica de Rocas [International Society for Rock Mechanics, 1985].

Se escogieron alrededor de entre 40 a 45 muestras de agregados para cada tipo de piedra a evaluar (granítica y reciclada). El ensayo consiste en aplicar una carga concentrada sobre la muestra mediante un par de puntas cónicas de $5 \mathrm{~mm}$ de diámetro, en la dirección de su menor dimensión hasta producir la rotura de la misma (Ver figura 3.4). Los requisitos son mostrados en la figura 3.5.

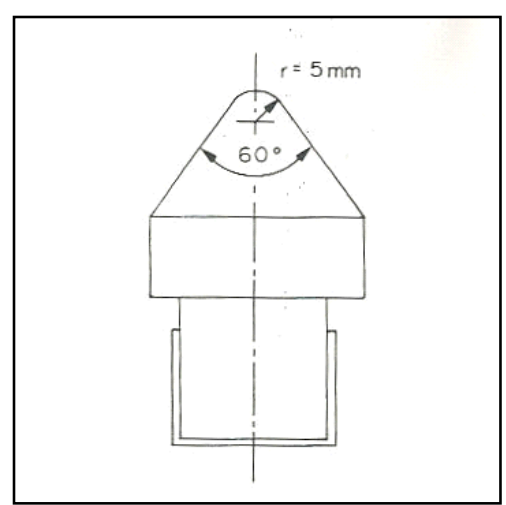

Figura 3.4: Forma y tamaño de las puntas utilizadas en el ensayo. 


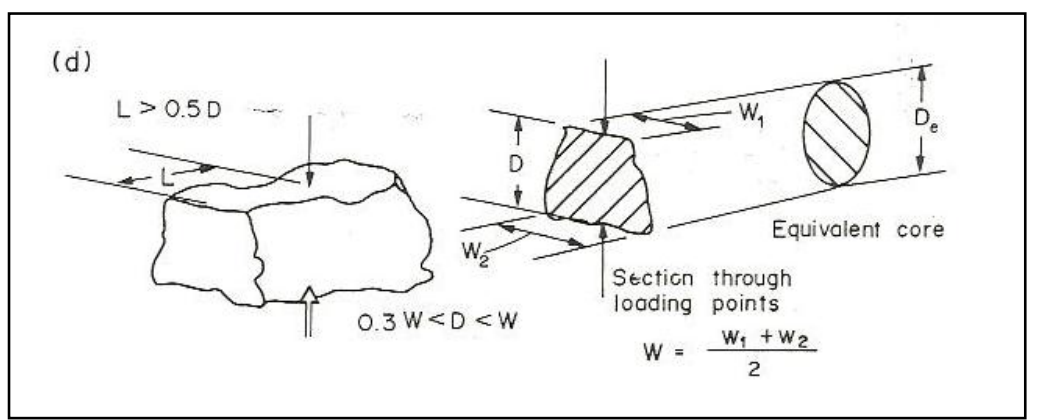

Figura 3.5: Característica de la muestra utilizada en el ensayo de carga puntual.

Sobre las muestras seleccionadas se realizaron los ensayos de carga puntual mediante el dispositivo descrito obteniéndose la carga de rotura $P(\mathrm{~kg})$. Se calcula el área de la sección de rotura $A\left(\mathrm{~cm}^{2}\right)$ como $A=W^{\star} D$ donde $D(\mathrm{~cm})$ es la altura de la sección de rotura de la muestra y $W(\mathrm{~cm})$ el ancho promedio de la muestra en dicha sección.

Con los datos anteriormente registrados se determinó el índice de carga puntual $/ s\left(\mathrm{~kg} / \mathrm{cm}^{2}\right)$ mediante la fórmula:

$$
I s=P \times D e^{2}
$$

Donde $D e(\mathrm{~cm})$ es el diámetro equivalente de la sección de rotura el cual se calcula como:

$$
D e=(4 / \pi) \times A
$$

Los valores experimentales obtenidos para el índice de carga puntual Is, se corrigieron por tamaño para obtener el índice estándar $I s(50)\left(\mathrm{kg} / \mathrm{cm}^{2}\right)$ mediante la siguiente expresión:

$$
I s(50)=F \times I s
$$

Donde $F$ es un factor de corrección adimensional calculado como:

$$
F=[D e(m m) / 50(m m)]^{0.45}
$$

Para obtener la resistencia a la compresión qu $\left(\mathrm{kg} / \mathrm{cm}^{2}\right)$, a partir del índice de carga puntual corregido por tamaño, se utilizó la siguiente fórmula: 


$$
q u=22 \times I s(50)
$$

Las propiedades evaluadas en los agregados para ser utilizados en mezclas asfálticas son prácticamente las mismas citadas anteriormente, con la diferencia que se debe determinar la densidad real de los agregados gruesos

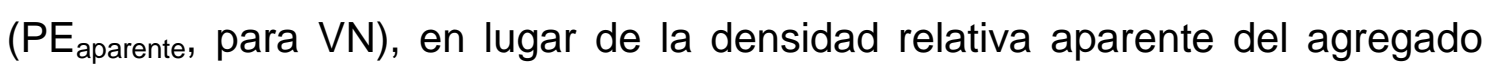
saturado utilizado en el diseño de hormigones.

\subsection{2.- CARACTERIZACION DE LOS AGREGADOS FINOS}

En el caso de los agregados finos reciclados o arena de trituración (0-6 mm) a ser utilizada en mezclas asfálticas se le realizaron granulometrías por vía húmeda, la densidad real y la densidad relativa aparente del agregado seco $\left(P E_{\text {aparente }}\right.$ y $P E_{\text {seco }}$ según DVN, respectivamente), equivalencia de arena y plasticidad de la fracción que pasa tamiz IRAM 0,075 mm. En la tabla 3.3 se indican las normas IRAM utilizadas para los ensayos nombrados anteriormente. Para el caso de las arenas naturales usadas en hormigones también se analizaron las mismas propiedades.

Tabla 3.3: Normas de ensayo para agregados finos.

\begin{tabular}{|l|c|}
\hline \multicolumn{1}{|c|}{ Propiedades } & Normas IRAM \\
\hline Granulometría vía húmeda & IRAM 1540 \\
\hline Densidad y Absorción & IRAM 1520 \\
\hline Equivalencia de Arena & IRAM 1682 \\
\hline Plasticidad de la fracción fina pasa tamiz $0,075 \mathrm{~mm}$ & IRAM 1851 \\
\hline
\end{tabular}

\subsection{3.- CARACTERIZACIÓN DE HORMIGONES}

Se estudiaron las propiedades en estado fresco y estado endurecido de los diferentes hormigones elaborados tanto con agregados gruesos naturales como con agregados reciclados. En estado fresco se determinaron propiedades tales como el asentamiento medido por el cono de Abrams [IRAM 1536], el peso por unidad de volumen (PUV) [IRAM 1562], el contenido de aire naturalmente incorporado empleando el método de presión [IRAM 1602] y fraguado [ASTM C 157].

En estado endurecido, en lo referente a la caracterización del comportamiento mecánico, se hicieron determinaciones de la resistencia a compresión $\left(f^{\prime} c\right)$ [IRAM 1546] y el módulo de elasticidad estático ( $E$ ) [ASTM C 
469], sobre probetas cilíndricas de 150 × 300 mm. Además se evaluó el módulo de rotura en flexión con carga centrada, sobre probetas prismáticas de $150 \mathrm{x}$ 150 x $600 \mathrm{~mm}$ y $450 \mathrm{~mm}$ de luz libre entre apoyos.

Para la determinación del módulo de elasticidad se consideraron la tensión correspondiente al $40 \%$ de la carga última y la deformación en correspondencia con ella, y la tensión correspondiente a una deformación longitudinal de 50 microstrains.

Complementariamente sobre las mitades resultantes del ensayo de flexión se realizaron ensayos de resistencia por compresión diametral ( $\left.f_{c d}\right)$. Según la norma IRAM 1658 (Ver figura 3.6 y 3.7) este ensayo consiste en someter a compresión diametral una probeta cilíndrica de hormigón, aplicando una carga de manera uniforme a lo largo de dos líneas generatrices opuestas hasta alcanzar la rotura. En este caso se utilizaron los pedazos de las vigas sometidas a flexión considerando el circulo inscripto en ellas, por lo cual la altura de la viga equivale al diámetro del cilindro y el ancho de la viga a la altura del cilindro. Se trazaron dos líneas contenidas en un plano que sirvieron como guía para la colocación de los listones de madera.

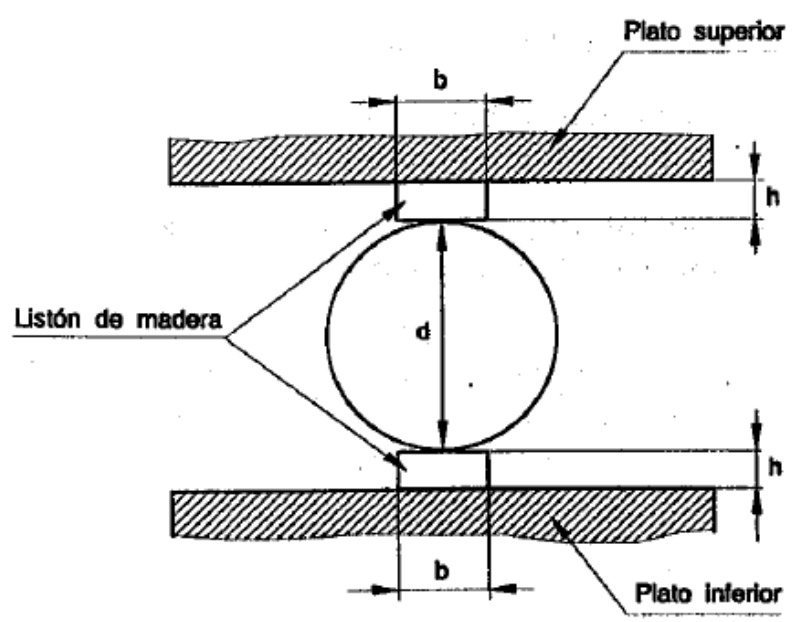

Figura 3.6: Ensayo de tracción indirecta según norma IRAM 1658. 


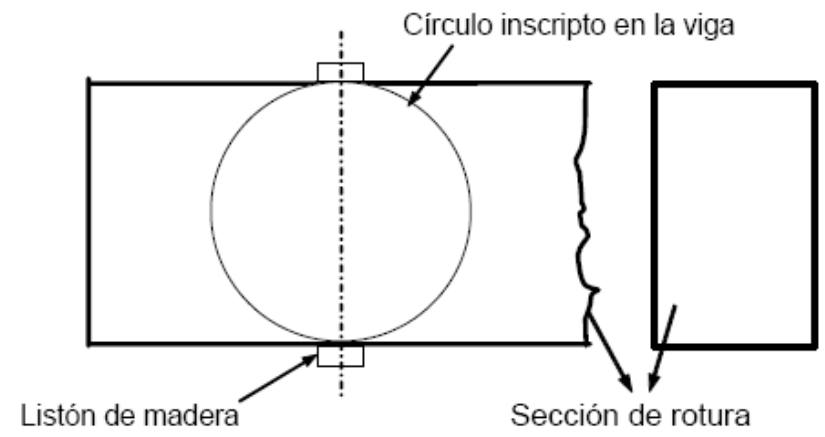

Figura 3.7: Ensayo de tracción indirecta.

Además de los ensayos para la caracterización del comportamiento mecánico del hormigón, se evaluó la contracción por secado que sufre el hormigón en presencia de áridos naturales y reciclados [ASTM C 403]. Para la realización de este ensayo se utilizaron probetas prismáticas de $75 \times 105 \times 430$ $\mathrm{mm}$. Las probetas son colocadas en un cuarto climatizado con una temperatura de $20 \pm 1 \stackrel{\circ}{\mathrm{C}}$ y una humedad de $45-55 \%$ para hacer las lecturas a partir del séptimo día. Las mediciones se realizaron con el comparador (Ver figura 3.8) colocando las probetas sobre dicho equipo. El aparato nos proporciona una base de lectura de 15" y las lecturas tomadas en los diferentes días se restan de la lectura obtenidas el primer día de medición, teniendo así la contracción o deformación por secado $(m i c r o ́ n / m)$ de la probeta con el tiempo. Una vez tomada las lecturas, los prismas de hormigón son pesadas con una balanza de precisión para poder también obtener la pérdida de peso de las probetas (\%).
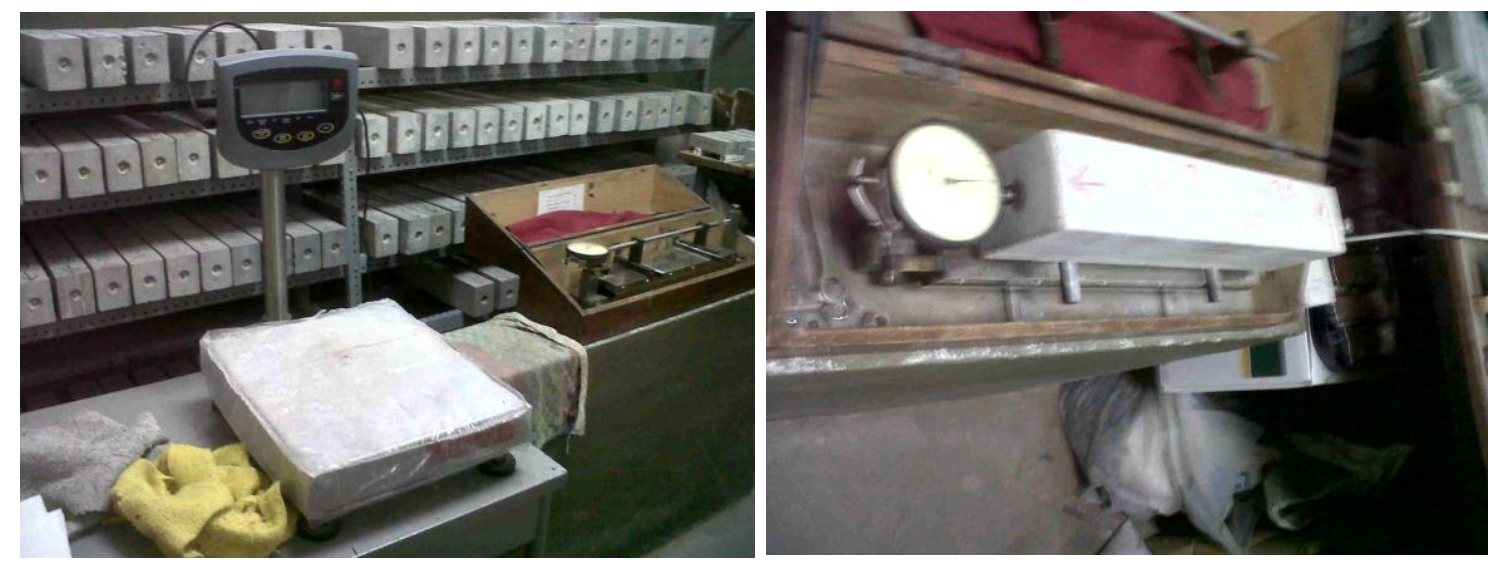

Figura 3.8: Equipos: Balanza y comparador empleados para medir la pérdida de peso y la contracción por secado respectivamente. 


\subsection{4.- CARACTERIZACIÓN DE MEZCLAS ASFALTICAS}

En las experiencias sobre mezclas asfálticas se consideraron como alternativas dos mezclas: una carpeta de rodadura y una base asfáltica. Para caracterizarlas se moldearon probetas sobre las que se determinaron los parámetros requeridos en el método de diseño Marshall (Estabilidad, Fluencia, Densidad, V.A.M, Porcentaje de vacíos y RBV). Las probetas para capa de rodadura primeramente se compactaron con 75 golpes/cara, pero al ver que la mezcla no cumplía con los parámetros requeridos por el método Marshall se decidió optar 50 golpes por cara del pisón Marshall. Las probetas para la base asfáltica también se compactaron con 50 golpes por cara. Una vez definido el contenido óptimo de ligante asfáltico mediante la metodología descrita en la norma VN-E9 se moldearon nuevas series de probetas con el objetivo de verificar otras propiedades mecánicas que actualmente son utilizadas para complementar el diseño Marshall, como tracción indirecta, módulo de rigidez, resistencia al ahuellamiento y daño por humedad.

\section{Confección de las probetas Marshall}

El Asphalt Institute recomienda calentar el cemento asfáltico dentro de las temperaturas definidas por un rango de viscosidades cinemáticas de $170 \pm$ 20 centistokes para el proceso de mezclado y dentro de las temperaturas definidas por un rango de viscosidades cinemáticas de $280 \pm 30$ centistokes, para el proceso de compactación.

El cemento asfáltico es calentado durante 30 á 40 minutos a la temperatura establecida para el mezclado. Los agregados minerales deberán a su vez permanecer como mínimo durante dos horas a dicha temperatura más $15 \stackrel{\circ}{\circ}$. La temperatura del molde y zapata del pisón de compactación para mezclas finas o gruesas con agregados porosos será inferior en $20{ }^{\circ} \mathrm{C}$ a los límites establecidos para el cemento asfáltico. Para mezclas gruesas con agregados no porosos, inferior en $10 \stackrel{\circ}{\circ} \mathrm{C}$ a los límites establecidos para el cemento asfáltico.

Para definir el contenido óptimo de betún se determina el promedio de tres valores de contenido de asfalto: el que corresponde a la mayor densidad, el contenido de asfalto que corresponda a la mayor Estabilidad y el porcentaje 
de betún que corresponda al valor medio de los porcentajes de vacíos, fijados como límites en las especificaciones de la carpeta o base en estudio.

Los ensayos adiciones al método Marshall que se le realizaron a las probetas asfálticas, como módulo de Rigidez, ensayo de rueda cargada (Wheel Tracking Test) y daño por humedad son descritos mediante la normativa extranjera adoptada para realizarlos. No existen para todos estos ensayos especificaciones que limiten sus resultados, si bien las nuevas especificaciones obligan a su determinación ya que están relacionados, en mayor o menor medida, con el comportamiento de una mezcla asfáltica en el camino.

\section{Resistencia a compresión diametral [IRAM 6846]}

Este ensayo consiste en someter a compresión diametral una probeta cilíndrica aplicando una carga de manera uniforme a lo largo de dos líneas o generatrices diametralmente opuestas hasta alcanzar la rotura. El ensayo permite, por una parte, definir un parámetro que caracteriza la mezcla bituminosa y, por otra parte, optimizar, en función del contenido de ligante, la cohesión de la mezcla y su resistencia al esfuerzo cortante.

Las probetas son cilíndricas, iguales a las compactadas para el ensayo de Estabilidad Marshall. El proceso de compactación (energía y temperatura) se efectúa de acuerdo con las características de la mezcla y del ligante asfáltico en estudio.

La probeta es cargada a compresión según un plano diametral vertical de la misma. Para poder cargar la probeta a compresión en un plano diametral vertical, se requiere un dispositivo de sujeción a través del cual se materialice dicho plano de carga. Como parte de este dispositivo y en contacto directo con dos generatrices diametralmente opuestas de la probeta, existen dos elementos encargados de evitar la rotura local de la probeta durante el ensayo. Se utilizan unas placas de apoyo curvo, con radio de curvatura igual al radio nominal de la probeta, de $12,7 \mathrm{~mm}$ de ancho, para que la distribución de tensiones no se altere significativamente y para que los cálculos de la resistencia se faciliten manteniendo constante el ancho de carga, en lugar de un ancho de carga variable durante el ensayo, que ocurriría con una placa de carga plana. 
La velocidad de desplazamiento del sistema durante la carga es uniforme e igual a 50,8 $\mathrm{mm} / \mathrm{min}$, igual a la empleada por la prensa en el ensayo de Estabilidad Marshall.

El ensayo de tracción indirecta tiene validez para materiales de comportamiento fundamentalmente elástico y lineal. La norma IRAM 6846 indica una temperatura de $25 \pm 1^{\circ} \mathrm{C}$, pero permite el uso de otras temperaturas para analizar la susceptibilidad térmica de la mezcla en estudio, aunque se sugiere no utilizar temperaturas superiores a los $35^{\circ} \mathrm{C}$ por ser predominante el carácter viscoso de las mezclas.

El ensayo de tracción indirecta no sólo da información de la resistencia del material sino que también puede informar sobre propiedades elásticas resilientes, fisuración térmica, fisuración por fatiga, deformación permanente y puede utilizarse para evaluar el efecto de la humedad en mezclas bituminosas.

Dado que el fallo inicial se produce por rotura a tracción, la resistencia a tracción indirecta se obtiene con la misma ecuación utilizada para hormigón.

\section{Rigidez en mezclas bituminosas [UNE-EN 12697-26]}

Al clasificar las mezclas bituminosas en función de la rigidez se pueden obtener datos para estimar el comportamiento estructural en la carretera, y juzgar los datos del ensayo de acuerdo a las especificaciones.

El ensayo de determinación del módulo de Rigidez mediante carga dinámica en compresión diametral es aplicable a probetas cilíndricas de diferentes diámetros y espesores, fabricadas en el laboratorio, como ha sido el caso, o también extraídas como testigos de una capa de carretera. El ensayo se basa en someter las probetas a deformación en su rango lineal, bajo cargas repetidas o cargas con velocidad de deformación controlada. Se miden las amplitudes del esfuerzo y de la deformación, junto con la diferencia de fase entre esfuerzo y deformación.

Las probetas cilíndricas deben tener un espesor de $30-75 \mathrm{~mm}$, y un diámetro nominal de 80, 100, 120, 150 o 200 mm. Ambas dimensiones se deben elegir con relación al tamaño del agregado nominal máximo de la mezcla. El espesor de cada probeta se debe medir de acuerdo con la Norma 
Europea EN 12697-29. Mediante un adecuado marcador, se traza un diámetro sobre una cara plana de la probeta y luego se traza un segundo diámetro a 90 $\pm 10^{\circ}$ del primero.

La temperatura de ensayo debe ser constante, estar dentro de la temperatura de referencia $\pm 1 \stackrel{\circ}{\circ} \mathrm{C}$ y la cabina estar adecuada con circulación de aire forzada, donde se pueda acondicionar la probeta y realizar el ensayo. La diferencia entre el exterior y el centro no debe ser superior a $0,4 \stackrel{\circ}{ } \mathrm{C}$.

El ensayo se ejecuta mediante un sistema de carga (Ver figura 3.9), que debe incorporar un actuador de carga adecuado, que pueda aplicar carga a lo largo del diámetro vertical de la probeta a través de las platinas de carga. El actuador de carga debe poder aplicar impulsos de carga repetidos que se alternen con periodos de descanso. La carga debe tener la forma de una onda de medio seno o parecida. Durante el ensayo es necesario controlar los tiempos de carga.

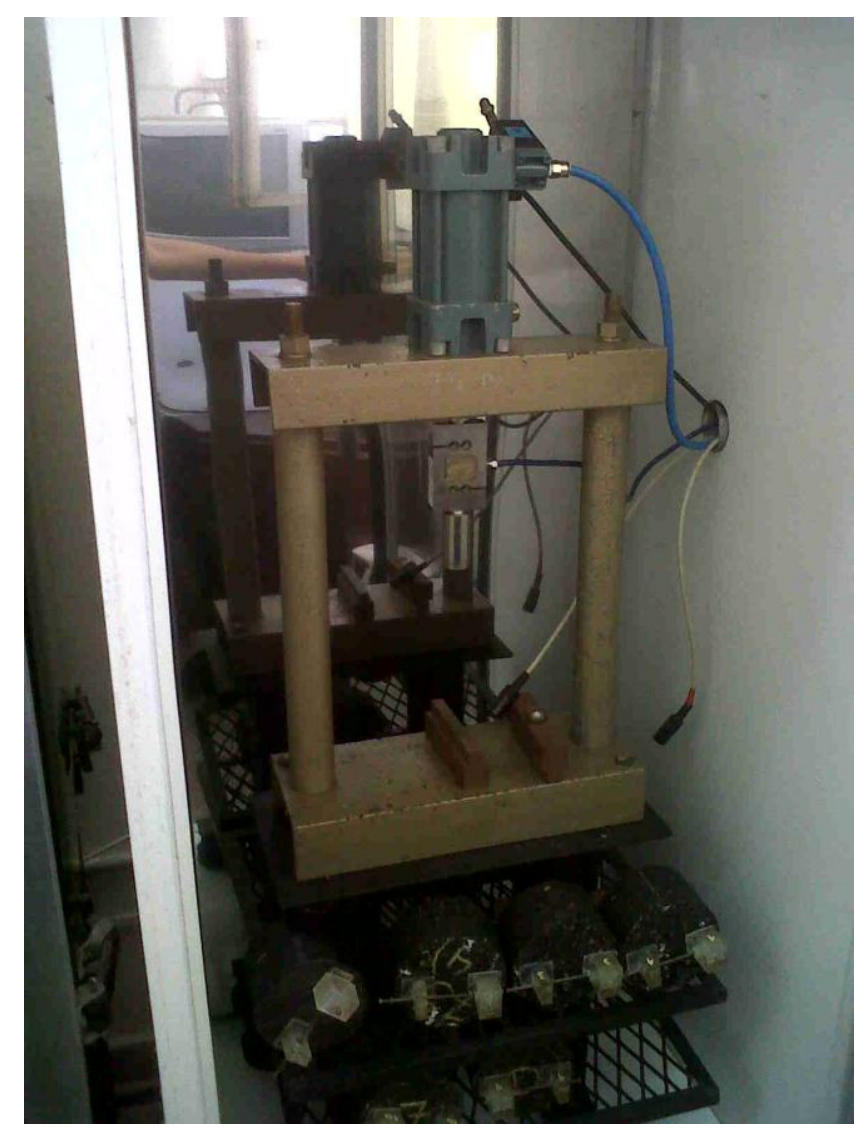

Figura 3.9: Equipo para la obtención del Módulo de Rigidez. 
El tiempo de subida, medido desde el comienzo del impulso de carga, es el tiempo necesario para que la carga aplicada aumente de cero hasta el valor máximo, que debe ser de $124 \pm 4 \mathrm{~ms}$ (milisegundos). El valor de la carga máxima se debe ajustar para alcanzar una deformación horizontal transitoria máxima de referencia del $0,0005 \%$ en el diámetro de la probeta.

El periodo de repetición de los impulsos debe ser de $3,0 \pm 0,1 \mathrm{~s}$ (segundos). Para cada una de las mediciones de los 5 pulsos de carga se debe determinar el módulo de rigidez medido y ajustarlo.

Se ha adaptado una base de medida de longitud $\mathrm{BM}=30 \mathrm{~mm}$ dispuesta en coincidencia con el sector central del diámetro horizontal normal al plano de carga, de tal manera que la fórmula utilizada para el cálculo para módulo dinámico de Rigidez de las mezclas asfálticas determinado sobre probetas de diámetro igual a 101,6 mm, la expresión resulta finalmente:

$$
E\left(\text { tiempo, } T^{o}\right)=\frac{100 P}{t \Delta} \quad(0,167+0,528 \mathrm{~V})
$$

Donde $E$ (tiempo, $T^{o}$ ): módulo de rigidez medido en MPa para condiciones particulares de temperatura y frecuencia de carga; P: Amplitud de la carga aplicada dinámicamente en $\mathrm{N}$; $\mathrm{t}$ : altura de la probeta en $\mathrm{cm} ; \Delta$ : variación de la longitud de la BM al finalizar el pulso de carga en $\mu$ y $v$ : relación de Poisson.

Con la base de medida de longitud BM = Diámetro horizontal normal al plano de carga la fórmula utilizada para el cálculo de módulo dinámico de rigidez de las mezclas asfálticas determinada sobre probetas (con mediciones de los 10 impulsos de carga, para cada impulso de carga un valor) de compactador giratorio Superpave o de compactador Marshall a partir de la anterior expresión, resulta finalmente:

$$
E\left(\text { tiempo, } T^{o}\right)=\frac{100 P}{t \Delta}(0,27+v)
$$


Con probetas del compactador giratorio Superpave y $\mathrm{BM}=0,5$ Diámetro, la fórmula a emplear es la siguiente:

$$
E\left(\text { tiempo, } T^{o}\right)=\frac{100 P}{t \Delta}(0,238+0,781 \mathrm{v})
$$

\section{Ensayo de Rueda Cargada (Medición de deformaciones permanentes) [BS-598]}

Este ensayo fue utilizado para caracterizar la performance frente a las deformaciones permanentes de una mezcla asfáltica en condiciones controladas de laboratorio.

El equipo consiste en una rueda de goma maciza de $207 \mathrm{~mm}$ de diámetro y $47 \mathrm{~cm}$ de ancho, que cargada con $520 \pm 5 \mathrm{~N}$, se desplaza con movimientos alternativos dentro de un recorrido de $230 \mathrm{~mm}$ a razón de 21 ciclos por minuto (42 pasadas de rueda por minuto) sobre la muestra de concreto asfáltico. La probeta es de 300 x $300 \mathrm{~mm}$ de lado y $50 \mathrm{~mm}$ de espesor y es compactada a la densidad Marshall de proyecto. El ensayo posee una duración de 120 minutos, durante los cuales se miden las deformaciones permanentes en la mezcla asfáltica. La temperatura de ensayo normalmente es de $60{ }^{\circ} \mathrm{C}$ simulando las condiciones más desfavorables para el pavimento.

Del ensayo se obtiene como resultado la velocidad de deformación y la correspondiente Estabilidad dinámica. La velocidad de deformación ( Vd) se define como la variación en el tiempo del incremento de la profundidad de huella. Esta es determinada sobre la última porción de la curva Deformación/Tiempo considerando el lapso de 15 minutos (Ver figura 3.10).

$$
\text { Vd. }[\mathrm{mm} / \mathrm{min}]=\frac{D_{120 \mathrm{~min}}-D_{105 \mathrm{~min}}}{15}
$$

Donde D120min y D105min corresponde a la deformación para 120 y 105 minutos respectivamente. La Estabilidad Dinámica $(\mathrm{Ed})$ indica el número de pasadas de la rueda para producir una deformación de $1 \mathrm{~mm}$.

$$
\text { Ed. [pasadas } / \mathrm{mm}]=\frac{42}{\mathrm{Vd}}
$$




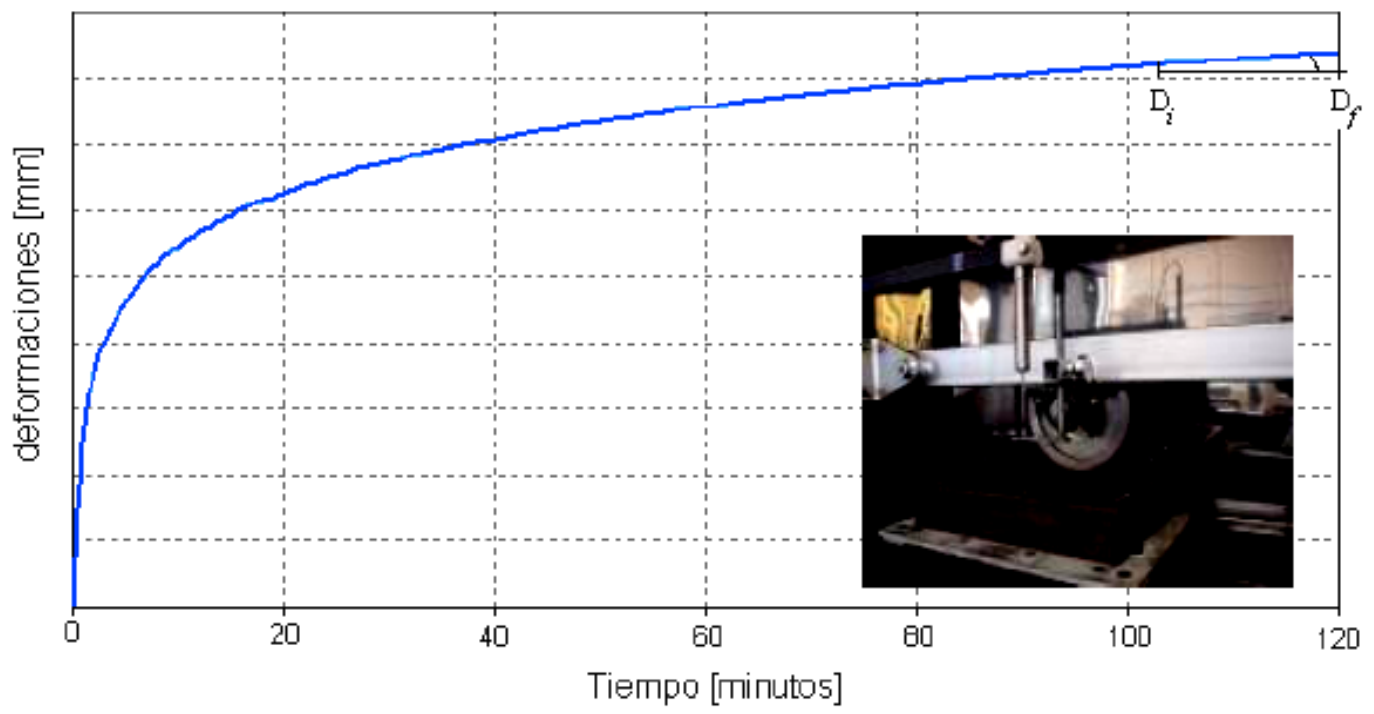

Figura 3.10: Curva Deformación - Tiempo en el ensayo de Wheel Tracking.

\section{Daño por Humedad [AASHTO T 283]}

La influencia destructiva de la humedad sobre las mezclas asfálticas ha sido reconocida desde hace varias décadas, ya que se reconoce su influencia en el deterioro del pavimento. Entre los principales mecanismos de daño inducido por la humedad se encuentran los siguientes:

- Presión de poros del agua en los huecos de la mezcla debido a las repeticiones de carga, diferencias térmicas que producen expansióncontracción por formación de hielo, ciclos de congelamiento-deshielo, choque térmico o una combinación de estos factores,

- Desprendimiento del ligante por efecto del agua en la mezcla a temperaturas moderadas y altas,

- Interacción agua-vapor con el mástico betún - filler y las interfaces de los áridos más grandes,

- Interacción del agua con minerales arcillosos en el árido fino.

Las mezclas dañadas por efecto de la humedad pierden cohesión y reducen la vida útil acelerando procesos de deterioro del pavimento. Lottman propone en su método evaluar este efecto mediante ensayos de tracción sobre probetas sometidas a distintas condiciones, intentando producir la situación que se encuentra el pavimento en servicio. 
Para desarrollar este ensayo, se moldean probetas según la metodología Marshall, de manera que las mismas tengan un $7 \pm 1 \%$ de vacíos en su estructura para favorecer el efecto de la acción del agua.

En esta variante, se moldean nueve probetas las cuales se unen en grupos de tres, de manera que el promedio de densidades de cada grupo sean similares. Uno de estos grupos se destina a grupo de control, por ende no sufre de ningún ciclo de acondicionamiento. El segundo y tercer grupo de probetas son colocados en una cuba con agua y sometidos a vacío de manera de provocar la salida de aire y facilitar la entrada de agua en las probetas hasta saturar sus vacíos entre $55 \%$ y $80 \%$. El segundo grupo es sometido a un ciclo de inmersión en agua a $60^{\circ} \mathrm{C}$ durante 24 horas (hs). El tercer grupo se somete a un primer ciclo de congelamiento a $-18^{\circ} \mathrm{C}$ durante un periodo de 16 a 18 hs y luego al ciclo de inmersión a $60 \stackrel{\circ}{\mathrm{C}}$ durante 24 horas. Luego de cumplimentado los ciclos de cada grupo, se colocan en un recipiente con agua a $25 \stackrel{\circ}{\mathrm{C}}$ durante 2 horas por lo menos para proceder después a la rotura de las probetas a través del ensayo de tracción indirecta (Ver figura 3.11) con el fin de tener una medida del daño generado por el agua en los distintos ciclos. Como ejemplo, en el método de diseño Superpave la resistencia conservada (cociente entre la resistencia de las probetas acondicionadas y la resistencia de las probetas de control) debe ser de al menos del $80 \%$.

Si bien aún no está normalizado este procedimiento en Argentina, se ha hecho práctica corriente su determinación con un ciclo de inmersión en agua a $60{ }^{\circ} \mathrm{C}$, tomando como valor mínimo de $80 \%$ para la resistencia conservada.

$$
\mathbf{R}_{\text {conservada }} \equiv \frac{R_{s}}{R_{c}}
$$

donde

$R_{s}:$ resistencia del grupo sometido a los ciclos $R_{c}$ :resistencia del grupode control.
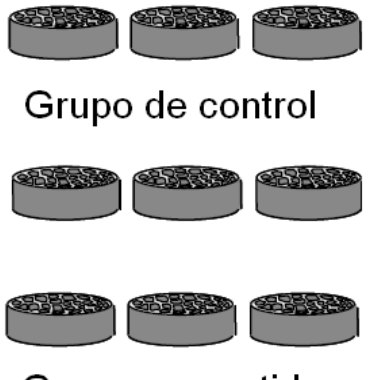

Grupos sometidos a algún ciclo

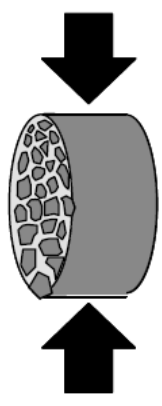

Tracción indirecta

Figura 3.11: Ensayo de Daño por humedad. 


\subsection{5.- ESTUDIO SOBRE SUELOS GRANULARES}

Se realizó el estudio de una base granular estabilizada utilizando tanto la fracción gruesa como fina del reciclado mezclados con un suelo estabilizado. Se estudiaron en primer término las características del suelo seleccionado: Granulometría Vía Húmeda [VN-E1-65], Límite Líquido [VN-E2-65], Límite Plástico [VN-E3-65] y la Clasificación H.R.B de Suelos [VN-E4-84].

La mezcla de material destinado a la conformación de bases o subbases responderá a las condiciones de granulometría, plasticidad, compactación y valor soporte que indique el Pliego de Especificaciones Técnicas Generales de la Dirección Nacional de Vialidad (PETG-DNV). El ensayo de Compactación del material fue realizado según la Norma VN-E5-93, ensayo Proctor.

En general es conveniente compactar el material granular para incrementar su resistencia al esfuerzo cortante, reducir su comprensibilidad y hacerlo más permeable. Bajo una misma energía de compactación se varían los contenidos de humedad. El ensayo permite obtener el contenido óptimo de humedad que maximiza la densidad, o sea el máximo peso seco obtenido del material.

Para obtener la capacidad portante de la base granular se empleó el ensayo de Valor Soporte e Hinchamiento de suelos, según la Norma VN-E6-84, Método Dinámico №1. Este ensayo brinda una medida de la resistencia al esfuerzo cortante de un suelo, bajo condiciones de densidad y humedad cuidadosamente controladas. EI CBR permite obtener un número de la relación de soporte, que no es constante para un suelo dado sino que se aplica sólo al estado en el cual se encontraba el material durante el ensayo. El CBR se expresa en porcentaje como la razón de la carga unitaria que se requiere para introducir un pistón dentro del material evaluado a la carga unitaria requerida para introducir el mismo pistón a la misma profundidad en una muestra de material patrón. 


\section{Capítulo 4}

\section{CARACTERIZACION DEL AGREGADO RECICLADO}

\section{1.- INTRODUCCION}

El estudio de las propiedades físicas y mecánicas del agregado reciclado es de vital importancia para establecer su influencia sobre las propiedades en las diversas aplicaciones en obras viales para los cuales pudieren destinarse, tales como capas de rodadura (flexibles o rígidas), capas asfálticas de base y bases granulares.

Las partículas que componen los AR pueden estar compuestas por roca natural y mortero en diferentes proporciones, por roca natural o solamente por mortero; las características del AR dependerán fundamentalmente de la calidad del mortero del hormigón de origen y del tipo de agregado natural utilizado para su elaboración. La mayor parte de la bibliografía disponible analiza y recomienda posibles usos para AGR, mientras que existe poca información sobre alternativas de empleo del AFR en pavimentos o en obras viales en general. En países como Japón o España se suelen aprovechar los finos obtenidos del reciclado de hormigones como arena para mortero de asiento de mampostería o como filler para cementos reciclados luego de moler las partículas hasta obtener la finura del cemento.

En esta tesis se analizarán alternativas para el aprovechamiento de las diferentes fracciones de AR, tanto gruesa como fina, dentro de las obras viales. Con propósito comparativo se incluye también en este capítulo la 
caracterización y análisis de las propiedades de los diversos agregados naturales empleados en las experiencias. Debido a que nivel nacional no existe normativa o recomendación para la utilización de AR y tampoco para valorar sus propiedades, se utilizarán en todos los casos las normas vigentes para agregados naturales tanto gruesos como finos.

\section{2.- CARACTERIZACION DE AGREGADOS GRUESOS}

El análisis granulométrico del material grueso tanto natural como reciclado se realizó según la norma IRAM 1505. Como fuera explicado en el capítulo anterior se separaron dos fracciones de AGR identificadas tomando en cuenta el tamaño máximo R38 y R19. Además para elaborar mezclas de referencia se utilizaron dos fracciones de piedra partida granítica identificadas como G25 y G19. Los datos obtenidos de cada uno de los materiales se expresan en la tabla 4.1 y las curvas granulométricas se representan en las figuras 4.1 y 4.2 .

En la figura 4.1 se observan las granulometrías de los agregados G25 y R38 que fueron las fracciones utilizados para la elaboración de hormigones de cemento portland. También se incluyen los husos granulométricos considerados en la norma IRAM 1677 referida a agregados gruesos para uso vial. El material granítico responde a un tamaño nominal 25-9,5 mm, mientras que el agregado reciclado R38 está dentro de los husos granulométricos para un tamaño nominal 38-19,0 mm.

En la figura 4.2 aparecen las curvas granulométricas tanto de agregados reciclados (R19) como natural (G19) utilizados para la elaboración de mezclas asfálticas. Se constata que las granulometrías de los dos materiales son muy parecidas y cumplen con los husos granulométricos para un tamaño nominal 19-4,5 mm según la norma IRAM 1677. 
Tabla 4.1: Granulometría de los agregados gruesos.

\begin{tabular}{|c|c|c|c|c|c|}
\hline \multirow{2}{*}{$\begin{array}{c}\text { TAMIZ } \\
\text { MM }\end{array}$} & TAMIZ & \multicolumn{4}{|c|}{ \% PASANTE } \\
\cline { 3 - 6 } & US & G25 & G19 & R38 & R19 \\
\hline 50,0 & $2 "$ & 100,0 & 100,0 & 100,0 & 100,0 \\
\hline 38,0 & $11 / 2^{\prime \prime}$ & 100,0 & 100,0 & 96,4 & 100,0 \\
\hline 25,0 & $1 "$ & 95,0 & 100,0 & 30,6 & 100,0 \\
\hline 19,0 & $3 / 4 "$ & 48,0 & 100,0 & 18,0 & 70,8 \\
\hline 12,5 & $1 / 2^{\prime \prime}$ & 3,0 & 93,2 & 5,4 & 49,4 \\
\hline 9,5 & $3 / 8^{\prime \prime}$ & 1,0 & 55,4 & 3,5 & 14,4 \\
\hline 4,75 & $\# 4$ & 0,0 & 34,5 & 0,5 & 2,5 \\
\hline 2,36 & $\# 8$ & 0,0 & 8,0 & 0,5 & 0,0 \\
\hline \multicolumn{2}{|l|}{ Módulo de finura } & 7,54 & 6,78 & 7,82 & 6,61 \\
\hline
\end{tabular}

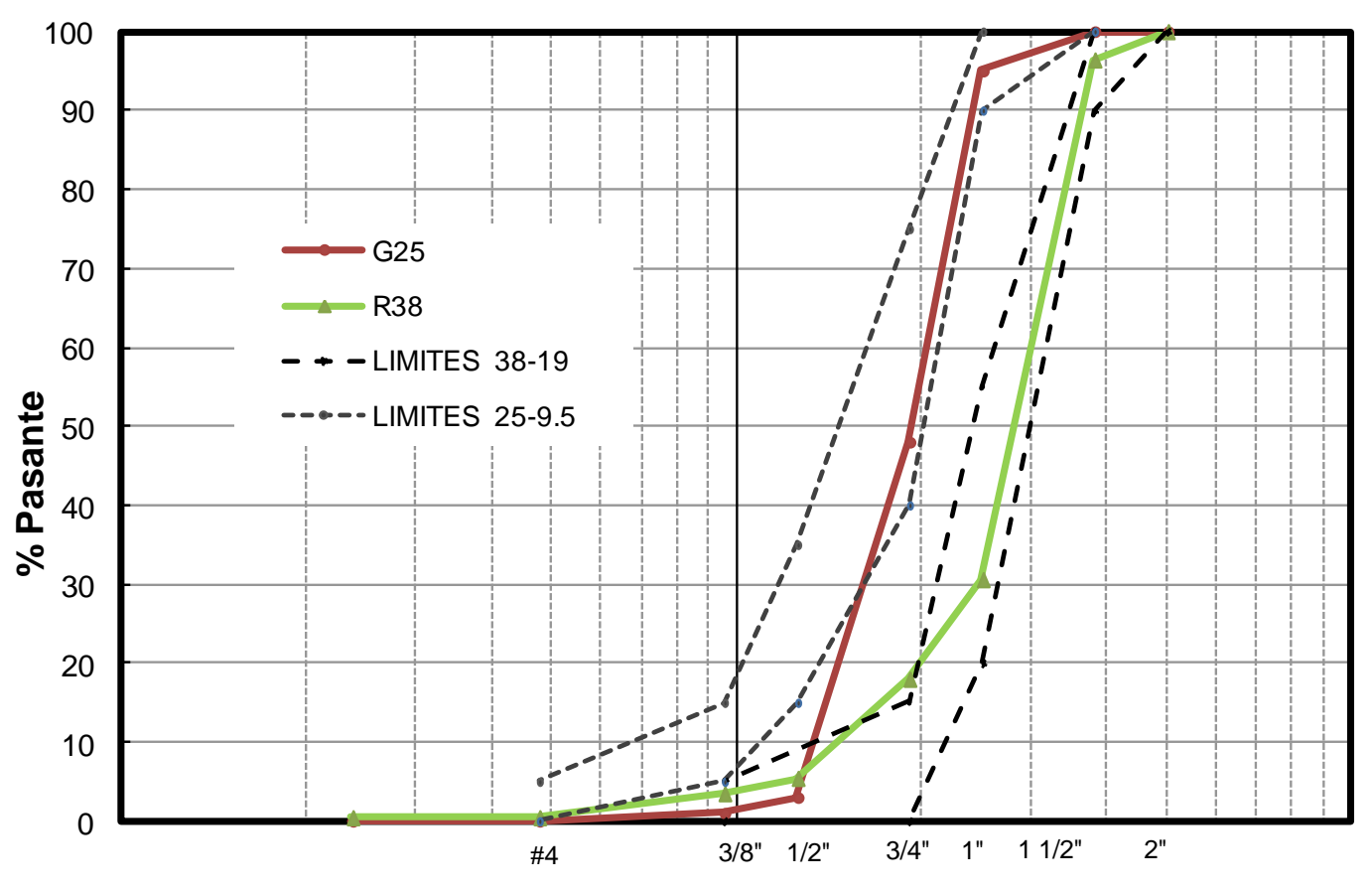

Abertura de tamiz

Figura 4.1: Curvas granulométricas de los agregados gruesos utilizados en pavimentos rígidos. 


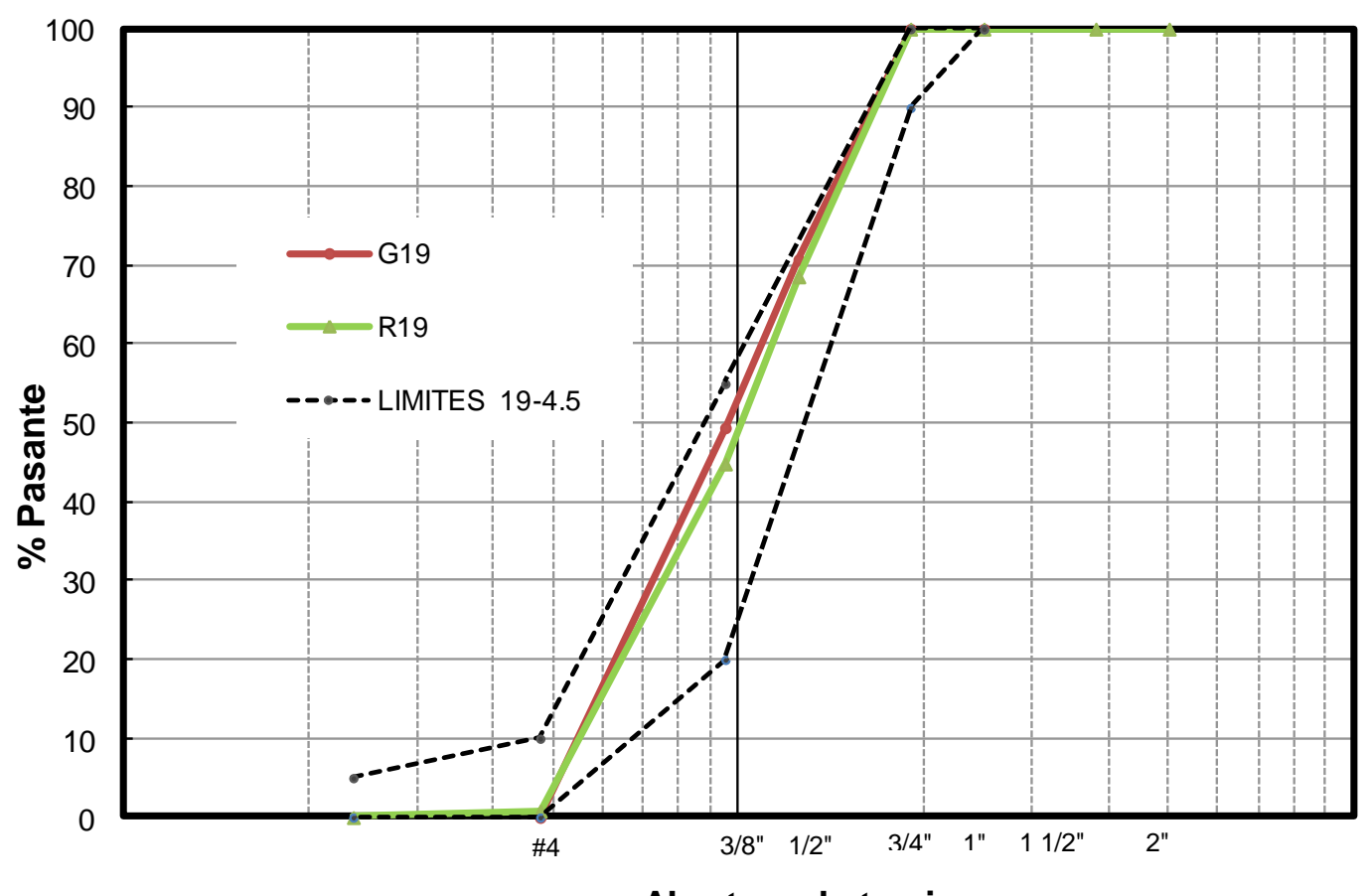

Abertura de tamiz

Figura 4.2: Curvas granulométricas de los agregados gruesos utilizados en mezclas asfálticas.

Para completar la caracterización se determinaron la densidad relativa aparente del agregado saturado superficie seca $\left(D_{s s s}\right)$, la densidad relativa aparente del agregado seco $\left(D_{s}\right)$, la absorción en agua durante 24 horas, la resistencia al desgaste con la máquina Los Ángeles, el material fino que pasa el tamiz de $75 \mu \mathrm{m}$, el peso por unidad de volumen en estado suelto (PUVs), y los índices de lajosidad (IL) y elongación (IE) para la valoración de la forma. EI análisis de estas propiedades resulta de importancia debido a que algunas propiedades del hormigón, como el módulo de elasticidad estático o la resistencia, se encuentran fuertemente relacionadas con las características de los agregados utilizados para su elaboración [Mehta y Monteiro, 1998].

En la tabla 4.2 se compara los resultados obtenidos para las diferentes fracciones de AGR y AGN. 
Tabla 4.2: Propiedades de los agregados gruesos.

\begin{tabular}{|l|c|c|c|c|}
\hline \multicolumn{1}{|c|}{ Propiedades } & G25 & G19 & R38 & R19 \\
\hline$D_{\text {sss }}$ & 2,72 & 2,66 & 2,49 & 2,43 \\
\hline$D_{\mathrm{s}}$ & 2,71 & 2,65 & 2,39 & 2,33 \\
\hline Absorción & 0,30 & 0,40 & 4,05 & 4,30 \\
\hline Desgaste Los Ángeles [\%] & 19,5 & 20,2 & 35,9 & 34,8 \\
\hline Pasa tamiz de 75 $\mu \mathrm{m}[\%]$ & 0,6 & 0,3 & 0,5 & 0,2 \\
\hline PUVs [kg/m3] & 1452 & 1466 & 1318 & 1297 \\
\hline Vacíos [\%] & 46 & 45 & 45 & 44 \\
\hline IL [\%] & \multicolumn{3}{|c|}{17,0} & \multicolumn{3}{c|}{8,4} \\
\hline IE [\%] & 48,1 & \multicolumn{3}{c}{} \\
\hline
\end{tabular}

En la tabla superior se observa que los agregados reciclados presentan menor densidad y mayor absorción que los AGN, lo que se debe al mortero presente en las partículas de AGR. Cabe mencionar que la densidad en estos AGR es superior a la densidad mínima $\left(2,00 \mathrm{tn} / \mathrm{m}^{3}\right)$ que pide la norma CIRSOC para poder ser usado en la construcción, aunque hay que hacer notar que esta norma se refiere específicamente a agregados naturales.

Otra propiedad que debe tomarse en cuenta es la pérdida por desgaste que sufre el AGR. El desgaste que sufre el AGR es bastante mayor a las pérdidas de peso encontradas en AGN. Al respecto cabe comentar que si bien el porcentaje de pérdida resulta inferior al límite de $50 \%$ establecido en la norma IRAM 1531, el Pliego de Especificaciones Técnicas de la Dirección Nacional de Vialidad exige que el desgaste Los Ángeles en agregados para pavimentos rígidos debe ser menor al $30 \%$, un valor similar al que pide el CIRSOC para hormigones estructurales [IRAM 1532]. Para el caso de mezclas asfálticas hay diferencias según la capa de la estructura de que se trate; para la capa de rodamiento el desgaste debe ser menor al $25 \%$ y para base asfáltica menor al $30 \%$. En cuanto al desgaste que deben tener los agregados para poder ser utilizados en bases o estabilizados granulares, el pliego de la DNV pide un desgaste inferior al $35 \%$ para bases y $40 \%$ para subbases granulares. No obstante cabe reiterar que todos estos valores corresponden a AGN, por lo que para establecer un valor específico para AGR debieran realizarse pruebas a escala real.

En referencia al porcentaje de material pasante por el tamiz de abertura de malla $75 \mu \mathrm{m}$ se puede observar que los AGR muestran valores iguales o 
menores que el AGN, ya que todos los agregados fueron tamizados para dar lugar a la fracción en estudio. El límite máximo estipulado en la norma IRAM 1531 es de $1,5 \%$.

El peso por unidad de volumen de los AGR en condición suelta (PUVs) muestra una disminución alrededor del $10 \%$ con respecto a los agregados naturales. Este hecho se asocia a la menor densidad que poseen los AGR por la presencia de mortero que presentan en su composición. También se observa que existen pocas diferencias en cuanto a la cantidad de vacíos de las diferentes fracciones de agregado grueso.

En cuanto a la forma de las partículas, los índices de lajosidad y elongación muestran que los AGR presentan menor lajosidad y formas más regulares que los $A G N$, esto permite decir que los agregados reciclados suelen tener mayor cubicidad que los agregados naturales en especial los de trituración. La existencia de planos preferenciales de fractura en algunas rocas naturales hace que durante el proceso de obtención se originen mayor cantidad de partículas lajosas en AGN [Poole y Sims, 2003; Czarnecka y Gillott, 1982].

Por último y considerando que la resistencia relativa de los agregados tienen influencia sobre el comportamiento del compuesto (hormigón) en especial a medida que se eleven los niveles de resistencia, se realizaron ensayos de carga puntual sobre las partículas de AGR y AGN a fin de comparar sus resistencias.

Se tomaron alrededor de 45 muestras (piedras) al azar con tamaños mayores de $19 \mathrm{~mm}$ tanto de agregados reciclados como graníticos. Sobre las muestras seleccionadas se realizó el ensayo de carga puntual obteniendo una carga de rotura $P(N)$, determinando posteriormente para cada una de ellas el índice de carga puntual $I s(50)\left(\mathrm{N} / \mathrm{mm}^{2}\right)$ y se estimó la resistencia a compresión qu (MPa) a partir del índice de carga puntual corregido por tamaño.

En la tabla 4.3 se muestra los valores estimados de la resistencia a la compresión de los diferentes agregados y en la figura 4.3 se observa el equipo y los agregados durante la realización del ensayo de carga puntual. 
Tabla 4.3: Resistencia estimada a partir de ensayos de carga puntual sobre las partículas de los agregados gruesos.

\begin{tabular}{|c|c|c|c|}
\hline Agregados & $\begin{array}{c}\text { Promedio } \\
(\mathbf{M P a})\end{array}$ & $\begin{array}{c}\text { Desviación } \\
\text { estándar (MPa) }\end{array}$ & CoV (\%) \\
\hline Granítico & 216 & 42 & 19 \\
\hline Reciclado & 86 & 35 & 41 \\
\hline
\end{tabular}
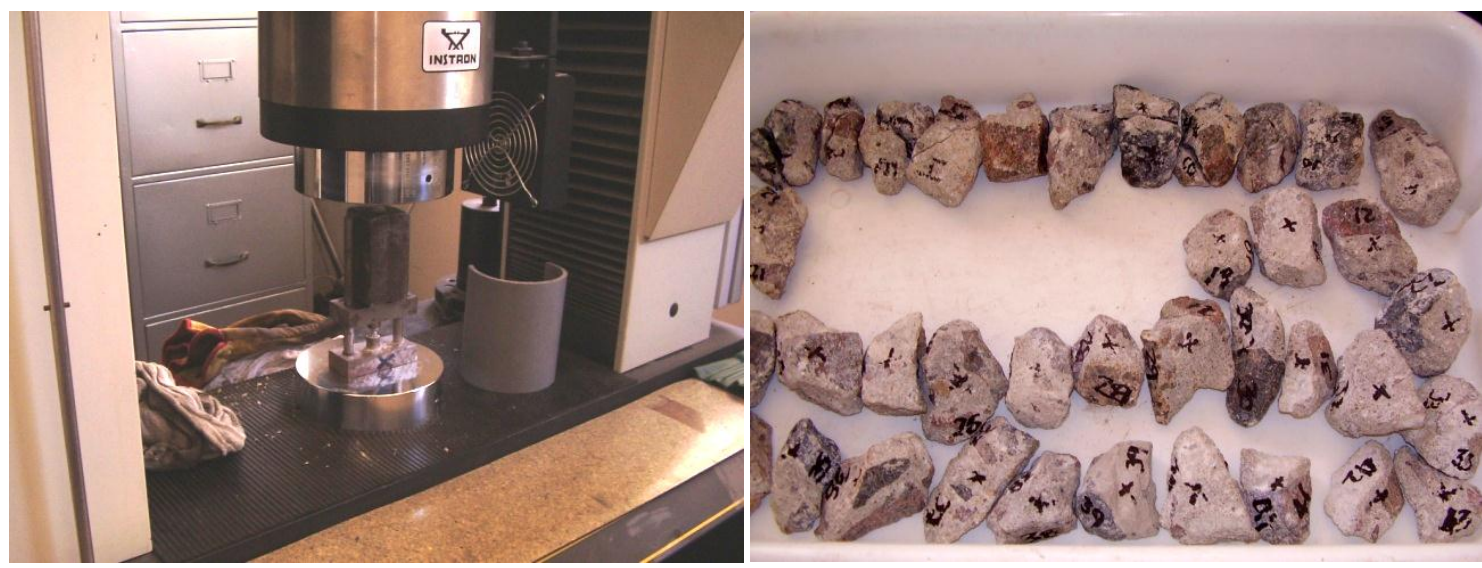

Figura 4.3: Desarrollo de ensayos de carga puntual y muestra de agregados ensayados.

\section{3.- CARACTERIZACION DEL AGREGADO FINO}

Para elaborar hormigones de cemento portland se combinaron dos arenas naturales de río con densidades iguales a 2,63 y 2,64, y módulos de finura 2,62 y 1,55, resultando un módulo de finura de la mezcla igual a 2,4.

Para la elaboración de mezclas asfálticas se estudió el uso alternativo de arena de trituración de origen natural (que es la usualmente empleada) o la fracción fina (pasa tamiz № 4) obtenida a partir del material reciclado. En todos los casos se siguieron los lineamientos de la norma IRAM 1540 que trata sobre el análisis granulométrico por vía húmeda. En la tabla 4.4 se observa las granulometrías de los agregados $\mathrm{G} 0-6$ y R0-6 y en la figura 4.4 se muestra las curvas granulométricas de los diferentes materiales, que se identifican como G0-6 y R0-6. 
Tabla 4.4: Granulometría de los agregados finos.

\begin{tabular}{|c|c|c|c|}
\hline TAMIZ & TAMIZ & \multicolumn{2}{|c|}{$\%$ PASANTE } \\
\hline MM & US & G 0-6 & R 0-6 \\
\hline 9,50 & $3 / 8 "$ & 100,0 & 100,0 \\
\hline 4,75 & $\# 4$ & 93,0 & 99,2 \\
\hline 2,36 & $\# 8$ & 63,3 & 71,1 \\
\hline 1,18 & $\# 16$ & 42,7 & 50,3 \\
\hline 0,60 & $\# 30$ & 30,5 & 32,1 \\
\hline 0,30 & $\# 50$ & 22,0 & 20,0 \\
\hline 0,15 & $\# 50$ & 15,1 & 11,3 \\
\hline 0,075 & $\# 50$ & 10,2 & 7,6 \\
\hline
\end{tabular}

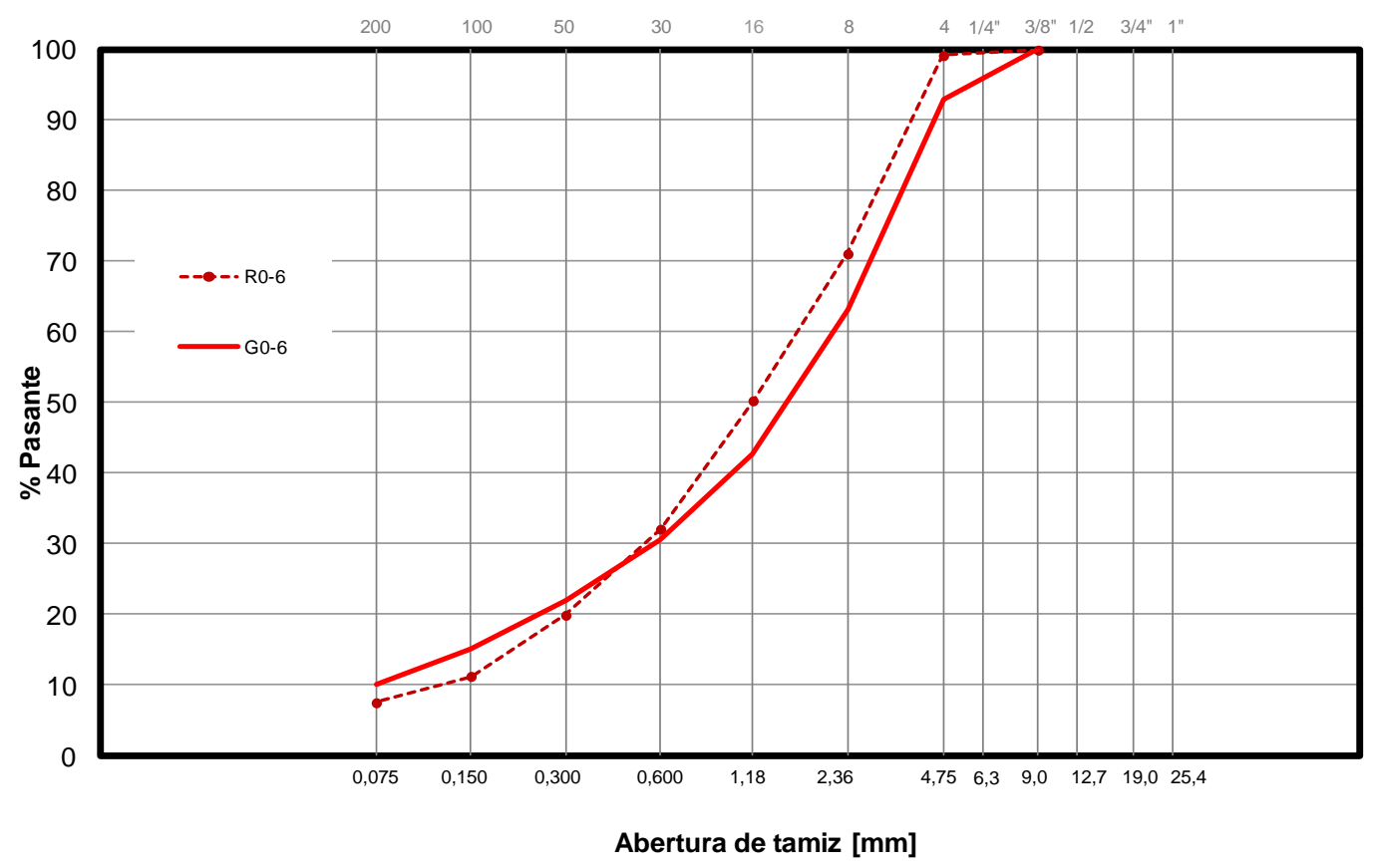

Figura 4.4: Curvas granulométricas de los agregados finos.

En la figura 4.4 se muestra las curvas granulométricas tanto de agregado reciclado (R0-6) como natural (G0-6) utilizados para la elaboración de mezclas asfálticas y se constata que las granulometrías de los dos materiales son muy parecidas.

Además se evaluaron otras propiedades de G0-6 y R0-6 como la densidad real $\left(D_{r}\right)$, la densidad aparente del agregado seco $\left(D_{S}\right)$, la absorción en agua durante 24 horas, el equivalente de arena y la plasticidad de la fracción que pasa tamiz IRAM 0,075 mm. En la tabla 4.5 se compara las 
propiedades de los agregados finos G0-6 y R0-6 que fueron los empleados en mezclas asfálticas.

Tabla 4.5: Propiedades de los agregados finos empleados en mezclas asfálticas.

\begin{tabular}{|l|c|c|}
\hline \multicolumn{1}{|c|}{ Propiedades } & G0-6 & R0-6 \\
\hline$D_{\mathrm{r}}$ & 2,735 & 2,542 \\
\hline $\mathrm{D}_{\mathrm{S}}$ & 2,652 & 2,229 \\
\hline Absorción [\%] & 1,1 & 5,5 \\
\hline Equivalencia de arena [\%] & 83,0 & 82,7 \\
\hline Plasticidad del pasa tamiz IRAM 0,075 mm & No plástico & No plástico \\
\hline
\end{tabular}

De la tabla 4.5 se observa que tanto la densidad real como la densidad aparente seca del AFR son inferiores a las densidades que tiene una arena de trituración de agregados naturales. La densidad real del AFN, para este caso es mayor en un $8 \%$ con respecto al AFR y la densidad aparente seca del árido natural es un $14 \%$ superior a la densidad que presenta el agregado reciclado. Esta disminución de la densidad se debe a que el agregado fino al igual que el agregado grueso presenta mortero en sus partículas.

Esta presencia de mortero en los áridos finos reciclados provoca también un aumento de absorción con respecto al agregado fino granítico, dicho incremento en este caso fue cinco veces mayor. La absorción del AFR obtenida está dentro del rango permitido por la norma ASTM D7172-06, la cual establece que la absorción del agregado fino para ser considerado como material apto para un pavimento debe estar dentro de 0,5 a 6,0 \%.

En cuanto al equivalente de arena, los dos materiales presentan porcentajes parecidos aunque algo superior el agregado fino natural. Los porcentajes dados en este ensayo cumplen el valor asignado por la norma IRAM 1682, la cual exige que la equivalencia de los áridos finos tiene que ser mayor al 50 \%. En cuanto al porcentaje que exige el Pliego de Especificaciones de la DNV también cumple ya que es mayor al $75 \%$.

En referencia al ensayo de Plasticidad de la fracción fina que pasa el tamiz 0,075 mm, tanto el AFR como la arena de trituración se presentan como no plásticos. Respecto al árido fino reciclado, se puede decir que el material pasante tamiz $0,075 \mathrm{~mm}$ no presenta plasticidad debido a que este proviene de 
la trituración de pedazos de hormigón por lo tanto estará conformado por los materiales finos componentes del hormigón. La mayoría de bibliografía confirma la existencia de propiedades cementicias en el fino reciclado debido a la presencia de cierta cantidad de compuestos no hidratados que al mezclarlo con agua a temperatura ambiente adquieren propiedades hidráulicas. 


\section{Capítulo 5}

\section{HORMIGONES RECICLADOS}

\section{1.- INTRODUCCION}

Este capítulo describe la obtención y compara las propiedades físicomecánicas de hormigones elaborados con AGR con respecto a hormigones con AGN. Considerando las posibles aplicaciones, se planteó la fabricación de hormigones con dos niveles de resistencia, asimilables a mezclas tipo $\mathrm{H} 13$ y H30 que podrían ser empleadas para la construcción de bases o de losas de pavimento. Se evaluaron las propiedades en estado fresco y endurecido; en el primer caso se determinaron el asentamiento, el contenido de aire incorporado, el peso unitario y el tiempo de fraguado mientras que en estado endurecido se evaluaron la resistencia a compresión, el módulo de elasticidad estático y la resistencia a tracción por compresión diametral y por flexión.

\section{2.- MATERIALES Y MEZCLAS}

Dada la mayor porosidad de los AGR sea por absorción de agua o por efecto de la humedad, en los agregados se pueden provocar cambios importantes en la trabajabilidad del hormigón con agregados reciclados con sus consecuentes efectos en el mezclado y las tareas posteriores de llenado y compactación. Varias recomendaciones hacen hincapié en prohibir la corrección de la trabajabilidad por medio de la adición de agua en la mezcla ya que se estaría aumentando la relación agua/cemento (a/c). Algunas normativas recomiendan humedecer el AGR unos 20 a 30 minutos antes de ser usado ya que en este tiempo la absorción del agregado llega a ser un $90 \%$ del total; otra opción es el uso de aditivos plastificantes para compensar la pérdida de 
asentamiento, logrando así una trabajabilidad del hormigón con agregados reciclados similar a la del hormigón elaborado con agregado natural.

En este caso y considerando el objetivo de la tesis de analizar las alternativas de empleo de AR en hormigón, se decidió en primer lugar utilizar solamente la fracción gruesa, dado que es un hecho aceptado con bastante generalidad que es menos eficiente el empleo de AFR. Para analizar la influencia del reciclado en los pavimentos de hormigón se tomaron como punto de partida las proporciones típicas empleadas para elaborar dos tipos de hormigones usados frecuentemente en la vialidad urbana, $\mathrm{H} 30$ y H13, esto es con resistencias características a compresión a los 28 días de 30 y $13 \mathrm{MPa}$, respectivamente. El hormigón tipo H30 es utilizado comúnmente para capa de rodadura y el hormigón $\mathrm{H} 13$ es usado como base de asiento del pavimento. Los hormigones de referencia se prepararon con el agregado grueso granítico G25, Cemento Portland Compuesto (CPC40), arena silícea natural de río como agregado fino y un aditivo reductor de agua.

De este modo, aunque no se conocían con precisión las características del cemento, se aseguraba que los hormigones de referencia con agregados naturales alcanzarían niveles de resistencia media dentro del orden habitualmente utilizado en las citadas aplicaciones. Para elaborar los hormigones reciclados se planteó como consigna el reemplazo en volumen del $100 \%$ de G25 por R38 sin modificar el contenido de cemento ni de aditivo, e incorporando el agua necesaria para lograr una trabajabilidad similar. Si bien esto podría ser algo desfavorable desde el punto de vista de la resistencia para el hormigón con AGR, se acerca en mayor medida a las condiciones en las cuales se podría realizar la aplicación. Considerando que el volumen de vacíos de ambas fracciones tampoco difiere demasiado, no fue necesario plantear cambios en las proporciones de la arena.

Los hormigones fueron elaborados con una hormigonera basculante y el procedimiento de mezclado consistió en premezclar los materiales con un $70 \%$ del agua total, incorporando el $30 \%$ restante junto con el aditivo. Este criterio se debió a que en experiencias anteriores se habían elaborado mezclas mediante dicho procedimiento utilizando los AGR en estado seco al aire, 
evitando de esta forma que la elevada absorción de estos agregados disminuya el efecto del aditivo por el efecto de absorción del AGR.

En la tabla 5.1 se indican las proporciones de materiales utilizadas en los hormigones. Las mezclas se identifican según el nivel de resistencia seguidas por la letra $\mathrm{N}$ si fue elaborado con agregados naturales o la letra $\mathrm{R}$ para los confeccionados con AGR.

Tabla 5.1: Proporciones de las distintas mezclas.

\begin{tabular}{|l|c|c|c|c|c|}
\hline \multirow{2}{*}{ Proporciones de los materiales } & \multicolumn{5}{|c|}{ Hormigón } \\
\cline { 3 - 6 } & & H13N & H13R & H30N & H30R \\
\hline Agua & $\mathrm{kg} / \mathrm{m}^{3}$ & 153 & 166 & 135 & 129 \\
\hline Cemento & $\mathrm{kg} / \mathrm{m}^{3}$ & 204 & 201 & 318 & 324 \\
\hline Agregado fino & $\mathrm{kg} / \mathrm{m}^{3}$ & 869 & 856 & 813 & 829 \\
\hline Agregado grueso & $\mathrm{kg} / \mathrm{m}^{3}$ & 1174 & 1052 & 1059 & 983 \\
\hline Superfluidificante & $\mathrm{kg} / \mathrm{m}^{3}$ & 0,4 & 0,4 & 0,6 & 0,6 \\
\hline
\end{tabular}

\section{3.- PROPIEDADES EN ESTADO FRESCO}

La tabla 5.2 presenta los resultados de los hormigones en estado fresco, se incluyen el asentamiento (As), el peso unitario en estado fresco, el contenido de aire y el tiempo de fraguado en el caso de los hormigones de mayor resistencia.

Tabla 5.2: Propiedades en estado fresco de los hormigones.

\begin{tabular}{|c|c|c|c|c|c|c|}
\hline \multirow{2}{*}{\multicolumn{3}{|c|}{ Propiedades en estado fresco }} & \multicolumn{4}{|c|}{ Hormigón } \\
\hline & & & \multirow{2}{*}{$\frac{\text { H13N }}{40}$} & \multirow{2}{*}{$\begin{array}{c}\text { H13R } \\
40\end{array}$} & \multirow{2}{*}{$\begin{array}{c}\text { H30N } \\
45\end{array}$} & \multirow{2}{*}{$\frac{\text { H30R }}{75}$} \\
\hline Asentamiento & & $\mathrm{mm}$ & & & & \\
\hline Aire incorporado & & $\%$ & 3,0 & 2,2 & 2,5 & 2,6 \\
\hline Peso unitario & & $\mathrm{kg} / \mathrm{m}^{3}$ & 2400 & 2275 & 2325 & 2300 \\
\hline Tiempo de fraguado & inicial & $\mathrm{h}: \min$ & & & $4: 35$ & $4: 29$ \\
\hline & final & $\mathrm{h}: \min$ & & & $7: 26$ & 7:07 \\
\hline
\end{tabular}

Los valores de asentamiento están en el rango $50 \pm 20 \mathrm{~mm}$, con un pequeño incremento en el asentamiento del hormigón H30R. La figura 5.1 muestra el aspecto de las mezclas luego del ensayo de asentamiento. Las mezclas con agregados reciclados disminuyeron su peso por unidad de volumen lo que se justifica por la menor densidad que poseen los mismos con respecto a los AGN. No obstante las diferencias son poco significativas desde el punto de vista práctico. El peso unitario del hormigón tipo H13R fue 125 
$\mathrm{kg} / \mathrm{m}^{3}$ inferior al peso unitario del hormigón con AGN. En el caso de los hormigones tipo $\mathrm{H} 30$, el hormigón con AGN tuvo un mayor peso unitario de 25 $\mathrm{kg} / \mathrm{m}^{3}$ con respecto al hormigón con AGR.
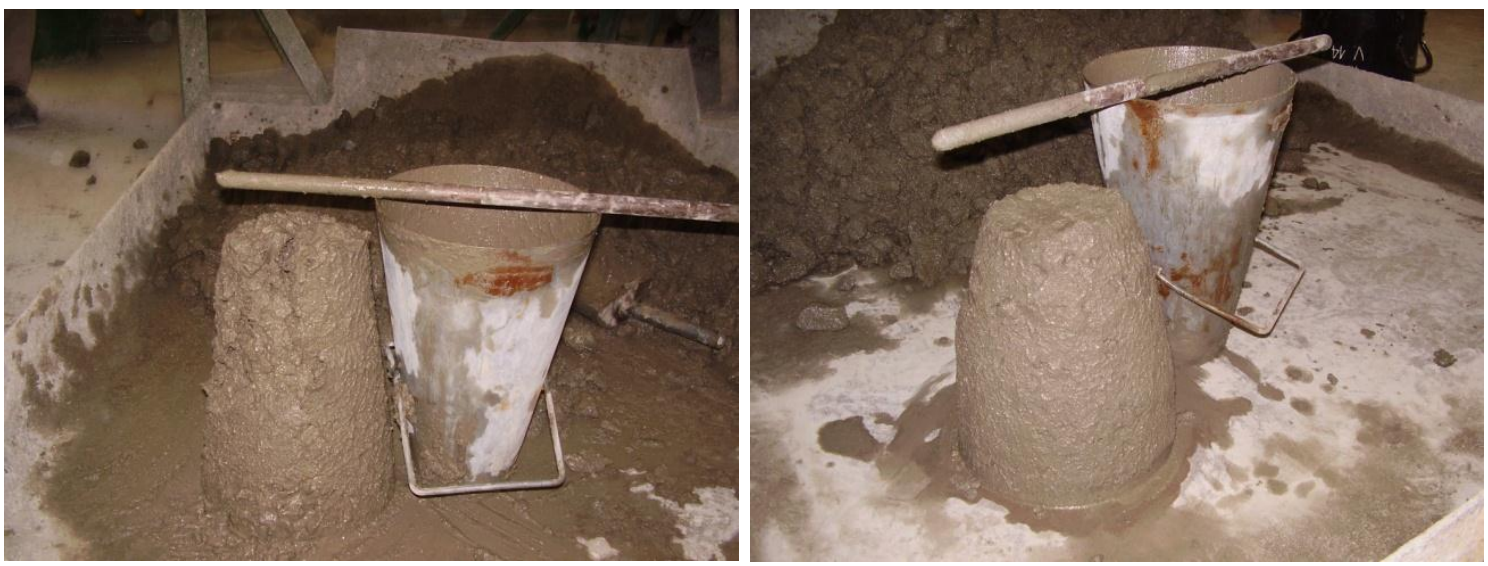

Figura 5.1: Asentamiento medido para hormigones tipo H30. (Izq. con AGN y Der. con AGR).

Las mezclas con AGR tipo $\mathrm{H} 30$ presentaron contenidos de aire ligeramente mayor, mientras que los hormigones tipo H13 mostraron una tendencia opuesta, sin embargo las diferencias tampoco resultan significativas en este caso.

En lo referente al tiempo de fraguado de los hormigones $\mathrm{H} 30$, se puede observar que el lapso correspondiente fue muy parecido para los dos hormigones elaborados con distintos agregados gruesos. El tiempo de fraguado del H30N fue de 2 horas 51 minutos mientras que para el H30R fue de 2 horas 38 minutos.

Con cada uno de los hormigones se moldearon probetas cilíndricas de 150 × 300 mm y vigas prismáticas de 150 × 150 mm de sección. Se moldearon 6 probetas cilíndricas para ensayos de compresión a 7 y 28 días y vigas para evaluar la resistencia a tracción (flexión y tracción por compresión diametral) a los 28 días. Todas las probetas fueron curadas en cámara húmeda hasta la edad de ensayo (T: $23 \pm 2{ }^{\circ} \mathrm{C}$; humedad relativa: $95 \%$ ). 


\section{4.- PROPIEDADES EN ESTADO ENDRECIDO}

En la tabla 5.3 se presentan los resultados de resistencia a compresión (f'c), módulo de elasticidad estático $(\mathrm{E})$, resistencia a tracción por compresión diametral (ftc) y módulo de rotura en flexión (MR) obtenidos en los hormigones con agregados gruesos naturales originales y con agregados reciclados.

Tabla 5.3: Propiedades mecánicas de los hormigones.

\begin{tabular}{|c|c|c|c|c|c|c|c|}
\hline & Edad & \multirow{2}{*}{\multicolumn{2}{|c|}{ Hormigón }} & \multirow{3}{*}{$\begin{array}{r}\text { H13N } \\
10,6\end{array}$} & \multirow{3}{*}{$\begin{array}{r}\text { H13R } \\
9,5\end{array}$} & \multirow{3}{*}{$\begin{array}{c}\text { H30N } \\
30,7\end{array}$} & \multirow{3}{*}{$\begin{array}{r}\text { H30R } \\
24,8\end{array}$} \\
\hline & (días) & & & & & & \\
\hline \multirow{6}{*}{$\begin{array}{c}f^{\prime} c \\
(M P a)\end{array}$} & \multirow{3}{*}{7} & Promedio & $\mathrm{MPa}$ & & & & \\
\hline & & $S$ & $\mathrm{MPa}$ & 0,7 & $\overline{0,4}$ & 0,4 & 0,8 \\
\hline & & COV & $\%$ & 7 & 4 & 1 & 3 \\
\hline & \multirow{3}{*}{28} & Promedio & $\mathrm{MPa}$ & 14,7 & 14,1 & 33,9 & 28,7 \\
\hline & & $\mathrm{S}$ & $\mathrm{MPa}$ & 0,7 & 0,5 & 2,2 & 0,9 \\
\hline & & COV & $\%$ & 5 & 3 & 7 & 3 \\
\hline \multirow{3}{*}{$\begin{array}{c}\text { MR } \\
(\mathrm{MPa})\end{array}$} & \multirow{3}{*}{28} & Promedio & $\mathrm{MPa}$ & 2,8 & 2,7 & $\overline{3,9}$ & 3,6 \\
\hline & & $S$ & $\mathrm{MPa}$ & 0,2 & 0,2 & 0,4 & 0,2 \\
\hline & & COV & & 9 & 7 & 11 & 5 \\
\hline \multirow{3}{*}{$\begin{array}{c}f t c \\
(\mathrm{MPa})\end{array}$} & \multirow{3}{*}{28} & Promedio & $\mathrm{MPa}$ & 1,5 & $\overline{1,5}$ & $\overline{2,1}$ & 1,8 \\
\hline & & $S$ & $\mathrm{MPa}$ & 0,1 & 0,2 & 0,3 & 0,2 \\
\hline & & COV & $\%$ & 9 & 11 & 13 & 14 \\
\hline$M R / f^{\prime} c$ & 28 & & $\%$ & 19 & 19 & 12 & 12 \\
\hline CD/f'c & 28 & & $\%$ & 10 & 11 & 6 & 6 \\
\hline \multirow{6}{*}{$E(G P a)$} & \multirow{3}{*}{7} & Promedio & GPa & 24,0 & 22,4 & 34,9 & 22,8 \\
\hline & & $S$ & GPa & 1,2 & 1,3 & 1,1 & 1,9 \\
\hline & & COV & $\%$ & 5 & 6 & 3 & 8 \\
\hline & \multirow{3}{*}{28} & Promedio & GPa & 28,0 & 24,5 & 37,8 & 29,0 \\
\hline & & $S$ & $\mathrm{GPa}$ & 4,3 & 0,2 & 0,8 & 2,2 \\
\hline & & COV & $\%$ & 15 & 1 & 2 & 8 \\
\hline
\end{tabular}

En el caso de la resistencia a compresión y el módulo de rotura en flexión, los valores informados corresponden al promedio de tres ensayos, mientras que en el ensayo de tracción por compresión diametral se realizaron cuatro determinaciones. En los ensayos de módulo de elasticidad estático, los valores se obtuvieron de dos determinaciones, que corresponden a la $2^{\underline{a}}$ y $3^{\text {a }}$ probeta de cada grupo, mientras que la primera se empleó para obtener el valor de la precarga a aplicar correspondiente al $40 \%$ de la resistencia a 
compresión. Se indica en cada caso el valor promedio, el desvío estándar (s) y coeficiente de variación (COV).

En la figura 5.2 se presentan las resistencias relativas a compresión de los hormigones elaborados con AGR y con AGN.

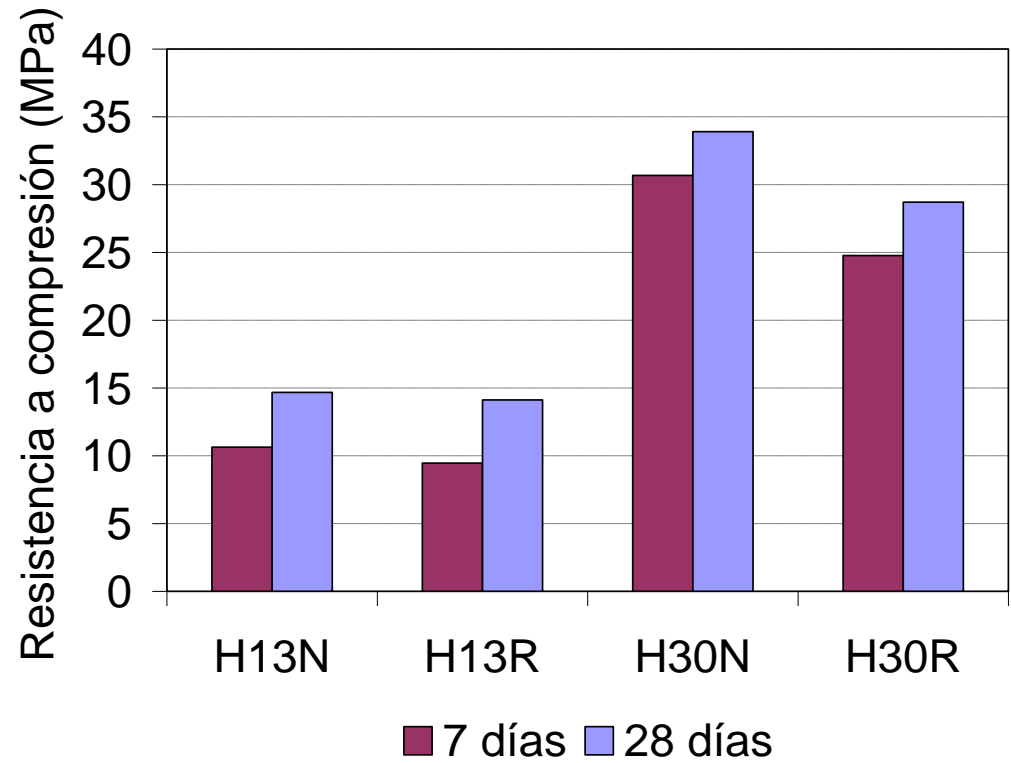

Figura 5.2: Resistencia a compresión de los hormigones.

Se puede observar que los hormigones tipo $\mathrm{H} 13$ alcanzan la misma resistencia tanto a 7 como a los 28 días sin importar el agregado grueso empleado. En cambio para los hormigones de mayor resistencia, el elaborado con agregados gruesos reciclados se encontró una disminución en la resistencia igual al $19 \%$ a los 7 días, en cambio a los 28 días la disminución de la resistencia fue del $16 \%$ con respecto a la resistencia del hormigón H30N.

En la figura 5.3 se muestra el rendimiento de las diferentes mezclas calculado a partir de la relación entre resistencia a compresión y cantidad de cemento. Se puede observar que los hormigones de menor resistencia requieren $(\mathrm{H} 13)$ la misma cantidad de cemento para obtener un nivel de resistencia sin importar el tipo de agregado que se esté utilizando. En cambio, en las mezclas tipo H30 el rendimiento disminuye cuando se utiliza AGR, lo que indica que para tener una resistencia similar habría que adicionar mayor cantidad de cemento. 


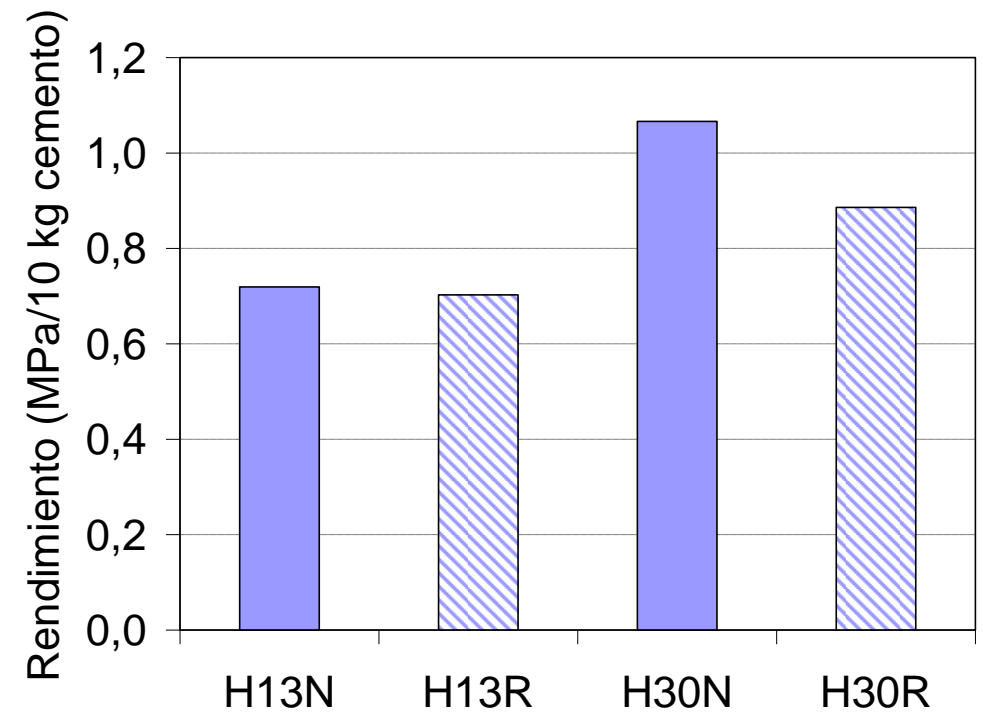

Figura 5.3: Rendimiento de los hormigones.

En cuanto a la resistencia a tracción, en la figura 5.4 se presentan los módulos de rotura a flexión obtenidos en los hormigones elaborados con los dos tipos de agregados gruesos. Se observa que las resistencias a flexión y a compresión diametral no se modificaron substancialmente por efecto del uso de AGR en los hormigones tipo H13. En cambio en los hormigones H3O se encontró una disminución de la resistencia a flexión del $8 \%$ en el hormigón H30R con respecto al hormigón H30N. Dicha disminución también se vio reflejada en el caso de la resistencia por compresión diametral, en donde los H30R tuvieron una disminución del $16 \%$ respecto a los H30N.

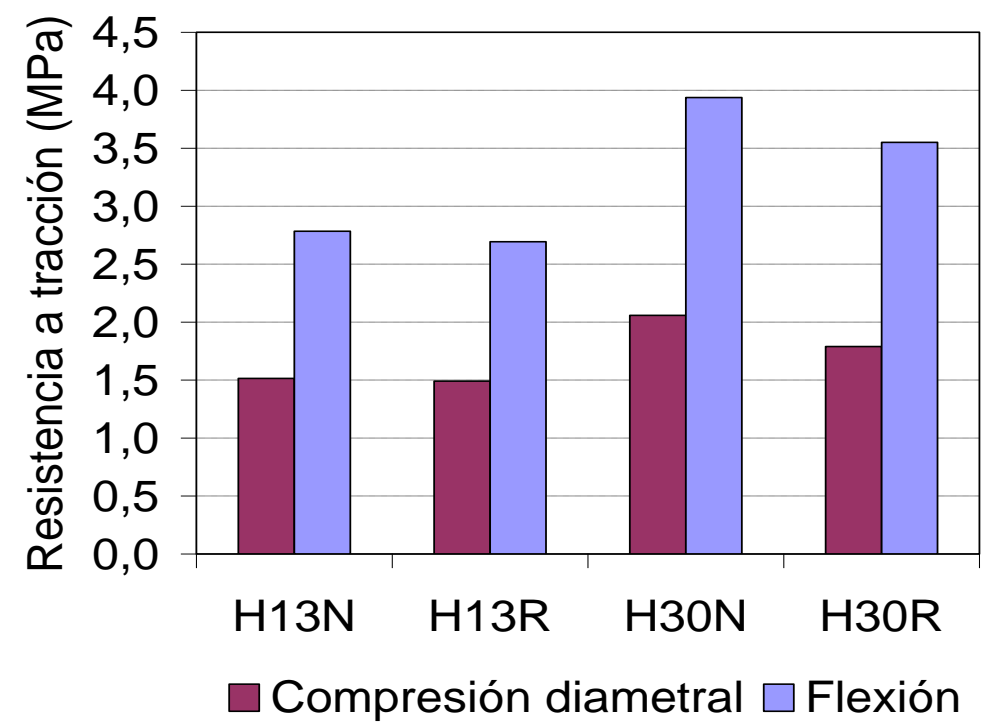

Figura 5.4: Resistencias a compresión diametral y flexión de los hormigones. 
El módulo de elasticidad estático está fuertemente vinculado al tipo de AGN y al nivel resistente del hormigón, por lo que una variación en cualquiera de ellos influirá en una modificación de la rigidez del hormigón [Neville, 1977; Mindess y Young, 1981]. Debido a la composición que poseen los agregados reciclados, en los cuales la roca y el mortero del hormigón original están presentes en proporciones variables, y donde el mortero es el material que posee una menor calidad y mayor deformabilidad, es esperable que el módulo de elasticidad del hormigón reciclado resulte inferior al de un hormigón de igual nivel resistente elaborado en su totalidad con AGN [Sri Ravindrarajah y Tam, 1985; Hansen, 1986; Zega et al, 2005; Zega y Di Maio, 2007]. Dicha diferencia será más importante cuanto mayor es el porcentaje de AGR empleado [Di Maio et al, 2002; Zega et al, 2006].

En la figura 5.5 se puede observar una disminución del módulo de elasticidad del $12 \%$ a 28 días para los hormigones H13R con respecto al H13N. Los hormigones H30R presentaron una disminución más acentuada del módulo de elasticidad en referencia a los hormigones $\mathrm{H} 30 \mathrm{~N}$, llegando a ser para este caso del $23 \%$.

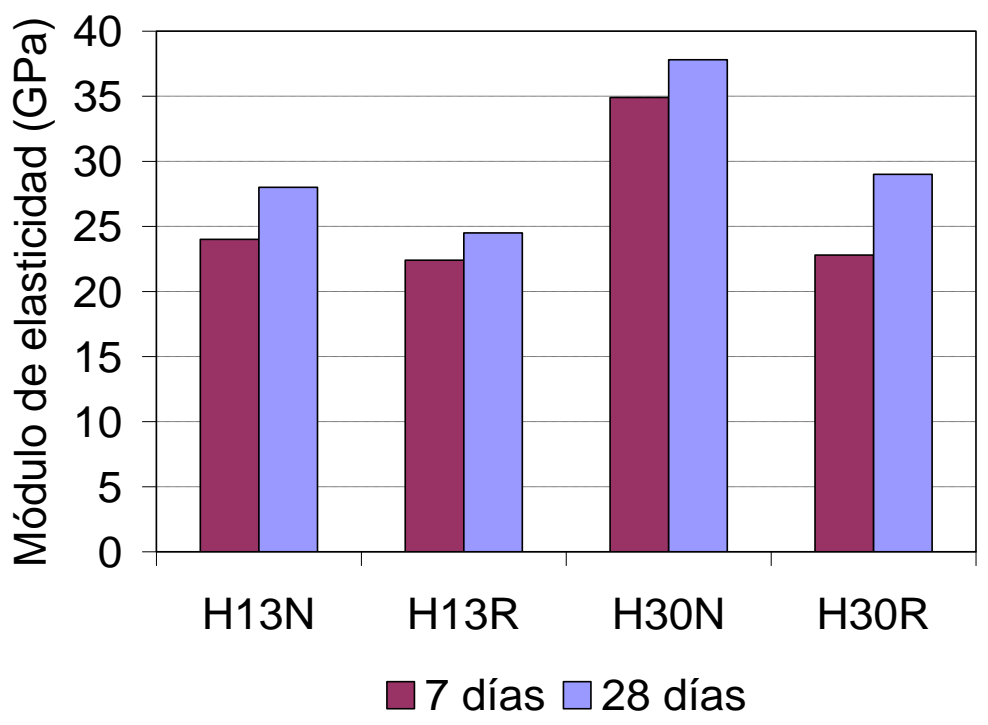

Figura 5.5: Módulos de elasticidad estático de los hormigones.

En relación a la contracción por secado se puede observar que las probetas elaboradas con AGR fue de 1,5 veces mayor que la contracción obtenida en las probetas con AGN (Ver figura 5.6). En el mismo ensayo se 
midió la pérdida de peso en porcentaje (\%); observando que los hormigones elaborados con AGR presentan mayor pérdida que los hormigones con AGN (Ver figura 5.7).

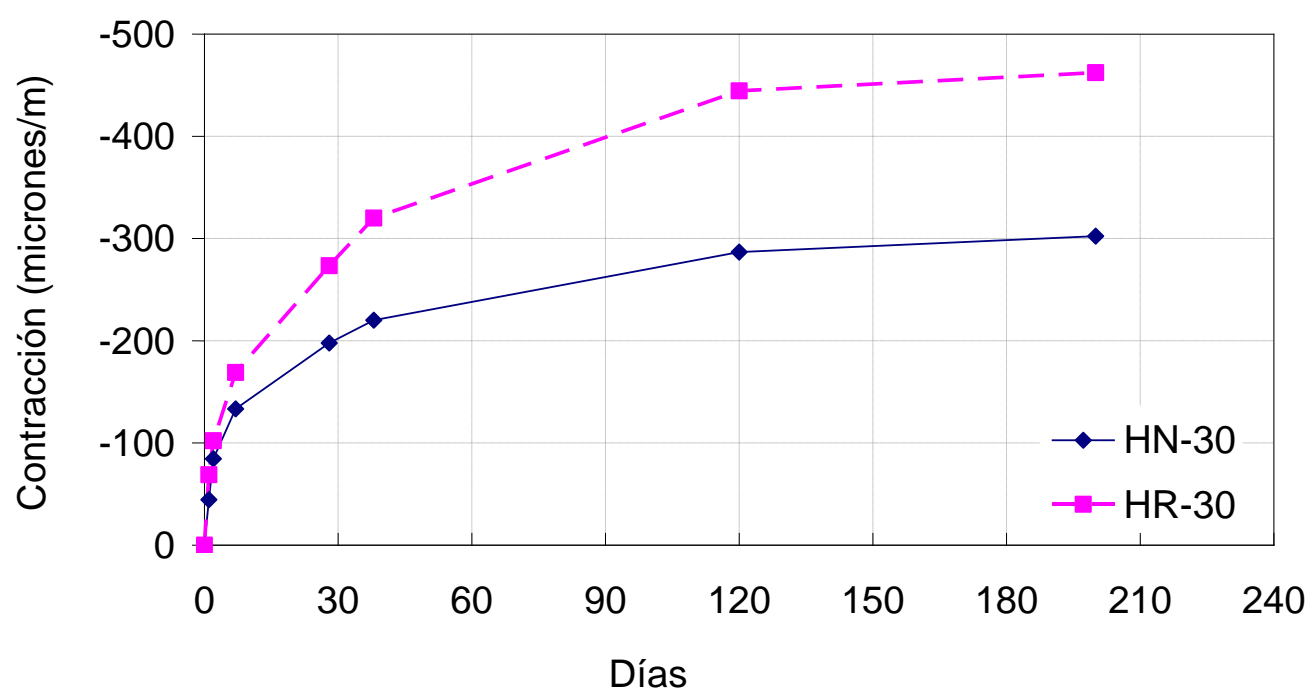

Figura 5.6: Contracción por secado de los hormigones.

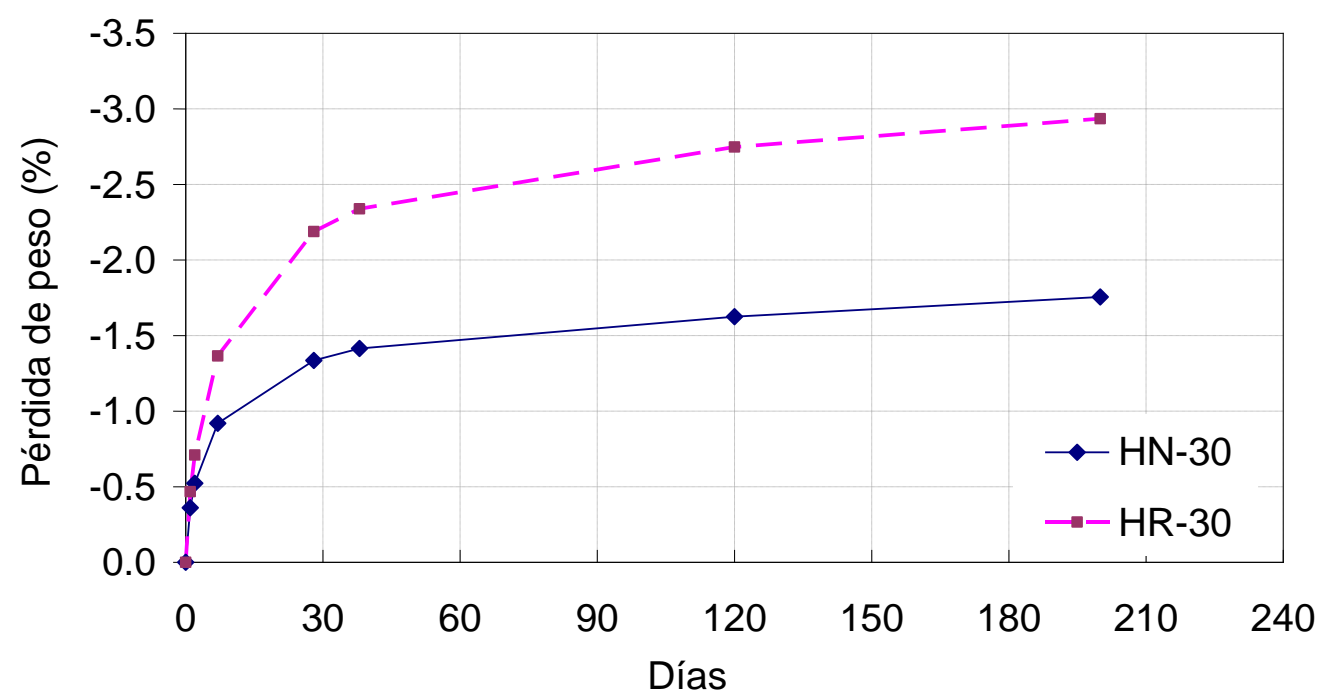

Figura 5.7: Pérdida de peso de los hormigones.

\section{5.- CONSIDERACIONES FINALES SOBRE LAS EXPERIENCIAS EN HORMIGONES}

Para el diseño del espesor del pavimento se utiliza como parámetro de cálculo la resistencia a la flexión del hormigón. En tanto que para la aprobación de los pavimentos se comparan la resistencia a la compresión medida sobre testigos calados y la resistencia obtenida en laboratorio. Para contemplar este aspecto del diseño las especificaciones técnicas exigen, como control de 
calidad del hormigón, que la resistencia a la compresión del hormigón [IRAM 1546] será tal que permita cumplir con un valor mínimo a compresión y a su vez con una resistencia media de rotura por flexión [IRAM 1547] con otro valor mínimo para flexión.

Entre los principales factores que alteran el comportamiento del hormigón en estado endurecido se encuentran la razón a/c, el tipo y contenido de cemento, y el tipo de curado efectuado, viéndose modificado también por la naturaleza del agregado grueso que contiene [Mehta y Monteiro, 1998].

Debido a las características distintivas que puede presentar los AGR, su utilización en pavimentos rígidos puede ocasionar diferencias significativas con relación a los producidos con AGN.

Los resultados muestran que:

Fue posible obtener hormigones con dos niveles resistentes ( $\mathrm{H} 13$ y H30) con propiedades en estado fresco similares empleando AGR y AGN. EI hormigón H13R presentó asentamiento igual, aire incorporado y peso unitario ligeramente menores que el hormigón elaborado con AGN, mientras que para el nivel de resistencia mayor (H30), el hormigón H30R presentó un asentamiento ligeramente mayor, tanto el peso unitario, el aire incorporado y los tiempos de fraguado fueron prácticamente coincidentes.

En los hormigones H13 se observaron resistencias a compresión y flexión parecidas sin importar el agregado grueso utilizado, en cambio el módulo de elasticidad de los hormigones con AGR tuvo una disminución del 10 $\%$ con respecto al módulo encontrado en hormigones con AGN.

En los hormigones $\mathrm{H} 30$, con contenidos de cemento similares, se observaron disminuciones en las propiedades mecánicas del H30R. La resistencia a compresión disminuyó un $16 \%$, la resistencia a flexión se redujo un $8 \%$ y el módulo de elasticidad un $23 \%$ con respecto al hormigón elaborado con agregados graníticos ( $\mathrm{H} 30 \mathrm{~N})$.

El hormigón H30R mostró mayor contracción por secado y mayor pérdida de peso que el H30N. Estas propiedades fueron del orden de 1,5 veces mayores para $\mathrm{H} 30 \mathrm{R}$. 
El Rendimiento ( $\mathrm{MPa} / 10 \mathrm{Kg}$ cemento) en los $\mathrm{H} 13$ es muy parecido mientras que en los $\mathrm{H} 30$, el uso de AGR requiere incrementar para este caso un $13 \%$ el contenido de cemento para obtener resistencias parecidas a los hormigones elaborados con AGN. 


\section{Capítulo 6}

\section{MEZCLAS ASFALTICAS CON AGREGADOS RECICLADOS}

\section{1.- INTRODUCCION}

Otra de las alternativas de uso de los residuos de losas de hormigón en carreteras consiste en incorporar los áridos reciclados (AR) en mezclas asfálticas para pavimentación. Debido a la naturaleza flexible del pavimento asfáltico, las carpetas siempre utilizan áridos gruesos y finos provenientes de la trituración de rocas de buena calidad. No obstante se admite una pequeña cantidad de áridos finos naturales en las capas de base.

En este capítulo se aborda el estudio de dos mezclas asfálticas en caliente del tipo Concreto Asfáltico Convencional (CAC) de diferente función estructural en el pavimento que incorporan árido reciclado. Se eligieron dos de los tipos de CAC más utilizados, un CAC de granulometría gruesa (G19) para capa de base y uno de granulometría densa (D19) para capa de rodadura. En principio, se proyectó el uso de la totalidad del AR como agregado en las mezclas (Serie I). Sin embargo al aplicar la metodología especificada en Argentina para el diseño y evaluación de los CAC, se presentaron altos porcentajes de AGR fracturado durante los procesos de mezclado $y$ compactación, por lo que de allí en adelante se decidió usar solamente el AFR (Series II y III). 


\section{2.- MATERIALES}

La vida útil de una capa de rodadura está determinada en gran medida por los materiales que la componen. El fallo estructural por grandes deformaciones plásticas en un pavimento flexible puede producirse por el uso de un árido con caras redondeadas, una granulometría poco adecuada, una arena de mala calidad o un porcentaje de ligante alto, entre otras causas.

Los materiales reciclados fueron caracterizados de acuerdo a lo descripto en el capítulo 4. A partir de los resultados allí consignados surge que los AGR cumplen con los requisitos exigidos por la Comisión Permanente del Asfalto (CPA) referentes a granulometría, índice de lajas y agujas, caras fracturadas, etc. El único requerimiento que no cumple es el de desgaste Los Ángeles; el material presenta porcentajes mayores a los límites máximos especificados: $25 \%$ para capa de rodadura y $30 \%$ para base asfáltica.

Tabla 6.1: Ensayo de Los Ángeles con distintas combinaciones de AGR y AGN.

\begin{tabular}{|c|c|c|}
\hline Graduación & $\begin{array}{c}\text { Combinación de } \\
\text { agregados }\end{array}$ & $\begin{array}{c}\text { Desgaste } \\
\text { Los Ángeles }\end{array}$ \\
\hline B & $100 \%$ AGR & 35,9 \\
\hline B & $50 \%$ AGR + 50 \% AGN & 28,2 \\
\hline B & $100 \%$ AGN & 20,2 \\
\hline C & $100 \%$ AGR & 37,4 \\
\hline C & $50 \%$ AGR + 50 \% AGN & 30,5 \\
\hline C & $100 \%$ AGN & 21,9 \\
\hline
\end{tabular}

La tabla 6.1 muestra los valores de desgaste correspondientes a diferentes combinaciones de AGR y AGN de origen granítico observando que a medida que aumenta el porcentaje de agregados naturales el desgaste disminuye tanto en la graduación $\mathrm{B}$ como en la $\mathrm{C}$, estando próximo al porcentaje permitido para la elaboración de bases asfálticas y capas de rodaduras.

Los límites de las especificaciones vigentes de la CPA corresponden a valores históricos de los agregados pétreos de gran calidad existentes en Argentina. Estos valores pueden considerarse muy estrictos comparados con la bibliografía internacional que permite el uso de agregados gruesos con desgaste Los Ángeles de hasta el 40 \% en EEUU y 35 \% en España. 
En cuanto a los límites especificados para el AFR como equivalencia de arena y plasticidad de la fracción pasa tamiz $0,075 \mathrm{~mm}$, cumple holgadamente como se expuso en el capítulo 4.

El ligante utilizado fue un cemento asfáltico comercial denominado ASFASOL F de YPF, que cumple los requerimientos de un asfalto Tipo II de la norma IRAM 6604. En la tabla 6.2 se presentan los resultados de los ensayos de caracterización del ligante utilizado y los límites especificados por dicha norma.

Tabla 6.2: Caracterización del asfalto para uso vial por Penetración.

\begin{tabular}{|c|c|c|c|}
\hline \multirow{3}{*}{ CARACTERISTICAS } & \multirow{3}{*}{ ASFASOL F } & \multirow{2}{*}{\multicolumn{2}{|c|}{$\begin{array}{c}\text { IRAM } 6604 \\
\text { TIPO II }\end{array}$}} \\
\hline & & & \\
\hline & & MIN & MAX \\
\hline Penetración $\left(25^{\circ} \mathrm{C}, 100 \mathrm{~g}, 5 \mathrm{~s}\right), 0.1 \mathrm{~mm}$ & 53 & 50 & 60 \\
\hline Índice de Penetración de Pfeiffer & $-0,8$ & $-1,5$ & 0,5 \\
\hline Ensayo de Oliensis & Negativo & \multicolumn{2}{|c|}{ Negativo } \\
\hline Ductilidad $\left(5 \mathrm{~cm} / \mathrm{min}, 25^{\circ} \mathrm{C}\right), \mathrm{cm}$ & $>150$ & 100 & - \\
\hline Punto de Inflamación en copa Cleveland, 으 & 302 & 230 & - \\
\hline Solubilidad en tricloroetileno, $\%$ & 99,90 & 99 & - \\
\hline Punto de ablandamiento, $\stackrel{\circ}{ } \mathrm{C}$ & 51,2 & & - \\
\hline \multicolumn{4}{|c|}{ Ensayo sobre el residuo de pérdida por calentamiento (RTFOT) } \\
\hline $\begin{array}{l}\text { Penetración retenida }\left(25^{\circ} \mathrm{C}, 100 \mathrm{~g}, 5 \mathrm{~s}\right), \% \text { de } \\
\text { la penetración original }\end{array}$ & 68 & 50 & - \\
\hline Pérdida por calentamiento, $\%$ & 0,5 & - & 0,8 \\
\hline Ductilidad del residuo $\left(5 \mathrm{~cm} / \mathrm{min}, 25^{\circ} \mathrm{C}\right), \mathrm{cm}$ & $>150$ & 50 & - \\
\hline
\end{tabular}

Tanto las temperaturas de mezclado como de compactación en laboratorio se obtuvieron trazando la curva de viscosidad (Ver figura 6.1).

Las temperaturas de trabajo fueron de $160{ }^{\circ} \mathrm{C}$ para mezclado y $148{ }^{\circ} \mathrm{C}$ para la compactación, definidas por los rangos de equiviscosidad normalizados, es decir, valores medios de 0,17 y 0,28 Pa.s. 


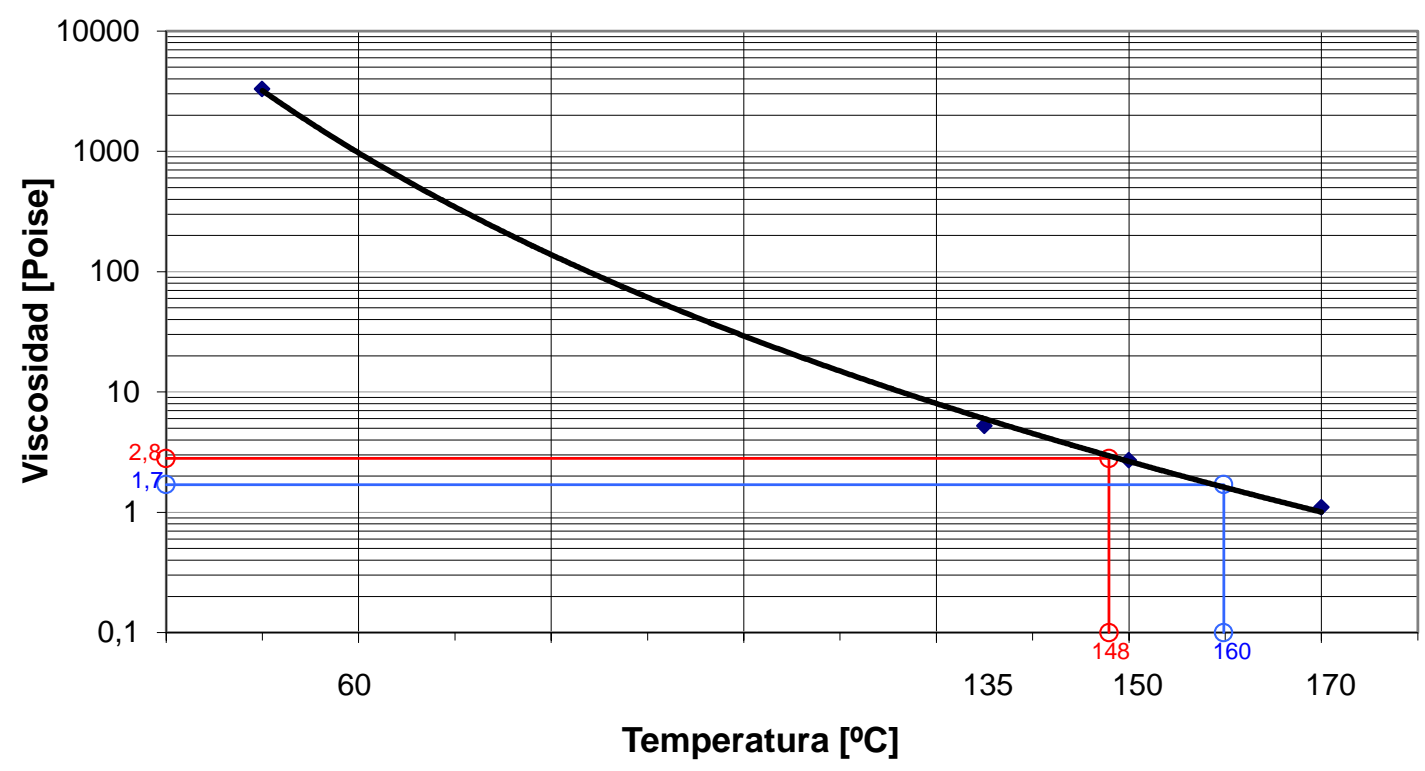

Figura 6.1: Temperaturas de mezclado y compactación.

\section{3.- MEZCLAS CON AGR Y AFR}

Tal como fuera indicado la primera alternativa explorada fue utilizar la totalidad de AR, incorporando tanto la fracción gruesa como la fina, y ajustando las mezclas de agregados de forma tal de cumplir con los límites de los husos granulométricos para mezclas D19 y G19, de acuerdo a las recomendaciones de la CPA.

En la serie I se prepararon 3 mezclas: un CAC D19 (I-D19) y dos CAC G19, con arena silícea natural de río (I-G19 CS) y sin arena silícea (I-G19 SS). Las proporciones de las mezclas se indican en la tabla 6.3.

Tabla 6.3: Serie I: CAC que incorporan la totalidad de AR.

\begin{tabular}{|l|c|c|c|c|c|}
\hline Mezcla & AGR & AFR & Filler calcáreo & Cal & Arena silícea \\
\hline & $\%$ & $\%$ & $\%$ & $\%$ & $\%$ \\
\hline I-D19 & 50 & 45 & 4 & 1 & 0 \\
\hline I-G19 SS & 67 & 31 & 0 & 2 & 0 \\
\hline I-G19 CS & 67 & 21 & 0 & 2 & 10 \\
\hline
\end{tabular}

Con cada mezcla se moldearon probetas con el compactador Marshall utilizando un 5,50 \% de ligante asfáltico, y se determinaron sus propiedades volumétricas y mecánicas. 
Las probetas de I-D19 se compactaron aplicando 75 golpes por cara mientras que en el caso de I-G19 CS y I-G19 SS se empleó menor energía de compactación, 50 golpes por cara.

En la tabla 6.4 se presentan los resultados obtenidos. Se observa que para la mezcla I-D19, la Estabilidad Marshall, y consecuentemente la relación Estabilidad/Fluencia, resultan en valores muy por encima de los límites establecidos para un pavimento flexible convencional. A la vez el contenido de vacíos también resulta muy alto.

Debido a la incorporación de arena silícea natural, que posee partículas redondeadas y lisas, las probetas de I-G19 CS presentaron valores de Estabilidad más parecidos a los típicamente obtenidos en mezclas con agregados convencionales y una mayor compactación que la mezcla I-G19 SS.

Tabla 6.4: Parámetros Marshall obtenidos en las distintas CAC.

\begin{tabular}{|l|c|c|c|}
\hline Parámetros Marshall & I-D19 & I-G19 SS & I-G19 CS \\
\hline Da & 2,175 & 2,138 & 2,188 \\
\hline D Rice & 2,328 & 2,308 & 2,315 \\
\hline Vacíos [\%] & 6,6 & 7,2 & 5,5 \\
\hline Estabilidad [N] & 24540 & 20320 & 14940 \\
\hline Fluencia [mm] & 3,0 & 3,1 & 2,6 \\
\hline Relación E/F [N/mm] & 8181 & 6550 & 5746 \\
\hline
\end{tabular}

La densidad de una mezcla con agregados naturales graníticos está en el orden de 2,38 a 2,43. Las densidades obtenidas en las mezclas realizadas con AR son notoriamente inferiores debido a la menor densidad de los mismos.

En la figura 6.2 se evidencia la fracturación que sufren los agregados reciclados en el proceso de mezclado y compactación. 


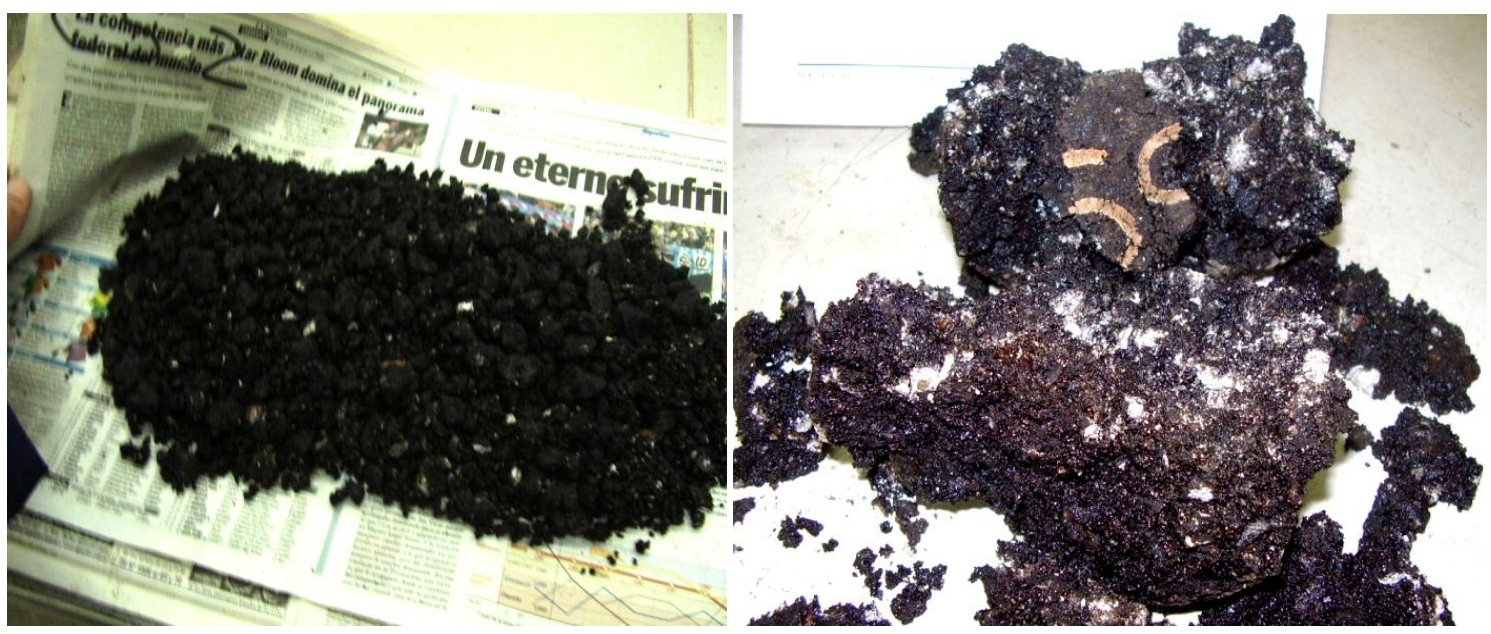

Figura 6.2: Degradación del material reciclado en el mezclado y compactación.

La foto a la izquierda muestra la mezcla asfáltica en estado suelto luego de disgregar probetas. Se observan agregados fracturados producto de la degradación ocurrida durante los procesos de mezclado y compactación.

La foto de la derecha muestra una probeta sometida al ensayo de Estabilidad Marshall y parcialmente disgregada. Se observa una gran cantidad de AGR fracturados.

Para evaluar la degradación de los agregados en cada una de las etapas en las que puede presentarse se han realizado los análisis granulométricos de los materiales recuperados luego del lavado por reflujo de solvente [VNE-7] de las mezclas asfálticas sometidas a: 1) procesos de mezclado, 2) procesos de mezclado y compactación y 3) procesos de mezclado, compactación y rotura en el ensayo de Estabilidad Marshall, de manera de cuantificar el deterioro del AR en las diferentes etapas del proceso de diseño y poder así discriminarlo de la degradación del material debido a la aplicación de las cargas durante el ensayo de Estabilidad Marshall.

Como límite admisible para la degradación del material se tomó como referencia las Franjas de trabajo que se utilizarían durante la etapa de Control de Ejecución de obra (Recomendaciones de la CPA), definidas por las tolerancias respecto de la granulometría de diseño. Los resultados obtenidos se incluyen en las figuras 6.3, 6.4 y 6.5, para las mezclas I-D19, I-G19 SS y IG19 CS respectivamente. 


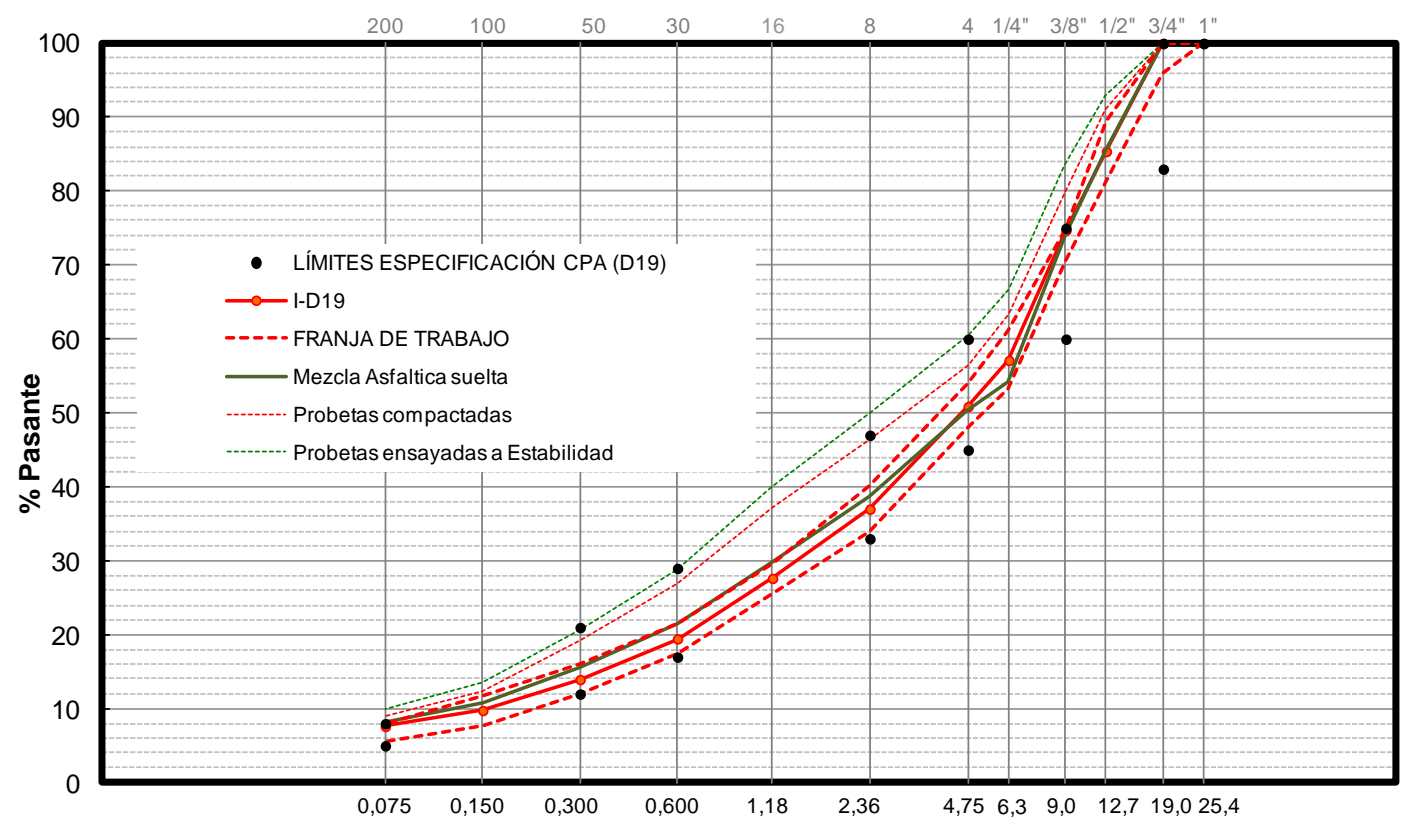

Abertura de tamiz [mm]

Figura 6.3: I-D19: Granulometrías originales y recuperadas.

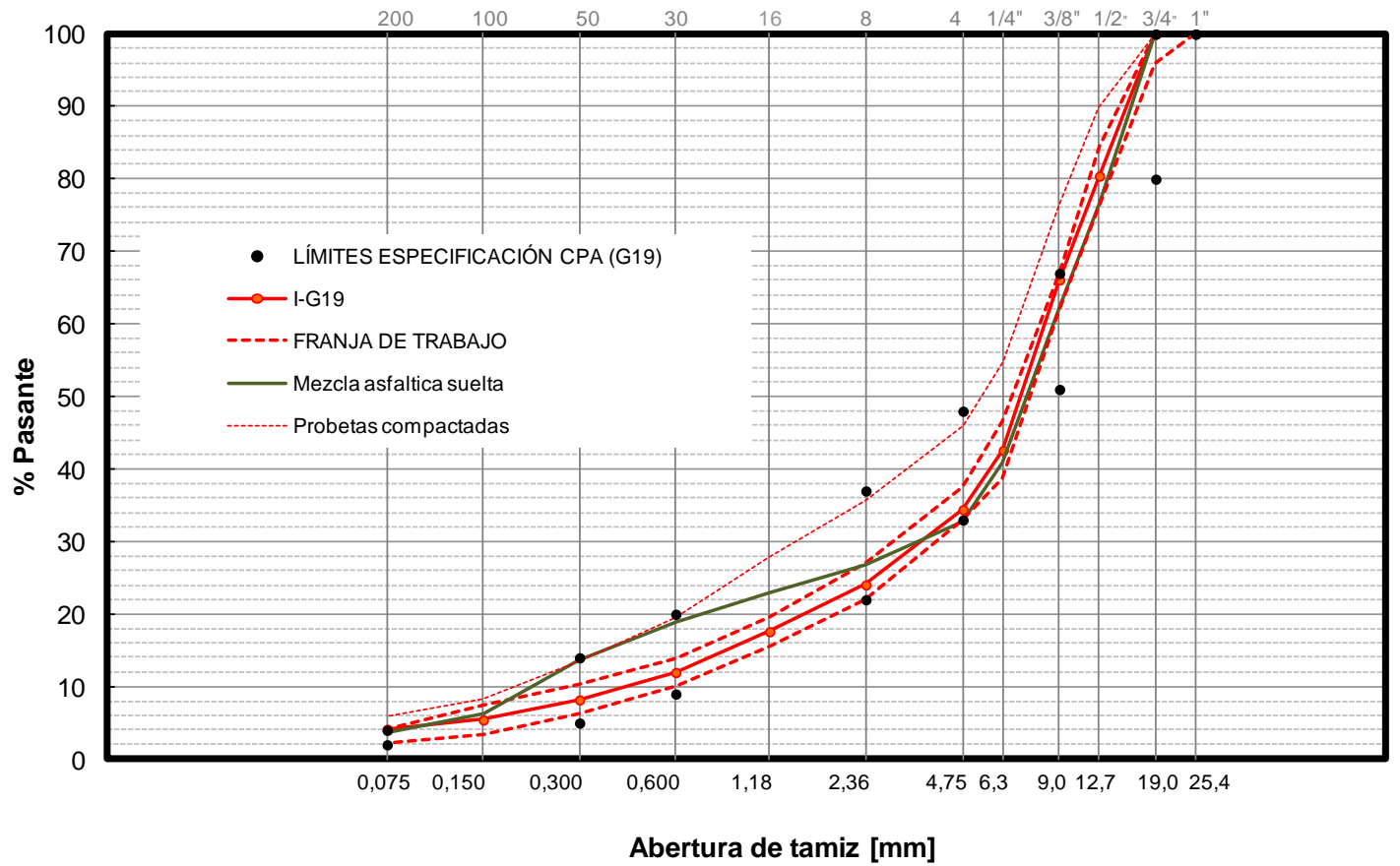

Figura 6.4: I-G19 SS: Granulometrías originales y recuperadas. 


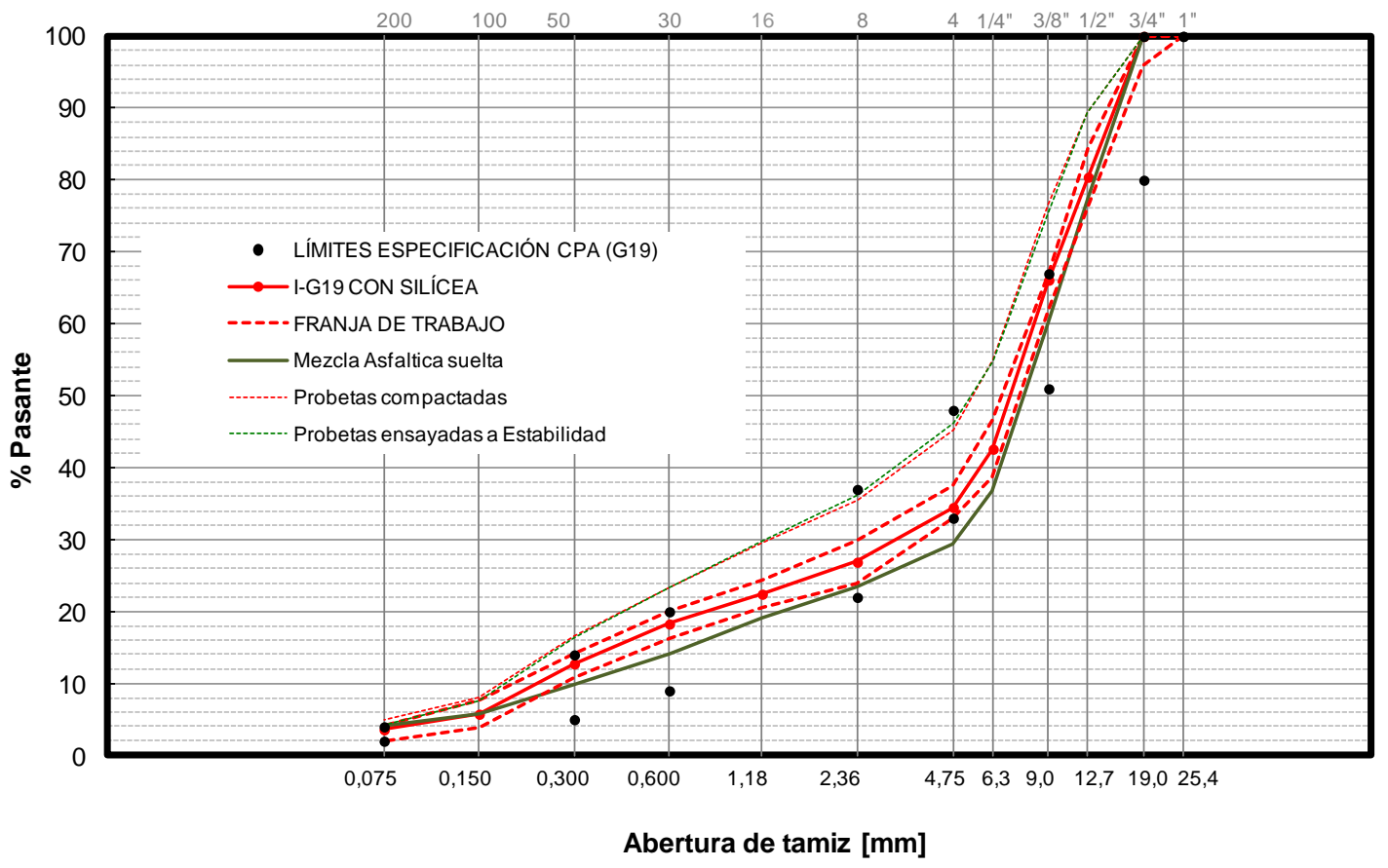

Figura 6.5: I-G19 CS: Granulometrías originales y recuperadas.

A partir de las recuperaciones realizadas se pudo observar que existen cambios significativos en las granulometrías debidos a la degradación del AGR durante la elaboración de las mezclas, siendo más importante este efecto en el proceso de compactación, no obstante de ello la degradación se acentúa durante el ensayo de Estabilidad Marshall (Ver figuras 6.6, 6.7 y 6.8).

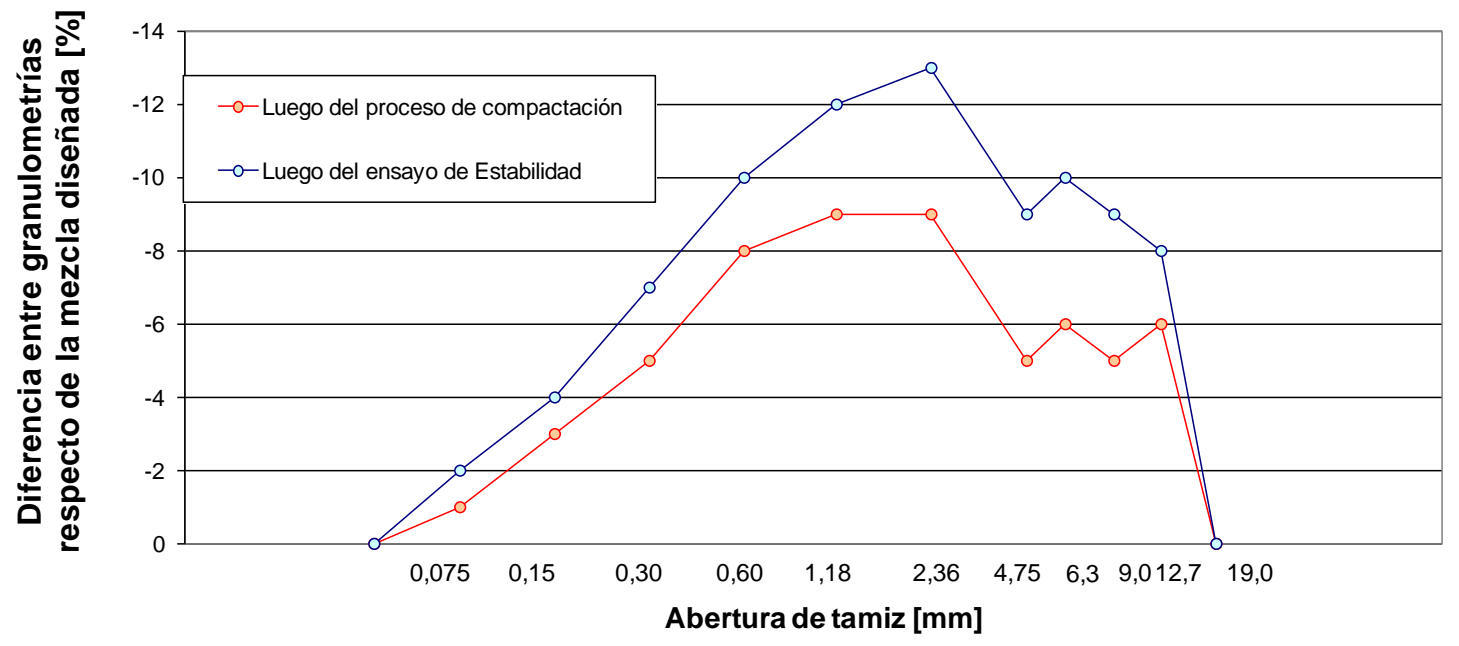

Figura 6.6: Degradación de la mezcla I-D19. 


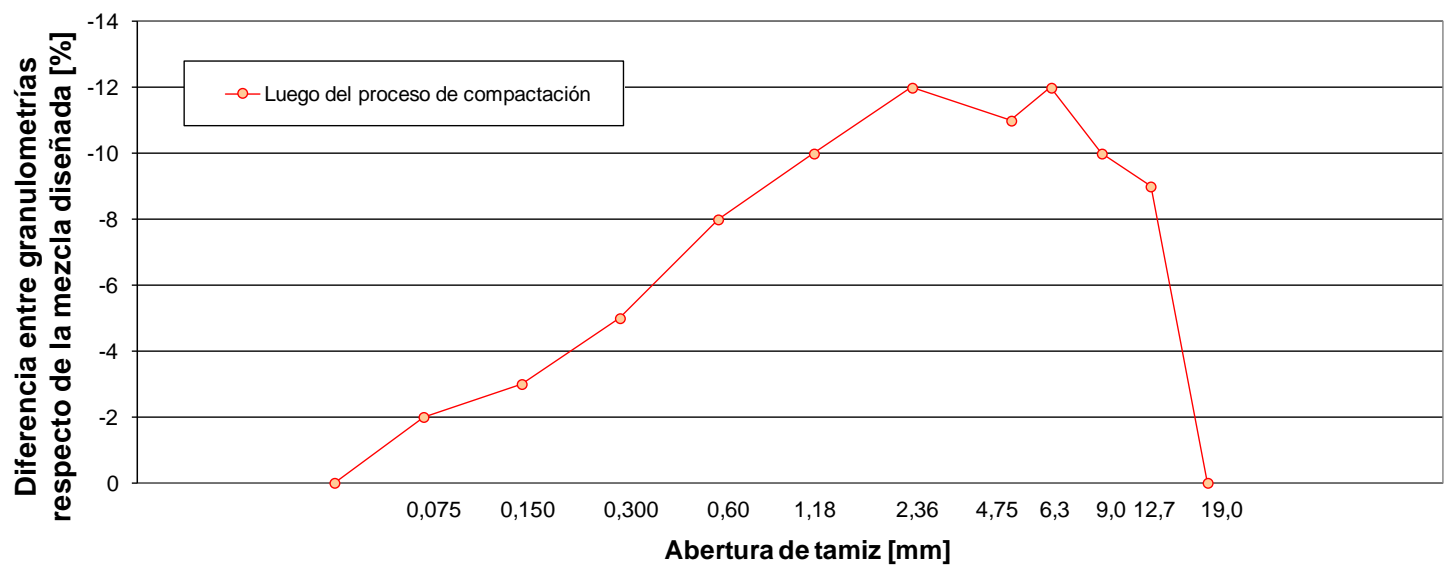

Figura 6.7: Degradación de la mezcla I-G19 SS.

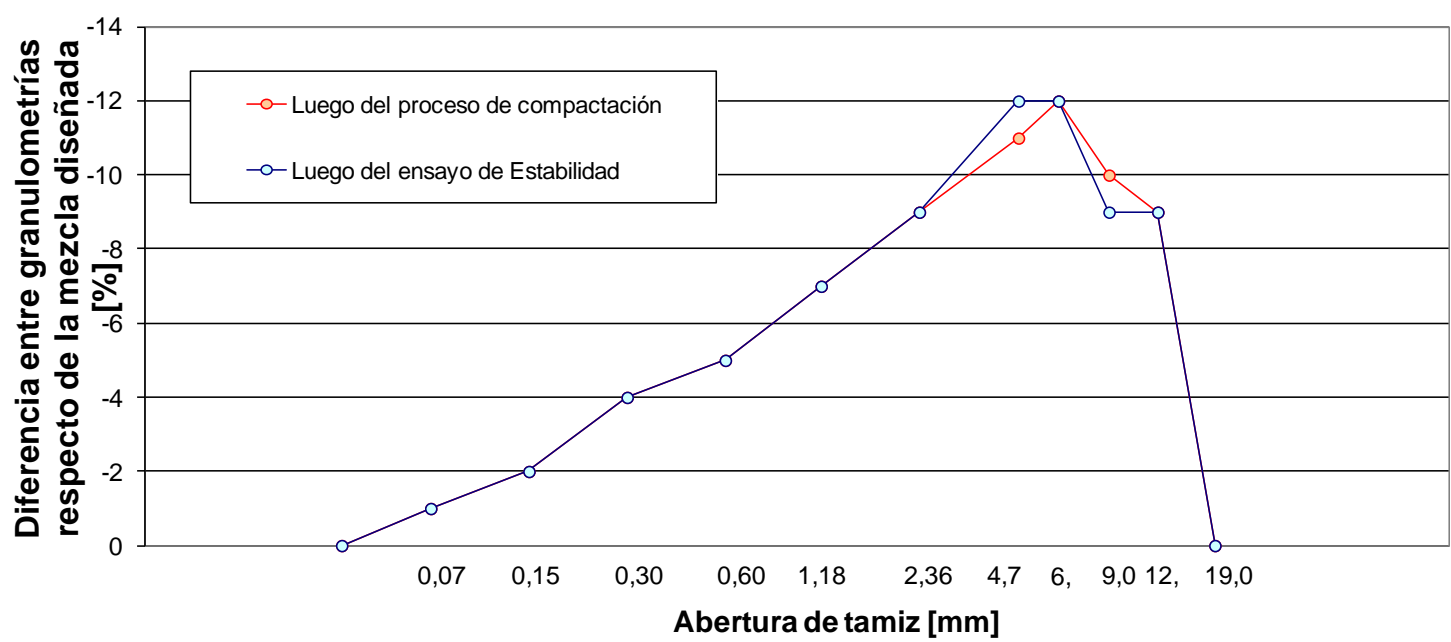

Figura 6.8: Degradación de la mezcla I-G19 CS.

El análisis conjunto indica que existe entre 12 y $13 \%$ más de material pasante en las granulometrías correspondiente a las partículas 2,36 y 6,3 mm, lo que evidencia la fractura de las partículas del agregado grueso. La degradación de los agregados reciclados fue algo mayor en la mezcla I-D19, sometidas a mayor energía de compactación (75 golpes/cara). Debido a la degradación que sufre el AR en la preparación y compactación de mezclas asfálticas, la granulometría original se modifica y queda por fuera de las tolerancias para el control en obra.

Esto verifica lo expuesto por Pérez et al [2007] respecto a la importante degradación que sufre AGR cuando las mezclas asfálticas se diseñan mediante la Metodología Marshall. La bibliografía consultada concluye que sólo pueden 
utilizarse en un porcentaje acotado por su desgaste y que la fracción gruesa deberá completarse con un material de mejor calidad. La bibliografía también expone el hecho de que la compactación dinámica Marshall no es un método adecuado para conocer las prestaciones de este material.

Dado que la interacción entre partículas de agregados gruesos constituye una contribución importante dentro del mecanismo resistente de un concreto asfáltico, la posibilidad de una fractura progresiva de dichas partículas resulta en principio inadmisible. Por tal motivo se planteó como segunda alternativa explorar el uso del AFR combinado con AG naturales.

\section{4.- MEZCLAS CON AFR Y AGN}

Las recomendaciones de la CPA prohíben el uso de arenas silíceas para carpetas de rodamiento, pero debido a que el estudio preliminar muestra muy altos valores de Estabilidad, se decidió incorporar arena silícea de río de manera de obtener mezclas menos rígidas y más trabajables.

La serie II incluye 2 mezclas utilizando AGN y el AFR: un CAC D19 (IID19) y un CAC G19 (II-G19). Las proporciones de las mismas se indican en la tabla 6.5 .

Tabla 6.5: Serie II: CAC que incorporan la totalidad de AFR y AGN.

\begin{tabular}{|c|c|c|c|c|c|}
\hline Mezcla & AGN & AFR & Filler calcáreo & Cal & Arena silícea \\
\hline & $\%$ & $\%$ & $\%$ & $\%$ & $\%$ \\
\hline II-D19 & 50 & 35 & 4 & 1 & 10 \\
\hline II-G19 & 67 & 21 & 0 & 2 & 10 \\
\hline
\end{tabular}

Para obtener el diseño definitivo de la mezcla se utilizó el Método Marshall con un barrido de contenidos de asfalto de 4,5\%, 5,0 \% y 5,5\%. Las probetas fueron moldeadas respetando la misma cantidad de golpes/cara anteriormente empleada, o sea 75 golpes/cara para la carpeta y 50 golpes/cara para la base. En las figuras 6.9 y 6.10 se muestran los parámetros volumétricos obtenidos con distintos tenores de asfalto. 

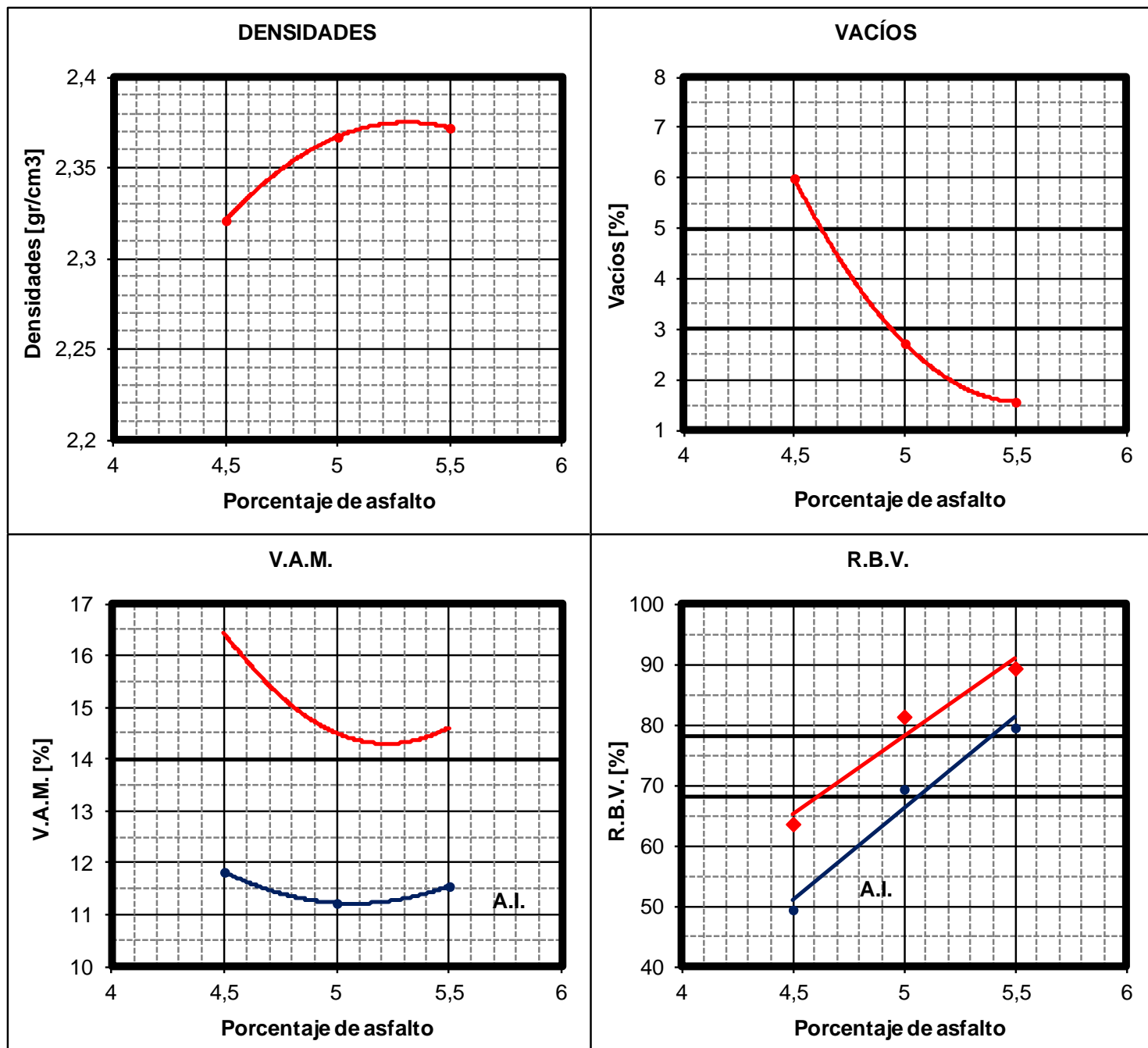

R.B.V.
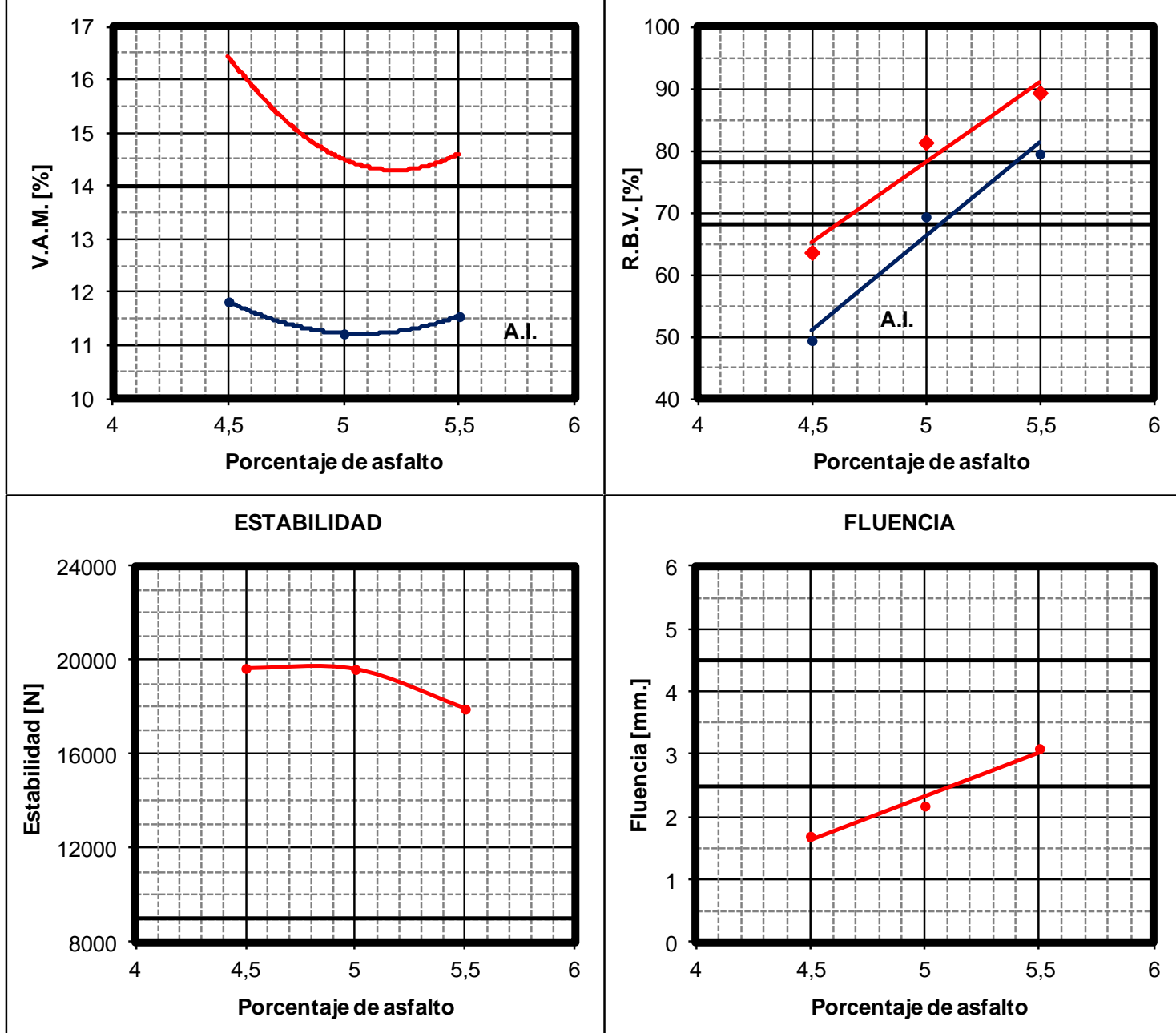

FLUENCIA

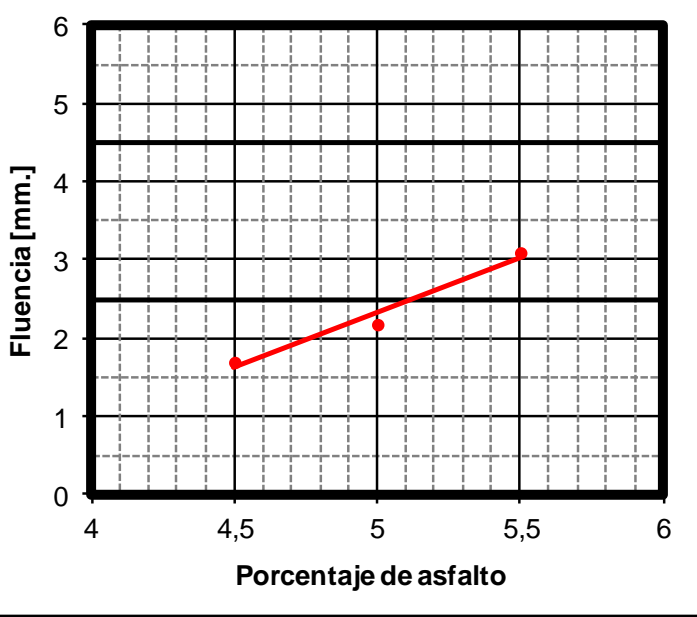

Figura 6.9: Parámetros volumétricos obtenidos con el barrido de ligante para CAC II-D19. 


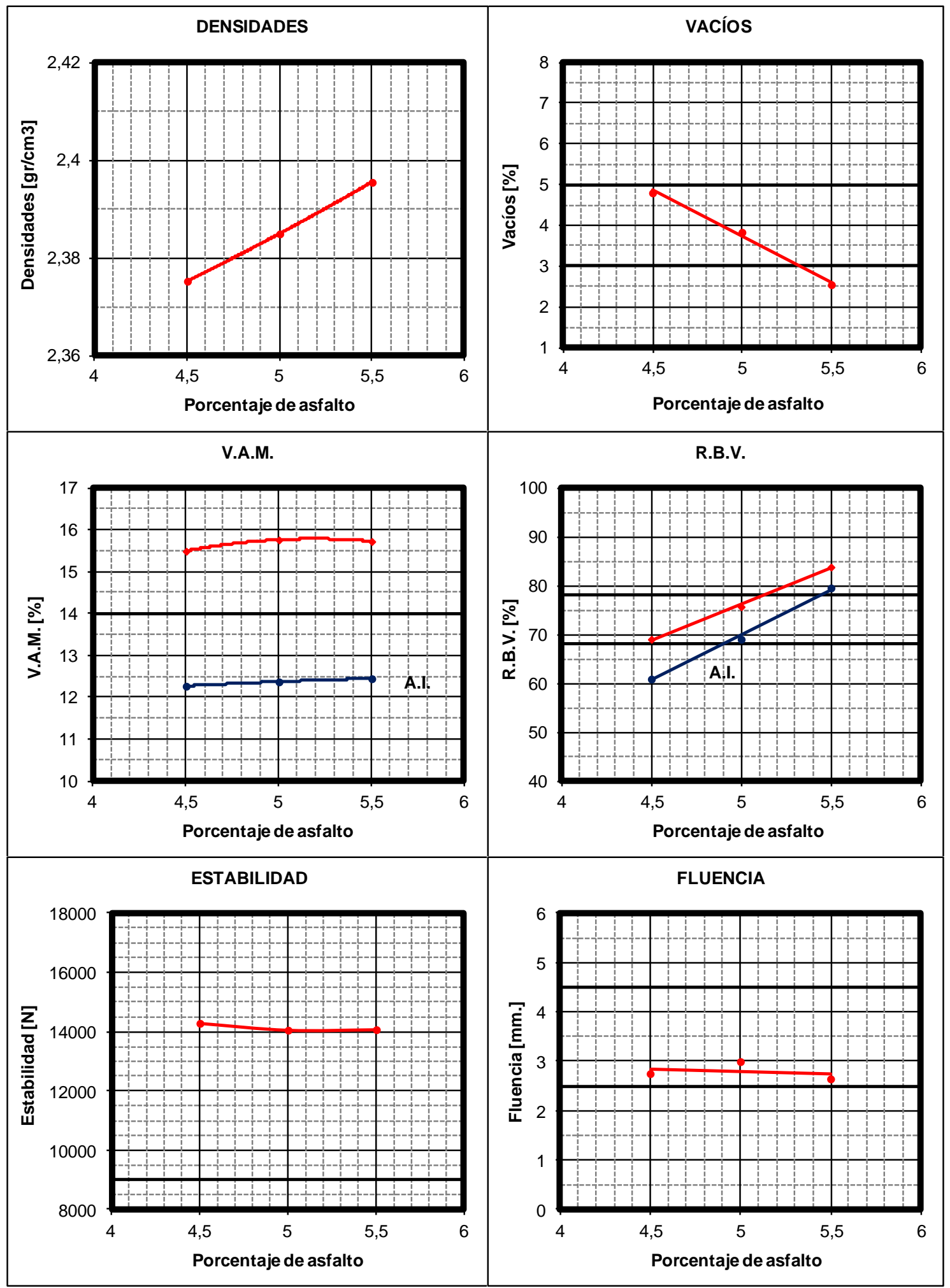

Figura 6.10: Parámetros volumétricos obtenidos con el barrido de ligante para CAC II-G19. 
Respecto de los parámetros mecánicos se encontraron resultados típicos de una mezcla poco flexible; la variación del contenido de asfalto no afecta significativamente dichos parámetros. En base a los datos obtenidos se adoptó el contenido óptimo de asfalto que cumple más ajustadamente los criterios de las recomendaciones de la CPA que se exponen en la tabla 6.6.

Tabla 6.6: Parámetros de las mezclas con el contenido óptimo de asfalto adoptado.

\begin{tabular}{|l|c|c|c|}
\hline \multicolumn{1}{|c|}{ PARAMETROS } & CARPETA & BASE & CRITERIO \\
\cline { 2 - 5 } & II-D19 & II-G19 & CPA \\
\hline Contenido de asfalto adoptado, \% & 5,0 & 5,0 & - \\
\hline Energía de compactación & 75 GPC & 50 GPC & $\begin{array}{c}\mathbf{7 5} \text { ó 50 } \\
\text { (Decide la E.T.P.) }\end{array}$ \\
\hline Estabilidad Marshall [N] & 19630 & 14061 & E > 9000 \\
\hline Relación E/F [N/mm] & 8991 & 4687 & $\mathbf{2 5 0 0}<$ E/F $<4500$ \\
\hline Porcentaje de vacíos [\%] & 2,7 & 3,8 & $\mathbf{3}$ a 5 \\
\hline Relación betún-vacíos [\%] & 78,0 & 75,7 & $\mathbf{6 8}$ a 78 \\
\hline Vacíos del agregado mineral [\%] & 14,5 & 15,8 & $\mathbf{2 1 4}$ \\
\hline
\end{tabular}

En vista que el porcentaje de vacíos para la capa de rodadura con un tenor de cemento asfáltico del $5 \%$ no cumplía con el mínimo requerido, se moldearon probetas con una menor energía de compactación (50 golpes/cara) adoptando el criterio de diseño de mezclas de tránsito medio del Instituto del Asfalto de EEUU (Al). Como se verá más adelante con menor energía de compactación se verifica que el porcentaje de vacíos está entre 3 y 5 \%.

Para las mezclas CAC II-G19 el porcentaje de asfalto adoptado cumple con todos los requisitos establecidos por la CPA excepto la relación Estabilidad/Fluencia que está por encima del límite superior.

Los criterios para obtener el porcentaje óptimo de ligante están referidos a mezclas con agregados naturales, en el caso de las probetas elaboradas con AFR se encontró que las mezclas se presentaban mucho más rígidas que las convencionales con AN. Esto puede ser causado por la presencia de material cementiceo proveniente de la trituración de hormigones y puede llegar a rigidizar excesivamente al mástico. Una posibilidad de reducir esta rigidez es a través del uso de asfaltos de menor consistencia, de esta manera la mezcla 
puede flexibilizarse sin cambiar significativamente los parámetros volumétricos. El estudio de esta alternativa excede el alcance del presente estudio.

La tabla 6.7 muestra las dosificaciones finales de las mezclas a estudiar:

Tabla 6.7: Dosificación definitiva de las mezclas de la serie II.

\begin{tabular}{|l|c|c|c|c|}
\hline \multirow{2}{*}{ MEZCLAS } & \multicolumn{2}{|c|}{ II-D19 } & \multicolumn{2}{c|}{ II-G19 } \\
\cline { 2 - 5 } & $\%$ Árido & \% en mezcla & \% Árido & \% en mezcla \\
\hline G6-20 & 50 & 47,5 & 67 & 63,7 \\
\hline R0-6 & 35 & 33,3 & 21 & 20,0 \\
\hline Arena silícea & 10 & 9,5 & 10 & 9,5 \\
\hline Cal & 1 & 1,0 & 2 & 1,9 \\
\hline Filler & 4 & 3,8 & - & - \\
\hline Asfalto & - & 5,0 & - & 5,0 \\
\hline \multirow{2}{*}{} & 100 & 100 & 100 & 100 \\
\hline
\end{tabular}

\section{5.- PERFORMANCE DE MEZCLAS CON AFR}

Los estudios anteriores muestran que debido a la degradación que pueden sufrir los AGR existen limitaciones en su utilización para la elaboración de mezclas asfálticas. Una alternativa es el uso de AFR bajando la energía de compactación de diseño (menor número de golpes por cara) de manera de obtener mezclas que cumplan con los parámetros volumétricos que piden las especificaciones técnicas.

En la serie III se prepararon un CAC tipo D19 (III-D19) y un CAC G19 (III-G19). Para estudiar el comportamiento de las mezclas se moldearon seis probetas de cada una de ellas con los correspondientes contenidos óptimos de asfalto aplicando 50 golpes por cara. Se determinaron las densidades y porcentajes de vacíos de cada probeta y se separaron en dos grupos de tres probetas cada uno cuyos promedios de densidad estén en el mismo orden. El primer grupo fue empleado para determinar la Estabilidad y Fluencia Marshall y el segundo grupo fue sometido, en primer término, al ensayo no destructivo de determinación del módulo de Rigidez para luego ensayarlo a rotura por compresión diametral para determinar su resistencia a Tracción indirecta.

Para evaluar el daño por humedad de cada una de las mezclas se moldearon otras nueve probetas con el número de golpes por cara necesario para obtener un porcentaje de vacíos de $7 \pm 1 \%$, según normativa. Se 
separaron en grupos de tres probetas cada uno con similares promedios de densidad y porcentaje de vacíos.

Los resultados obtenidos se presentan en las tablas 6.8 y 6.9.

Tabla 6.8: Serie III: Propiedades de las mezclas.

\begin{tabular}{|c|c|c|c|}
\hline PARAMETROS & III-D19 & III-G19 & Criterio CPA \\
\hline Energía de compactación & $50 \mathrm{GPC}$ & $50 \mathrm{GPC}$ & $\begin{array}{c}75 \text { ó } 50 \\
\text { (Decide la E.T.P.) }\end{array}$ \\
\hline Densidad $\left[\mathrm{g} / \mathrm{cm}^{3}\right]$ & 2,336 & 2,380 & - \\
\hline Densidad Rice $\left[\mathrm{g} / \mathrm{cm}^{3}\right]$ & 2,433 & 2,472 & - \\
\hline Estabilidad Marshall [N] & 16306 & 12707 & $E>9000$ \\
\hline Relación E/F [N/mm] & 6611 & 5431 & $2500<E / F<4500$ \\
\hline Porcentaje de vacíos [\%] & 4,0 & 3,7 & 3 a 5 \\
\hline Relación betún-vacíos [\%] & 74,7 & 76,2 & 70 a 80 \\
\hline Vacíos del agregado mineral [\%] & 15,6 & 15,7 & $\geq 14$ \\
\hline Relación filler-asfalto & 1,42 & 0,72 & $0,8-1,3$ \\
\hline $\mathrm{Cv} / \mathrm{Cs}=$ & 0,98 & 0,88 & $<1$ \\
\hline $\begin{array}{l}\text { Resistencia a Tracción, } 25^{\circ} \mathrm{C}[\mathrm{kPa}] \\
\text { (IRAM 6846) }\end{array}$ & 1850 & 1614 & - \\
\hline $\begin{array}{l}\text { Módulo de Rigidez, } 20{ }^{\circ} \mathrm{C} \text { [MPa] } \\
\text { (UNE-EN 12697-26) }\end{array}$ & 12049 & 11874 & - \\
\hline
\end{tabular}

Se observa que la mayoría de los casos se cumple con lo requerido por las recomendaciones de la CPA. Sin embargo se advierte que los valores de relación Estabilidad/Fluencia se encuentran muy por encima de los límites (mezclas menos flexibles que lo recomendado). Cabe comentar que las recomendaciones de la CPA para CAC son válidas para diseño de pavimentos de alto tránsito, en las que mezclas asfálticas poco flexibles fabricadas con asfaltos convencionales tienden a ser menos durables pues tienden a agrietarse prematuramente bajo grandes volúmenes de tránsito. A partir de lo expuesto surge que la factibilidad del uso de AR en mezclas asfálticas está vinculada con el diseño de pavimentos de bajo tránsito, como lo afirma la bibliografía internacional. 
Si bien en ambas mezclas se cumplen los límites de las relaciones volumétricas entre filler y el sistema filler-asfalto, no se cumple en la relación filler-asfalto en peso.

La Resistencia a tracción fue un poco elevada en comparación con las mezclas elaboradas con agregados naturales y asfalto CA-30 que presentan valores del orden de 1100 a $1200 \mathrm{kPa}$. El Módulo de rigidez está muy por encima de los encontrados para mezclas convencionales con este tipo de asfalto, dando valores cercanos a $6000 \mathrm{MPa}$.

En la tabla 6.9 se observa los resultados obtenidos en el ensayo de Daño por humedad.

Tabla 6.9: Daño por humedad.

\begin{tabular}{|c|c|c|c|}
\hline Ensayos & III-D19 & III-G19 & CRITERIO \\
\hline Energía de compactación & 14 & 12 & - \\
\hline Porcentaje de vacíos [\%] & 6,7 & 7,0 & AASHTO T-283 \\
\hline Daño por humedad (24 h a $60 \stackrel{\circ}{\circ})$, [\%] & 78 & 83 & $\begin{array}{l}>80 \% \text { ANEXO } \\
\text { I, PETG-CPA }\end{array}$ \\
\hline Daño por humedad (16 h a $-18^{\circ} \mathrm{C}+24 \mathrm{~h}$ a $\left.60^{\circ} \mathrm{C}\right)$, [\%] & 77 & 78 & $\begin{array}{c}>80 \% \\
\text { MANUAL SP-2 }\end{array}$ \\
\hline
\end{tabular}

La mezcla III-D19 no cumple el porcentaje mínimo exigido por la CPA, no obstante ciertas normativas internaciones son menos exigentes al respecto, con un mínimo de $75 \%$.

En forma similar a lo realizado en la serie I, conociendo la degradación que presentan los AR, se realizó la verificación de las granulometrías luego del ensayo de Estabilidad. 


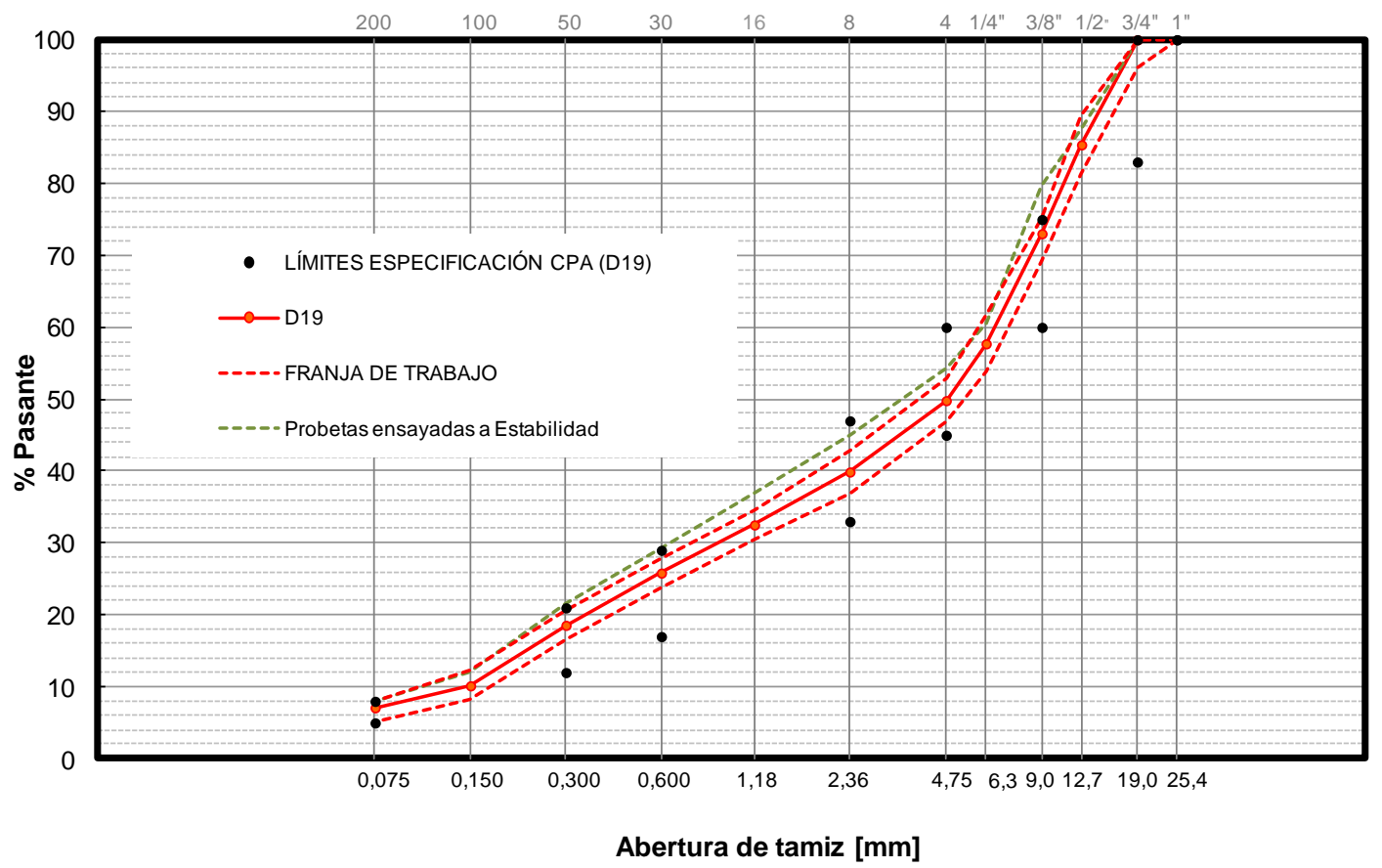

Figura 6.11: III-D19: Granulometrías originales y recuperadas.

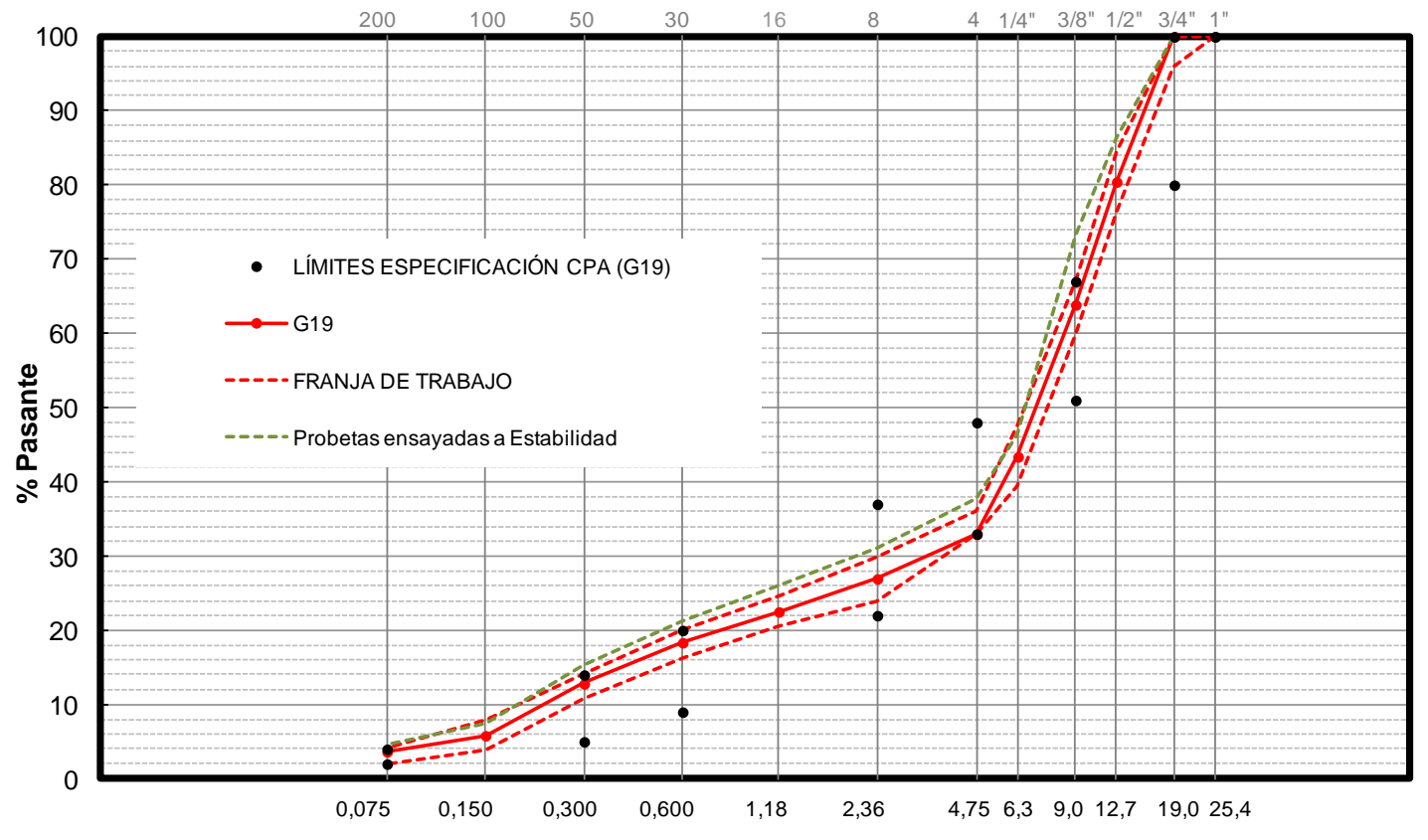

Abertura de tamiz $[\mathrm{mm}]$

Figura 6.12: III-G19: Granulometrías originales y recuperadas.

En las figuras 6.11 y 6.12 se presentan las curvas resultantes de la recuperación por lavado de las mezclas. Se observa que las granulometrías se encuentran muy próximas al límite superior de la franja de trabajo. Puede ser necesario definir nuevas tolerancias para la utilización de materiales de esta 
naturaleza en mezclas para caminos de tránsito medio a bajo, que es donde la bibliografía indica la factibilidad del uso de AR.

El ensayo de rueda cargada [BS-598] tiene como finalidad evaluar la resistencia a la deformación plástica de las mezclas bituminosas. Teniendo en cuenta que la normativa de la CPA sólo exige este ensayo para capas de rodadura, se realizó para la mezcla III-D19. Se moldearon probetas de $300 \mathrm{~mm}$ x $300 \mathrm{~mm}$ x $50 \mathrm{~mm}$ utilizando el compactador de rodillo. La densidad de compactación fue de $2,336 \mathrm{~g} / \mathrm{cm}^{3}$, correspondiente a la densidad de diseño. Posteriormente fueron sometidas al ensayo de rueda cargada (WTT) a $60{ }^{\circ} \mathrm{C}$.

Los parámetros obtenidos en el WTT son la pendiente de la curva en los últimos 15 minutos del ensayo (velocidad de deformación) y la correspondiente estabilidad dinámica, que es la cantidad de pasadas necesarias para lograr 1 $\mathrm{mm}$ de huella. En la figura 6.13 se grafica la curva de Profundidad de Huella vs Tiempo representativa de este ensayo.

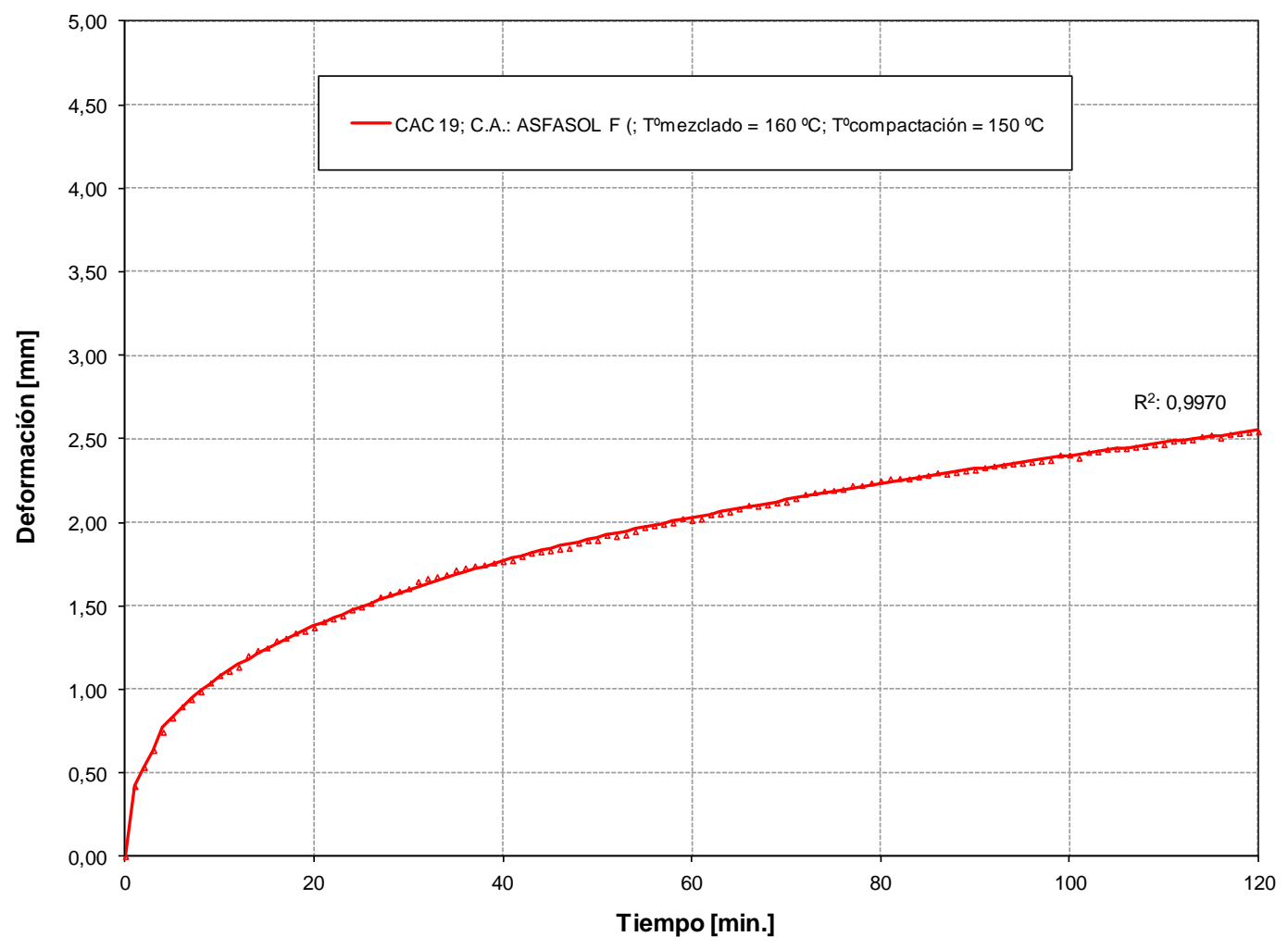

Figura 6.13: Curva de profundidad de huella en el ensayo de WTT. 
En la tabla 6.10 se indican los resultados obtenidos de la figura 6.13 . Se observa que no se cumplen los valores mínimos recomendados por el LEMIT para que una mezcla diseñada para volúmenes de tránsito normal a alto presente buen comportamiento frente a las deformaciones plásticas (Ahuellamiento).

Tabla 6.10: Parámetros de ahuellamiento en la mezcla III-D19.

\begin{tabular}{|c|c|c|c|c|}
\hline & \multicolumn{2}{|c|}{ Valores Medios } & \multicolumn{2}{|c|}{ Recomendaciones LEMIT } \\
\hline & $120 \mathrm{~min}$ & $60 \mathrm{~min}$ & $120 \mathrm{~min}$ & $60 \mathrm{~min}$ \\
\hline Profundidad de huella [mm] & 2,55 & 2,03 & - & - \\
\hline $\begin{array}{l}\text { Velocidad de Deformación } \\
\text { [mm/min] }\end{array}$ & 0,0073 & 0,0122 & $<0,0052$ & $<0,0093$ \\
\hline $\begin{array}{ll}\text { Estabilidad } & \text { Dinámica } \\
\text { [pasadas } / \mathrm{mm} \text { ] } & \end{array}$ & 5753 & 3430 & $>8000$ & $>4500$ \\
\hline
\end{tabular}

\section{6.- CONSIDERACIONES FINALES SOBRE LAS EXPERIENCIAS EN MEZCLAS ASFALTICAS}

En este capítulo se estudiaron alternativas para el aprovechamiento de agregados reciclados en mezclas asfálticas. Se analizaron tres series que incluyen mezclas asfálticas con distintos contenidos de AGR y AFR, variando también la energía de compactación. De los resultados obtenidos surgen las siguientes conclusiones:

1. EI AGR no se puede utilizar en su totalidad debido al desgaste que sufre en la fase de mezclado y compactación. Esto implica que se necesiten AGN en porcentajes superiores al $70 \%$ de la totalidad de AG, lo que limita el uso de AGR.

2. La degradación que sufren los $A R$ durante el proceso de diseño de las mezclas asfálticas para alto tránsito hace prever una degradación similar durante los procesos de fabricación, tendido, compactación y servicio. Esto limita el uso de AR en este tipo de pavimento, pudiendo ser objeto de estudio de pavimentos de bajo tránsito compactados con menor energía.

3. Las mezclas elaboradas con AFR y AGN resultaron poco flexibles, evaluadas con los parámetros convencionales para mezclas de alto tránsito exigido por las recomendaciones de la CPA. 
4. Las mezclas fabricadas con AFR presentan altos valores de módulo de rigidez.

5. Una alternativa para el uso de AFR es compactar con menor energía siguiendo las recomendaciones de la bibliografía internacional para mezclas de bajo tránsito.

6. Los valores obtenidos en el ensayo de Resistencia al Ahuellamiento, de Estabilidad Dinámica de 5753 pasadas/minutos no cumplen para tránsito medio a alto.

\section{7.- RECOMENDACIONES}

De acuerdo a lo expuesto puede decirse que es factible la fabricación de mezclas asfálticas con árido reciclado en carreteras de bajo tránsito. Al respecto se presenta una serie de recomendaciones para alcanzar resultados más favorables en el futuro.

1. Considerar que puede ser beneficioso el uso de asfaltos menos consistentes (CA-20, CA-10 ó 70-100) en vez de CA-30, de uso mandatorio actualmente en Argentina y de ser necesario, incorporar los contenidos habituales de aditivos mejoradores de adherencia.

2. Evaluar el uso de menores energías de compactación acordes con el diseño de caminos de bajo tránsito. Se recomienda verificar la potencial degradación del material utilizando el compactador giratorio y el compactador de rodillo y su relación con el valor de desgaste Los Ángeles.

3. Construir tramos experimentales para hacer un seguimiento del comportamiento de mezclas con AFR durante los procesos constructivos y bajo cargas de tránsito. 


\section{Capítulo 7}

\section{BASE GRANULAR CON}

AGREGADOS RECICLADOS

\section{1.- INTRODUCCION}

Una de las primeras posibilidades exploradas para el aprovechamiento de los agregados procedentes de la demolición de losas de pavimentos fue la ejecución de terraplenes, rellenos y agregados para gaviones, sin embargo se encontró que existen otros usos que aprovechan mucho mejor las propiedades de este material. Una de las alternativas de uso de los agregados reciclados en el campo de la vialidad es la conformación de capas granulares (CEDEX, 2007).

Este capítulo trata el estudio de una base granular que incorpora áridos reciclados. La base granular fue elaborada con la totalidad de AR, utilizando las dos fracciones gruesas y la fracción fina que fueran obtenidas de la trituración de las losas combinadas con un suelo seleccionado.

El análisis realizado incluye la caracterización del suelo seleccionado, la composición granulométrica de los materiales de forma tal que cumpla las especificaciones vigentes, y la determinación del contenido de humedad óptimo para la compactación del material y del valor soporte. 


\section{2.- MATERIALES Y MEZCLAS}

Para la elaboración de la base granular se emplearon las dos fracciones gruesas obtenidas de la trituración de losas (R38 y R19), el agregado fino procedente de la misma trituración (R0-6) y un suelo seleccionado proporcionado por el laboratorio de suelos de la Dirección de Vialidad de la Provincia de Buenos Aires.

El PETG-DNV prevé el aporte de suelo para aportar cohesión a los estabilizados granulométricos e indica que dicho suelo debe corresponder a un suelo seleccionado y homogéneo. Si bien el porcentaje de suelo utilizado es del $5 \%$ en peso, se ha verificado igualmente que resulta apropiado realizar los ensayos requeridos en la norma VN-E4-84 para clasificarlo según H.R.B. (Highway Research Board). En la tabla 7.1 se muestran las propiedades del suelo, que se caracteriza como un suelo tipo A4.

Tabla 7.1: Propiedades del suelo empleado para la elaboración de la base granular.

\begin{tabular}{|l|c|c|}
\hline \multicolumn{1}{|c|}{ Propiedad } & Valor medio & Límites para suelo tipo A4 \\
\hline Pasa tamiz IRAM № 200 [\%] & 84 & Min. 36\% \\
\hline Límite Líquido [\%] & 34 & Max. 40\% \\
\hline Límite Plástico [\%] & 25 & \\
\hline Índice de Plasticidad [\%] & 9 & Max. 10\% \\
\hline Índice de Grupo & 8 & \\
\hline
\end{tabular}

Se realizó la composición granulométrica de los AR con el suelo a fin de obtener una curva resultante dentro de los límites impuestos en la Sección C.II.2.3 del PETG de la DNV, correspondiente a Bases y Subbases de agregados pétreos y suelo. En la tabla 7.2 se muestra la dosificación elegida para la conformación de la base y en la tabla 7.3 se exponen las granulometrías de cada uno de los materiales por separado y la resultante.

Tabla 7.2: Composición de la base granular.

\begin{tabular}{|c|c|}
\hline Material & $\begin{array}{c}\text { Peso } \\
\%\end{array}$ \\
\hline R38 & 40 \\
R19 & 20 \\
AFR & 35 \\
Suelo & 5 \\
\hline
\end{tabular}


Tabla 7.3: Granulometría de los distintos materiales y la resultante para elaborar una base granular.

\begin{tabular}{|c|c|c|c|c|c|}
\hline TAMIZ & $\mathbf{R 3 8}$ & $\mathbf{R 1 9}$ & $\mathbf{R 0 - 6}$ & Suelo & $\begin{array}{c}\text { Granulometría } \\
\text { Resultante }\end{array}$ \\
\hline 1" & 100,0 & 100,0 & 100,0 & 100,0 & 100,0 \\
\hline 3/4" & 65,3 & 100,0 & 100,0 & 100,0 & 86,1 \\
\hline 1/2" & 39,7 & 85,8 & 100,0 & 100,0 & 73,1 \\
\hline 3/8" & 17,5 & 61,9 & 100,0 & 100,0 & 59,4 \\
\hline № 4 & 2,6 & 1,8 & 99,3 & 100,0 & 41,1 \\
\hline № 10 & & & 62,6 & 99,9 & 26,9 \\
\hline № 40 & & & 24,6 & 97,6 & 13,5 \\
\hline № 100 & & & 11,2 & 91,2 & 8,5 \\
\hline № 200 & & & 7,3 & 84,7 & 6,8 \\
\hline
\end{tabular}

En la figura 7.1 se presenta la curva granulométrica resultante y los límites previstos en el PETG-DNV.

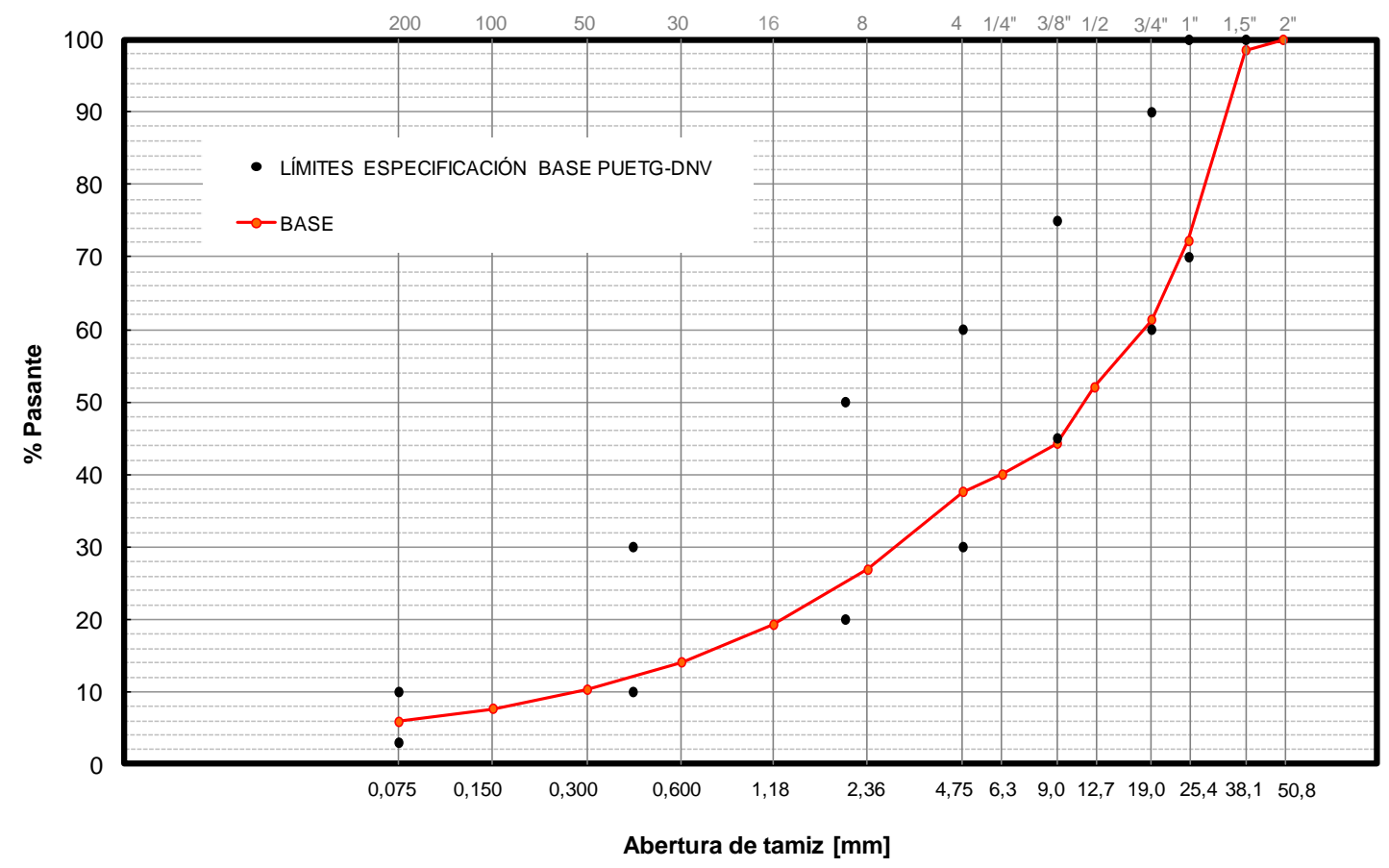

Figura 7.1: Granulometría de la base granular con AR.

Una vez definida la curva granulométrica se realizó el ensayo de compactación Proctor Modificado [VN-E5-93]. El ensayo consiste en determinar los Pesos por Unidad de Volumen Seco (P.U.V.S.) de muestras compactadas con diferentes contenidos de humedad a fin de definir el P.U.V.S.máx del material en estudio y el correspondiente contenido de humedad con que se logra. 
En un molde Proctor de $15 \mathrm{~cm}$ de diámetro se coloca el material en 5 capas, aplicando en cada capa una energía de compactación de 56 golpes. Debido al tamaño del molde, debe corregirse la granulometría original mediante el reemplazo del material de tamaño superior a $19 \mathrm{~mm}$ compensándolo por un mismo peso de material comprendido entre los tamices $19 \mathrm{~mm}$ (3/4") y 4,75 mm (№ 4) que reproduzca la granulometría de esta fracción del material original [VN-E5-93].

El material así corregido es separado por cuarteo en porciones a las que se le agregarán distintos contenidos de agua de manera de definir por lo menos 5 puntos de la curva de densificación Proctor, tres en la parte seca de la curva y dos en la parte húmeda.

La figura 7.2 muestra dicha curva de Densificación Proctor. En la misma se ha señalado la condición de humedad para la que se obtiene el P.U.V.S. máx. Para este caso la humedad óptima fue $8,2 \%$ y el P.U.V.S $S_{\text {máx }} 1,906 \mathrm{~g} / \mathrm{cm}^{3}$. Se destaca que la humedad óptima encontrada en la base granular con agregados reciclados es mucho mayor que la encontrada con materiales naturales, debido a la mayor absorción que presentan los AR.

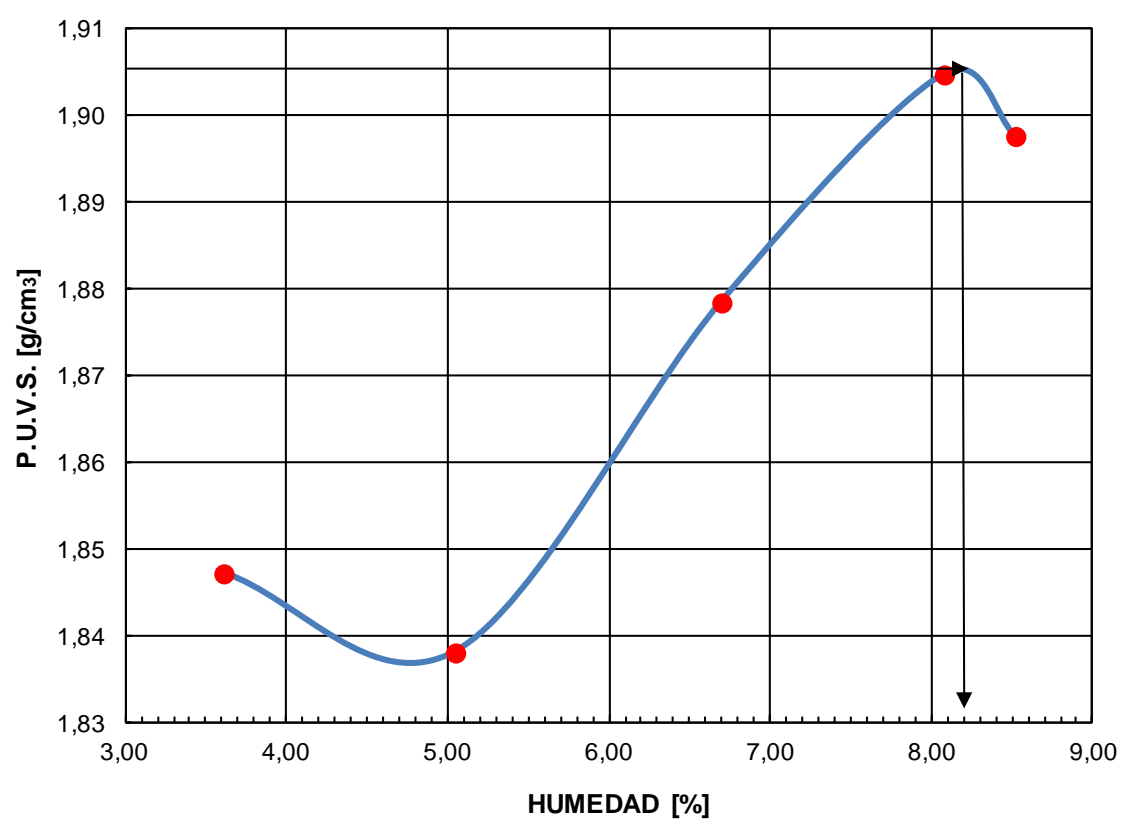

Figura 7.2: Obtención de las condiciones óptimas de compactación.

En el capítulo anterior fue constatado que el material reciclado presenta cambios importantes en su granulometría luego del proceso de compactación. 
Para evaluar la potencial degradación del material se realizaron granulometrías sobre el material recuperado luego del ensayo Proctor. En la figura 7.3 se presentan las curvas granulométricas con distintos porcentajes de humedad, donde se observan importantes variaciones respecto de la granulometría del material corregido. Es importante destacar que si bien el material estuvo sometido en todos los casos a la misma energía de compactación, a mayor humedad de moldeo se observó menor degradación.

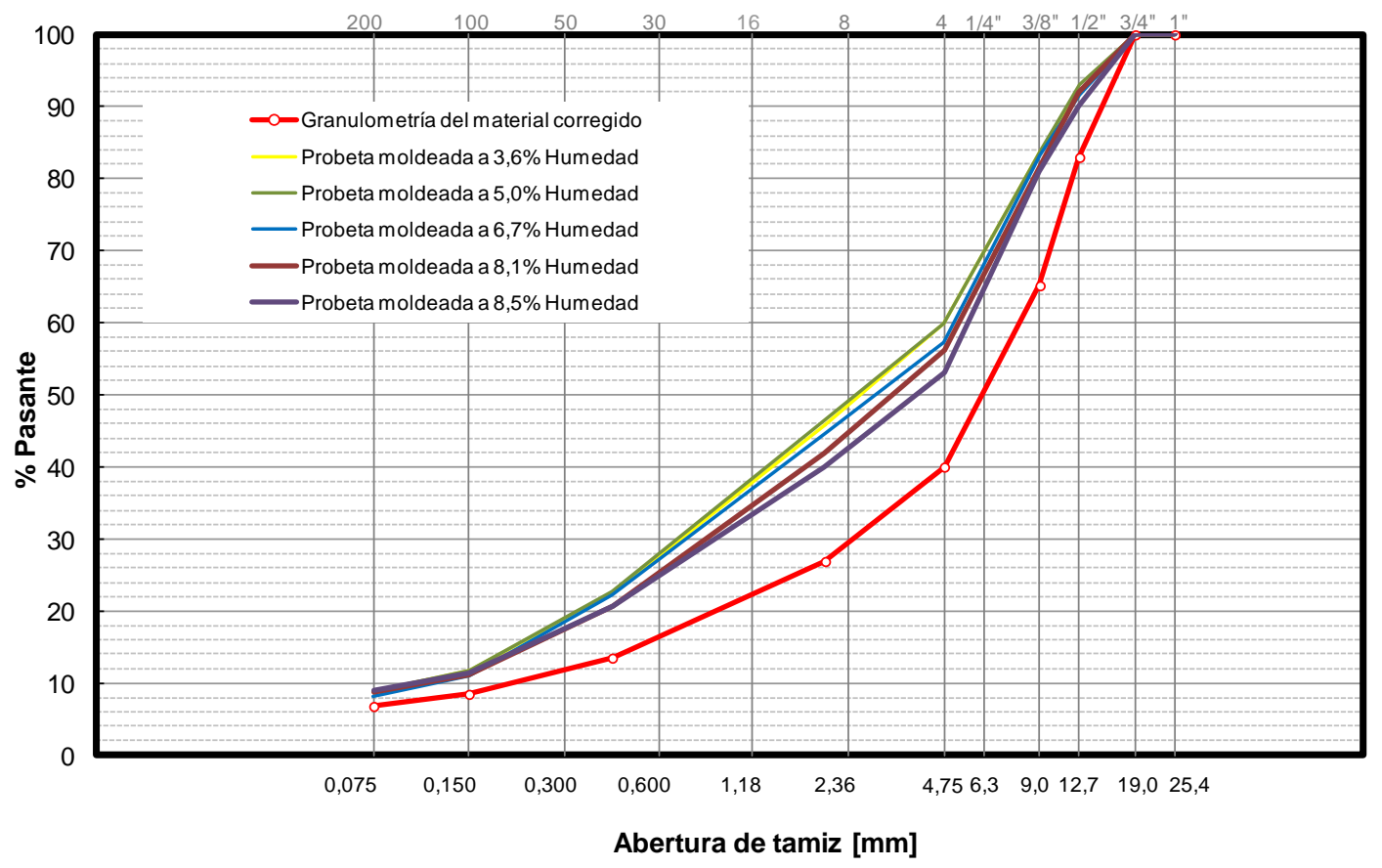

Figura 7.3: Degradación de los agregados reciclados después del ensayo Proctor.

Una vez determinadas las condiciones óptimas de compactación se moldearon probetas para la determinación del Valor Soporte (CBR). EI PETG indica que el Valor Soporte de una base granular deberá obtenerse mediante el Método Dinámico Simplificado №1 de la norma VN-E6 y deberá alcanzar un valor mínimo de 80 \% para el material compactado al $97 \%$ de su P.U.V.S.máx.

Se moldearon seis probetas con el contenido de humedad óptimo colocando el material húmedo en 5 capas, variando el número de golpes (G) por capa: dos probetas con 56 golpes en cada capa, otras dos con 25 golpes en cada capa y las dos restantes con 12 golpes por capa. Las probetas fueron separadas para los ensayos de CBR en estado seco y en estado embebido. 
Las probetas en condición seca se ensayaron inmediatamente a penetración para determinar el valor soporte. Las probetas utilizadas para obtener el CBR en estado embebido fueron sumergidas en agua durante cuatro días, midiendo todos los días el hinchamiento mediante un extensómetro mecánico dispuesto sobre un trípode (Ver figura 7.4). El valor obtenido al cuarto día es el hinchamiento total. En ninguna de las probetas sumergidas hubo variaciones de lectura significativas, lo que indica que la base diseñada con estos materiales reciclados no sufrió cambios de volumen ante la presencia de agua.
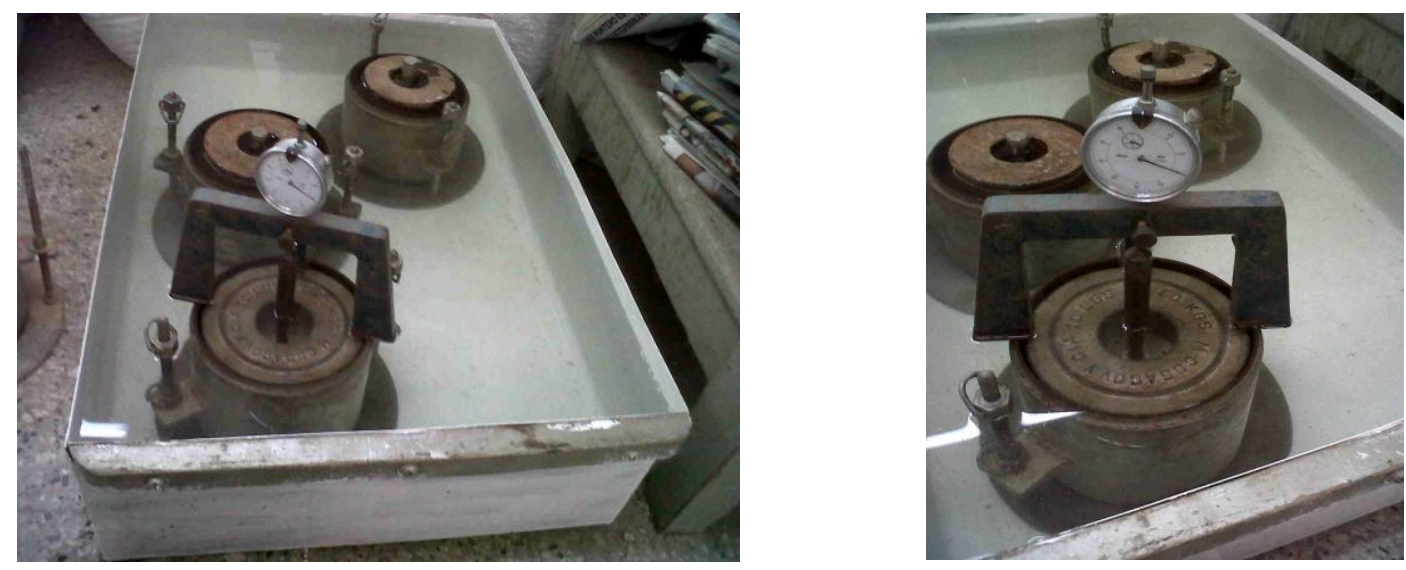

Figura 7.4: Hinchamiento de las probetas sumergidas en agua.

Una vez transcurridos los cuatro días de inmersión en agua las probetas fueron escurridas y sometidas inmediatamente a penetración para determinar su CBR.

En la figura 7.5 se muestran los resultados de Presión vs Penetración de las probetas ensayadas, en la misma se aprecia el efecto que tiene la saturación de la base en el CBR. Las probetas se identifican conforme el número de golpes aplicado (56, 25 o 12 golpes) agregando s/emb en los casos en que se ensayaron en condición seca. Puede observarse que las probetas embebidas sometidas a 56 y 25 golpes requirieron mayores presiones de penetración que las probetas compactadas con igual energía de compactación ensayadas en estado seco. 


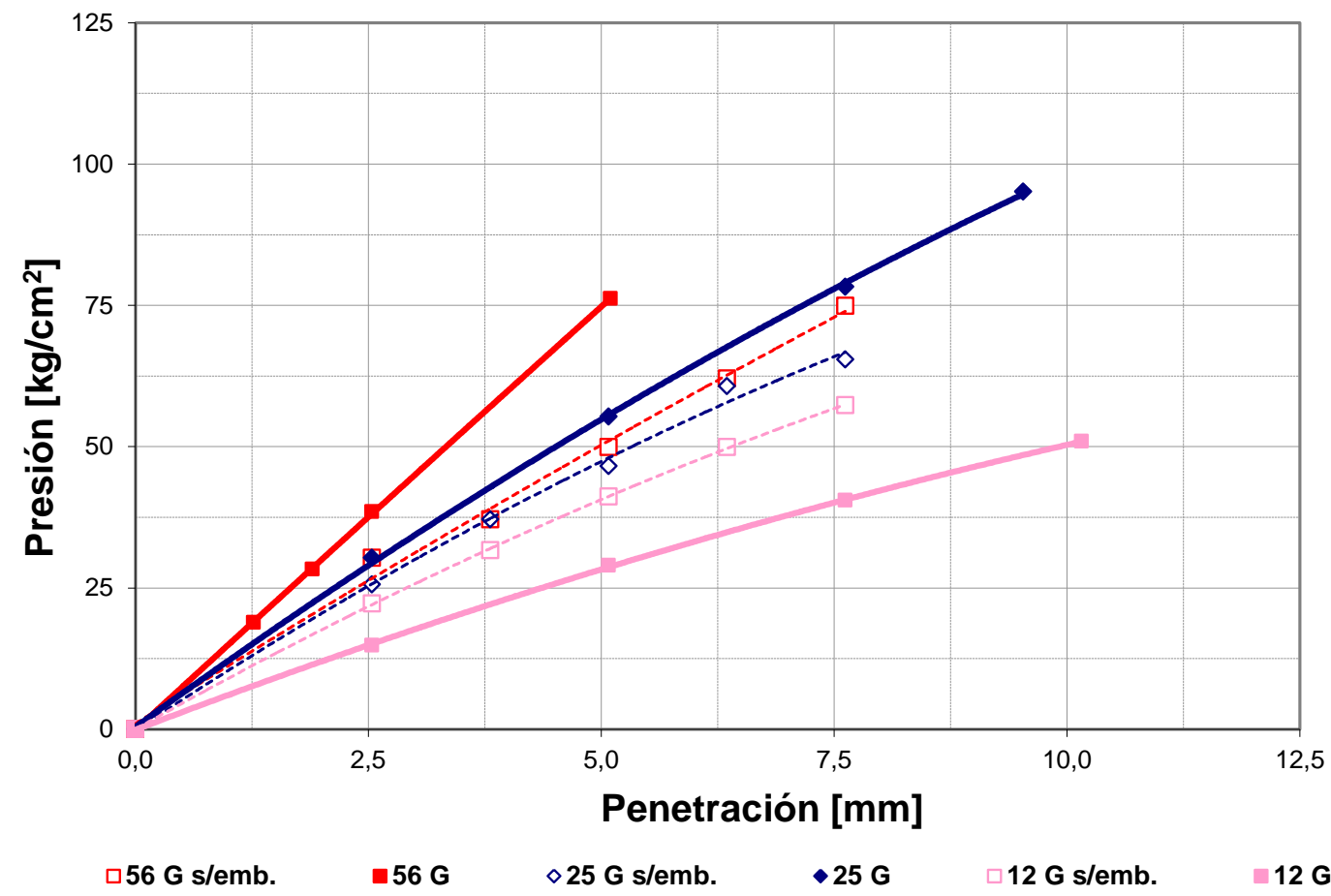

Figura 7.5: Ensayos de Valor Soporte (CBR) sobre probetas de base granular.

La bibliografía (CEDEX, 2011) asocia este efecto a reacciones de compuestos no hidratados presentes en el agregado fino provenientes del cemento portland del hormigón reciclado, los que en presencia de agua a temperatura ambiente adquieren propiedades hidráulicas.

En la figura 7.6 se presenta la relación entre el P.U.V. seco y los resultados de CBR para los estados seco y embebido. Ingresando en el gráfico con el valor del $97 \%$ del P.U.V.S.máx (Proctor), es decir $1,849 \mathrm{~g} / \mathrm{cm}^{3}$, surge un CBR de $56 \%$ para el estado embebido y de $47 \%$ para el estado seco. En este caso correspondería usar para el diseño la condición más desfavorable, es decir CBR en estado seco, sin tener en cuenta la aparente cementación. 


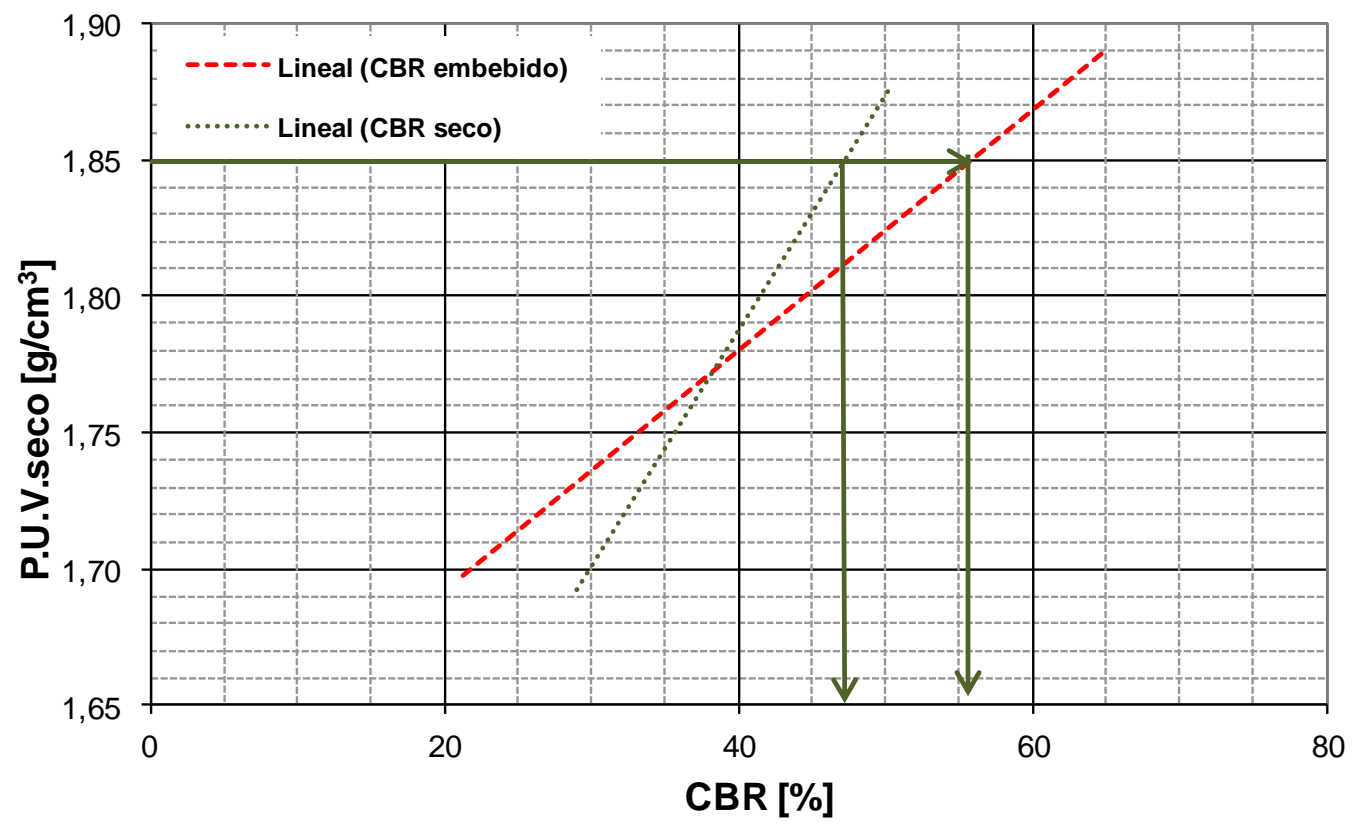

Figura 7.6: P.U.V. seco vs CBR.

En la tabla 7.4 se presentan los requisitos exigidos por el PETG-DNV para la construcción de bases. Se observa que el estabilizado granulométrico diseñado no alcanza el valor mínimo de CBR requerido en ninguno de los dos estados (embebido o seco).

Tabla 7.4: Valores obtenidos y requisitos de DNV para bases de pavimento.

\begin{tabular}{|l|c|c|}
\hline \multicolumn{1}{|c|}{ Parámetros } & Valores medidos & $\begin{array}{c}\text { Requisitos para BASES } \\
\text { PETG-DNV }\end{array}$ \\
\hline Límite Líquido (\%) & 20 & $<$ de 25 \\
Índice Plástico & 0 & $<$ de 4 \\
CBR (\%) & 47 & $>$ de 80 \\
\hline
\end{tabular}

En la figura 7.7, se compara la dosificación estudiada para la base con los límites para subbases del PETG-DNV. Se observa que se requiere un pequeño cambio en la dosificación de los materiales evaluados para cumplir con los límites granulométricos de una subbase, para la cual podrían cumplirse los requerimientos de CBR mínimo de $40 \%$. 


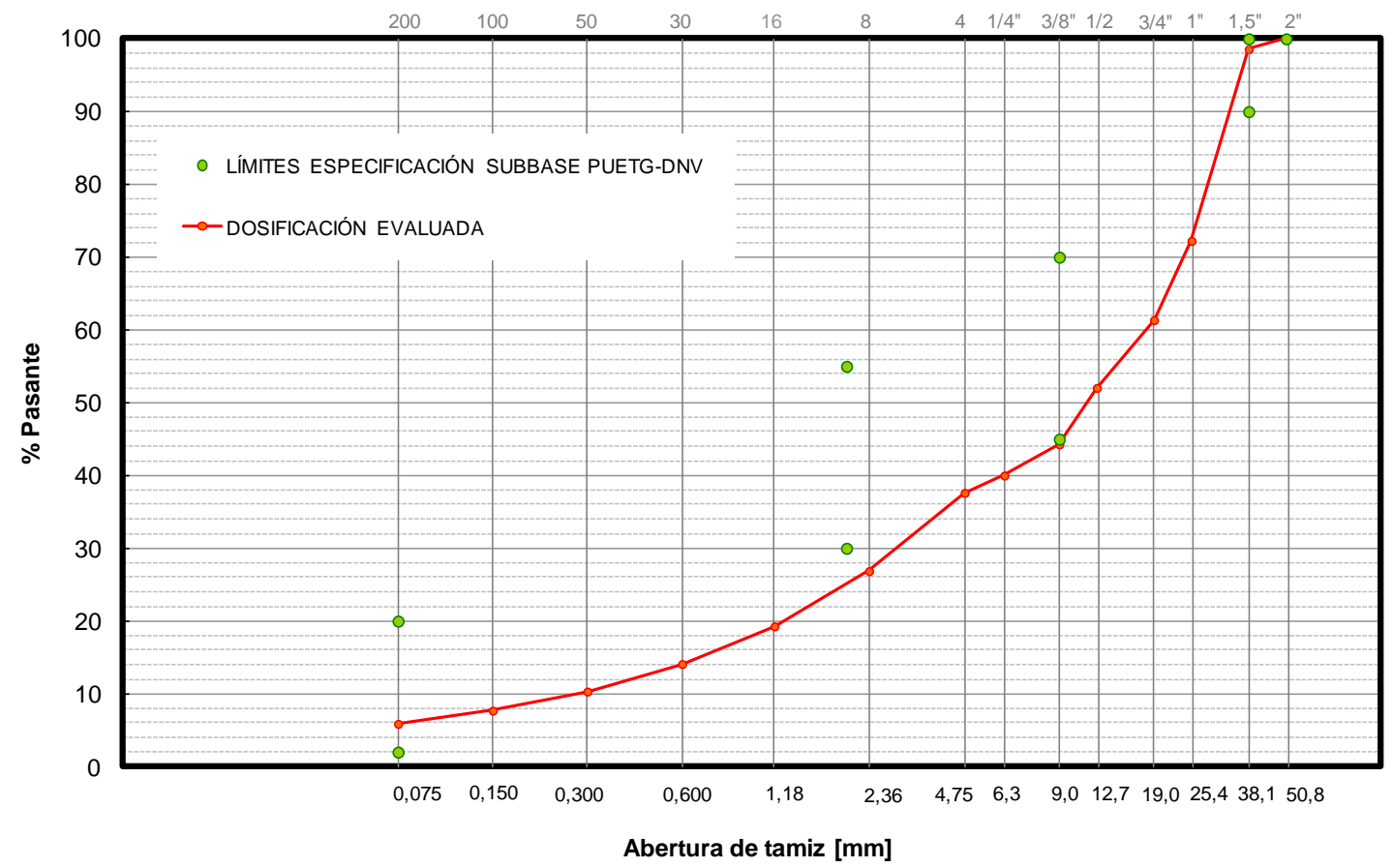

Figura 7.7: Granulometría de una subbase granular con AR.

\section{3.- CONSIDERACIONES FINALES}

De la evaluación técnica presentada en este capítulo para el posible uso de agregados reciclados proveniente del hormigón (AR) como material para la elaboración de bases granulares para carreteras, surge que:

1. Los AR cumplen con las requisitos granulométricos establecidos en el PETG de la DNV para agregados a utilizar en capas granulares estructurales (subbases y bases).

2. En el ensayo Proctor modificado, el estabilizado con agregados reciclados presenta menor Peso por Unidad de Volumen Seco máximo (P.U.V.S.máx) y mayor contenido de humedad óptima que los elaborados con agregados naturales de trituración. Esto se atribuye a la menor densidad y mayor absorción de los agregados reciclados.

3. Las probetas que fueron sumergidas en agua por cuatro días presentan mayor valor CBR que las ensayadas en estado seco y no sufrieron cambios de volumen ante la presencia de agua. 
4. El Valor Soporte de la base granular obtenido con AR no cumple con el valor mínimo exigido para bases (> $80 \%$ ), por lo que la alternativa es emplear los AR para la construcción de subbases granulares. 


\section{Capítulo 8}

\section{ANALISIS DE COSTOS}

\section{1.- INTRODUCCION}

En la construcción de carreteras se utiliza gran cantidad de materiales que deben ofrecer ciertas prestaciones para la elaboración de terraplenes, subbases, bases y capas de rodadura. Mientras que las capas superiores de la sección han de ser más resistentes a la flexión, la misión de las capas inferiores consiste, simplemente, en transmitir esfuerzos de compresión. Debido a ello, los requerimientos de los materiales utilizados en estas últimas capas no son tan exigentes y es factible el uso de materiales reciclados en su totalidad mientras en las capas de rodadura sólo se permite un cierto porcentaje de este material.

Los costos de construcción se componen de costos directos y costos indirectos. Los costos directos son aquellos que quedan insumidos en una obra y están dados por la suma de los costos parciales de todos sus componentes: materiales, equipos, herramientas y mano de obra. En cambio los costos indirectos son aquellos que no pueden aplicarse a una partida específica y tienen incidencia sobre toda la obra. Están compuestos por los gastos generales y las utilidades. Los gastos generales son aquellos que debe efectuar el contratista durante la construcción derivado de la propia actividad empresarial. Las utilidades representan el monto que percibe el contratista por ejecutar la obra.

La construcción de una obra vial en países en vías de desarrollo como la Argentina depende muchas veces del costo de ejecución. Este costo está 
influenciado claramente por los componentes directos debido a que los materiales y el transporte de los insumos generalmente representan entre un 40 y un $60 \%$ de los costos directos (Costo-Costo).

La mayoría de los proyectos de infraestructura de carreteras provocan impactos ambientales significativos. Los más importantes relacionados a este tipo de construcción son aquellos que corresponden a la pérdida de la capa vegetal, su exclusión para otros usos para la tierra, deforestación, alteración del paisaje, modificación de patrones naturales de drenaje; cambios en la elevación de las aguas subterráneas, entre otros, debidos a la explotación de materiales naturales en las canteras, la instalación de campamentos y áreas de almacenamiento de materiales. Adicionalmente, los proyectos pueden generar impactos ambientales y socioculturales adversos tanto durante la construcción como por actividades de mantenimiento en proyectos de gran envergadura se puede sumar la presencia de mano de obra no residente.

En este capítulo se realiza una comparación de costos que permite reflexionar acerca de las alternativas de disposición y aprovechamiento de las distintas fracciones de agregados obtenidas de pavimentos reciclados en obras viales. Entre ellas se contemplan pavimentos de hormigón de diferentes resistencias para capas de rodamiento o para bases, bases asfálticas y subbases granulares. Entre los costos se contemplan la fabricación, tendido y compactación de las diferentes capas de pavimento y se comparan los valores con los que surge del uso exclusivo de agregados naturales. Sin embargo, a pesar de lo expuesto anteriormente, sólo se limitará el análisis al costo del material en sí mismo y no se contemplarán dentro del costo los beneficios que podrían resultar de los impactos ambientales positivos que genere el uso de agregados reciclados, ya que dicha valoración excede el alcance de la presente tesis.

\section{2.- ANALISIS DE PRECIOS}

Los precios de los materiales, mano de obra como las tarifas de transporte fueron proporcionados por el Departamento de Estudios y Proyecto de la DVPBA. El estudio a realizar compara costos directos reemplazando cierta proporción de agregados naturales por agregados reciclados. 


\subsection{1.- Datos de referencia}

Los costos de materiales utlizados para el análisis de costos se muestran en la tabla 8.1. Las diferentes columnas (col.) para obtener el costo del material (incluido pérdidas) están compuestas por:

- Columna 1: los diferentes materiales a utilizar,

- Columna 2: la unidad con la que se comercializa cada material,

- Columna 3: costo por unidad de cada material vigentes para finales del 2011 (sin impuestos IVA),

- Columna 4: refiere a las pérdidas existentes en obra,

- Columna 5: se refiere al costo unitario de las perdidas,

- Columna 6: es el costo por unidad de cada material incluyendo las pérdidas.

En la tabla 8.2 se observan los costos generales relacionados con la Mano de Obra. Las diferentes columnas están compuestas por:

- Columna 1: constan las diferentes categorias de mano de obra,

- Columna 2: se refiere al salario por hora vigente desde 31/03/2011,

- Columna 3: premios por asistencia completa por quincena, siendo el 20 $\%$ del salario por hora;

- Columna 4: muestra el Jornal directo (incluye salario y premios por asistencia),

- Columna 5: trata las Mejoras Sociales del empleado, siendo este para el sector de la construccion del $70 \%$,

- Columna 6: destinada para el Seguro obrero donde el empleado aporta de su sueldo el $9,5 \%$ y el empleador el $14,5 \%$,

- Columna 7: es el Jornal Total (suma de costo del jornal directo, mejoras sociales y seguro obrero),

- Columna 8: trata del aumento por tiempo extra que se deberá pagar al trabajador pasadas las 44 horas de trabajo semanales exigido por ley,

- Columna 9: es el costo total por hora de cada categoria. 
Tabla 8.1: Planilla General de costos de Materiales.

\begin{tabular}{|c|c|c|c|c|c|}
\hline Designación & $\mathrm{U}$. & $\begin{array}{c}\begin{array}{c}\text { Costo por } \\
\text { unidad }\end{array} \\
\$\end{array}$ & $\%$ & $\begin{array}{c}\text { Costo } \\
\text { unitario de } \\
\text { las pérdidas } \\
\$\end{array}$ & $\begin{array}{c}\text { Costo por } \\
\text { unidad } \\
\text { incluido } \\
\text { pérdidas }\end{array}$ \\
\hline 1 & 2 & 3 & 4 & $5=3 * 4$ & $6=3+5$ \\
\hline Aditivos para hormigón & $\mathrm{kg}$ & 11,10 & 0,03 & 0,33 & 11,43 \\
\hline Acero ADN 420 s/pliego & tn & $5.953,30$ & 0,03 & 178,60 & $6.131,90$ \\
\hline Acero AL 220 Ф 32mm & tn & $5.661,25$ & 0,03 & 169,84 & $5.831,09$ \\
\hline Arena de trituración & tn & 18,00 & 0,05 & 0,90 & 18,90 \\
\hline Arena fina (Capital) & tn & 68,00 & 0,05 & 3,40 & 71,40 \\
\hline Arena silícea p/hormigón & tn & 68,80 & 0,05 & 3,44 & 72,24 \\
\hline Material p/tomado juntas s/pliego & $\mathrm{kg}$ & 250,00 & 0,05 & 12,50 & 262,50 \\
\hline Cal hidráulica hidratada & tn & 301,20 & 0,05 & 15,06 & 316,26 \\
\hline Cemento portland granel & tn & 388,35 & 0,05 & 19,42 & 407,77 \\
\hline Cemento asfáltico $70-100$ o 50-60 & tn & $1.904,60$ & 0,05 & 95,23 & $1.999,83$ \\
\hline Riego asfáltico de liga & It & 1,50 & 0,03 & 0,05 & 1,55 \\
\hline Riego asfáltico p/imprimación & It & 3,00 & 0,03 & 0,09 & 3,09 \\
\hline Membrana de curado p/hormigón & $\mathrm{kg}$ & 15,83 & 0,03 & 0,47 & 16,31 \\
\hline Piedra cuarcítica 10-30 o 6-20 mm & tn & 40,00 & 0,05 & 2,00 & 42,00 \\
\hline Piedra partida $10-30 \circ 6-20 \mathrm{~mm}$ & tn & 56,10 & 0,05 & 2,81 & 58,91 \\
\hline Piedra reciclada $10-30$ o 6-20 mm & tn & 10,50 & 0,05 & 0,53 & 11,03 \\
\hline Arena fina reciclada & tn & 10,50 & 0,05 & 0,53 & 11,03 \\
\hline Suelo seleccionado & $\mathrm{m}^{3}$ & 9,45 & 0,05 & 0,47 & 9,92 \\
\hline
\end{tabular}


Tabla 8.2: Planilla General de costo de Mano de Obra.

\begin{tabular}{|l|c|c|c|c|c|c|c|c|}
\hline \multicolumn{1}{|c|}{ Categoría } & Salario & $\begin{array}{c}\text { Premio } \\
\text { por } \\
\text { asistencia } \\
20 \% \times 2\end{array}$ & $\begin{array}{c}\text { Jornal } \\
\text { directo }\end{array}$ & $\begin{array}{c}\text { Mejoras } \\
\text { sociales }\end{array}$ & $\begin{array}{c}\text { Seguro } \\
\text { obrero }\end{array}$ & $\begin{array}{c}\text { Jornal } \\
\text { Total }\end{array}$ & $\begin{array}{c}\text { Otros } \\
70 \% \times 4\end{array}$ & $\begin{array}{c}\text { Costo } \\
\text { Unidad } \\
\text { Hora }\end{array}$ \\
\hline 1 & 2 & 3 & 4 & 5 & 6 & $7+5+6$ & $50 \%$ & 8 \\
\hline $\begin{array}{l}\text { Oficial } \\
\text { especializado }\end{array}$ & 17,88 & 3,58 & 21,46 & 15,02 & 1,35 & 37,83 & 18,91 & 56,74 \\
Oficial & 15,23 & 3,05 & 18,28 & 12,79 & 1,15 & 32,22 & 6,11 & 48,33 \\
Medio Oficial & 14,02 & 2,80 & 16,82 & 11,78 & 1,06 & 29,66 & 4,83 & 44,49 \\
Ayudante & 12,89 & 2,58 & 15,47 & 10,83 & 0,97 & 27,27 & 3,64 & 40,91 \\
\hline
\end{tabular}

En la tabla 8.3 se observa los costos generales relacionados con el Transporte de los insumos de construcción. Las diferentes columnas de la tabla 8.3 indican:

- Columna 1: los distintos materiales a utilizar,

- Columna 2: la unidad de transporte,

- Columna 3: la distancia existente entre el obrador y la cantera o lugar de venta del material,

- Columna 4: muestra el costo unitario de transporte por kilómetro recorrido (\$/u.km),

- Columna 5: se refiere a las pérdidas de material durante el transporte,

- Columna 6: consta el costo unitario de pérdidas por unidad,

- Columna 7: presenta los valores unitarios de transporte incluido pérdidas (sumatoria de los costos unitario de transporte y los costos unitario de las pérdidas),

- Columna 8: expone el costo de transporte a obra incluyendo pérdidas. 
Tabla 8.3: Planilla General de costo de Transporte de materiales.

\begin{tabular}{|c|c|c|c|c|c|c|c|}
\hline Tipo de Material & & Dist. & $\begin{array}{c}\text { Costo } \\
\text { Unitario }\end{array}$ & $\begin{array}{c}\text { Pérdidas } \\
\%\end{array}$ & $\begin{array}{c}\text { Costo } \\
\text { unit. de } \\
\text { las } \\
\text { pérdidas } \\
\$ / \text { u.km }\end{array}$ & $\begin{array}{c}\text { Costo } \\
\text { unitario } \\
\text { transp. } \\
\text { Incl. } \\
\text { pérdidas } \\
\$ / \mathrm{u} . \mathrm{km}\end{array}$ & $\begin{array}{c}\text { Costo } \\
\text { transporte } \\
\text { a obra } \\
\$ / u\end{array}$ \\
\hline 1 & 2 & 3 & 4 & 5 & $6=4 * 5$ & $7=4+6$ & $8=3^{*} 7$ \\
\hline Acero en barras & tn & 60 & 0,3500 & 0,03 & 0,3800 & 0,7300 & 43,80 \\
\hline Arena de trituración & tn & 320 & 0,1600 & 0,03 & 0,1900 & 0,3500 & 112,00 \\
\hline Arena fina & tn & 60 & 0,3500 & 0,03 & 0,3800 & 0,7300 & 43,80 \\
\hline Cal hidráulica & tn & 320 & 0,1600 & 0,03 & 0,1900 & 0,3500 & 112,00 \\
\hline Cemento portland & tn & 320 & 0,1600 & 0,05 & 0,2100 & 0,3700 & 118,40 \\
\hline $\begin{array}{l}\text { Cemento asfáltico } \\
70-100 \text { o } 50-60\end{array}$ & tn & 40 & 0,4340 & 0,03 & 0,4640 & 0,8980 & 35,92 \\
\hline Suelo seleccionado & $\mathrm{m}^{3}$ & 30 & 0,3700 & 0,03 & 0,4000 & 0,7700 & 23,10 \\
\hline $\begin{array}{l}\text { Piedra } \\
\text { granítica }\end{array}$ & tn & 320 & 0,1600 & 0,03 & 0,1900 & 0,3500 & 112,00 \\
\hline
\end{tabular}

\subsection{2.- Análisis comparativo de precios unitarios para diferentes aplicaciones}

Con el fin de valorar el impacto económico que generaría el uso de agregados reciclados en obras viales, se seleccionaron los siguientes casos:

1. Subbase de estabilizado granulométrico con AN y AR (espesor $0,20 \mathrm{~m}$ ),

2. Pavimento de hormigón simple tipo $\mathrm{H} 13$ con AN y AR (espesor $0,20 \mathrm{~m}$ ),

3. Pavimento de hormigón simple tipo H30 con AN y AR (espesor 0,25 m),

4. Base Asfáltica incluyendo riego de liga con AFN y AFR (espesor 0,10 m).

El empleo de AR en subbases granulares y pavimentos de hormigón simple tipo $\mathrm{H} 13$ fueron aplicaciones seleccionadas en base a los resultados satisfactorios obtenidos en laboratorio y por los antecedentes obrantes en países desarrollados para la construcción de capas inferiores de pavimentos. Los casos de uso en pavimentos de hormigón simple tipo $\mathrm{H} 30$ y bases asfálticas se seleccionaron debido a que representan alternativas para capas de rodadura en diseños en los que se prevea tránsito medio y bajo. 
Para realizar el Análisis de Precio Unitario (APU) sobre Pavimentos de hormigón simple tipo H30 o H13 se reemplazó el AGN por el AGR según el diseño obtenido en el laboratorio. Considerando que con el hormigón H30R se obtuvo una resistencia menor a la obtenida con AN se decidió aumentar la cantidad de cemento en un $13 \%$ para compensar esta diferencia tal de realizar el estudio comparativo para la misma resistencia. A tal efecto se tomó como referencia el rendimiento de las mezclas (Resistencia/kg de cemento).

Referente al APU para mezclas asfálticas se remplazó el agregado fino granítico de trituración por AFR. Sabiendo que los datos obtenidos con un asfalto CA-30 no fueron los mejores, se tomaron como referencia los resultados obtenidos por Appolloni et al (2009) con un betún más blando (CA-20).

Para el análisis de costo de la subbase granular se remplazaron los agregados naturales, tanto la fracción fina como la gruesa, por agregados reciclados. En los APU se tomaron en cuenta los diferentes porcentajes de costos indirectos comúnmente utilizados.

Cabe comentar que el precio que se utilizó para el agregado reciclado tanto fino como grueso fue 11,03 \$ la tonelada y el mismo incluye la trituración de losas en planta fija de $180 \mathrm{HP}$ con un rendimiento de $50 \mathrm{tn} / \mathrm{h}$. Sin embargo, el rendimiento estará en función del espacio entre las mandíbulas de la trituradora empleada. Si se pretende obtener preferentemente AGR, lo experimentado en laboratorio indicó rendimientos de un $80 \%$ de material grueso (retenido tamiz 4,75 mm o № 4) y un $20 \%$ de material fino, lo cual concuerda con la bibliografía internacional. En el caso de desear obtener mayores fracciones de AFR es evidente que se tendrá que volver a triturar con equipos que tengan mandíbulas o conos menos espaciados, lo que modificará muy poco los costos.

Los precios finales obtenidos para cada caso se sintetizan en las tablas 8.4 a 8.11 . Las tablas 8.4 y 8.5 corresponden al caso 1, la construcción de una la Subbase Granular de 0,20 m de espesor con AR y AN respectivamente. Las diferencias en uno y otro caso se deben al costo de los materiales y al transporte de los mismos. El costo de los materiales se quintuplica diferenciando entre uno y otro agregado, en cambio el transporte de los 
materiales vírgenes incide directamente debido a que los AR se los obtiene de la misma obra mientras que los AN hay que transportarlos desde yacimientos muy alejados del Gran La Plata.

Para hacer más sencilla la comparación entre el uso de $A R$ y $A N$, en las tablas con AN no se realiza la discriminación dentro de los rubros en los cuales no existen cambios en costo. En general no existen cambios en los rubros mano de obra, mantenimiento, reparaciones e insumos para los equipos. 
Tabla 8.4: APU de la Subbase Granular con AR de espesor $=0,20 \mathrm{~m}\left(\mathrm{U}=\mathrm{m}^{2}\right)$.

Materiales

\begin{tabular}{|c|c|c|c|c|}
\hline Descripción & Unidad & Cuantía & Precio & Importe \\
\hline Suelo seleccionado & $m^{3}$ & 0,0185 & $9,92 \$$ & $0,18 \$$ \\
\hline Piedra partida reciclada 10-30 o 6-20 & tn & 0,3024 & $11,03 \$$ & $3,33 \$$ \\
\hline \multirow[t]{3}{*}{ Arena fina reciclada } & tn & 0,1617 & $11,03 \$$ & $1,78 \$$ \\
\hline & & \multicolumn{2}{|c|}{ SUMA PARCIAL } & $5,29 \$$ \\
\hline & & VARIOS & $5,00 \%$ & $0,26 \$$ \\
\hline Rendimiento: & & \multicolumn{2}{|c|}{ TOTAL MATERIALES } & $5,55 \$$ \\
\hline
\end{tabular}

Mano de obra

$100 \quad \mathrm{~m}^{2} / \mathrm{h}$

\begin{tabular}{lccrr}
\hline Categoría & Unidad & Cuantía & Precio & Importe \\
\hline Oficial especializado & $\mathrm{h}$ & 0,0600 & $56,74 \$$ & $3,40 \$$ \\
Oficial & $\mathrm{h}$ & 0,0200 & $48,33 \$$ & $0,97 \$$ \\
Medio Oficial & $\mathrm{h}$ & 0,0200 & $44,49 \$$ & $0,89 \$$ \\
Ayudante & $\mathrm{h}$ & 0,0100 & $40,91 \$$ & $0,41 \$$ \\
\hline
\end{tabular}

Transporte

\begin{tabular}{lccrr}
\hline Materiales & Unidad & Cuantía & Precio & Importe \\
\hline Suelo seleccionado & m3 & 0,019 & $23,10 \$$ & $0,43 \$$ \\
\hline & TOTAL TRANSPORTE & & $\mathbf{0 , 4 3 \$}$ \\
\hline
\end{tabular}

Equipos

Amortización e intereses

\begin{tabular}{|c|c|c|c|c|}
\hline Descripción & Unidad & Cuantía & Precio & Importe \\
\hline Motoniveladora C $120 \mathrm{H}$ & $\mathrm{h}$ & 0,0100 & $38,43 \$$ & $0,38 \$$ \\
\hline Comp. rodillo liso CAT 533 & $\mathrm{~h}$ & 0,0100 & $35,23 \$$ & $0,35 \$$ \\
\hline Cargador frontal CAT 966 & $\mathrm{~h}$ & 0,0100 & $64,05 \$$ & $0,64 \$$ \\
\hline Grupo electrógeno 250 KVA & $\mathrm{h}$ & 0,0100 & $16,01 \$$ & $0,16 \$$ \\
\hline Planta estabilizadora CIBER 100 ton/h & $\mathrm{h}$ & 0,0100 & $48,04 \$$ & $0,48 \$$ \\
\hline Camión volcador $6 \mathrm{~m}^{3}$ & $\mathrm{~h}$ & 0,0600 & $25,62 \$$ & $1,54 \$$ \\
\hline Camión regador agua & $\mathrm{h}$ & 0,0100 & $12,81 \$$ & $0,13 \$$ \\
\hline
\end{tabular}

Reparaciones y repuestos

\begin{tabular}{|c|c|c|c|c|}
\hline Descripción & Unidad & Cuantía & Precio & Importe \\
\hline Motoniveladora C $120 \mathrm{H}$ & $\mathrm{h}$ & 0,0100 & $30,74 \$$ & $0,31 \$$ \\
\hline Comp. rodillo liso CAT 533 & $\mathrm{~h}$ & 0,0100 & $28,18 \$$ & $0,28 \$$ \\
\hline Cargador frontal CAT 966 & $\mathrm{~h}$ & 0,0100 & $51,24 \$$ & $0,51 \$$ \\
\hline Grupo electrógeno 250 KVA & $\mathrm{h}$ & 0,0100 & $12,81 \$$ & $0,13 \$$ \\
\hline Planta estabilizadora CIBER 100 ton/h & $\mathrm{h}$ & 0.0100 & $38,43 \$$ & $0.38 \$$ \\
\hline Camión volcador $6 \mathrm{~m}^{3}$ & $\mathrm{~h}$ & 0,0600 & $20,50 \$$ & $1,23 \$$ \\
\hline Camión regador agua & $\mathrm{h}$ & 0,0100 & $10,25 \$$ & $0,10 \$$ \\
\hline
\end{tabular}

Combustible y lubricantes

\begin{tabular}{|c|c|c|c|c|}
\hline Descripción & Unidad & Cuantía & Precio & Importe \\
\hline Motoniveladora C $120 \mathrm{H}$ & $\mathrm{h}$ & 0,0100 & $67,08 \$$ & $0,67 \$$ \\
\hline Comp. rodillo liso CAT 533 & $\mathrm{~h}$ & 0,0100 & $81,06 \$$ & $0,81 \$$ \\
\hline Cargador frontal CAT 966 & $\mathrm{~h}$ & 0,0100 & $151,58 \$$ & $1,52 \$$ \\
\hline Grupo electrógeno 250 KVA & $\mathrm{h}$ & 0,0100 & $363,35 \$$ & $3,63 \$$ \\
\hline Camión volcador $6 \mathrm{~m}^{3}$ & $\mathrm{~h}$ & 0,0600 & $72,24 \$$ & $4,33 \$$ \\
\hline \multirow[t]{11}{*}{ Camión regador agua } & $\mathrm{h}$ & 0,0100 & $70,95 \$$ & $0,71 \$$ \\
\hline & \multicolumn{3}{|c|}{ SUBTOTAL COMBUSTIBLES Y LUBRICANTES } & $11,67 \$$ \\
\hline & \multicolumn{3}{|c|}{ TOTAL DE EQUIPOS } & $18,29 \$$ \\
\hline & \multicolumn{3}{|c|}{ COSTO-COSTO } & $29,94 \$$ \\
\hline & \multicolumn{2}{|c|}{ Gastos generales } & $23,00 \%$ & $6,89 \$$ \\
\hline & \multicolumn{2}{|c|}{ Costo } & & $36,83 \$$ \\
\hline & \multicolumn{2}{|c|}{ Gastos financieros } & $1,00 \%$ & $0,37 \$$ \\
\hline & \multicolumn{2}{|c|}{ Beneficios } & $10,00 \%$ & $3,68 \$$ \\
\hline & \multicolumn{2}{|c|}{ Suma parcial } & & $40,88 \$$ \\
\hline & \multicolumn{2}{|c|}{ Gastos impositivos } & $24,50 \%$ & $10,02 \$$ \\
\hline & \multicolumn{3}{|c|}{ Precio adoptado del Ítem } & $50,90 \$$ \\
\hline
\end{tabular}


Tabla 8.5: APU de la Subbase Granular con $A N$ de espesor $=0,20 m\left(U=m^{2}\right)$. Materiales

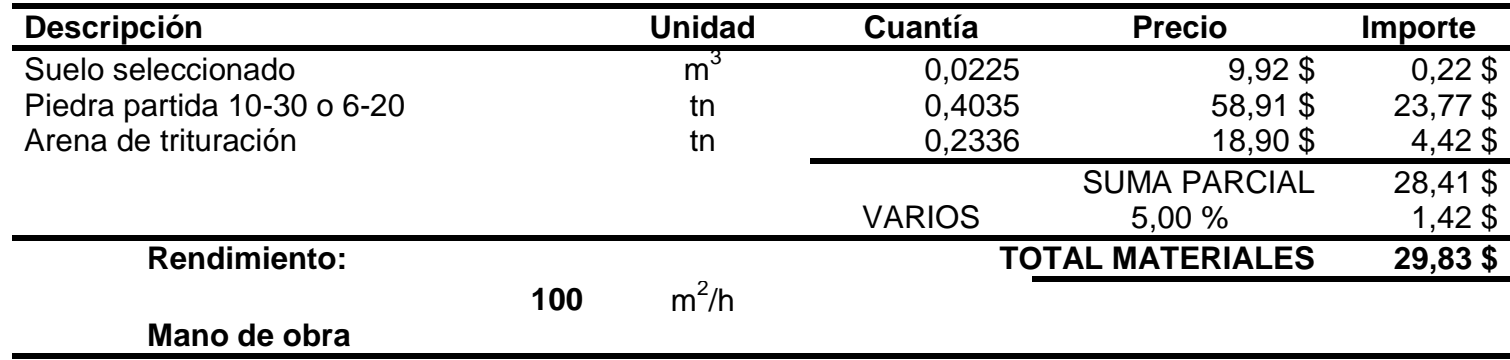

TOTAL MANO DE OBRA $\quad 5,67 \$$

Transporte

\begin{tabular}{lcrrr}
\hline Materiales & Unidad & Cuantía & \multicolumn{1}{c}{ Precio } & \multicolumn{1}{c}{ Importe } \\
\hline Suelo seleccionado & $\mathrm{m} 3$ & 0,023 & $9,24 \$$ & $0,21 \$$ \\
Piedra partida 10-30 o $6-20$ & tn & 0,404 & $89,25 \$$ & $36,01 \$$ \\
Arena de trituración & tn & 0,234 & $89,25 \$$ & $20,85 \$$ \\
\hline \multicolumn{1}{c}{ Equipos } & TOTAL TRANSPORTE & & $\mathbf{5 7 , 0 7 \$}$ \\
\cline { 2 - 5 } Amortización e intereses & & & \\
\hline
\end{tabular}

SUBTOTAL AMORTIZACIÓN E INTERESES $\quad 3,68 \$$

Reparaciones y repuestos

SUBTOTAL REPARACIONES Y REPUESTOS $2,94 \$$

Combustible y lubricantes

\begin{tabular}{lrr} 
SUBTOTAL COMBUSTIBLES Y LUBRICANTES & $\mathbf{1 1 , 6 7 \$}$ \\
\cline { 3 - 3 } TOTAL DE EQUIPOS & & $\mathbf{1 8 , 2 9} \$$ \\
\hline COSTO-COSTO & $\mathbf{1 1 0 , 8 6} \mathbf{\$}$ \\
Gastos generales & $23,00 \%$ & $25,50 \$$ \\
\hline Costo & & $136,36 \$$ \\
Gastos financieros & $1,00 \%$ & $1,36 \$$ \\
Beneficios & $10,00 \%$ & $13,64 \$$ \\
\hline Suma parcial & & $151,36 \$$ \\
Gastos impositivos & $24,50 \%$ & $37,08 \$$ \\
\hline Precio adoptado del İtem & & $\mathbf{1 8 8 , 4 4} \$$
\end{tabular}

Las tablas 8.6 y 8.7 corresponden al caso 2, la construcción de un Pavimento de hormigón simple tipo $\mathrm{H} 13$ de $0,20 \mathrm{~m}$ de espesor con AGR y AGN respectivamente. Las diferencias en uno y otro caso se deben igualmente al costo de los materiales y al transporte de los mismos. 
Tabla 8.6: APU de Pavimento de hormigón simple H13R, e =0,20 $m\left(U=m^{2}\right)$. Materiales

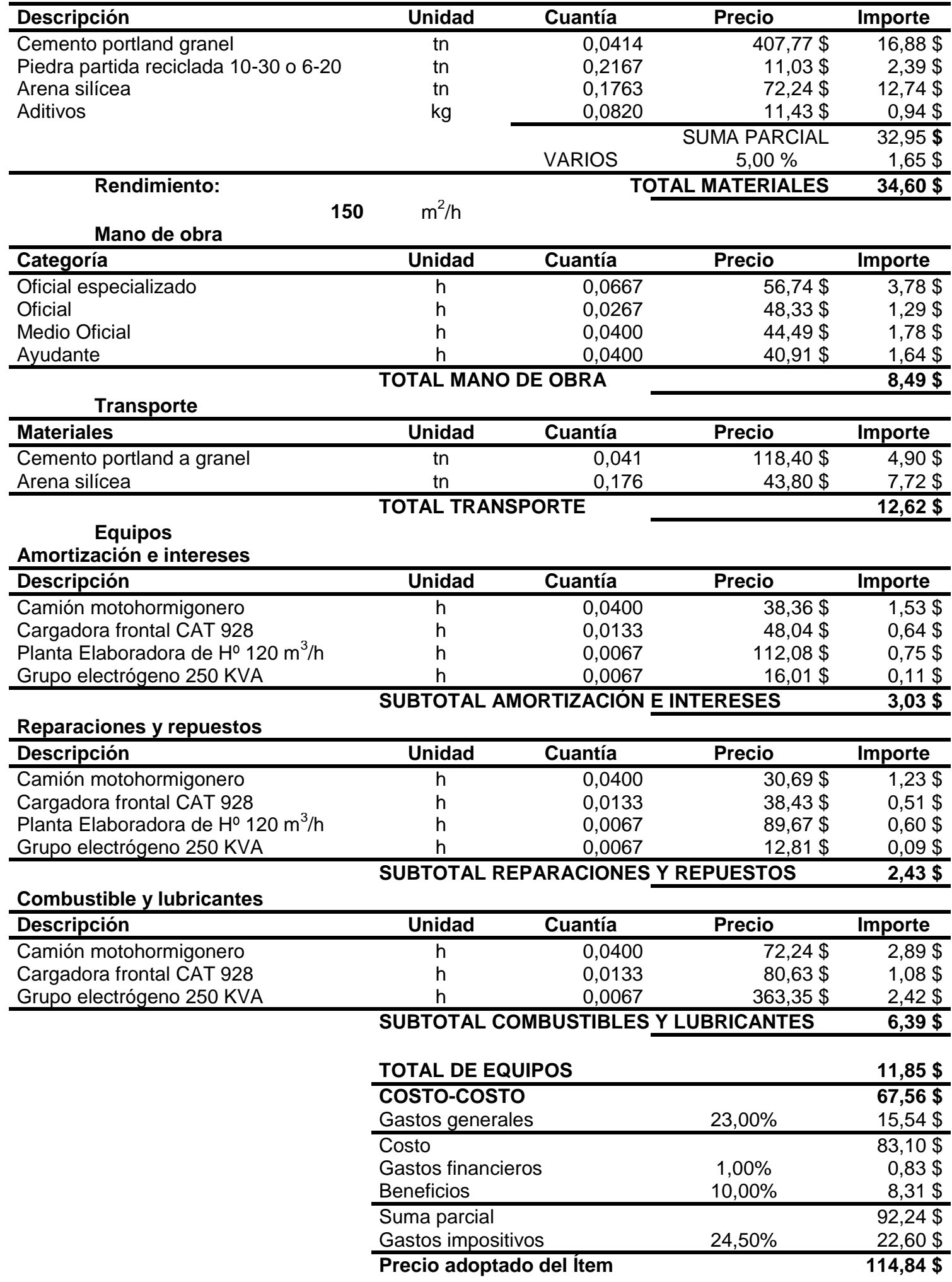


Tabla 8.7: APU de Pavimento de hormigón simple H13N, $e=0,20 \mathrm{~m}\left(\mathrm{U}=\mathrm{m}^{2}\right)$.

Materiales

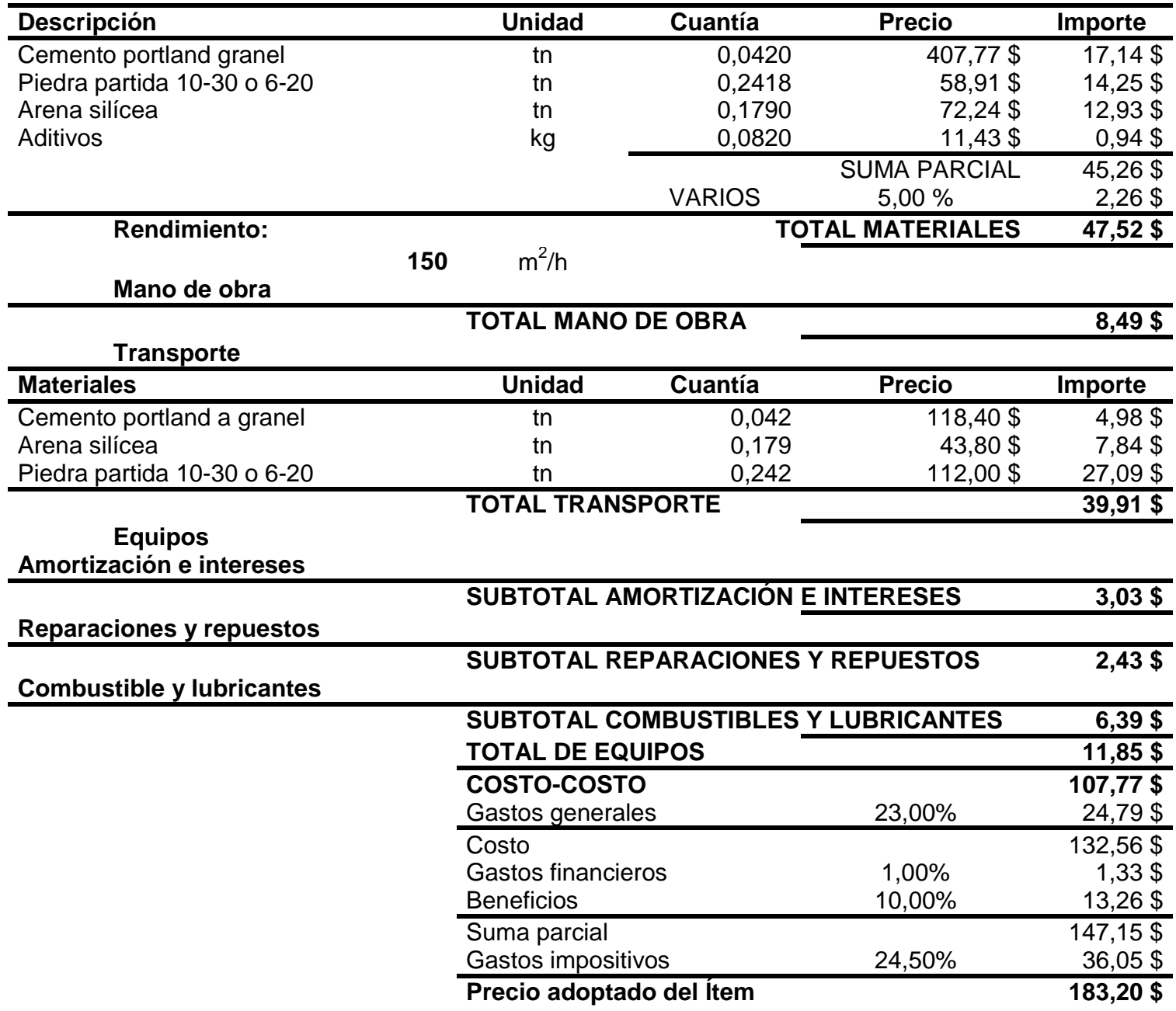

Las tablas 8.8 y 8.9 corresponden al caso 3 , la construcción de un Pavimento de hormigón simple tipo H30 de 0,25 m de espesor con AGR y AGN respectivamente. Las diferencias en uno y otro caso se deben igualmente al costo de los materiales y al transporte de los mismos, así como al aumento del contenido de cemento en el caso de pavimentos con agregados reciclados (H30R) para obtener resistencias similares. 
Tabla 8.8: APU de Pavimento de hormigón simple H30R, e = 0,25 $m\left(U=m^{2}\right)$.

Materiales

\begin{tabular}{|c|c|c|c|c|}
\hline Descripción & Unidad & Cuantía & Precio & Importe \\
\hline Cemento portland granel & $\operatorname{tn}$ & 0,0945 & $407,77 \$$ & $38,54 \$$ \\
\hline Piedra partida reciclada $10-30 \circ 6-20$ & tn & 0,2531 & $11,03 \$$ & $2,79 \$$ \\
\hline Arena silícea & tn & 0,2135 & $72,24 \$$ & $15,42 \$$ \\
\hline Acero AL $220 \phi 32 \mathrm{~mm}$ & tn & 0,0023 & $5.831,09 \$$ & $13,34 \$$ \\
\hline Acero ADN 420 s/pliego & tn & 0,0001 & $6.131,90 \$$ & $0,70 \$$ \\
\hline Material p/tomado juntas s/pliego & $\mathrm{kg}$ & 0,2300 & $262,50 \$$ & $60,38 \$$ \\
\hline Aditivos & $\mathrm{kg}$ & 0,1625 & $11,43 \$$ & $1,86 \$$ \\
\hline \multirow[t]{2}{*}{ Membrana de curado } & $\mathrm{kg}$ & 0,2280 & $16,31 \$$ & $3,72 \$$ \\
\hline & & VARIOS & $\begin{array}{c}\text { SUMA PARCIAL } \\
5,00 \%\end{array}$ & $\begin{array}{r}136,75 \$ \\
6,84 \$\end{array}$ \\
\hline Rendimiento: & & & AL MATERIALES & $143,59 \$$ \\
\hline
\end{tabular}

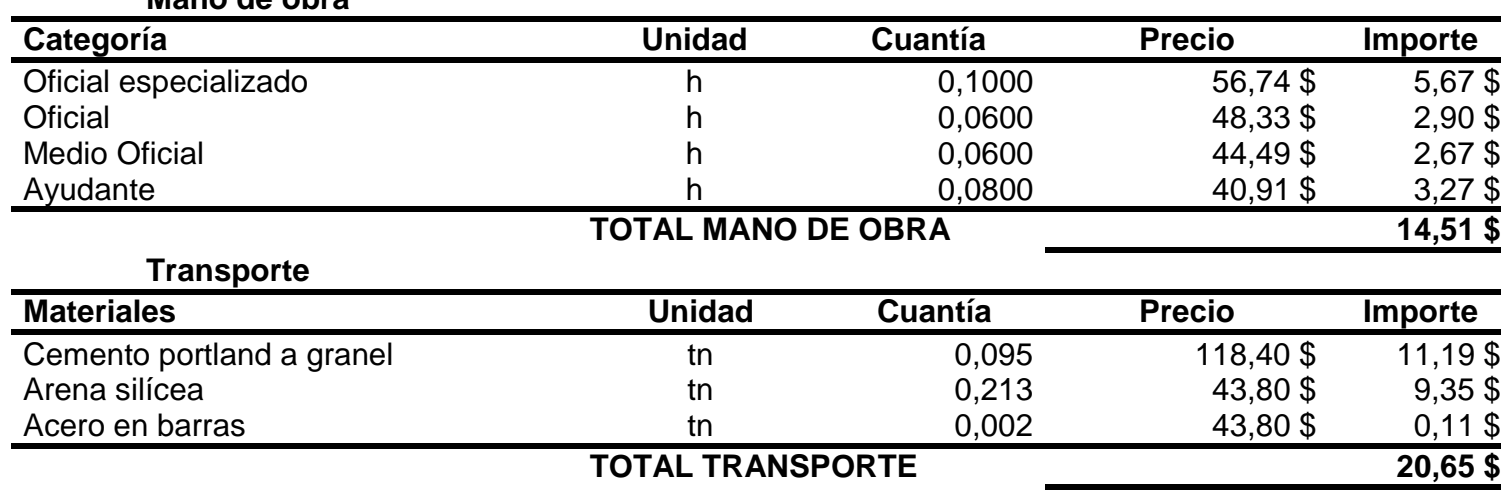

Equipos: Amortización e intereses

\begin{tabular}{lcrrr}
\hline Descripción & Unidad & Cuantía & \multicolumn{1}{c}{ Precio } & Importe \\
\hline Camión motohormigonero & $\mathrm{h}$ & 0,0400 & $38,36 \$$ & $1,53 \$$ \\
Cargadora frontal CAT 928 & $\mathrm{h}$ & 0,0200 & $48,04 \$$ & $0,96 \$$ \\
Planta Elaboradora de Ho $120 \mathrm{~m}^{3} / \mathrm{h}$ & $\mathrm{h}$ & 0,0100 & $112,08 \$$ & $1,12 \$$ \\
Aserradora de pavimento & $\mathrm{h}$ & 0,0200 & $8,01 \$$ & $0,16 \$$ \\
Selladora de juntas & $\mathrm{h}$ & 0,0200 & $7,69 \$$ & $0,15 \$$ \\
Grupo electrógeno 250 KVA & $\mathrm{h}$ & 0,0200 & $16,01 \$$ & $0,32 \$$ \\
\hline
\end{tabular}

Equipos: Reparaciones y repuestos

\begin{tabular}{|c|c|c|c|c|}
\hline Descripción & Unidad & Cuantía & Precio & Importe \\
\hline Camión motohormigonero & $\mathrm{h}$ & 0,0400 & $30,69 \$$ & $1,23 \$$ \\
\hline Cargadora frontal CAT 928 & $\mathrm{~h}$ & 0,0200 & $38,43 \$$ & $0,77 \$$ \\
\hline Planta Elaboradora de $\mathrm{H}^{\circ} 120 \mathrm{~m}^{3} / \mathrm{h}$ & $\mathrm{h}$ & 0,0100 & $89,67 \$$ & $0,90 \$$ \\
\hline Aserradora de pavimento & $\mathrm{h}$ & 0,0200 & $6,40 \$$ & $0,13 \$$ \\
\hline Selladora de juntas & $\mathrm{h}$ & 0,0200 & $6,15 \$$ & $0,12 \$$ \\
\hline Grupo electrógeno 250 KVA & $\mathrm{h}$ & 0,0200 & $12,81 \$$ & $0,26 \$$ \\
\hline & \multicolumn{3}{|c|}{ SUBTOTAL REPARACIONES Y REPUESTOS } & $3,41 \$$ \\
\hline \multicolumn{5}{|l|}{ Equipos: Combustible y lubricantes } \\
\hline Descripción & Unidad & Cuantía & Precio & Importe \\
\hline Camión motohormigonero & $\mathrm{h}$ & 0,0400 & $72,24 \$$ & $2,89 \$$ \\
\hline Cargadora frontal CAT 928 & $\mathrm{~h}$ & 0,0200 & $80,63 \$$ & $1,61 \$$ \\
\hline Grupo electrógeno 250 KVA & $\mathrm{h}$ & 0,0100 & $363,35 \$$ & $3,63 \$$ \\
\hline Aserradora de pavimento & $\mathrm{h}$ & 0,0200 & $26,83 \$$ & $0,54 \$$ \\
\hline Selladora de juntas & $\mathrm{h}$ & 0,0200 & $25,80 \$$ & $0,52 \$$ \\
\hline & \multicolumn{3}{|c|}{ SUBTOTAL COMBUSTIBLES Y LUBRICANTES } & $9,19 \$$ \\
\hline & \multicolumn{3}{|c|}{ TOTAL DE EQUIPOS } & $16,84 \$$ \\
\hline & \multicolumn{3}{|c|}{ COSTO-COSTO } & $195,59 \$$ \\
\hline & \multicolumn{2}{|c|}{ Gastos generales } & $23,00 \%$ & $44,99 \$$ \\
\hline & \multicolumn{3}{|c|}{ Costo } & $240,58 \$$ \\
\hline & \multicolumn{2}{|c|}{ Gastos financieros } & $1,00 \%$ & $2,41 \$$ \\
\hline & \multicolumn{2}{|c|}{ Beneficios } & $10,00 \%$ & $24,06 \$$ \\
\hline
\end{tabular}




\begin{tabular}{lrr}
\hline Suma parcial & $267,05 \$$ \\
Gastos impositivos & $24,50 \%$ & $65,43 \$$ \\
\hline Precio adoptado del Ítem & $\mathbf{3 3 2 , 4 8 ~ \$}$
\end{tabular}

Tabla 8.9: APU de Pavimento de hormigón simple $\mathrm{H} 30 \mathrm{~N}, \mathrm{e}=0,25 \mathrm{~m}\left(\mathrm{U}=\mathrm{m}^{2}\right)$.

\section{Materiales}

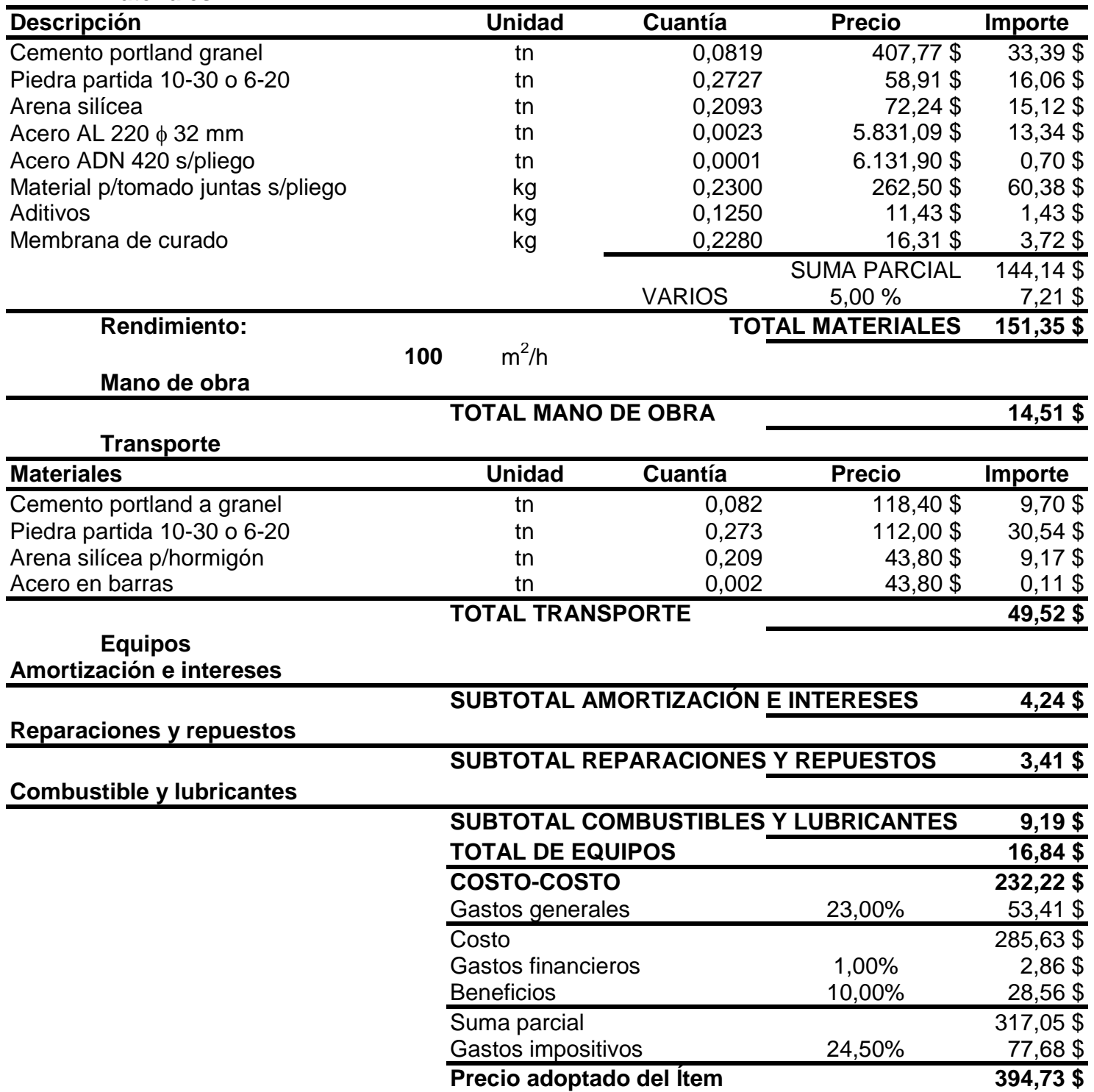

Las tablas 8.10 y 8.11 corresponden al caso 4 , la construcción de una Base asfáltica de $0,10 \mathrm{~m}$ de espesor con AFR y AFN respectivamente incluyendo riego de liga. Como en los casos anteriores las diferencias en uno y otro caso se debe igualmente al costo de los materiales y al transporte de los mismos. 
Tabla 8.10: APU de Base asfáltica con $A F R, e=0,10 m$ (inc. Riego de liga) $\left(U=m^{2}\right)$.

Materiales

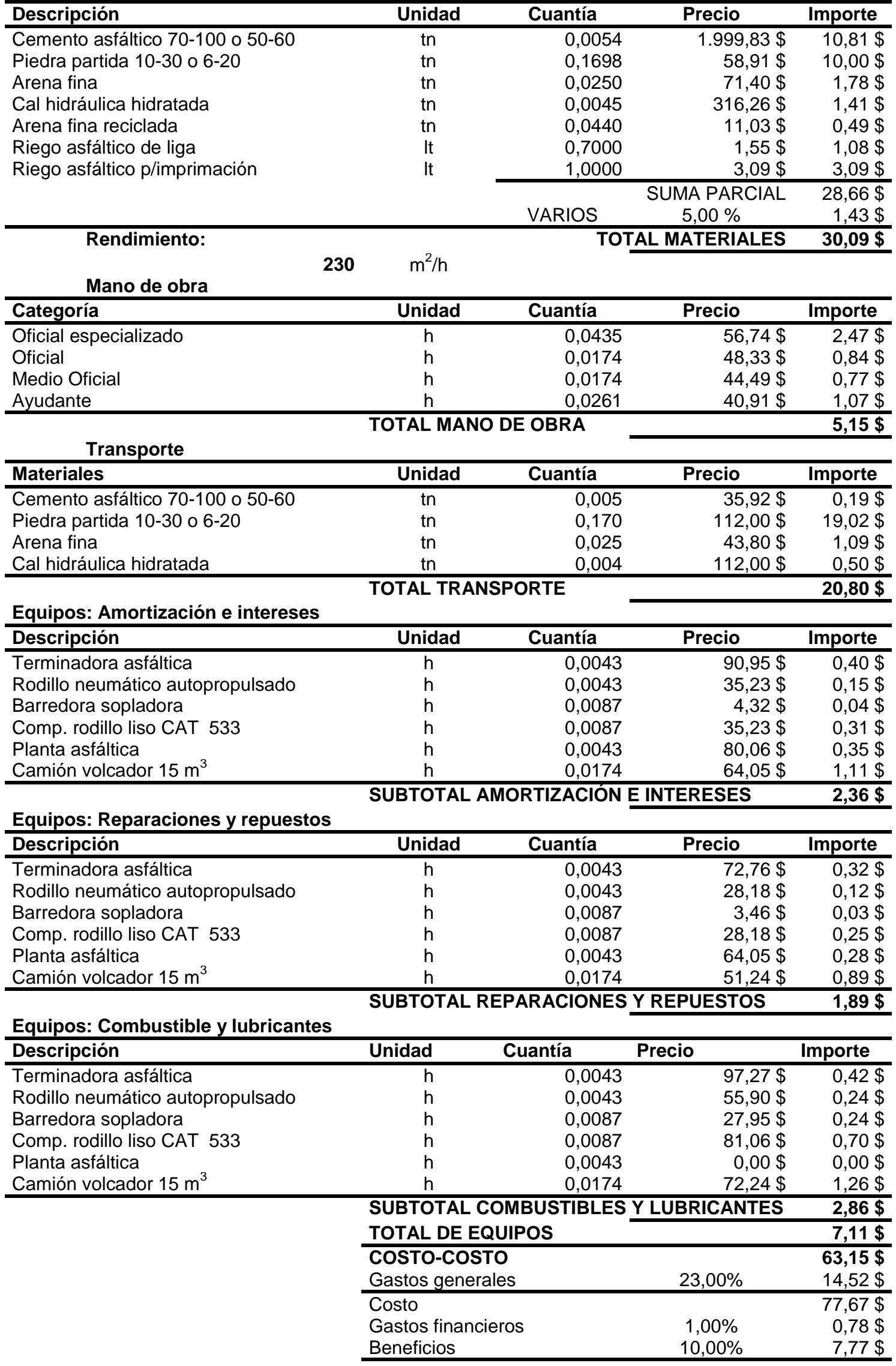




\begin{tabular}{lrr}
\hline Suma parcial & $86,22 \$$ \\
Gastos impositivos & $24,50 \%$ & $21,12 \$$ \\
\hline Precio adoptado del Ítem & $\mathbf{1 0 7 , 3 4 \$}$
\end{tabular}

Tabla 8.11: APU de Base asfaltica con $A F N, e=0,10 m$ (inc. Riego de liga) $\left(U=m^{2}\right)$.

Materiales

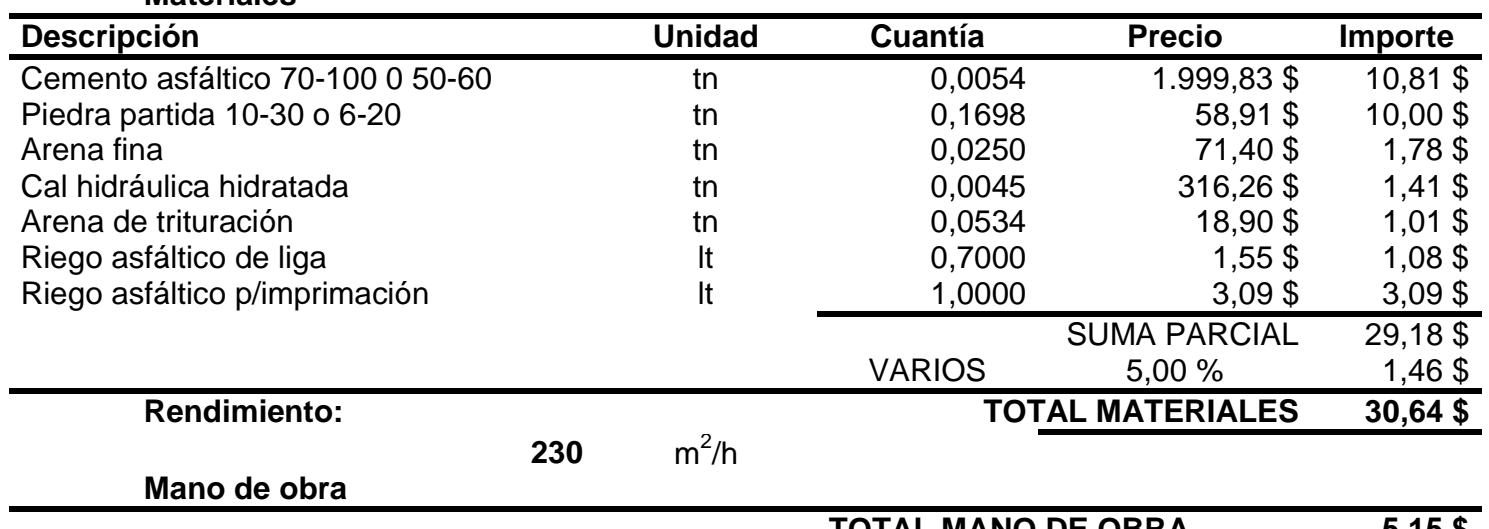

Transporte

\begin{tabular}{|c|c|c|c|c|}
\hline Materiales & Unidad & Cuantía & Precio & Importe \\
\hline Cemento asfáltico 70-100 0 50-60 & th & 0,005 & $35,92 \$$ & $0,19 \$$ \\
\hline Piedra partida 10-30 o 6-20 & tn & 0,170 & $112,00 \$$ & $19,02 \$$ \\
\hline Arena fina & tn & 0,025 & $43,80 \$$ & $1,09 \$$ \\
\hline Cal hidráulica hidratada & $\operatorname{tn}$ & 0,004 & $112,00 \$$ & $0,50 \$$ \\
\hline Arena de trituración & tn & 0,053 & $112,00 \$$ & $5,98 \$$ \\
\hline \multicolumn{4}{|c|}{ TOTAL TRANSPORTE } & $26,78 \$$ \\
\hline \multicolumn{5}{|l|}{$\begin{array}{c}\text { Equipos } \\
\text { Amortización e intereses }\end{array}$} \\
\hline & \multicolumn{3}{|c|}{ SUBTOTAL AMORTIZACIÓN E INTERESES } & $2,36 \$$ \\
\hline \multicolumn{5}{|l|}{ Reparaciones y repuestos } \\
\hline & \multicolumn{3}{|c|}{ SUBTOTAL REPARACIONES Y REPUESTOS } & $1,89 \$$ \\
\hline \multicolumn{5}{|l|}{ Combustible y lubricantes } \\
\hline & \multirow{2}{*}{\multicolumn{3}{|c|}{$\begin{array}{l}\text { SUBTOTAL COMBUSTIBLES Y LUBRICANTES } \\
\text { TOTAL DE EQUIPOS }\end{array}$}} & $2,86 \$$ \\
\hline & & & & $7,11 \$$ \\
\hline & \multicolumn{2}{|c|}{$\begin{array}{l}\text { COSTO-COSTO } \\
\text { Gastos generales }\end{array}$} & $23,00 \%$ & $\begin{array}{l}69,68 \$ \\
16,03 \$\end{array}$ \\
\hline & \multicolumn{2}{|c|}{ Costo } & & $85,71 \$$ \\
\hline & \multicolumn{2}{|c|}{ Gastos financieros } & $1,00 \%$ & $0,86 \$$ \\
\hline & \multicolumn{2}{|c|}{ Beneficios } & $10,00 \%$ & $8,57 \$$ \\
\hline & \multicolumn{2}{|c|}{ Suma parcial } & & $95,14 \$$ \\
\hline & \multirow{2}{*}{\multicolumn{2}{|c|}{$\begin{array}{l}\text { Gastos impositivos } \\
\text { Precio adontado del Ítem }\end{array}$}} & $24,50 \%$ & $23,31 \$$ \\
\hline & & & & $118,45 \$$ \\
\hline
\end{tabular}

En la tabla 8.12 se sintetizan para cada uno de los casos estudiados el costo resultante. 
Tabla 8.12: Análisis de Precio Unitario de los diferentes casos.

\begin{tabular}{|c|l|r|}
\hline Caso & \multicolumn{1}{|c|}{ DESCRIPCION } & PU / $\mathbf{~}^{\mathbf{2}}$ \\
\hline 1.a & Subbase de estabilizado granulométrico con AR $(\mathrm{e}=0,20 \mathrm{~m})$ & 50,90 \\
1.b & Subbase de estabilizado granulométrico con AN $(\mathrm{e}=0,20 \mathrm{~m})$ & 188,44 \\
2.a & Pavimento de hormigón simple H13R $(\mathrm{e}=0,20 \mathrm{~m})$ & 114,84 \\
2.b & Pavimento de hormigón simple H13N $(\mathrm{e}=0,20 \mathrm{~m})$ & 183,20 \\
3.a & Pavimento de hormigón simple H30R $(\mathrm{e}=0,25 \mathrm{~m})$ & 332,48 \\
3.b & Pavimento de hormigón simple H30N $(\mathrm{e}=0,25 \mathrm{~m})$ & 394,73 \\
4.a & Base Asfáltica con AFR, e $=0,10 \mathrm{~m}$ (inc. Riego de liga) & 107,34 \\
4.b & Base Asfáltica con AFN, e =0,10 $\mathrm{m}$ (inc. Riego de liga) & 118,45 \\
\hline
\end{tabular}

A partir de los precios obtenidos surge que:

1. El costo de construcción de la subbase con $A R$ es de 3,7 veces más económico al obtenido con $\mathrm{AN}$. Las reducciones de costo se deben fundamentalmente al costo del material y del transporte del AGN que representa traslados de casi 320 km en esta región.

2. Para el caso de pavimento de hormigon tipo $\mathrm{H} 13$, el costo obtenido con AGN es $60 \%$ mayor que el obtenido en hormigones con AGR. Las diferencias se deben nuevamente al costo del material y del transporte del AGN. Es interesante observar que además queda un remanente de $20 \%$ por cada tonelada de agregado triturado de material fino que puede aprovecharse para otras alternativas.

3. El costo de un pavimento de hormigón H30 con AGN resulta un $19 \%$ más caro que el elaborado con AGR. Las reducciones de costo se deben fundamentalmente al costo del material y su acarreo, pero son menores a las anteriores debido a la necesidad de incrementar ligeramente el contenido de cemento en el caso del AGR para alcanzar los mismos niveles de resistencia.

4. Las ventajas de utilizar en esta región $A R$ relacionadas con al costo de los materiales se repiten al comparar una base asfáltica elaborada con AFR con la confeccionada con AFN, pero en este caso las diferencias sólo alcanzan un $10 \%$. En este caso el costo del AFN no incide tanto.

A modo de síntesis, en la tabla 8.13 se desglosan cada uno de los componentes directos. Se observa que no existen diferencias en los costos de 
equipos, reparaciones y repuestos, combustibles y mano de obra, sino que la principal ventaja económica se refiere al costo de los agregados naturales y su transporte a esta zona, dada la distancia donde se encuentran los yacimientos.

Al respecto surge que para esta región, la mejor alternativa se relaciona con la generación de AGR para empleo en hormigones, principalmente en subbases y luego pavimentos de resistencias bajas tipo $\mathrm{H} 13$.

Tabla 8.13: Síntesis del Precio Unitario de los diferentes rubros.

\begin{tabular}{|c|c|c|c|c|c|c|c|}
\hline Ítem & Materiales & $\begin{array}{c}\text { Mano } \\
\text { de } \\
\text { Obra }\end{array}$ & Transporte & $\begin{array}{c}\text { Amortización } \\
\text { e Interés }\end{array}$ & $\begin{array}{c}\text { Reparaciones } \\
\text { y Repuesto }\end{array}$ & $\begin{array}{c}\text { Combustibles } \\
\text { y Lubricantes }\end{array}$ & $\begin{array}{c}\text { Costo } \\
\text { Costo }\end{array}$ \\
\hline 1.a & $\mathbf{5 , 5 5}$ & 5,67 & $\mathbf{0 , 4 3}$ & 3,68 & 2,94 & 11,67 & 29,94 \\
$\mathbf{1 . b}$ & $\mathbf{2 9 , 8 3}$ & 5,67 & $\mathbf{5 7 , 0 7}$ & 3,68 & 2,94 & 11,67 & 110,86 \\
2.a & $\mathbf{3 4 , 6 0}$ & 8,49 & $\mathbf{1 2 , 6 2}$ & 3,03 & 2,43 & 6,39 & 67,56 \\
2.b & $\mathbf{4 7 , 5 2}$ & 8,49 & $\mathbf{3 9 , 9 1}$ & 3,03 & 2,43 & 6,39 & 107,77 \\
3.a & $\mathbf{1 4 3 , 5 9}$ & 14,51 & $\mathbf{2 0 , 6 5}$ & 4,24 & 3,41 & 9,19 & 195,59 \\
3.b & $\mathbf{1 5 1 , 3 5}$ & 14,51 & $\mathbf{4 9 , 5 2}$ & 4,24 & 3,41 & 9,19 & 232,22 \\
4.a & $\mathbf{3 0 , 0 9}$ & 5,15 & $\mathbf{2 0 , 8 0}$ & 2,36 & 1,89 & 2,86 & 63,15 \\
4.b & $\mathbf{3 0 , 6 4}$ & 5,15 & $\mathbf{2 6 , 8 7}$ & 2,36 & 1,89 & 2,86 & 69,68 \\
\hline
\end{tabular}

\section{3.- ANALISIS DEL APROVECHAMIENTO DE HORMIGON RECICLADO EN UN CASO ESPECÍFICO}

Dada la influencia considerable que tienen los costos de los materiales y su transporte se realizará un presupuesto de obra considerando el aprovechamiento del hormigón reciclado para la reconstrucción de una vía que presenta losas de hormigón fisuradas. Las mismas tienen una densidad promedio de $2,35 \mathrm{tn} / \mathrm{m}^{3}$ y un espesor de $0,25 \mathrm{~m}$. La vía existente tiene una longitud de 0,500 km y un ancho de 8,00 m, obteniéndose con la trituración de las losas 2350 tn de AR, de los cuales $80 \%$ es AGR y el resto, AFR.

La tabla 8.14 muestra las cantidades de materiales necesaria para reconstruir un área de $4000 \mathrm{~m}^{2}$, diferenciando las diferentes capas donde es posible el uso de agregados reciclados. Se puede observar que las 2350 toneladas de AR (AGR + AFR) obtenidas de la trituración es posible usarlas en diferentes capas de la misma obra. Las losas de hormigón existentes deben ser demolidas tal como especifica el pliego en pedazos de $30 \times 30 \mathrm{~cm}$. En el caso 
de que solo se utilizara el AGR, el material fino obtenido de la trituración se podrá utilizar en canalización como cama de tuberías, o como mejoramiento, relleno y nivelación de la subrasante.

Tabla 8.14: Cantidad de material necesario para la vía.

\begin{tabular}{|l|c|c|c|c|}
\hline \multicolumn{1}{|c|}{ Descripción } & $\begin{array}{c}\text { AGR } \\
\left(\mathbf{t n}_{\mathbf{m}} \mathbf{m}^{2}\right)\end{array}$ & $\begin{array}{c}\text { AFR } \\
\left(\mathbf{t n} / \mathbf{m}^{2}\right)\end{array}$ & $\begin{array}{c}\text { AGR } \\
(\mathbf{t n})\end{array}$ & $\begin{array}{c}\text { AFR } \\
(\mathbf{t n})\end{array}$ \\
\hline Material triturado & & & 1.880 & 470 \\
Subbase granular $(\mathrm{e}=0,20 \mathrm{~m})$ & 0,360 & 0,193 & 1.440 & 770 \\
Pavimento de hormigón simple H13R $(\mathrm{e}=0,20 \mathrm{~m})$ & 0,217 & ---- & 867 & ---- \\
Pavimento de hormigón simple H30R $(\mathrm{e}=0,25 \mathrm{~m})$ & 0,253 & ---- & 1.012 & ---- \\
\hline
\end{tabular}

Para reconstruir la misma se plantean las siguientes alternativas:

1. Estabilizado granular $+\mathrm{H} 30$,

2. Hormigón tipo $\mathrm{H} 13+\mathrm{H} 30$.

Analizando la primera alternativa, el paquete estructural propuesto para la reconstrucción de esta ruta estará compuesto de: una subbase granular como base y una capa de rodadura compuesto por un hormigón simple H30.

La tabla 8.15 compara los presupuestos para la reconstrucción de la vía usando en sus capas estructurales tanto agregados gruesos naturales como reciclados, observando un ahorro económico en el costo total de la obra de $31,0 \%$ utilizando los agregados reciclados en una subbase granular $+\mathrm{H} 30$. 
Tabla 8.15: Presupuestos de obra para el tramo de vía: Estabilizado granular + H30.

\begin{tabular}{|c|c|c|c|c|c|c|}
\hline \multirow{2}{*}{ Ítem } & \multirow{2}{*}{ Descripción } & \multirow[t]{2}{*}{ U. } & \multirow{2}{*}{ Cant. } & \multicolumn{2}{|l|}{ Oferta } & \multirow[t]{2}{*}{ Incidencia } \\
\hline & & & & $\mathbf{P U}$ & Importes & \\
\hline 1 & Demolición de losas de hormigón & $\mathrm{m}^{2}$ & $4.000,00$ & 48,23 & $192.920,00$ & $7,49 \%$ \\
\hline 2 & Perfilado y Recompactación de & $\mathrm{m}^{2}$ & $4.000,00$ & 3,27 & $13.080,00$ & $0,51 \%$ \\
\hline 3 & Excavación a máquina & $\mathrm{m}^{3}$ & $1.000,00$ & 36,81 & $36.810,00$ & $1,43 \%$ \\
\hline 4 & $\begin{array}{l}\text { Subbase granular con AN } \\
(e=0,20 \mathrm{~m})\end{array}$ & $\mathrm{m}^{2}$ & $4.000,00$ & 188,44 & $753.760,00$ & $29,27 \%$ \\
\hline \multirow[t]{2}{*}{5} & $\begin{array}{l}\text { Pavimento de hormigón simple } \\
\mathrm{H} 30 \mathrm{~N}(\mathrm{e}=0,25 \mathrm{~m})\end{array}$ & $\mathrm{m}^{2}$ & $4.000,00$ & 394,73 & $1.578 .920,00$ & $61,31 \%$ \\
\hline & \multicolumn{4}{|l|}{ PRECIO TOTAL DE LA OBRA } & $\$ 2.575 .490,00$ & $100,00 \%$ \\
\hline 1 & Demolición de losas de hormigón & $\mathrm{m}^{2}$ & $4.000,00$ & 48,23 & $192.920,00$ & $10,86 \%$ \\
\hline 2 & $\begin{array}{l}\text { Perfilado y Recompactación de } \\
\text { la subrasante }\end{array}$ & $\mathrm{m}^{2}$ & $4.000,00$ & 3,27 & $13.080,00$ & $0,74 \%$ \\
\hline 3 & Excavación a máquina & $\mathrm{m}^{3}$ & $1.000,00$ & 36,81 & $36.810,00$ & $2,07 \%$ \\
\hline 4 & $\begin{array}{l}\text { Subbase granular con AR } \\
(e=0,20 \mathrm{~m})\end{array}$ & $\mathrm{m}^{2}$ & $4.000,00$ & 50,90 & $203.600,00$ & $11,46 \%$ \\
\hline \multirow[t]{3}{*}{5} & $\begin{array}{l}\text { Pavimento de hormigón simple } \\
\mathrm{H} 30 \mathrm{R}(\mathrm{e}=0,25 \mathrm{~m})\end{array}$ & $\mathrm{m}^{2}$ & $4.000,00$ & 332,48 & $1.329 .920,00$ & $74,87 \%$ \\
\hline & \multicolumn{4}{|l|}{ PRECIO TOTAL DE LA OBRA } & $\$ 1.776 .330,00$ & $100,00 \%$ \\
\hline & \multicolumn{4}{|l|}{ AHORRO ECONOMICO } & $\$ 799.160,00$ & $31,00 \%$ \\
\hline
\end{tabular}

En la tabla 8.16 se observan los presupuestos para la reconstrucción de la vía usando en sus capas estructurales un H13 como base y un H30 como capa de rodadura. El ahorro económico en el costo total de la obra utilizando agregados gruesos reciclados es de $20,45 \%$.

Tabla 8.16: Presupuestos de obra para el tramo de vía: $\mathrm{H} 13$ + H30.

\begin{tabular}{|c|c|c|c|c|c|c|}
\hline \multirow[t]{2}{*}{ Ítem } & \multirow[t]{2}{*}{ Descripción } & \multirow[t]{2}{*}{ U. } & \multirow[t]{2}{*}{ Cant. } & \multicolumn{2}{|l|}{ Oferta } & \multirow[t]{2}{*}{ Incidencia } \\
\hline & & & & $\mathbf{P U}$ & Importes & \\
\hline 1 & Demolición de losas de hormigón & $\mathrm{m}^{2}$ & $4.000,00$ & 48,23 & $192.920,00$ & $7,55 \%$ \\
\hline 2 & Perfilado y Recompactación de & $\mathrm{m}^{2}$ & $4.000,00$ & 3,27 & $13.080,00$ & $0,51 \%$ \\
\hline 3 & Excavación a máquina & $\mathrm{m}^{3}$ & $1.000,00$ & 36,81 & $36.810,00$ & $1,44 \%$ \\
\hline 4 & $\begin{array}{l}\text { Pavimento de hormigón simple } \\
\mathrm{H} 13 \mathrm{~N}(\mathrm{e}=0,20 \mathrm{~m})\end{array}$ & $\mathrm{m}^{2}$ & $4.000,00$ & 183,20 & $732.800,00$ & $28,69 \%$ \\
\hline \multirow[t]{2}{*}{5} & $\begin{array}{l}\text { Pavimento de hormigón simple } \\
\text { H30N }(e=0,25 \mathrm{~m})\end{array}$ & $\mathrm{m}^{2}$ & $4.000,00$ & 394,73 & $1.578 .920,00$ & $61,81 \%$ \\
\hline & \multicolumn{4}{|l|}{ PRECIO TOTAL DE LA OBRA } & $\$ 2.554 .530,00$ & $100,00 \%$ \\
\hline 1 & Demolición de losas de hormigón & $\mathrm{m}^{2}$ & $4.000,00$ & 48,23 & $192.920,00$ & $9,49 \%$ \\
\hline 2 & $\begin{array}{l}\text { Perfilado y Recompactación de } \\
\text { la subrasante }\end{array}$ & $\mathrm{m}^{2}$ & $4.000,00$ & 3,27 & $13.080,00$ & $0,64 \%$ \\
\hline 3 & Excavación a máquina & $\mathrm{m}^{3}$ & $1.000,00$ & 36,81 & $36.810,00$ & $1,81 \%$ \\
\hline 4 & $\begin{array}{l}\text { Pavimento de hormigón simple } \\
\mathrm{H} 13 \mathrm{R}(\mathrm{e}=0,20 \mathrm{~m})\end{array}$ & $\mathrm{m}^{2}$ & $4.000,00$ & 114,84 & $459.360,00$ & $22,61 \%$ \\
\hline \multirow[t]{3}{*}{5} & $\begin{array}{l}\text { Pavimento de hormigón simple } \\
\text { H30R }(e=0,25 \mathrm{~m})\end{array}$ & $\mathrm{m}^{2}$ & $4.000,00$ & 332,48 & $1.329 .920,00$ & $65,45 \%$ \\
\hline & \multicolumn{4}{|l|}{ PRECIO TOTAL DE LA OBRA } & $\$ 2.032 .090,00$ & $100,00 \%$ \\
\hline & \multicolumn{4}{|l|}{ AHORRO ECONOMICO } & $\$ 522.440,00$ & $20,45 \%$ \\
\hline
\end{tabular}


Comparando las dos alternativas descritas anteriormente se puede observar que la primera opción presenta un mayor ahorro que la segunda opción. Este ahorro disminuiría en algo debido a que en el primer caso se necesitaría transportar 450 tn de agregado natural para poder reconstruir totalmente la vía.

\section{4.- CONSIDERACIONES FINALES}

En este capítulo se realizó un estudio comparativo del efecto del uso de hormigón reciclado en los costos de las obras viales en la región del Gran La Plata. A partir del mismo surge que:

1. La utilización de agregados reciclados como componentes de capas estructurales de pavimentos puede dar lugar a ahorros económicos considerables.

2. El costo de reciclar es pequeño en comparación de los costos que se necesitan para disponer de agregados naturales en esta región, en particular piedra triturada. A esto se suma que mediante el reciclado se efectiviza la disposición del viejo hormigón y además se evita el impacto ambiental que implica el uso de agregados naturales (consumo de recursos no renovables, empleo de explosivos, equipos pesados, extracción de capa vegetal, etc.).

3. En el caso estudiado el costo del material y el transporte del agregado natural constituyen los factores que más inciden en los presupuestos habiéndose estimado al momento actual ahorros del $370 \% / \mathrm{m}^{3}, 60 \% / \mathrm{m}^{3}, 19$ $\% / \mathrm{m}^{3}$ y $10 \% / \mathrm{m}^{3}$ para la construcción de subbases, bases de hormigón pobre, capas de rodamiento de pavimentos de hormigón y de concreto asfáltico respectivamente.

4. El uso de agregados reciclados en distintas capas estructurales de una carretera trae consigo ahorros económicos importantes que pueden fluctuar entre un 10 a $30 \%$.

5. Si bien el impacto positivo al medio ambiente no se estudió en este capítulo, se considera sumamente importante destacarlo, considerando que la sustentabilidad en las construcciones civiles y en los procesos industriales en general representa uno de los mayores desafíos del siglo XXI. Además del 
consumo de recursos no renovables y del hecho que se dejan de extraer grandes superficies de capas vegetales, se disminuye en el caso estudiado el consumo de combustibles y de neumáticos para el transporte de agregados.

6. Finalmente el uso de los agregados reciclados colabora con el paisaje preservando el medio ambiente, debido a que, por lo general los residuos de este tipo de obras viales quedan acopiados en predios o como material de relleno en lugares inapropiados. 


\section{Capítulo 9}

\section{CONCLUSIONES Y}

\section{RECOMENDACIONES}

\section{1.- CONCLUSIONES:}

El principal objetivo de este trabajo de tesis fue evaluar diferentes alternativas de uso del hormigón reciclado para su aprovechamiento como agregados en obras viales. Los estudios se realizaron sobre el material resultante de la trituración de los pedazos de losas de hormigón que estaban siendo removidas para la reparación de un sector del pavimento próximo a la intersección de la avenida 122 y la calle 43 de la ciudad de La Plata. Se procedió al análisis de las dos fracciones obtenidas (gruesa y fina) realizando varios programas específicos para explorar su uso en reemplazo de agregados naturales, que comprenden la elaboración de nuevos hormigones con distintos niveles de resistencia, y el uso en mezclas asfálticas o bases granulares. Se presentan a continuación las principales conclusiones:

\section{Propiedades de los agregados reciclados}

Las dos fracciones de agregados reciclados (AR) generados por una trituradora de mandíbulas presentan una distribución granulométrica que los hace aptos para su empleo en hormigones, mezclas asfálticas y estabilizados granulares dentro de los límites establecidos por la norma IRAM 1677 y el PETG-DNV.

El análisis del agregado grueso reciclado (AGR) muestra que algunas propiedades como índice de lajosidad y elongación o pasa tamiz de $75 \mu \mathrm{m}$ son 
mejores a las de los agregados gruesos naturales (AGN) habitualmente empleados en la región (piedra granítica), mientras que otras como la densidad, absorción de agua y pérdida por abrasión presentan diferencias considerables debido a la presencia de mortero entre los agregados, que deben ser tenidas en cuenta al momento de emplear AGR en las mezclas.

Del análisis del agregado fino reciclado (AFR) surge que algunas propiedades como la densidad y absorción de agua resultan técnicamente inferiores a las de la arena silícea natural o granítica que se emplea en la zona, mientras que no hay mayores diferencias en el equivalente arena y la plasticidad de la fracción pasa tamiz IRAM 0,075 mm.

\section{Uso de AR en hormigón:}

En los estudios sobre hormigón pobre, tipo $\mathrm{H} 13$ se observó: en estado fresco una disminución en el peso unitario y en el aire incorporado en aquellos elaborados con AGR con respecto a las mezclas con AGN con igual asentamiento. En estado endurecido no se observaron diferencias en las resistencias a compresión y flexión, en cambio los hormigones con AGR mostraron una disminución del $10 \%$ en el módulo de elasticidad con respecto al encontrado en hormigones con AGN.

En los hormigones tipo H30 para iguales proporciones de materiales, se observaron en estado fresco disminuciones en el peso unitario, aire incorporado y tiempo de fraguado y mayor asentamiento en los elaborados con AGR. En estado endurecido con contenidos de cemento similares se observó una disminución en las propiedades mecánicas al incorporar AGR. La resistencia a compresión disminuyó un $16 \%$, la resistencia a flexión se redujo un $8 \%$ y el módulo de elasticidad un $23 \%$ con respecto al hormigón con agregados graníticos (H30N). Asimismo se encontró una mayor contracción por secado y pérdida de peso en los H30 elaborados con AGR, hecho que no puede soslayarse al momento de plantear su uso como capa de rodamiento.

\section{Empleo de AR en mezclas asfálticas:}

Los AGR utilizados en mezclas asfálticas sufren importantes degradaciones durante las etapas de mezclado y compactación en laboratorio. Esto podría ser producto del alto valor de desgaste Los Ángeles que presentan 
estos agregados. Para cumplir los requerimientos más exigentes de este ensayo deberíamos reemplazar más del $70 \%$ por AGN.

Las mezclas elaboradas con AFR resultaron poco flexibles evaluadas mediante ensayos dinámicos de tracción indirecta. Los valores de ahuellamiento no cumplen las recomendaciones para tránsito medio a alto.

En función de lo evaluado en esta tesina no es factible el uso de agregados reciclados en mezclas asfálticas diseñadas para alto tránsito según el pliego de la CPA. La bibliografía consultada coincide en la factibilidad del uso del AR en la construcción de mezclas asfálticas de bajo tránsito. En Argentina no se aplica métodos reglamentados para el diseño de mezclas de tránsito bajo ya que no existe normativa alguna, por lo tanto se deberá guiarse de reglamentaciones y experiencias internacionales.

\section{Aprovechamiento de AR en bases granulares:}

Los AR presentan propiedades que cumplen con las requisitos granulométricos establecidos en el PETG de la DNV para agregados a utilizar en capas granulares estructurales (subbases y bases).

Las bases granulares elaboradas con AR presentan menor peso unidad de volumen suelto y mayor contenido de humedad óptima que los elaborados con agregados naturales de trituración. Esto se atribuye a la menor densidad y mayor absorción de los agregados reciclados. Las probetas que fueron sumergidas en agua por cuatro días no sufrieron cambios de volumen ante la presencia de agua y presentan mayor valor CBR que las ensayadas en estado seco. El valor soporte obtenido en la base granular elaborada no cumple con el valor mínimo exigido por las normativas, sin embargo cumple con el valor solicitado para la realización de subbases.

\section{Análisis de Costos:}

El aprovechamiento de los AR permite obtener beneficios económicos y medio ambientales, al no tener que abrir nuevos yacimientos para la extracción de áridos naturales o reducir las reservas existentes. También permite la eliminación o reducción de botaderos públicos o ilegales para destino de este material, temas que no fueron considerados en el análisis de esta tesina. 
La reutilización de los materiales reciclados trae consigo ahorros importantes, al disminuir al mínimo el volumen necesario de nuevos áridos a utilizar en obra y el costo de su transporte debido a la dificultad cada vez mayor de encontrar canteras de materiales cercanas al lugar de trabajo.

Otro ahorro económico que trae consigo el uso de $A R$, es la gran reducción en el transporte de materiales naturales contribuyendo a la conservación de la red de caminos y carreteras situadas en las proximidades de la obra. Además existen ahorros de consumo de combustibles (menos emanaciones de $\mathrm{CO}_{2}$ ), lubricantes, repuestos, neumáticos y disminución de extracción de grandes áreas de tierra vegetal.

Tomando como hipótesis un caso en la zona del Gran La Plata, se percibe que se podría reutilizar el hormigón de las losas en la reparación/reconstrucción de una carretera, teniendo como opción más conveniente el estabilizado granular debido a que se usan las dos fracciones (tanto fina como gruesa), como segunda elección la elaboración de hormigones pobres y como tercera opción la elaboración de hormigones para capas de rodadura, acarreando consigo ahorros económicos importantes que pueden fluctuar entre un 10 a $30 \%$ del monto total de la obra.

En los casos estudiados, el costo del material y del transporte del agregado natural constituyen los factores que más inciden en un presupuesto de obra habiéndose estimado al momento actual ahorros del $370 \% / \mathrm{m}^{3}, 60$ $\% / \mathrm{m}^{3}, 19 \% / \mathrm{m}^{3}$ y $10 \% / \mathrm{m}^{3}$ para la construcción de subbases, bases de hormigón pobre, capas de rodamiento de pavimentos de hormigón y de concreto asfáltico respectivamente.

\section{2.- RECOMENDACIONES:}

El estudio desarrollado ha mostrado aspectos técnicos y económicos relacionados con el aprovechamiento del hormigón de desecho en las obras viales para la obtención de agregados reciclados. De este modo se contribuye a la sustentabilidad de este tipo de emprendimientos. Sin embargo merecen indicarse en este apartado algunas recomendaciones y necesidades de estudio futuro, en especial si se plantea su uso en otras regiones. 
Conforme el ambiente en el cual se pretenda utilizar el hormigón de cemento portland que incorpore agregados reciclados, será necesario atender los aspectos vinculados a la durabilidad del hormigón elaborado con AR. Al respecto puede ser necesario considerar su performance frente a acciones de: congelación y deshielo, humedecimiento y secado, o el ataque por sulfatos. En caso que la degradación del pavimento existente no se deba a las acciones de las cargas, o defectos en las bases sino a problemas asociados a reacciones deletéreas en el mismo hormigón, deberán realizarse estudios específicos adicionales, tal sería el caso por ejemplo de pavimentos degradados por efecto de la reacción álcali-sílice.

En cuanto al uso en concreto asfáltico se sugiere en el futuro verificar el comportamiento mecánico de mezclas asfálticas diseñadas con AFR compactadas con menor energía, siguiendo las recomendaciones de la bibliografía internacional para mezclas de bajo tránsito, verificando la potencial degradación del agregado reciclado grueso o fino mediante el compactador giratorio y el compactador de rodillo y su relación con el valor de desgaste Los Ángeles.

También resulta necesario estudiar los parámetros de mezclas asfálticas elaboradas con asfaltos menos consistentes (CA-20, CA-10 ó 70-100) ya que el asfalto más blando ayudaría a reducir el alto módulo y Estabilidad que presenta la mezcla con AFR.

Finalmente y como marco referencial para la mayor sustentabilidad de las obras viales será importante aunar esfuerzos en vías de elaborar una normativa que ayude a la utilización de agregados reciclados en diferentes campos de la construcción como existe en la mayoría de países del norte. Vinculado con esto es menester reflexionar acerca de la creación de incentivos o beneficios económicos para los constructores que usen estos agregados en diversas obras. 


\section{Capítulo 10}

\section{REFERENCIAS \\ BIBLIOGRAFICAS}

1. AASHTO T-283/89, 1989. Resistance of Compacted Bituminous Mixture to Moisture Induced Damage. American Association of State Highway and Transportation Officials.

2. AENOR, 2004. Métodos de ensayo para mezcla bituminosa en caliente. Parte 26: Rigidez (UNE-EN 12697-26). Madrid.

3. Appolloni, O., Morano, P., 2009. "Dos viejos adversarios se unen para el mismo objetivo. Base Granular Asfáltica - Empleo de hormigón triturado como agregado pétreo". XV $\mathrm{V}^{\circ}$ Congreso Argentino de Vialidad y Tránsito, edición en CD.

4. Arm, M., 2001. "Self-cementing properties of crushed demolished concrete in unbound layers: results from triaxial tests and field tests". Waste Management 21 (3), pp. 235-239.

5. ASTM C403, 2008. Standard Test method for time of setting of concrete Mixtures by penetration resistance. ASTM International, EEUU.

6. ASTM C157, 2008. Standard Test method for length change of hardened hydraulic cement mortar and concrete. ASTM International, EEUU.

7. ASTM D7172-06, 2007. Determining the Relative Density and Absorption of fine aggregates using infrared. Road and Paving materials; Vehicles Pavement Systems. Vol. 04.03. ASTM International, EEUU. 
8. Barra, M., 2006. "Estudio de la Durabilidad del Hormigón de Árido Reciclado en su aplicación como Hormigón Estructural". Tesis Doctoral. Universidad Politécnica de Cataluña, pp. 130-196.

9. Buttler, A.M., 2003. Concreto com agregados graúdos reciclados de concreto - Influência da idade de reciclagem nas propriedades dos agregados e concretos reciclados. Tesis de Magíster, Escola de Engenharia de São Carlos, Universidad de São Paulo, pp. 199.

10.Buyle-Bodin, F., Hadjieva-Zaharieva, R., 2002. Influence of industrially produced recycled aggregates on flow properties of concrete. Materials and Structures, Vol. 35, № 252, pp. 504-509.

11. CEDEX, 2011. Uso de Áridos Reciclados Mixtos procedentes de Residuos de construcción y demolición. Investigación Pre normativa del Gobierno Vasco, pp. 10-19.

12. Cerutti, N., 2009. "Parámetros mecánicos de capas estructurales para ser utilizados en el mejoramiento de la red terciaria con materiales recuperados de la demolición de pavimentos". XVº Congreso Argentino de Vialidad y Tránsito, edición en CD.

13. Chen, M., Lin, J., Wu, Sh., 2011. "Potential of recycled fine aggregate powder as filler in asphalt mixture". Construction and Building Materials, pp. 1-6.

14. Cho, H., Yun, T., Kim, I., Choi, N., 2010. "The application of recycled concrete aggregate (RCA) for Hot Mix Asphalt (HMA) Base layer aggregate. Journal of Civil Engineering, pp. 1-6.

15. Evangelista, L., Brito, J., 2007. "Mechanical behavior concrete made with fine recycled concrete aggregates". Cement and concrete composites. Vol. 29, pp. 397-401.

16.Gokce, A., Nagataki, S., Saeki, T., Hisada, M., 2004. Freezing and thawing resistance of air-entrained concrete incorporating recycled coarse aggregate: The role of air content in demolish concrete. Cement and Concrete Research, Vol. 34, № 5, pp. 799-806.

17. International society for rock mechanics commission on testing methods Working group on revision of the point load test method, 1985. "Suggested method for determining point load strength", International Journal of Rock Mechanics and Mining Sciences, Vol. 22, № 2, pp. 51-60. 
18. IRAM 1505:2005. Agregados. Análisis granulométrico. Instituto Argentino de Normalización y Certificación, Argentina.

19. IRAN 1520:2002. Agregados finos. Método de laboratorio para la determinación de la densidad relativa real, de la densidad relativa aparente y de la absorción del agua. Instituto Argentino de Normalización y Certificación, Argentina.

20. IRAM 1531:2006. Agregado grueso para hormigón de cemento. Instituto Argentino de Normalización y Certificación, Argentina.

21. IRAM 1532:2009. Agregados gruesos. Método de ensayo de resistencia al desgaste con la máquina Los Ángeles. Instituto Argentino de Normalización y Certificación, Argentina.

22. IRAM 1533:2002. Agregados Gruesos. Métodos de laboratorio para la determinación de la densidad relativa real, de la densidad relativa aparente y de la absorción de agua. Instituto Argentino de Normalización y Certificación, Argentina.

23. IRAM 1534:2004. Hormigón. Preparación y curado de probetas en laboratorio para ensayos de compresión y de tracción por compresión diametral. Instituto Argentino de Normalización y Certificación, Argentina.

24. IRAM 1536:1978. Hormigón fresco de cemento Portland. Método de ensayo de la consistencia utilizando el tronco de cono. Instituto Argentino de Normalización y Certificación, Argentina.

25. IRAM 1540:2004. Agregados. Método de ensayo del material fino que pasa por el tamiz IRAM $75 \mu \mathrm{m}$, por lavado. Instituto Argentino de Normalización y Certificación, Argentina.

26. IRAM 1546:1992. Hormigón de cemento Portland. Método de ensayo de compresión. Instituto Argentino de Normalización y Certificación, Argentina.

27. IRAM 1548:2003. Agregados. Determinación de la densidad a granel y de los espacios vacíos. Instituto Argentino de Normalización y Certificación, Argentina.

28. IRAM 1562:1978. Hormigón fresco de cemento Portland. Método de determinación de la densidad, el rendimiento y el contenido de aire. Instituto Argentino de Normalización y Certificación, Argentina. 
29. IRAM 1602-1:1988. Hormigón de cemento Portland. Método por presión para la determinación del contenido de aire en mezclas frescas de hormigones y morteros. Parte 1: Método A. Instituto Argentino de Normalización y Certificación, Argentina.

30. IRAM 1627:1997. Agregados. Granulometría de los agregados para hormigones. Instituto Argentino de Normalización y Certificación, Argentina.

31. IRAM 1658:1995. Hormigón. Determinación de la resistencia a la tracción simple por compresión diametral. Instituto Argentino de Normalización y Certificación, Argentina.

32. IRAM 1682:1992. Equivalente de Arena. Instituto Argentino de Normalización y Certificación, Argentina.

33. IRAM 1687-1:1996. Agregados. Método de determinación del índice de lajosidad. Instituto Argentino de Normalización y Certificación, Argentina.

34. IRAM 1687-2:1997. Agregados. Determinación del índice de elongación. Instituto Argentino de Normalización y Certificación, Argentina.

35. IRAM 1693:1969. Hormigones. Método de determinación de las frecuencias fundamentales de vibración de probetas de hormigón. Instituto Argentino de Normalización y Certificación, Argentina.

36. IRAM 1851:1998. Agregados. Determinación en una mezcla de la proporción de agregado grueso con dos o más caras de fractura. Instituto Argentino de Normalización y Certificación, Argentina.

37. IRAM 1677:1971. Agregados gruesos para uso vial. Granulometría. Instituto Argentino de Normalización y Certificación, Argentina.

38. IRAM 1678:1990. Agregados gruesos para uso vial en mezclas bituminosas. Instituto Argentino de Normalización y Certificación, Argentina.

39. IRAM 1542:1983. Material de relleno "filler" para mezclas asfálticas. Método de determinación de la relación crítica (concentración crítica) y de la densidad. Instituto Argentino de Normalización y Certificación, Argentina.

40. IRAM 1641:1983. Material de relleno "filler" para mezclas asfálticas. Método de ensayo de finura, por tamizado húmedo. Instituto Argentino de Normalización y Certificación, Argentina. 
41. IRAM 1652:1981. Mezclas asfálticas en caliente. Método de determinación de la densidad relativa aparente efectiva y de la absorción de asfalto del agregado. Instituto Argentino de Normalización y Certificación, Argentina.

42. IRAM 6579:2005. Asfaltos para uso vial. Determinación de la ductilidad. Instituto Argentino de Normalización y Certificación, Argentina.

43. IRAM 6594:2004. Asfaltos para uso vial. Ensayo de Oliensis. Instituto Argentino de Normalización y Certificación, Argentina.

44.IRAM-IAPG A 6604:2002. Asfaltos para uso vial. Clasificación por penetración. Instituto Argentino de Normalización y Certificación, Argentina.

45. IRAM 6831:2008. Asfalto. Determinación del punto de rotura de Fraass. Instituto Argentino de Normalización y Certificación, Argentina.

46. IRAM 6835:2002. Asfalto para uso vial. Clasificación por viscosidad. Instituto Argentino de Normalización y Certificación, Argentina.

47. IRAM 6839:2003. Asfalto para uso vial. Determinación del efecto del calor y del aire sobre una película de asfalto en movimiento. Ensayo de calentamiento en la película delgada rotativa - Ensayo RTFOT test. Instituto Argentino de Normalización y Certificación, Argentina.

48. IRAM 6841:2002. Asfalto para uso vial. Determinación del punto de ablandamiento. Método del anillo y la esfera. Instituto Argentino de Normalización y Certificación, Argentina.

49. IRAM 6845. Mezclas asfálticas. Método de ensayo para mezclas asfálticas densas en caliente. En estudio. Instituto Argentino de Normalización y Certificación, Argentina.

50. Jiménez, J.R., Agrela, F., Ayuso, J. y López, M., 2010. "Estudio comparativo de los áridos reciclados de hormigón y mixtos como material para sub-bases de carreteras". Materiales de Construcción.

51.Khatib, J.M., 2005. Properties of concrete incorporating fine recycled aggregate. Cement and Concrete Research, Vol. 35, № 4, pp. 763-769.

52. Katz, A., 2003. Properties of Concrete made with Recycled Aggregate from Partially Hydrated Old Concrete. Cement and Concrete Research, Vol. 33, № 5, pp. 703-711. 
53. Katz, A., Baum, H., Nissim, I., 2005. Overview regarding construction and demolition waste in Israel. Use of Recycled Materials, RILEM TC 198URM, Final Report, pp. 13-14.

54. Kashino, N., Takahashi, Y., 1988. "Experimental Studies on Placement of Recycled Aggregate Concrete"; Demolition and Reuse of Concrete and Masonry, Vol.2 Reuse of Demolition Waste, Proceedings of the Second International RILEM Symposium; pp. 669-708.

55. Hansen, T.C., Narud, H., 1983. Strength of recycled concrete made from crushed concrete coarse aggregate. Concrete International, Vol. 5, № 1, pp. 79-83.

56. Hansen, T.C., 1986. Recycled aggregates and recycled aggregate concrete. Second State of the art. Report developments 1945-1985. RILEM Technical Committee-37-DRC, Demolition and Recycling of Concrete. Materials and Structures, Vol. 19, № 111, pp. 201-246.

57. López, F., 2008. "Influencia y variación de los parámetros de dosificación y fabricación de Hormigón Reciclado Estructural sobre sus propiedades Físicas y Mecánicas". Tesis Doctoral. Universidad de Oviedo. pp. 22-32.

58. Mills-Beale, J., You, Z., 2010, "The mechanical properties of asphalt mixtures with Recycled Concrete Aggregates". Construction and Building Materials 24, pp. 230-235.

59. Nagataki, S., Gokce, A., Saeki, T., 2000. "Effects of recycled aggregate characteristics on the performance parameters of recycled aggregate concrete". Proceeding of the Fifth Canmet/ACI International Conference on Durability of Concrete in Barcelona, pp. 51-71.

60. NLT-346-90. Resistencia a la compresión diametral (Ensayo brasilero) de mezclas bituminosas. CEDEX, Ministerio del Fomento.

61. NLT-354-91. Índice de lajas y agujas de los áridos para carreteras. CEDEX, Ministerio del Fomento.

62. Norma BS-598 part 110, 1996. Sampling and examination of bituminous mixture for road and other paved areas- Methods of test for determination of wheel tracking rate.

63.Paranavithana, S., Mohajerani, A., 2006. "Effects of recycled concrete aggregates on properties of asphalt concrete". Resources, Conservation and Recycling, Volume 48, Issue 1, pp. 1-12. 
64.Pérez, I., Toledano M., Gallego, J., Taibo, J., 2007, "Propiedades mecánicas de mezclas bituminosas en caliente fabricadas con áridos reciclados de residuos de construcción y demolición". Materiales de Construcción, Vol. 57, 285, pp. 17-29.

65. Pérez, I., Toledano M., Gallego, J. y Taibo, J., 2007, "Características el comportamiento a fatiga de Mezclas Bituminosas en caliente fabricadas con Áridos Reciclados". Anales de la Mecánica de Fractura, Vol. 1, pp. 157-162.

66. Poole, A., Sims, I., 2003. Geology, aggregates and classification. In: "Advanced Concrete Technology-Constituent Materials", Ed. John Newman y Ban Seng-Choo, Elsevier Ltd.

67.Poon, C.S., Chan, D., 2006, "Feasible use of recycled concrete aggregates and crushed clay brick as unbound road sub-base", Construction and Building Materials 20, pp. 578-585.

68.Poon, C.S., Chan, D., 2006."The cause and influence of self- cementing properties of fine recycled concrete aggregates on the properties of unbound sub-base". Waste Management 26, pp. 1166-1172.

69. Sánchez de Juan, M., 2003. "Estudio sobre la utilización de árido reciclado para la fabricación de Hormigón". Tesis Doctoral. Universidad Politécnica de Madrid, pp. 24-34.

70. Sherwood, P., 2001. Alternative materials in road construction, Thomas Telford, London, pp. 58-65.

71. Thom, N. H. and Brown, S. F., 1989, "The mechanical properties of unbound aggregates from various sources" In: Proc. International Symposium of Unbound Aggregates in Roads (UNBAR3), held at University of Nottingham, U.K., 1989, Jones, R. H. and Dawson, A. R. (eds), pp. 130-142. Butterworth, London.

72. Vegas, I., Ibáñez, J.A., San José, J., Urzelai, A., 2008. "Construction demolition wastes, Waelz slag and MSWI bottom ash: A comparative technical analysis as material for road construction", Waste Management: pp. 565-574.

73. Vegas, I., Ibáñez, J.A., Lisbona, A., Sáez de Cortázar, A. Frías, M., 2011. "Pre normative research $O$ the use of mixed recycled aggregates is 
unbound road sections", Construction and Building Materials 25, pp. 2674-2682.

74. VN-E1-65. Granulometría Vía Húmeda. Norma de Ensayo de la Dirección Nacional de Vialidad.

75. VN-E2-65. Ensayo de Limite Líquido. Norma de Ensayo de la Dirección Nacional de Vialidad.

76. VN-E3-65. Ensayo de Limite Plástico. Norma de Ensayo de la Dirección Nacional de Vialidad.

77.VN-E4-84. Clasificación de Suelos. Norma de Ensayo de la Dirección Nacional de Vialidad.

78. VN-E5-93. Compactación de Suelos. Norma de Ensayo de la Dirección Nacional de Vialidad.

79. VN-E6-84. Determinación de Valor Soporte e Hinchamiento de suelos. Norma de Ensayo de la Dirección Nacional de Vialidad.

80. VN-E9-86. Ensayo de Estabilidad y Fluencia por el método Marshall. Norma de Ensayo de la Dirección Nacional de Vialidad.

81. VN-E27-84. Determinación del peso específico y absorción de asfalto de agregados pétreos para mezclas asfálticas en caliente. Norma de Ensayo de la Dirección Nacional de Vialidad.

82.Wong, Y., Sun, D., Lai, D., 2007."Value-added utilization of recycled concrete in hot mix asphalt". Waste Management 27, pp. 294-301. 